\title{
Development and Application of Quantitative Gene Expression Assays in Wild-Caught, Non-Model Fish Species
}

\author{
Cassidy Megan Hahn
}

Follow this and additional works at: https://researchrepository.wvu.edu/etd

\section{Recommended Citation}

Hahn, Cassidy Megan, "Development and Application of Quantitative Gene Expression Assays in WildCaught, Non-Model Fish Species" (2016). Graduate Theses, Dissertations, and Problem Reports. 5733. https://researchrepository.wvu.edu/etd/5733

This Dissertation is protected by copyright and/or related rights. It has been brought to you by the The Research Repository @ WVU with permission from the rights-holder(s). You are free to use this Dissertation in any way that is permitted by the copyright and related rights legislation that applies to your use. For other uses you must obtain permission from the rights-holder(s) directly, unless additional rights are indicated by a Creative Commons license in the record and/ or on the work itself. This Dissertation has been accepted for inclusion in WVU Graduate Theses, Dissertations, and Problem Reports collection by an authorized administrator of The Research Repository @ WVU.

For more information, please contact researchrepository@mail.wvu.edu. 


\title{
Development and Application of Quantitative Gene Expression Assays in Wild-Caught, Non-Model Fish Species
}

\author{
Cassidy Megan Hahn \\ Dissertation submitted to the \\ Davis College of Agriculture, Natural Resource and Design \\ at West Virginia University \\ in partial fulfillment of the requirements \\ for the degree of \\ Doctor of Philosophy in \\ Forest Resources Science \\ Patricia Mazik, Ph.D., Committee Chair \\ Vicki S. Blazer, Ph.D. \\ Luke Iwanowicz, Ph.D. \\ Amy Welsh, Ph.D. \\ Kyle Hartman, Ph.D. \\ Wildlife and Fisheries Resources Program \\ Morgantown, West Virginia \\ 2016
}

Keywords: gene expression, non-model species, smallmouth bass, largemouth bass, white sucker, brown bullhead, Great Lakes, transcriptome, fish health, hepatitis B, emerging contaminants, areas of concern, next generation sequencing

Copyright 2016 Cassidy Hahn 


\section{ABSTRACT \\ Development and Application of Quantitative Gene Expression Assays in Non-Model Fish Species}

\section{Cassidy Megan Hahn}

The Great Lakes Basin is the most significant freshwater resource in North America. It is a central location for diverse anthropogenic enterprises and consequently has been heavily impacted by the release of toxic substances. Environmental studies increasingly identify the presence of both contaminants of emerging concern (CECs) and legacy contaminants in aquatic environments; however, the biological effects of these compounds on resident fishes remain largely unknown. To address this issue, the U.S. Fish and Wildlife Service Environmental Contaminants Programs initiated a multiagency, collaborative study which included chemical analysis of water and benthic sediment, assessment of caged fathead minnows and assessment of wild fish health using a suite of biological endpoints. In an effort to accurately and efficiently assess the ecological risks of complex chemical mixtures through the integration and synthesis of data from many levels of biological organization, sequence databases for non-model, resident fish species were required. This dissertation contains chapters that describe; 1.) The development of partial transcriptomes for three wild-caught, resident fish species 2.) The utilization of these sequence databases in the development of quantitative gene expression assays 3.) The application of these assays in both laboratory and environmental analyses and 4.) The use of transcriptome sequence databases in the identification of a novel virus. 


\section{DEDICATION}

For my Dad. 


\section{ACKNOWLEDGMENTS}

I would like to thank the Great Lakes Restoration Initiative for funding of this research. I would like to gratefully acknowledge my committee, Vicki Blazer, Patricia Mazik, Luke Iwanowicz, Amy Welsh and Kyle Hartman for their time and guidance throughout my time as a graduate student. Many people at the Leetown Science Center have helped make this research possible. Thank you to Ryan Braham, Heather Walsh, Adam Sperry, Rachel Harrison and Kyra Wood for assistance with field work. Thank you to Kathy Spring, Darlene Bowling, Pam Whittington, Deborah Iwanowicz, Laykn Sanders, Scott Cornman, Tim King, Barb Lubinski and Robin Johnson for assistance in the laboratory. Thank you to my family and friends for sticking with me and supporting me through 11 years of college. Lastly, I'd like to thank my fiancé George for always listening to me and encouraging me. 


\section{FOREWORD}

This dissertation is comprised of five chapters which have been formatted as manuscripts according to the style of various journals. Chapter two is written in the format of the Journal of Comparative Biochemistry and Physiology: Part D and has been accepted for publication with the following co-authors: Luke Iwanowicz, Robert Cornman, Patricia Mazik, and Vicki Blazer. Chapter three is written in the format of the Journal of Great Lakes Research. Chapter four is written in the format of Environmental Toxicology. Chapter five has been published in the Journal of Virology with the following co-authors: Luke Iwanowicz, Robert Cornman, James Winton. Carla Conway and Vicki Blazer. 


\section{TABLE OF CONTENTS}

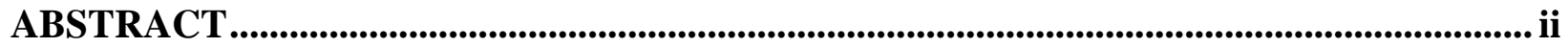

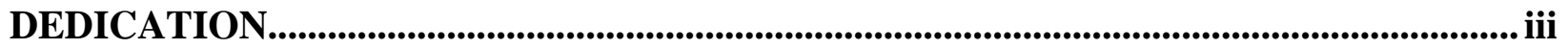

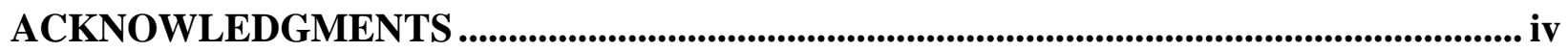

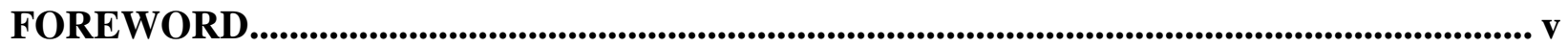

Chapter One: Introduction and Literature Review

Introduction ........................................................................................................................................ 1

Sample Collection...................................................................................................................................... 5

Gene Expression Biomarkers.................................................................................................................... 6

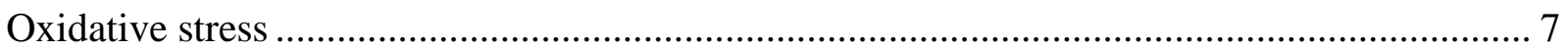

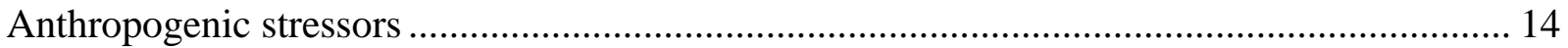

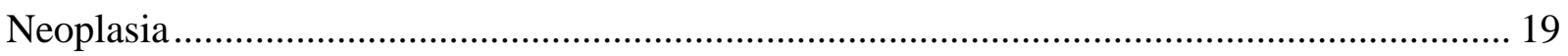

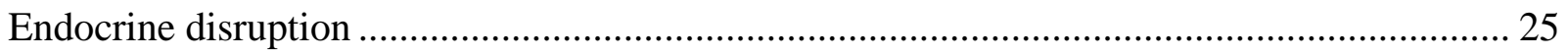

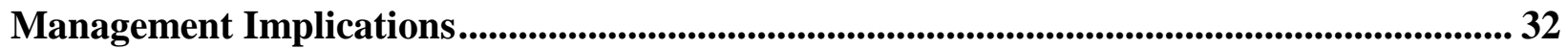

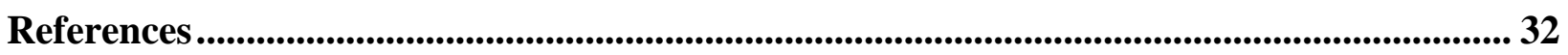

Figures............................................................................................................................................................ 50

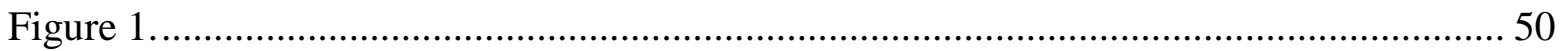

Chapter Two: Transcriptome Discovery in Non-Model Wild Fish Species for the Development of Quantitative Gene Expression Assays

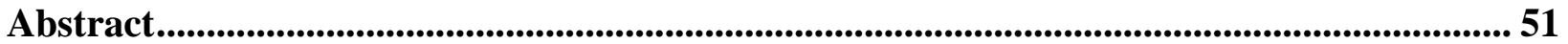

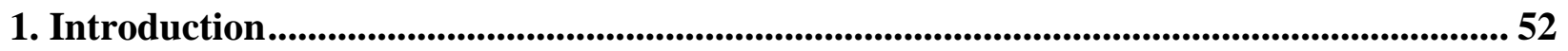

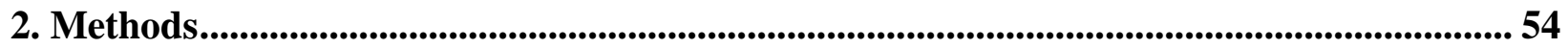

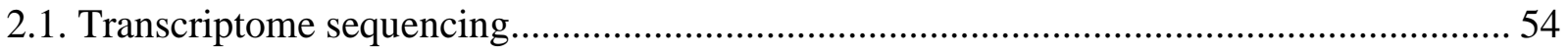

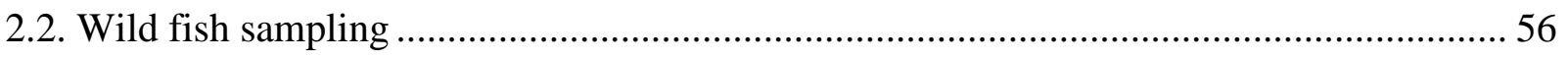

2.3. Gene expression analysis .......................................................................................... 56

2.4. Cross-species probe hybridization .............................................................................. 57

2.5. Comparison of nCounter analysis with quantitative real-time PCR ................................ 58

2.6. Normalization of nCounter gene expression data ........................................................ 59 


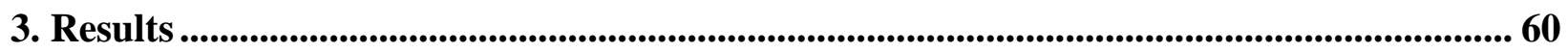

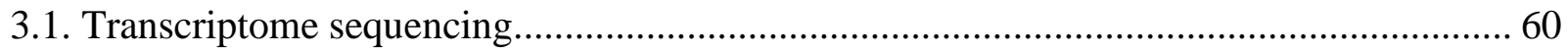

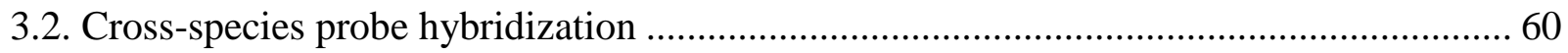

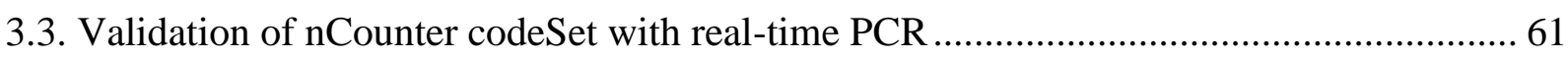

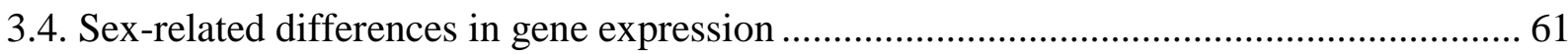

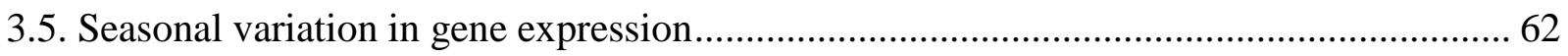

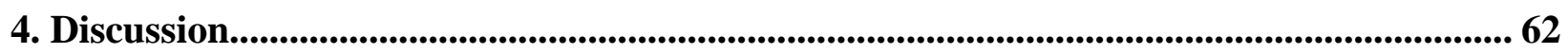

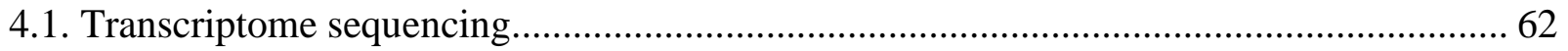

4.2. Baseline differences in gene expression between sexes and seasons................................. 64

Acknowledgements ............................................................................................................................. 67

References......................................................................................................................................... 67

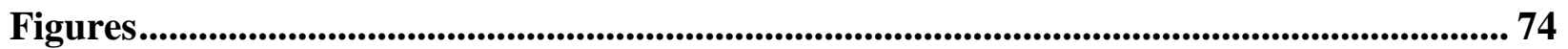

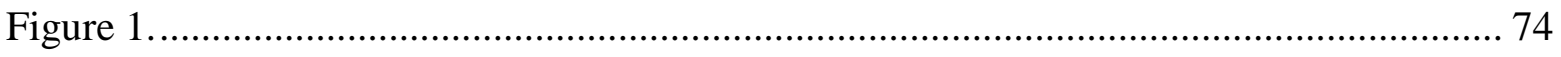

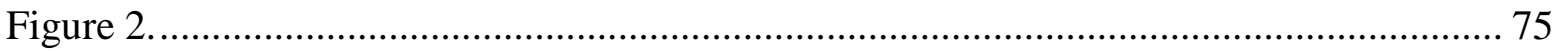

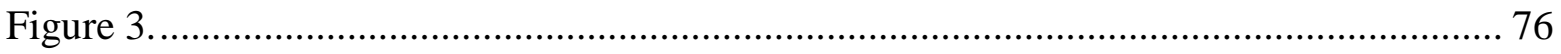

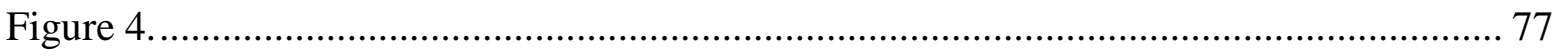

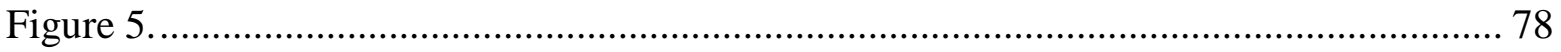

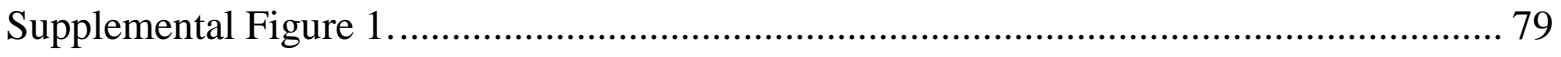

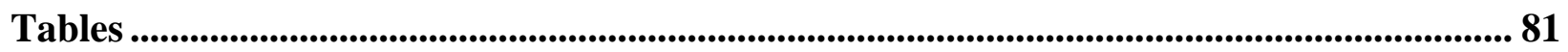

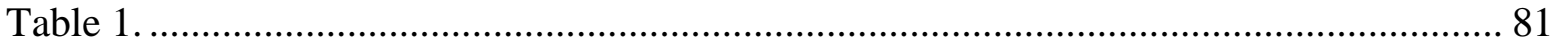

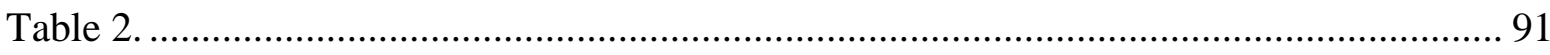

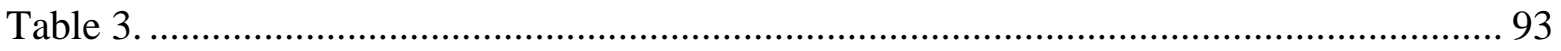

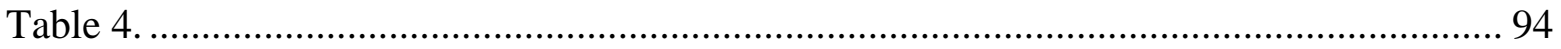

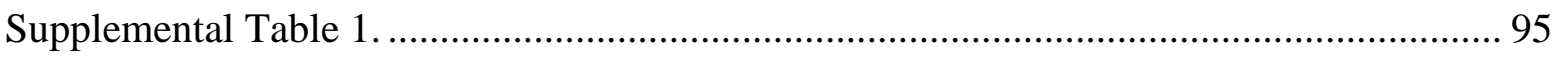

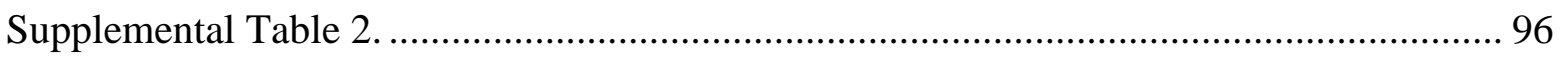

Chapter Three: Assessing the health of resident largemouth bass (Micropterus salmoides) and brown bullhead (Ameiurus nebulosus) from the Rochester Embayment of Lake Ontario, NY

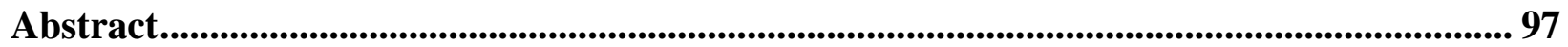


Introduction ....................................................................................................................................................... 98

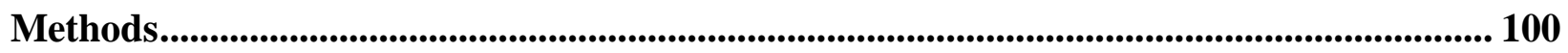

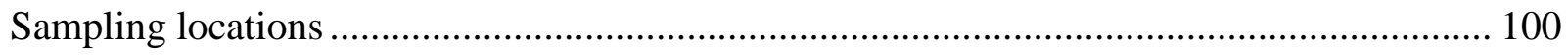

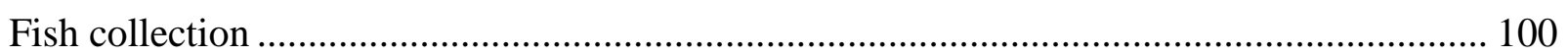

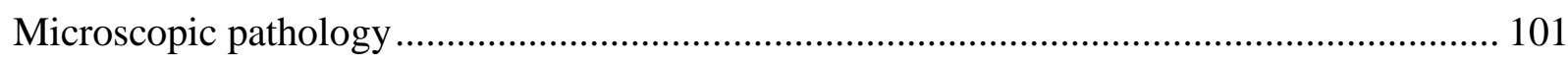

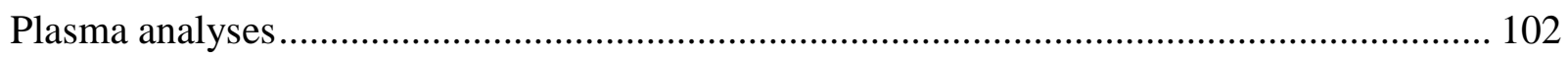

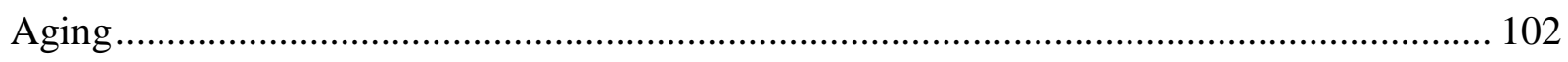

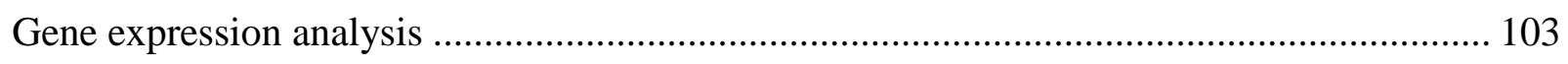

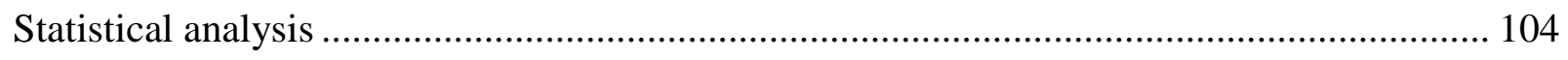

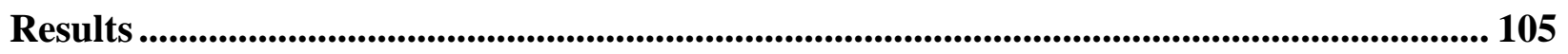

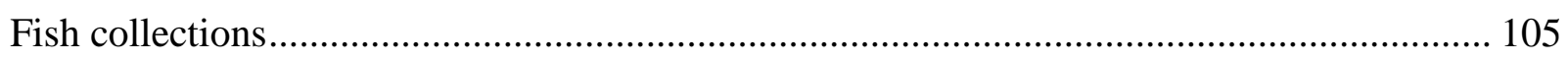

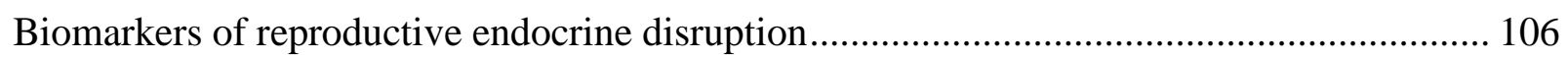

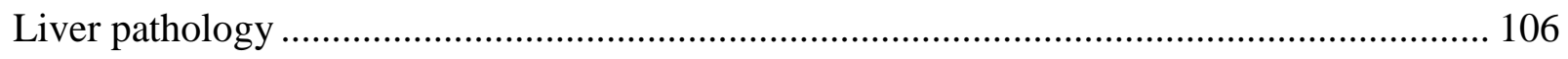

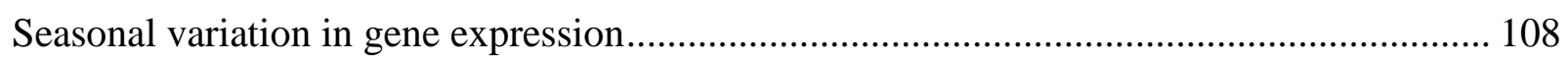

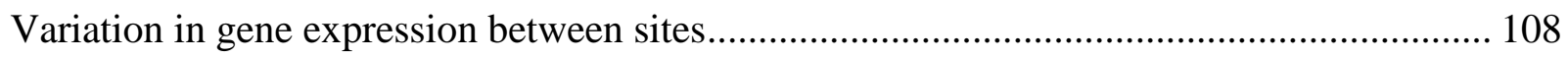

Variation in gene expression between species ................................................................ 109

Comparison of histological and gene expression endpoints ................................................. 110

Discussion....................................................................................................................................... 110

Comparison of plasma and hepatic vitellogenin biomarkers ................................................ 110

Seasonal variation in gene expression........................................................................... 111

Variation in gene expression between sites..................................................................... 112

Variation in gene expression between species .................................................................... 116

Comparison of histological and gene expression endpoints ............................................... 117

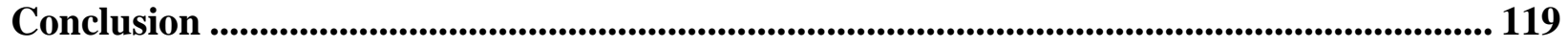

References.............................................................................................................................................. 119

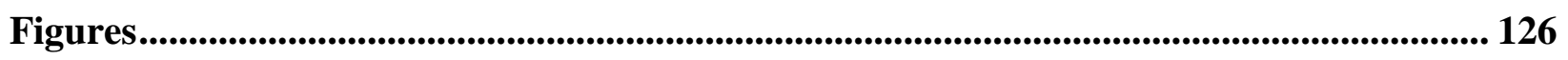

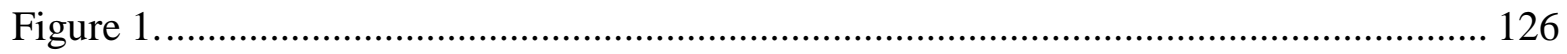

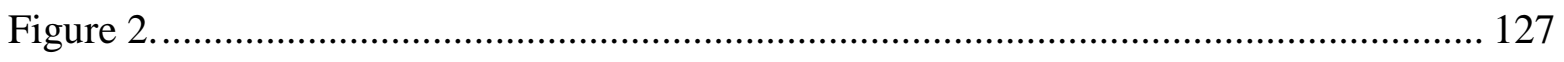

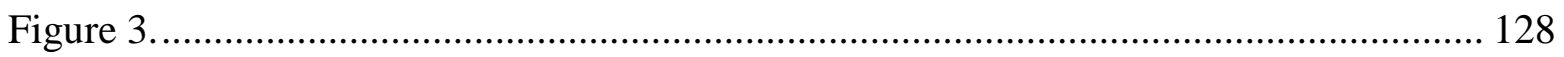

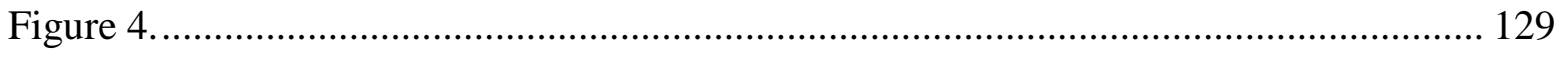




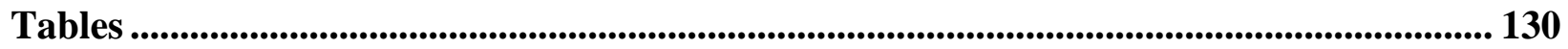

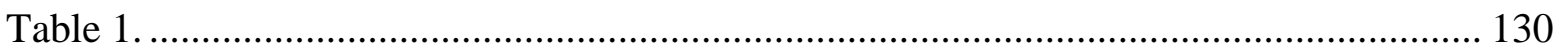

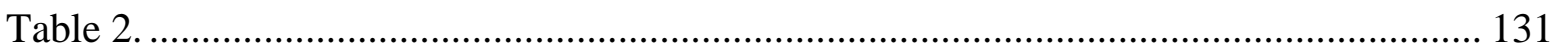

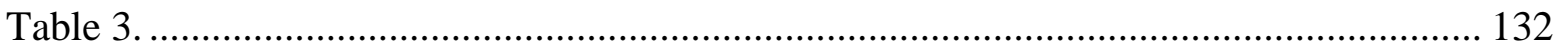

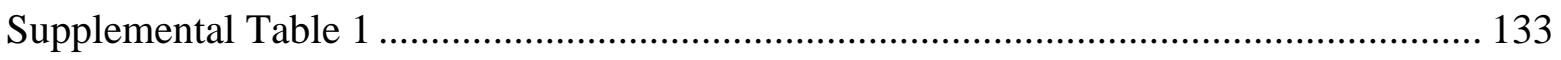

Chapter Four: Effects of environmentally relevant concentrations of tonalide (AHTN) on genotoxic and gene expression biomarkers in brown bullhead (Ameiurus nebulosus)

Abstract..................................................................................................................................................... 135

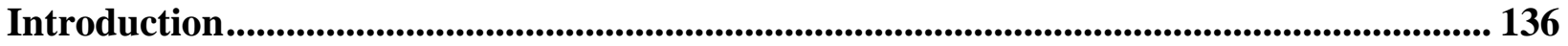

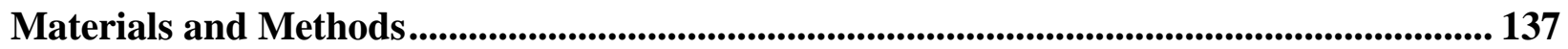

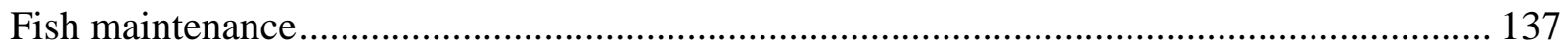

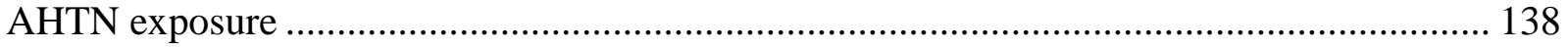

Gene expression analysis ............................................................................................. 139

Micronuclei and nuclear abnormalities ......................................................................... 139

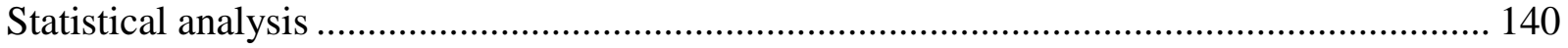

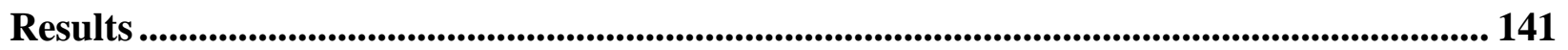

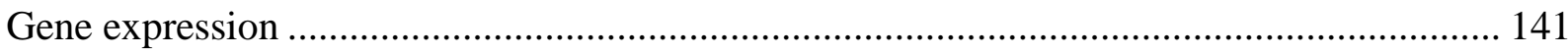

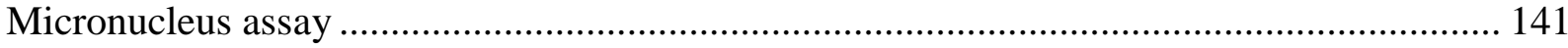

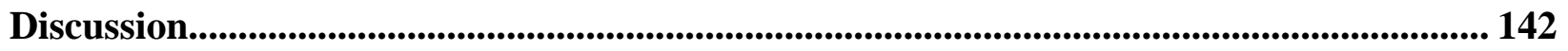

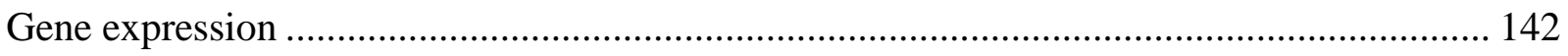

Micronucleus assay ………………………………………………………………….... 146

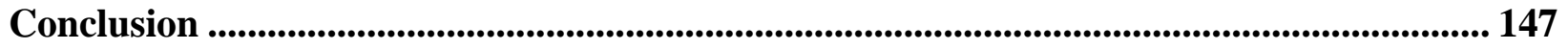

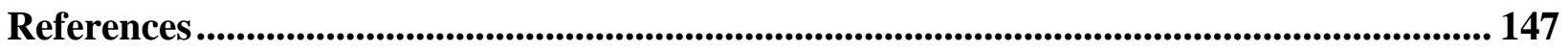

Figures................................................................................................................................................... 153

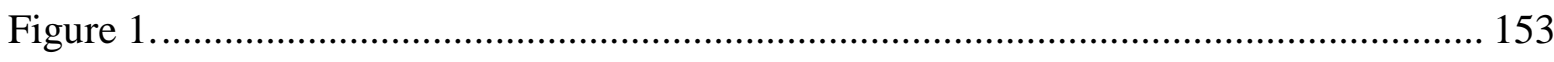

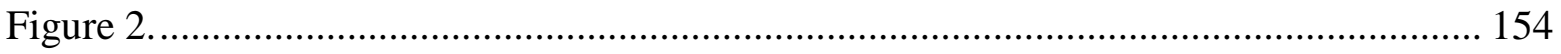

Figure 3

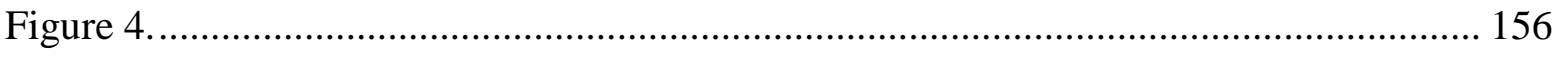

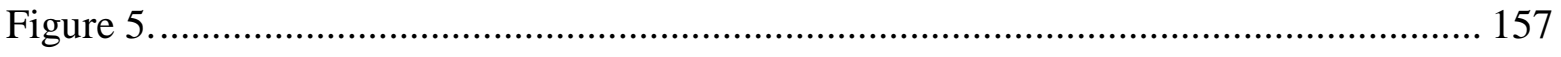

Tables …........................................................................................................................................ 158 
Table 1.

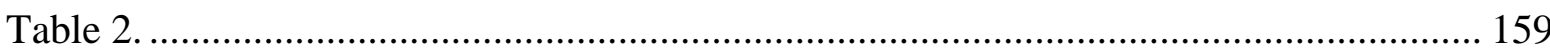

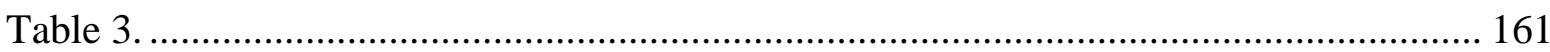

Chapter Five: Characterization of a Novel Hepadnavirus in the White Sucker (Catostomus commersonii) from the Great Lakes Region of the USA

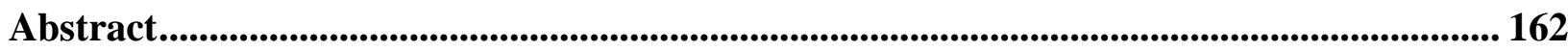

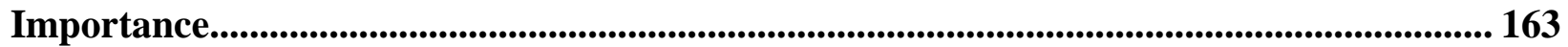

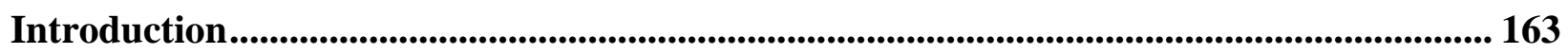

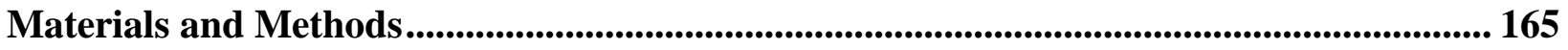

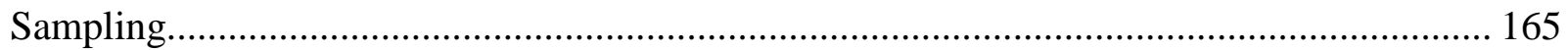

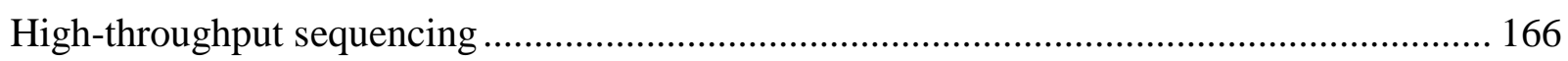

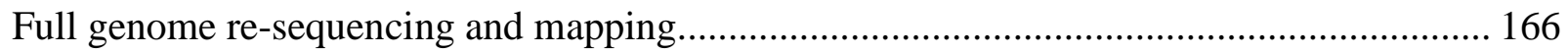

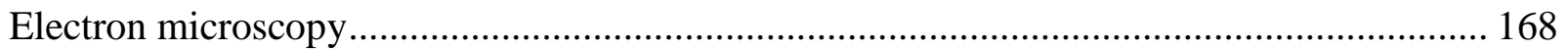

Survey of hepadnavirus prevalence in white sucker ................................................ 168

Relationship between WSHBV and liver tumor prevalence ......................................... 169

Sequence Comparisons and Phylogenetic Analysis ................................................... 169

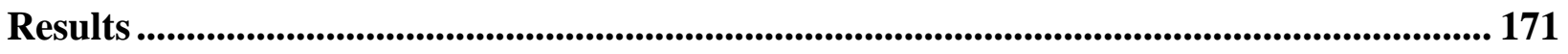

Sequencing the viral genome and ORF organization.................................................. 171

Identification of additional fish hepadnavirus sequence .............................................. 173

Phylogenetic analysis and amino acid conservation ............................................... 174

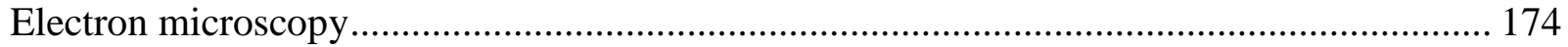

Survey of hepadnavirus prevalence in white sucker ................................................. 175

Association of WSHBV replication and liver neoplasms ............................................ 175

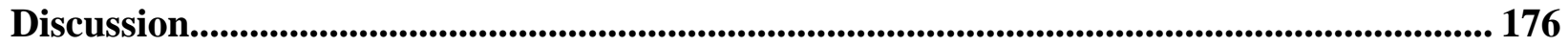

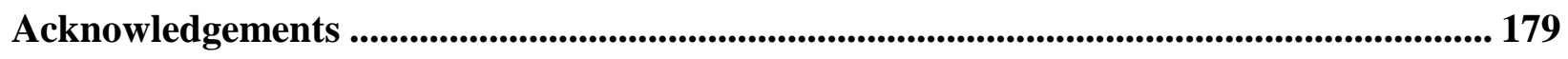

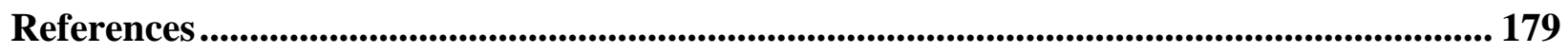

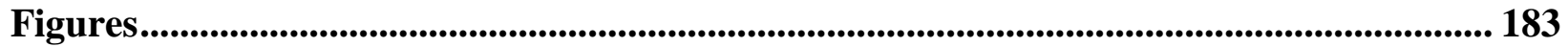

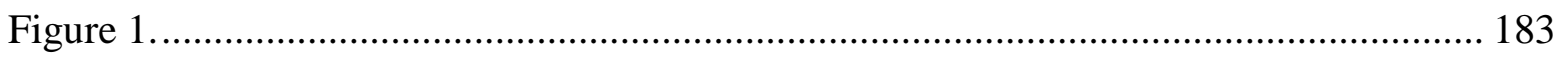

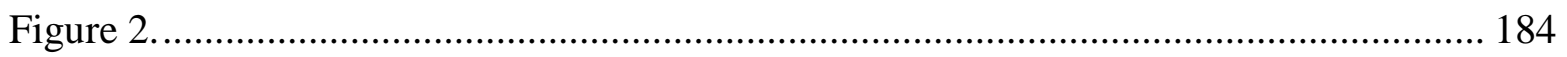

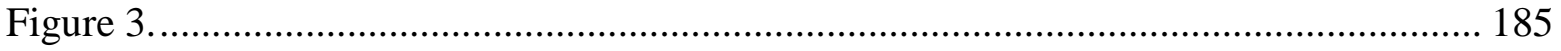




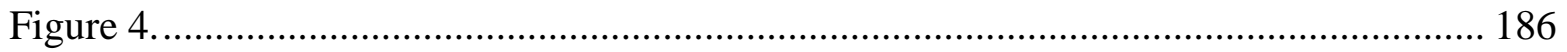

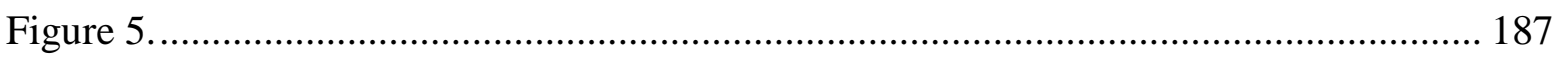

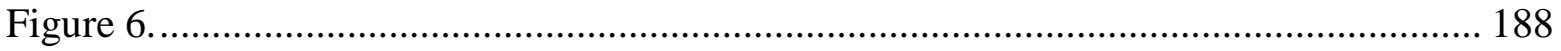

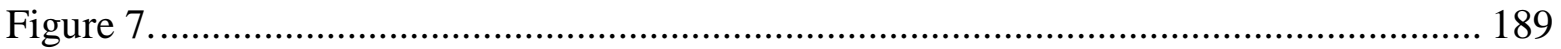

Figure 8

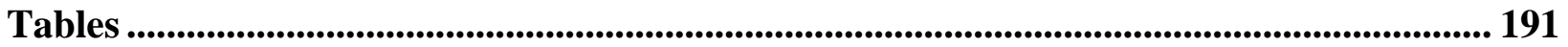

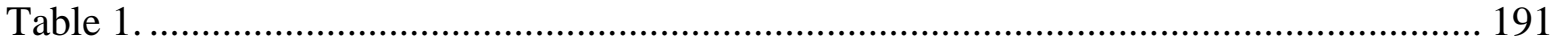

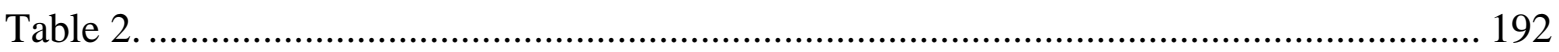

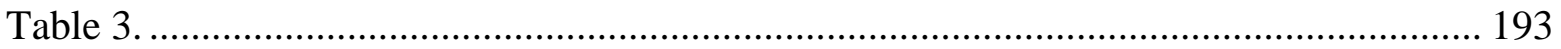

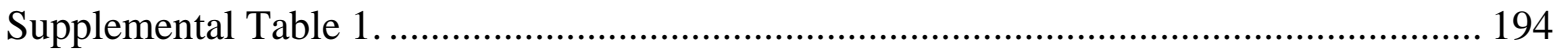

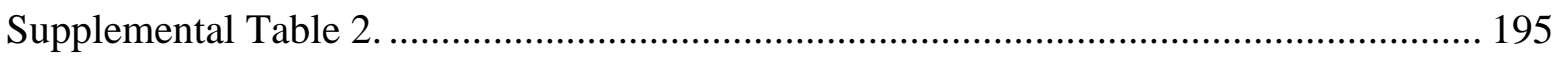

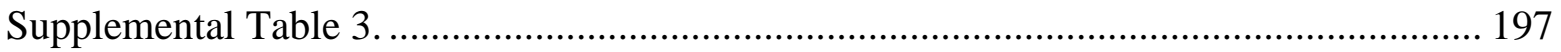




\section{Chapter One: Introduction and Literature Review}

\section{Introduction}

The Great Lakes Restoration Initiative (GLRI) was launched in 2010 in an effort to understand and address persistent and emerging challenges in the Great Lakes ecosystem. As the most significant freshwater resource in North America, the Great Lakes Basin is a central location for diverse anthropogenic enterprises and is heavily impacted by industrial, agricultural and commercial sources. Harmful chemicals released by these activities continue to enter the Great Lakes region where they may adversely impact ecosystems. Priorities for the GLRI were broken into five focus areas that included the remediation of toxic substances and areas of concern, control of invasive species, reduction of nonpoint source pollution, habitat protection and restoration, and evaluation and monitoring of these efforts. Under the U.S.-Canada Great Lakes Water Quality Agreement, Areas of Concern (AOCs) in the Great Lakes were defined as, "geographic areas that fail to meet the general or specific objectives of the agreement where such failure has caused or is likely to cause impairment of beneficial use of the area's ability to support aquatic life ("Great Lakes Water Quality Agreement," 2012).” To evaluate AOCs, the International Joint Commission (IJC) identified 14 beneficial use impairments (BUIs) which are employed during the development of Remedial Action Plans (RAPs) and during the assessment of the achievements of restoration efforts. Included among these BUIs is the health and degradation of fish and wildlife populations and the presence of fish tumors and other deformities (IJC, 1991), both of which may potentially be caused by exposure to contaminants.

Toxic substances that have been reported in the Great Lakes are broadly classified as legacy contaminants or contaminants of emerging concern (CECs). Although the original focus in the determination of AOCs include well-known legacy contaminants such as heavy metals, 
polycyclic aromatic hydrocarbons (PAHs) and polycyclic aromatic biphenyls (PCBs), a recent shift has brought to attention the presence of a new class of compounds collectively referred to as contaminants of emerging concern (CECs). These contaminants can be defined as synthetic or naturally occurring chemicals that are newly recognized, not commonly monitored, but have the potential to enter the environment and cause known or suspected adverse ecological and/or human health effects. This class of contaminants includes current use pesticides, personal care products, pharmaceuticals and detergents, plasticizers, brominated flame retardants, and biogenic hormones (Klaper \& Welch, 2011; Klecka, Persoon, \& Currie, 2010) that currently lack regulations pertaining to their release into air, water and sediment. Studies have identified the presence of such contaminants in aquatic environments throughout the Great Lakes region (Blair, Crago, Hedman, \& Klaper, 2013; Li, Helm, \& Metcalfe, 2010; Metcalfe, Miao, Koenig, \& Struger, 2003); however, little information is available regarding the biological effects of exposure to these compounds (IJC, 2009). This lack of information is confounded further by the fact that in most cases CECs are present as complex mixtures that may also include legacy contaminants.

The accumulation of CECs and other contaminants in aquatic systems and sediments make fish species ideal bioindicators and integrators of chemical mixture effects given that they are chronically exposed to these stressors. Prior research has shown discrepancies in the sensitivity of species following contaminant exposure (Hinck, Blazer, Schmitt, Papoulias, \& Tillitt, 2009) and the formation of various biological responses. The selection of an appropriate model species to accurately represent the biological effects experienced by wild, resident fish is therefore difficult, if not impossible as even resident species have different responses. As a result, the use of wild-caught, resident fish species was preferred. Species of interest in this and 
previous contaminant monitoring studies include both benthic and pelagic species. Indications of reproductive endocrine disruption, including intersex (testicular oocytes), has been described in the pelagic smallmouth bass Micropterus dolomieu and largemouth bass M. salmoides (Blazer et al., 2007; Blazer et al., 2012; Hinck et al., 2009; Iwanowicz et al., 2009; Iwanowicz et al., 2016; Sepulveda et al., 2002; Tetreault et al., 2011). Benthic species, including the brown bullhead Ameiurus nebulosus and white sucker Catostomus commersonii, have been widely used in ecotoxicological studies evaluating the presence of liver and skin tumors and other adverse effects (Baumann, Smith, \& Metcalfe, 1996; Blazer, Hoffman, et al., 2014; Blazer, Rafferty, Baumman, Smith, \& Obert, 2009a, 2009b; Hayes et al., 1990; Pinkney et al., 2011; Premdas, Metcalfe, Bailey, \& Metcalfe, 1995; Pyron, Obert, \& Wellington, 2001; Rafferty et al., 2009; Smith, Ferguson, \& Hayes, 1989) and in the case of white sucker, reproductive endocrine disruption as well (Sikstrom, Metner, \& Lockhart, 1975; Woodling, Lopez, Maldonado, Norris, \& Vajda, 2006).

Although the prevalence of intersex or neoplasia provide valuable information on biological changes that have occurred presumably as a result of exposure to contaminants, they represent organismal level responses that have manifest over long periods of time. In order to evaluate more recent environmental conditions biomarkers at lower levels of biological organization are required. These endpoints include analysis of plasma for vitellogenin, 11-keto testosterone and estradiol. Vitellogenin is an egg-yolk precursor protein normally found in adult female oviparous vertebrates that has become a well-accepted indicator of exposure to estrogenic compounds when detected in male fishes (Cheek et al., 2001; Denslow, Chow, Kroll, \& Green, 1999; Tyler, Lange, Paull, Katsu, \& Iguchi, 2007). Additionally, a decrease in the level of vitellogenin in females may result in the formation of lower quality eggs (Miller et al., 2007; 
Wheeler, Gimeno, Crane, Lopez-Juez, \& Morritt, 2005). Plasma hormone concentrations, including 11-keto testosterone and estradiol, can also be measured in the plasma as an indicator of exposure to contaminants (Cheshenko, Pakdel, Segner, Kah, \& Eggen, 2008; Hinck et al., 2007; Munkittrick, McMaster, McCarthy, Servos, \& Van Der Kraak, 1998; Sepulveda et al., 2002). Measureable changes in plasma hormone concentrations are induced several days following exposure and may remain elevated for several weeks (Hansen et al., 1998).

The focus of previous contaminant monitoring studies has been placed on the evaluation of cellular and organismal levels effects. While these endpoints are generally indicative of long term exposure to contaminants, evaluation of current and/or recent biological effects requires the inclusion of biomarkers from the molecular level (Garcia-Reyero et al., 2014). Ankley et al. (2010) introduced the concept and use of adverse outcome pathways (AOPs) which link molecular initiation events to adverse outcomes at higher levels of biological organization. Unfortunately, much of the information available on AOPs is specific to model species such as fathead minnow (Pimephales promelas), zebrafish (Danio rerio) and medaka (Oryzias latipes). Although this information has greatly contributed to our understanding of mechanisms, similar information for wild fish species is lacking. Hence, following the AOP framework, our objectives were to develop gene expression endpoints for non-model, but environmentally relevant, species to be utilized in conjunction with organismal level indicators.

The use of high throughput sequencing technology in the establishment of partial transcriptomes for smallmouth bass, white sucker and brown bullhead is discussed in chapter two. Nucleotide databases obtained from this sequencing were used in the development of custom nCounter analysis assays (Nanostring Technologies, Seattle, WA) for the evaluation of differential gene expression in liver tissue of wild-caught fishes. Gene expression biomarkers 
included in assay development were determined by literature review of commonly modulated genes in model species exposed to CECs and legacy contaminants. The use of nucleotide information developed for smallmouth bass in the closely related largemouth bass was also evaluated. Variation in gene expression between species, seasons and sexes was evaluated in an effort to determine the natural physiological fluctuations of the chosen biomarker genes.

Developed gene expression markers were then used in both environmental and laboratory studies. In chapter three, largemouth bass and brown bullhead collected from the Rochester Embayment AOC were assessed for variation between species, season and sampling locations. In an effort to utilize the AOP framework, changes in gene expression endpoints were also evaluated for association with plasma and histological analyses. In chapter four, modulation of gene expression in brown bullhead was determined following exposure to a commonly identified CEC in the Great Lakes region, Tonalide (Lee et al., 2012; Lee et al., 2015).

In addition to the development of gene expression markers, the transcriptome database was also exploited for the identification of unknown risk factors. In chapter five, a novel hepadnavirus from white sucker was discovered. Prior to the transcriptome sequencing presented here, hepadnaviruses had only been identified in birds and mammals. The prevalence of the virus was also assessed using a gene expression biomarker.

\section{Sample Collection}

Samples utilized in this research were collected as part of a larger study initiated by the U.S. Fish and Wildlife Service Environmental Contaminants Program. The program aimed to detect and identify CECs as well as assess their effects on fish and wildlife. A total of nine AOCs were targeted for sampling: the Rochester Embayment AOC, the St. Louis River AOC, the Maumee AOC, the Detroit River AOC, the River Raisin AOC, the Lower Green Bay and Fox 
River AOC, the Milwaukee Estuary AOC, the Ashtabula River AOC and the Niagara River AOC (Figure 1). Collaborative sampling by the U.S. Geological Survey (USGS) included the collection of water and bottom sediment which were analyzed for a broad suite of chemicals though to be indicative of industrial, domestic and agricultural pollution (Lee et al., 2012; Lee et al., 2015). Caged fathead minnows were also deployed by the Environmental Protection Agency and U.S. Fish and Wildlife Service at each of these locations and subsequently sampled for gene expression effects. We attempted to collect 20 mature fish, defined as greater than $250 \mathrm{~cm}$ in length, from each of two species. A comprehensive necropsy-based assessment was then conducted on each fish collected to provide samples for the analysis of a broad suite of biological effects.

\section{Gene Expression Biomarkers}

The following is a review of the literature used in the determination of gene expression biomarkers evaluated by this study. Biomarkers were chosen to assess effects from a broad range of chemicals, transcriptional changes which may be associated with endocrine disruption and tumor formation, immune response and general stress levels. In addition to literature review, several markers were chosen to coordinate with the genes used by the Environmental Protection Agency in the assessment of caged fathead minnows deployed at the same locations as wild fish collections.

Multiple housekeeping genes were chosen for this study including elongation factor $1 \alpha$, $\beta$-actin, ribosomal protein $\mathrm{L} 8$, hypoxanthine phosphoribosyltrasferase 1, tata box binding protein, eukaryotic translation initiation factor $3 \mathrm{~d}$ and RNA binding motif protein. Typically, housekeeping genes are transcribed at a relatively constant level and therefore are unaffected by environmental and/or experimental conditions. In this way, these genes can be used to account 
for transcriptional variation which may occur between individual fish. Housekeepers for this study were chosen based upon literature reviews of similar studies (Deloffre, Andrade, Filipe, \& Canario, 2012; Filby \& Tyler, 2007; Vandesompele et al., 2002) as well as recommendations from Nanostring Technologies. All housekeeping genes were evaluated statistically for their utility prior to normalization.

The liver was selected as the target organ for gene expression analysis in part for its critical roles in reproduction, immunity and metabolic function. The hypothalamus-pituitarygonadal (HPG) axis consists of glands and organs which operate together in the development and regulation of both reproductive and immune systems. In oviparous teleosts, the HPG axis includes the liver as many egg-yolk and chorionic proteins, i.e. vitellogenin and choriogenin, are synthesized there. The liver is also responsible for the maintenance of appropriate plasma hormone levels through the biotransformation of steroid hormones by monoxygenase enzymes. Additionally, metabolic homeostasis is maintained in the liver and therefore it is responsible for the biotransformation and detoxification of xenobiotics. Monitoring the response of gene expression endpoints which are synthesized in liver tissue therefore provides a multitude of measurable endpoints with biological effects that may result following exposure to complex contaminant mixtures.

\section{Oxidative stress}

Gene expression biomarkers associated with oxidative stress response in fishes include catalase (CAT), glucocorticoid receptor (GR), glutathione peroxidase (GPX), heat shock proteins (HSPs), superoxide dismutase (SOD), glutathione-s-transferase (GST), cytochrome C oxidase (COX) and warm temperature acclimation protein (WAP65). Oxidative stress occurs when the balance between the reactive oxygen species (ROS) and the ability of an organism to detoxify 
reactive intermediates and/or repair the resulting damage is interrupted and can occur as the result of exposure to environmental influences such as pathogens or xenobiotics. Antioxidants provide the first line of defense against this mechanism and can be divided into two groups. The first includes vitamins A, C and E while the second includes enzymes such as superoxide dismutase, catalase, glutathione peroxidase, and glutathione-S-transferase. The enzymes are further classified by their cellular location. Superoxide dismutase located on the cell surface is considered a first line of defense while a second line of defense, glutathione-S-transferase, is located within the cell (Hellou, Ross, \& Moon, 2012). Also included as markers of stress are glucokinase (GLK) and phosphoenolpyruvate carboxykinase (PEPCK) both of which are associated with metabolic function and may therefore be indicative of the onset of secondary stress response. Additionally, interferon 1 (IFN1) has been included as a measurement of both infection and stress.

The antioxidant defense system of many living organisms including fish consists of a series of genes that incorporate superoxide dismutase, catalase, glutathione-S-transferase, and glutathione peroxidase. These genes assist in the protection of tissue from damage caused by oxidative stress in several ways. Superoxide dismutase cooperates with other antioxidants to remove by-products of oxygen metabolism from cells which can otherwise results in membrane degradation (Hassan, 1988). A variety of contaminants and conditions have been reported to affect superoxide dismutase expression. Analysis of liver samples for superoxide dismutase found significantly higher activity in brown bullhead from sites contaminated with PAHs and PCBs in the Black River, $\mathrm{OH}$ and St. Lawrence River, NY in relation to a reference location (McFarland et al., 1999; Otto \& Moon, 1996). Conversely, organochlorine pesticides were found to significantly suppress superoxide dismutase activity (Karaca et al., 2014). Temperature 
has been shown to influence superoxide dismutase expression, specifically, significant increases in expression of superoxide dismutase in liver tissue concurrent with increasing temperatures has been reported (Parihar, Dubey, Javeri, \& Prakash, 1996). Like superoxide dismutase, catalase is an important antioxidant that catalyzes the conversion of hydrogen peroxide to water and oxygen. Hydrogen peroxide is a ROS that can penetrate biological membranes and damage cellular structures. A number of studies have focused on the expression of catalase in relation to exposure to heavy metals. The accumulation of heavy metals leads to increases in hydrogen peroxide and may result in oxidative damage. Altered catalase expression in response to heavy metals exposure has been reported in several fish species in both field and laboratory experiments (Atli, Alptekin, Tükel, \& Canli, 2006; Mehinto et al., 2014). As a first line of defense against oxidative damage, monitoring of both superoxide dismutase and catalase markers will be important in the evaluation of ROS induced by external stimuli.

Glutathione-S-transferases represent a group of detoxification enzymes that facilitate conjugation of the antioxidant glutathione. As a main component in detoxification processes, glutathione-S-transferase provides cellular protection against toxic environmental contaminants and can be indicative of an oxidative stress response in an organism. In previous studies, glutathione-S-transferase mRNA expression has been shown to indicate the effects of exposure to lead (Mager, Wintz, Vulpe, Brix, \& Grosell, 2008) and organochlorine pesticides (Karaca et al., 2014) and has also been reported at increasing levels in association with increased urbanization (Crago, Corsi, Weber, Bannerman, \& Klaper, 2011). Glutathione-S-transferase, and an additional biomarker of this study, glutathione peroxidase, has also been studied in relation to the prevalence of neoplasm. Comparisons of hepatic glutathione-S-transferase levels in fishes known to be particularly susceptible to liver neoplasm, brown bullhead and English sole 
(Parophrys vetulus), have identified lower expression levels relative to species which are known to be less susceptible to liver neoplasia, channel catfish (Ictalurus punctatus) and starry flounder (Platichthys stellatus) (Collier, Singh, Awasthi, \& Varanasi, 1992; Hasspieler, Behar, \& Digiulio, 1994). Hepatocellular glutathione-S-transferase loss was also suggested to be indicative of preneoplastic progression and/or increased susceptibility to DNA damage by exposure to environmental contaminants in white suckers (Stalker, Kirby, Kocal, Smith, \& Hayes, 1991). Endocrine disrupting effects may also be associated with the down regulation of glutathione-S-transferase and was reported at sites contaminated by agrichemicals in white sucker (Dorval, Leblond, Deblois, \& Hontela, 2005). The monitoring of these biomarkers may therefore be useful in the assessment of detoxification and identification of preneoplastic and neoplastic liver lesions.

Glutathione peroxidase is the main mechanism for detoxification of peroxides in living cells. Glutathione peroxidase plays a critical role in protecting cells against oxidative damage resulting from peroxide decomposition and the subsequent creation of free radicals. Studies on glutathione peroxidase are limited relative to other antioxidants markers chosen for this study. A recent study of the piscivorous double-crested cormorant (Phalacrocorax auritus) found positive correlations between blood mercury levels and glutathione peroxidase and glutathione-Stransferase expression levels at five sites with varying contamination levels across the Great Lakes Region (Gibson, Lavoie, Bissegger, Campbell, \& Langlois, 2014). The current lack of information regarding fluctuations in the expression of this gene and its correlation to glutathione peroxidase and glutathione-S-transferase presents the opportunity for the results of this study to add novel information on the expression patterns of these genes in non-model species. 
Cytochrome $\mathrm{C}$ oxidase is the terminal enzyme in the electron transport chain which catalyzes the reduction of $\mathrm{O}_{2}$ to water. It is the rate-limiting enzyme of the mitochondrial respiratory chain and essential to the production of ROS, cell signaling and survival. A minimal number of studies of cytochrome $\mathrm{C}$ oxidase expression in teleosts are available in contrast to other antioxidant markers included in this study. Cytochrome $\mathrm{C}$ oxidase expression has been reported as differentially expressed under hypoxic conditions in muscle tissue of longjaw mudsucker (Gillichthys mirabilis) and common carp (Gracey, Troll, \& Somero, 2001; Zhou et al., 2000). The inclusion of this marker for the assessment of species of interest in our study will add to the limited amount of knowledge currently available on the modulation of expression of this gene under varying environmental conditions.

Glucocorticoid receptors are members of the steroid/thyroid/retinoid receptor superfamily whose primary function is to regulate the effects of corticosteroid hormones via the binding of glucocorticoids, which include cortisol and corticosterone. In teleosts, cortisol is the predominant glucocorticoid released in times of stress and may influence metabolism, reproduction, anti-inflammatory functions and osmoregulation. Glucocorticoid receptors are known to mediate the stress response and may act as immune suppressants and antiinflammatories. Several contaminants including brominate flame retardants (Pradhan, Kharlyngdoh, Asnake, \& Olsson, 2013) and PCBs (Aluru, Jorgensen, Maule, \& Vijayan, 2004; Desaulniers, Xiao, \& Cummings-Lorbetskie, 2013) have been shown to interfere with glucocorticoid receptor expression. Evaluation of glucocorticoid receptor provides an additional measurement of stress response and as many Great Lakes AOCs have been historically reported as contaminated with PCBs may also prove to be a marker of exposure of non-model fishes to these conditions. 
Heat shock proteins are a family of highly conserved cellular proteins involved in the protection and repair of cells following cellular damage. Heat shock proteins are chaperones which stabilize new proteins and mediate the folding of proteins which were damaged by oxidative stress. In fish species, three major families of heat shock proteins have been detected and are classified by molecular weight as heat shock protein $90(85-90 \mathrm{kDa})$, heat shock protein 70 (68-73 kDA) and low molecular weight heat shock protein (Basu et al., 2002). In a number of laboratory experiments, these proteins have been shown to be up-regulated in many different tissues after exposure to a variety of contaminants including heavy metals (Airaksinen et al., 2003; Heikkila, Schultz, Iatrou, \& Gedamu, 1982; Sanders, Nguyen, Martin, Howe, \& Coventry, 1995), pesticides (Hassanein et al., 1999) and PAHs (Vijayan, Pereira, Kruzynski, \& Iwama, 1998). Field investigations have also reported elevated levels of heat shock protein in contaminated systems relative to unexposed control fish (An, Lei, \& Zheng, 2014; Janz, McMaster, Munkittrick, \& Van Der Kraak, 1997; J. Wang et al., 2007). Expression of heat shock protein 90 has also been examined as an indicator of proteotoxicity and disruption of glucocorticoid receptors signaling (Deane \& Woo, 2011; Vijayan, Prunet, \& Boone, 2005). Its responsiveness to a variety of stimulus makes this marker a good indicator of general stress in wild fish and may be particularly useful in general assessments of differences between sampling locations.

Warm temperature acclimation protein 65 is essential to acclimation of fish to warm temperatures. Significant physiological and gene expression changes are required in response to seasonal fluctuations and a number of studies have reported differential expression of warm temperature acclimation protein 65 during temperature acclimation (Kikuchi, Yamashita, Watabe, \& Aida, 1995; Sha et al., 2008; Watabe, Kikuchi, \& Aida, 1993). In addition to this 
function, it has been suggested that warm temperature acclimation protein 65 may be associated with acute immune response as its expression has been significantly up-regulated in fish after lipopolysaccharides injection (Kikuchi, Watabe, \& Aida, 1997) and experimental infection with pathogenic microorganisms (Sha et al., 2008; Shi, Chen, Li, \& Li, 2010). The induction of warm temperature acclimation protein 65 has also been reported following exposure to copper (Aliza, Ismail, Kuah, Shu-Chien, \& Tengku Muhammad, 2008) and may consequently be modulated by exposure to copper and other heavy metals in environmental settings.

Glucokinase plays a key role in the metabolism of glucose through the phosphorylation of glucose to glucose 6-phosphate. In rats, glucokinase was shown to be glucocorticoidregulated in hepatocytes and may therefore play a part in the oxidative stress response. In fish, a 7-day chronic stress test in Mummichog (Fundulus heteroclitus) identified a similar oxidative stress response (Picard \& Schulte, 2004). Other roles of glucokinase activity in the liver of teleosts remain largely unknown. In a recent study, Caseras et al. (2000) suggested that modulation in glucokinase expression was influenced by both starvation and energy restriction. Glucokinase activity was modulated by nutritional intake and therefore may play a role in the inability of carnivorous fish to metabolize carbohydrates (Caseras, Metón, Fernández, \& Baanante, 2000). Phosphoenolpyruvate carboxykinase (PEPCK), like glucokinase, is involved in the metabolism of glucose and is an important rate-limiting enzyme. Stressors which cause elevation of plasma cortisol activate glucocorticoid receptors in an effort to maintain elevated plasma glucose levels which ultimately leads to increased transcription of phosphoenolpyruvate carboxykinase. This has been demonstrated in trout, where cortisol levels have been shown to up-regulate phosphoenolpyruvate carboxykinase in both hepatocytes (Sathiyaa \& Vijayan, 2003) as well as in fish receiving intraperitoneal injections (Vijayan, Raptis, \& Sathiyaa, 2003). 
Interferons are cytokines which are secreted in response to the invasion of pathogens and specifically viral infections. They can be divided into two classes, type I-interferon and type IIinterferon. For the purposes of this study, focus will be on type I- interferon which is produced by all cell types. Type I interferon limits the spread of virions and is therefore considered the first line of defense against viral infections, allowing time for adaptive immune response to begin. Up-regulated expression of interferon has been reported in fish infected with nodavirus (Chen et al., 2014), infectious pancreatic necrosis virus and infectious salmon anaemia virus (McBeath, Snow, Secombes, Ellis, \& Collet, 2007). In this study, the interferon biomarker may be assessed to indicate the presence of similar infections.

\section{Anthropogenic stressors}

Modulation of gene expression biomarkers has also been identified in response to various known environmental contaminants. Literature review determined a number of potential markers for contaminants thought to be present at AOCs sampled in this study. These markers include metallothionein (MT), apolipoprotein (APA1), aryl hydrocarbon receptor (AHR), hypoxia-inducible factor (HIF), cytochrome P450 genes (CYP1A, CYP1B2, and CYP3A), epoxide hydrolase (EH), ferritin (FR), and hepcidin (HEP).

Metallothioneins are cysteine-rich, low molecular weight metal binding proteins which are thought to play a role in both the detoxification and tolerance of metals in fishes (Hamilton \& Mehrle, 1986; Hodson, 1988). Metallothioneins are known to bind copper, zinc, cadmium, mercury, and silver (Amiard, Amiard-Triquet, Barka, Pellerin, \& Rainbow, 2006). Not only has the transcription of this gene been shown to be induced by these metals (Hogstrand \& Haux, 1990), a study conducted on net held rainbow trout found hepatic metallothionein induction to be concentration dependent (Roch \& McCarter, 1984). In largemouth bass from a system of known 
contamination, a positive linear relationship between metallothionein expression and levels of copper, zinc, manganese, aluminum and nickel has also been reported (Gehringer, Finkelstein, Coale, Stephenson, \& Geller, 2013). Additionally, metallothionein has been shown to be induced by hormones, specifically, estradiol (Olsson, Zafarullah, \& Gedamu, 1989) and glucocorticoids (Hyllner, Andersson, Haux, \& Olsson, 1989) and thus may provide an indicator of exposure to both EDCs and heavy metals.

Ferritin plays a key role in iron storage and detoxification. Generally, ferritin is synthesized when iron is available and repressed in times of iron deprivation. Up-regulation of ferritin has been shown to occur with increasing temperature (Salinas-Clarot, Gutiérrez, NúñezAcuña, \& Gallardo-Escárate, 2011), during infection and iron overload (Neves, Wilson, \& Rodrigues, 2009) as well as during periods of oxidative stress (Orino et al., 2001). Increased ferritin activity has also been identified in response to other heavy metals such as cadmium, copper, zinc, and lead (Jin, Li, Su, \& Li, 2011; Zhang et al., 2006; Zhang et al., 2013). This marker may therefore be useful in assessing exposure to metals, immune response and oxidative stress.

Apolipoproteins are antimicrobial proteins which play an important role in the primary defense barrier of fishes. These proteins are also major components of high density lipoprotein in fishes. Immune related functions of apolipoprotein include inhibition of bacterial endotoxin and inflammatory cytokines as well as antiviral activities (Johnston et al., 2008). These proteins have been reported as highly effective antimicrobials against a variety of Gram positive and Gram negative bacteria including Escherichia coli, Mycobacterium marinum, and Streptococcus sp., (Concha, Molina, Oyarzún, Villanueva, \& Amthauer, 2003; Concha et al., 2004; Johnston et al., 2008). Previous evaluation of gene expression found apolipoprotein activity to be down- 
regulated in common carp exposed to industrial effluent. The authors suggests that this downregulation may be the result of increased lipid and fatty acid oxidation which occurs when lipid resources become depleted as a result of pollutant exposure and/or stress (Handy, Sims, Giles, Campbell, \& Musonda, 1999). The evaluation of apolipoprotein may therefore be used to indicate stress, contaminants exposure and/or immune response.

Similar to apolipoprotein, hepcidin is an antimicrobial peptide involved in innate immune responses. In fishes, hepcidin expression is induced during bacterial infections (Li et al., 2013; Shike et al., 2002) or iron overload (Hu et al., 2007). The role of estrogenic EDCs in hepcidin expression has also been evaluated. In both largemouth and smallmouth bass, hepcidin-1 was down-regulated, while hepcidin-2 expression appeared to be inhibited, following $17 \beta$-estradiol exposure (Robertson, Iwanowicz, \& Marranca, 2009). Benzo(a)pyrene (BaP), another known EDC, has also been shown to alter hepcidin expression in embryo and fry of red sea bream (Pagarus major) (Wang et al., 2009). These antimicrobial markers may therefore be indicative of stress through pollutant exposure, increased susceptibility of an individual to infections, iron overloading and/or exposure to EDCs.

Cytochromes P450 (CYP) are a diverse multi-gene family of heme-containing proteins which may oxidize, hydrolyze or reduce compounds through the insertion of an atom of atmospheric oxygen. Several genes from this family will be evaluated including CYP1A, CYP1B, CYP3A, CYP11C, CYP17 and CYP19A. The most commonly measured of the cytochrome P450 family, CYP1A, is often associated with adverse effects including apoptosis, embryonic mortality, or the general need for detoxification of the liver (Whyte, Jung, Schmitt, \& Tillitt, 2000). Induction of CYP1A occurs via the binding of structurally similar contaminants including polychlorinated dibenzo-p-dioxins (PCDDs), PCBs, polychlorinated bibenzofurans 
(PCDFs) and PAHs, to the cytosolic aryl hydrocarbon receptor (AHR). This receptor binding triggers expression of multiple genes, including CYP1A, known as the Ah-gene battery (Nebert et al., 2000). Closely related CYP3A is considered the principal drug-metabolizing enzyme in fishes. Increased expression of CYP3A has been identified in aquatic species in response to PCBs (Gräns et al., 2015), nonylphenol (Meucci \& Arukwe, 2006), tetrachlorodibenzodioxin (Tseng, Hseu, Buhler, Wang, \& Hu, 2005), pregnenolone 16 $\alpha$-carbonitrile (Bresolin, de Freitas Rebelo, \& Celso Dias Bainy, 2005) and is likely to occur following exposure to many other compounds which to date remain unevaluated. Evaluation of these members of the CYP family will therefore allow the detection of responses of non-model fishes to exposure to a broad range of contaminants.

Aryl hydrocarbon receptor is a ligand-activated transcription factor which mediates the expression of a variety of genes, particularly those involved in metabolizing xenobiotics such as CYP1A and CYP1B. Aryl hydrocarbon receptor occurs in association with chaperone molecules including heat shock protein 90. Following ligand binding, aryl hydrocarbon receptor is released from the heat shock protein 90 complex and forms a new complex with aryl hydrocarbon receptor nuclear translocator (ARNT). This complex binds dioxin response elements leading to their increased expression. Molecules known to bind aryl hydrocarbon receptor include aromatic hydrocarbons, chlorinated dioxins, and halogenated aromatic hydrocarbons. In fish, two aryl hydrocarbon receptor forms have been identified (AHR1 and AHR2). The regulation of aryl hydrocarbon receptor expression has been studied in a number of fish species in both laboratory (Arukwe, Nordtug, Kortner, Mortensen, \& Brakstad, 2008; Holth et al., 2008; Lu et al., 2013) and wild caught individuals (Meyer, Wassenberg, Karchner, Hahn, \& Di Giulio, 2003) and is well established as a marker of biodegradation of toxic and carcinogenic compounds. 
Epoxide hydrolase functions in detoxification during drug metabolism by converting epoxides to transdihydrodiols which can be extracted from the body. Epoxides are often present as a result of degradation of aromatic compounds following their biotransformation by cytochrome P450. Information on the expression of epoxide hydrolase in fish species is limited; however, up-regulation of epoxide hydrolase has been reported after exposure to oil-derived PAHs and alkylphenols in zebra fish (Holth et al., 2008). Interestingly in rats, epoxide hydrolase expression has been experimentally induced in neoplastic nodules and primary hepatocellular carcinomas (Kondo et al., 1990). The measurement of epoxide hydrolase may therefore be useful in assessing metabolism of xenobiotics and may also coordinate with analysis of histological endpoints.

Hypoxia-inducible factor is thought to be the primary regulator of hypoxia-inducible gene expression in both mammals and fish (Nikinmaa \& Rees, 2005). Hypoxia-inducible factor1 is part of a complex which is expressed in conjunction with aryl hydrocarbon receptor nuclear translocator and aryl hydrocarbon receptor. In times of reduced oxygen tension, aryl hydrocarbon receptor nuclear translocator binds to hypoxia-inducible factor and then to hypoxia response elements (HRE) which control the transcription of more than 100 genes (Kodama, Saydur Rahman, Horiguchi, \& Thomas, 2012). Previous studies of aquatic organisms have shown evidence of increased activity of hypoxia-inducible factor in response to low oxygen levels (Thomas \& Rahman, 2009; Thomas, Rahman, Khan, \& Kummer, 2007). Activation of hypoxia-inducible factor has also been identified following the binding of contaminants including dioxin (Gradin et al., 1996) and BaP (Yu et al., 2008). Evaluation of this biomarker may therefore provide evidence of exposure to hypoxic conditions and/or contaminants. 


\section{Neoplasia}

At several of the AOCs sampled in this study increased prevalence of both skin and liver tumors has been identified. In an effort to increase understanding of the mechanisms by which tumors are initiated and promoted, gene expression markers which have been associated with neoplasia in our species of interest or other model organisms were included. These markers include transforming growth factor $\beta$ (TGF $\beta$ ), cystenin-rich protein (CRP), epidermal growth factor receptor (EGFR), granulin (GRN), catenin $\beta$ ( $\beta$-CAT), fibroblast growth factor (FGF), tumor suppression gene p53 (TP53), K-ras oncogene (v-K-ras), tumor necrosis factor (TNF), keratin (KRT), proliferation cell nuclear antigen (PCNA) and arginase (ARG).

Cystenin-rich proteins are involved in processes of cell proliferation and are known to function in specific protein-protein interactions during cellular differentiation. Evidence of the regulatory functions of cystenin-rich proteins include the association of carcinogenesis, processes associated with wound healing, and fibrogenic-inflammatory disorder to down regulation of the gene (Weiskirchen $\&$ Gunther, 2003). In liver tissue, cystenin-rich protein may play a role in liver cell differentiation. Increased expression of cystenin-rich protein was associated with moderately and well differentiated hepatocellular carcinomas. Furthermore, it was one of seven genes identified as highly predictable in correlation with moderately to welldifferentiated hepatocellular carcinomas (Midorikawa et al., 2002). In this study, the monitoring of variation in the regulation of this gene between normal and abnormal liver tissue, as identified by histology, may present evidence for its influence in the manifestation of liver lesions in fishes.

Transforming growth factor $\beta$ is a polypeptide that performs a multitude of cellular functions, including the control of cell growth, cell proliferation, cell differentiation and apoptosis as well as the activation and deactivation of immune cell functions (Li, Wan, Sanjabi, 
Robertson, \& Flavell, 2006). Low expression of transforming growth factor $\beta$ is thought to be associated with the recruitment and activation of leukocytes, resolution of inflammation and tissue repair. High expression however, can be indicative of unresolved inflammation and fibrosis (Wahl, 1994). Increased transforming growth factor $\beta$ activity has also been associated with proliferative mycobacterial infections and increased pathology in mammals (McCartneyFrancis \& Wahl, 1994). Though more often measured in the anterior kidney, this marker was included for general assessment of infection and inflammatory status of sampled fishes.

Epidermal growth factor receptor is a transmembrane tyrosine kinase that is essential to cellular growth, proliferation and apoptosis. Increases in the activity of epidermal growth factor receptor have the potential to cause unregulated cell division and has been associated with tumor progression in epithelial neoplasms of humans (Fogarty, Conus, Chu, \& McArthur, 2007). Epidermal growth factor receptor was also identified as a potential biomarker of arsenic exposure in humans (Sung, Wang, Chen, Hung, \& Guo, 2012). To date, no studies have been conducted regarding the expression of epidermal growth factor receptor in fishes; therefore, inclusion of this marker may provide the first information available for fishes on the role of this gene in the formation of liver lesions.

Granulins are part of a family of cysteine-rich proteins reported to have similar physiological effects as epidermal growth factor receptor and transforming growth factor $\beta$. Overexpression of granulin in humans is associated with various cancers where it suppresses apoptosis and promotes tumor invasion and expansion (Bateman \& Bennett, 1998). Additionally, granulin is known to be secreted by adult liver flukes Opisthorchis viverrini, $O$. felineus, and Chlonorchis sinensis. These secretions become bound to epithelial cells of the infected host (Sripa et al., 2012). Liver fluke infections are linked to both bile duct cancer and 
cholangiocarcinoma (Sripa et al., 2007). In this study, histological diagnosis of infection by liver fluke, bile duct cancer and cholangiocarcinoma may potentially be linked to the expression of this gene in fishes.

Catenin- $\beta$ controls the expression of genes which regulate cellular differentiation, proliferation, migration, apoptosis and tumorigenesis. It is activated by the Wnt pathway which has been shown to play many roles in liver development, regeneration and pathology. In humans, the activation of this pathway has been established in hepatoblastoma and hepatocellular carcinoma (Nejak-Bowen \& Monga, 2011). In teleosts, Wnt signaling has been studied during liver development and regeneration (Goessling et al., 2008); however, research has yet to be conducted regarding the potential role of this gene in hepatic neoplasia.

The fibroblast growth factor family consists of 23 structurally related proteins involved in physiological processes including cellular proliferation, migration, differentiation and wound healing. The binding of fibroblast growth factor to a receptor can result in the activation of one of three pathways: the RAS/mitogen-activation protein (MAP) kinase pathway, the phosphoionsitide 3 (PI3) kinase/AKT pathway or the phospholipase C gamma (PLC $\gamma$ ) pathway. The RAS/MAP kinase pathway is most commonly associated with fibroblast growth factor binding and is involved in cellular proliferation and differentiation (Teven, Farina, Rivas, \& Reid). Altered regulation of fibroblast growth factor signaling may promote tumor development by directly driving cancer cell proliferation or by supporting tumor angiogenesis (Turner \& Grose, 2010). In the liver, fibroblast growth factor 7 has been reported as a key regulator of CYP7A1 and as such aids in the maintenance of bile acid homeostasis and the protection of hepatocytes from excessive bile acid toxicity (Sun et al., 2012). 
The tumor suppression gene TP53 is one of the most frequently mutated genes identified in various types of cancer. Two conserved functions of mammalian TP53, tumor suppression and induction of apoptosis, have been reported in fish (Berghmans et al., 2005). Increased activity of the TP53 gene has been reported in fish following exposure to PAHs and EDCs (Min, Lee, \& Gu, 2003). In killifish (Kryptolebia marmoratus) exposed to EDCs, initial up-regulation of TP53 was followed by suppressed expression. This suppressed regulation of TP53 is suggested to predispose the host to tumorigenesis following long term exposure to contaminants (Lee et al., 2008). In brown bullhead, TP53 activity was significantly higher in fish collected from contaminated areas of Lake Erie relative to those from control locations. It is suggested that these bullhead populations may have acquired resistance to contaminants by selecting phenotypes with low CYP1A expression and high TP53 expression. In this case, conclusions were drawn based on exposure to a single compound (BaP); therefore, assessment of exposure to contaminant mixtures is required for the application of these findings to wild populations (Williams \& Hubberstey, 2014). In addition to its function as a tumor suppression protein, TP53 may also play a role in innate immunity and has been identified as up-regulated in channel catfish in response to bacterial infection (Mu et al., 2015).

The v-K-ras oncogene is crucial to normal tissue signaling. Mutation of this gene has been identified as an essential step in the development of many cancers. The gene received its name in the late 1970s when the transforming activity of the rat-derived Harvey and Kirsten murine sarcoma retroviruses were identified and termed ras for rat sarcoma virus. In human liver cancers, approximately $7 \%$ of patients display mutations in the v-K-ras gene (Karnoub \& Weinberg, 2008). Little work has been done to assess potential correlations between v-K-ras expression and liver neoplasia in fish. A transgenic zebrafish model for hepatocellular 
carcinoma was established by overexpression of v-K-ras. Using this model, high levels of v-Kras expression were found to be crucial in the progression of liver tumorigenesis from hyperplasia to carcimona (Nguyen et al., 2011). The inclusion of v-K-ras in this study may help to corroborate these findings and provide evidence between $\mathrm{v}$-K-ras expression and progression of liver tumors in wild caught fishes.

Tumor necrosis factor gene belongs to a superfamily which was initially named for its hemorrhagic necrosis of tumors. Tumor necrosis factor regulates immune responses and inflammation as well as cellular survival and apoptosis. Despite its importance in these pathways very little work has been done on its expression in fishes. In largemouth bass, tumor necrosis factor was down-regulated following exposure to methoxychlor (Martyniuk, Spade, Blum, Kroll, \& Denslow, 2011). Additional information regarding the effects of contaminants and other stressors on the expression of this gene is lacking; therefore, the results of this study may contribute significantly to current knowledge of the regulation of this gene.

Keratin functions as intermediate filaments which attach epithelial cells to desmosomes to provide strength and shape to cells. Keratin primarily provides epithelial cells protection from mechanical and non-mechanical stressors and prevents cell death through the regulation of cell signaling and apoptosis (Coulombe \& Omary, 2002). Its function in innate immunity is not fully understood; however, up-regulation has been reported in crucian carp (Carassius auratus gibelio) following herpsevirus challenges (Podok, Wang, Xu, Xu, \& Lu, 2014). In human cancer diagnostics, keratins are commonly used markers. Keratin- 8 is the primary keratin in simple epithelial cells, including hepatocytes. Mutations in keratin- 8 have been linked to predisposition to chronic (Omary, Ku, Strnad, \& Hanada, 2009) and acute liver disease (Strnad et al., 2010). 
Research on the role of keratin-8 in skin and liver tumors in teleosts is currently lacking and thus data obtained from this marker will be useful in assessing its utility in fishes.

Proliferation cell nuclear antigen is an important regulator of the cell cycle. It has been previously used as an immunohistochemical marker for liver carcinogenesis and was detected at elevated levels in all stages of tumor development (Köhler, Bahns, \& Van Noorden, 1998). Increased proliferation cell nuclear antigen expression has also been associated with exposure to a suspected carcinogen ( $\mathrm{N}$-nitrosodiethylamine) and pre-neoplasic changes in liver tissue (Machado, Cunha, Reis-Henriques, \& Ferreira, 2014). In the liver of perch infected by tapeworm (Triaenophorus nodulosus), proliferation cell nuclear antigen-positive hepatocytes were identified in significantly higher numbers (Dezfuli, Giari, Lorenzoni, Manera, \& Noga, 2014). Analysis of proliferation cell nuclear antigen expression may therefore be representative of exposure to carcinogens or parasites or the development of hepatic tumors.

Arginase is an enzyme which catalyzes the last step of the urea cycle by converting Larginine to L-ornithine and urea. Two forms of arginase have been identified, cystolic arginase I and mitochondrial arginase II. The wide distribution of arginase throughout many tissues suggests its importance in functions other than the urea cycle (Srivastava \& Ratha, 2010). Arginase may play a vital role in the immune system as it can deplete arginine, which is essential to proliferation and survival of pathogens and host cells (Vincendeau, Gobert, Daulouede, Moynet, \& Mossalayi, 2003). Arginine requirements are elevated during acute stress and malignant cell growth and therefore, in many tumors, and particularly in hepatic cancers, arginine demand is beyond its natural supply (Wheatley \& Campbell, 2002). The application of arginase to rat carcinoma by intraperitoneal injection was able to reduce tumor growth by 31 71\% (Bach \& Swaine, 1995). Most patients with hepatocellular carcinoma who were 
experimentally treated to leak arginase from the liver into circulation depleted arginine successfully and experienced varying degrees of remission in all primary tumors (Cheng, Leung, Lo, Tsui, \& Lam, 2005). Although arginase has been isolated in fishes, no research on its expression or potential role in liver tumors has been reported to date.

\section{Endocrine disruption}

In fish species, reproduction is regulated by the hypothalamic-pituitary-gonadal (HPG) axis as well as the liver. Dysregulated expression of genes along this axis associated with signaling, biosynthesis or metabolism may cause disruption of the endocrine system and adversely affect the reproductive success of individuals. Numerous EDCs have been shown to cause such modulation by blocking or mimicking the activities of natural estrogens through the binding of either estrogen and/or androgen receptors. Biomarkers for the assessment of the effects of EDCs include estrogen receptors (ER), androgen receptors (AR), peroxisome proliferator-activated receptors (PPAR), hydroxysteroid dehydrogenases (3 $\beta \mathrm{HSD}, 11 \beta \mathrm{HSD}$, 17ßHSD), steroidogenic acute regulatory protein (STAR), vitellogenin (VTG), choriogenin (CGR), insulin-like growth factor (IGF1), thyroid hormone receptors (THR), iodothyronine deiodinases (DIO), CYP19 and CYP17.

Estrogen receptors are transcription factors which control the expression of genes involved in metabolism, development, reproduction and homeostasis. Generally, estrogen receptors are activated upon the binding of hormonal molecules, either natural or synthetic, resulting in the synthesis of a number of estrogen response genes. In teleosts, three subtypes of estrogen receptors exist, estrogen receptor $\alpha$, estrogen receptor $\beta$ and estrogen receptor $\gamma$. Estrogen receptor $\alpha$ is most commonly expressed in liver tissue while estrogen receptor $\beta$ and estrogen receptor $\gamma$ are predominately found in other tissues. Up-regulation of estrogen receptor 
$\alpha$ has been shown in the hepatic tissue of multiple fish species exposed to $17 \beta$-estradiol treatments (Davis et al., 2008; Filby, Thorpe, \& Tyler, 2006; Halm et al., 2004; Marlatt et al., 2008). Additionally, EDCs such as methoxychlor, atrazine, p,p'-DDE and nonylphenol, have been known to modulate estrogen receptors (Martyniuk et al., 2011; Wu et al., 2014; Yang et al., 2010). The estrogen receptor pathway is closely associated with vitellogenin, arguably the most commonly measured marker of exposure to EDCs in males (Marlatt et al., 2008). The expression of estrogen receptors will vary temporally and between sexes. Previously in largemouth bass, estrogen receptor $\alpha$ was found to be more highly up-regulated than estrogen receptor $\beta$ or estrogen receptor $\gamma$ in the spring when plasma $17 \beta$-estradiol and vitellogenin levels were elevated (Sabo-Attwood, Kroll, \& Denslow, 2004). The sensitivity of these markers and their divergent expression between seasons, sexes and presumably species will allow for essential comparisons in their activity under variable conditions which may assist in providing a baseline for normal physiological responses with which to assess the effects of exposure to EDCs.

Vitellogenin is the precursor of egg yolk protein in oviparious teleosts. Vitellogenin synthesis is mediated through the estrogen receptor pathway and occurs in the liver following the stimulation of ovarian estrogens. It is then transported via the blood to the ovary and used in the production of oocytes (Yamaguchi, Ishibashi, Kohra, Arizono, \& Tominaga, 2005). In general, levels of vitellogenin in either the plasma or hepatic tissue should be high in female fish and absent or relatively low in males; however, recent studies have shown the induction of vitellogenin in male fish exposed to EDCs (Blazer, Iwanowicz, et al., 2014; Iwanowicz et al., 2016). As a result, vitellogenin production in male or juvenile fish has become a useful biomarker for detecting estrogenic contamination of aquatic environments (Sumpter \& Jobling, 
1995). Similarly, choriogenin, a precursor protein of egg envelope will be assessed and is expected to show analogous modulation patterns to vitellogenin (Yu, Wong, Kong, $\mathrm{Wu}, \&$ Cheng, 2006).

Androgen receptor is a steroid-hormone activated transcription factor which plays an essential role in sexual differentiation and maturation. After being bound, the androgen receptor translocates and stimulates the transcription of androgen response genes. In teleost fish, two different subtypes, androgen receptor $\alpha$ and androgen receptor $\beta$ have been reported (Douard, Robinson-Rechavi, Laudet, \& Guiguen, 2003). Endocrine disrupting compounds may interfere with androgen action; however, relatively little is known about the androgenic/antiandrogenic activities of EDCs. Androgen receptor disruptors are broadly classified as agonists that bind the receptor to mimic the action of natural androgen, or antagonist, which bind and block androgen receptor activation. In either case, disruption of the androgen receptor can result in altered sexual development or spermatogenesis and overall feminization of male individuals (LuccioCamelo \& Prins, 2011).

Peroxisome proliferator-activated receptor belongs to the superfamily of nuclear hormone receptors involved in controlling cellular functions including lipid metabolism, inflammation and cellular differentiation. They are activated by substances which increase the number and size of peroxisomes within an organism. In teleosts, peroxisomes are increased after treatment with pesticides, phthalates, alkylphenols and estrogens (Ortiz-Zarragoitia \& Cajaraville, 2005). Significant up-regulation of peroxisome proliferator-activated receptors $\alpha$ was seen following exposure of benthic sole (Solea solea) to 4-nonylphenol, a well-known EDC (Cocci, Mosconi, \& Palermo, 2013). Peroxisome proliferator-activated receptors may also interact with estrogen receptor. The exact mechanism by which this occurs is not fully understood but it has been 
suggested that peroxisome proliferator-activated receptors may act by directly binding estrogen response elements (Nunez et al., 1997) or may inhibit estrogen receptors by competitively binding estrogen response elements (Keller, Givel, Perroud, \& Wahli, 1995).

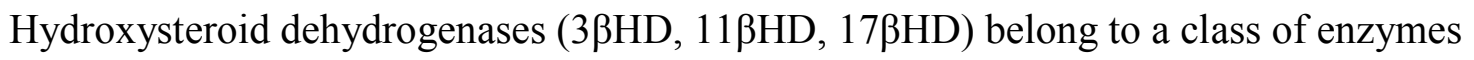
which are involved in the last step of steroid synthesis. Depending on type, $17 \beta$-hydroxysteroid dehydrogenase is involved in the conversion of estrone to estradiol or androstenedione to testosterone. $11 \beta$-hydroxysteroid dehydrogenase maintains steroid regulation through the balance of glucocorticoids by converting cortisone to cortisol or vice versa. $3 \beta$-hydroxysteroid dehydrogenase catalyzes the synthesis of progesterone from pregnenolone, 17hydroxyprogesterone from 17-hydroxypregnenoion and androstenedione from dehydropiandrosterone. Various expression studies have been performed for each of these genes. Down regulation of $17 \beta$-hydroxysteroid dehydrogenase has been reported in both male and female zebrafish exposed to PAHs and alkylphenols (Holth et al., 2008). Gender-specific and seasonal variation of $17 \beta$-hydroxysteroid dehydrogenase in brown trout was examined by Castro et al. (2009) who reported seasonal variation in females only during vitellogenesis. Down regulation of both $3 \beta$-hydroxysteroid dehydrogenase and $17 \beta$-hydroxysteroid dehydrogenase was found in rat models exposed to PCBs (Andric, Kostic, Stojilkovic, \& Zovaceciv, 2000). In catfish, 11 $\beta$-hydroxysteroid dehydrogenase expression was correlated with circulating 11ketotestosterone and $11 \beta$-hydroxytestosterone suggesting a role in testicular differentiation and seasonal variation (Rasheeda, Kagawa, Kirubagaran, Dutta-Gupta, \& Senthilkumaran, 2010). Collectively, the inclusion of these markers may provide evidence of disruption of steroid synthesis as a result of environmental stressors and/or contaminant exposure. 
Aromatase (CYP19A) catalyzes the final step of the conversion of androgen to estrogen. In teleosts, two different aromatase genes have been found which are structurally and functionally different CYP19A1 and CYP19B, which is also known as CYP19A2 (Cheshenko et al., 2008). These genes are primarily expressed in the ovary and brain, respectively, and therefore their inclusion in the analysis of liver gene expression is experimental. The closely related CYP17 gene, also known as $17 \alpha$-hydroxylase, produces steroid hormones during oocyte maturation. In teleosts, two forms of 17 $\alpha$-hydroxylase have been identified (CYP17-1 and CYP17-2). Like aromatase, it is mainly expressed in gonad and anterior kidney (Ding et al., 2013) and was included in liver expression analysis for experimental purposes.

Another member of the cytochrome P450 family, CYP11A is involved in the initiation of synthesis of corticosteroids and sex steroids. Cholesterol for the side chain cleavage and subsequent steroid synthesis performed by CYP11A is delivered by the steroidogenic acute regulatory protein. Activity of steroidogenic acute regulatory protein can therefore be representative of the rate at which steroid synthesis occurs. A large majority of research on the effects of EDCs on steroidogenic acute regulatory protein expression have focused on gonadal tissue (Liu et al., 2014; Nakamura, Kusakabe, \& Young, 2009; Zhang et al., 2014). In hepatic tissue, overexpression of steroidogenic acute regulatory protein has been linked to increased bile acid production in humans and rats (Hall et al., 2005; Pandak et al., 2002). Further information on steroidogenic acute regulatory protein expression in the hepatic tissue of fishes is limited; therefore, results of this study may add substantially to our knowledge of the modulation of this gene in wild-caught aquatic species.

The insulin-like growth factor system is part of the growth hormone/insulin-like growth factor axis and is essential for cell growth, differentiation, metabolism and reproduction. Insulin- 
like growth factor is mainly produced in the liver where its synthesis and release into circulation is stimulated by growth hormone (GH). In turn, serum insulin-like growth factor levels stimulate the release of growth hormone in a system known as the growth hormone/insulin-like growth factor route (Shved, Berishvili, Mazel, Baroiller, \& Eppler, 2011). Insulin-like growth factor may be influenced by sex steroids, thyroid hormones and glucocorticoids (Wood, Duan, \& Bern, 2005). Exposure of tilapia (Oreochromis mossambicus) to E2 produced significant reduction of insulin-like growth factor expression in males while converse exposure of females to the androgen dihydrotestosterone resulted in up-regulation of insulin-like growth factor expression (Riley, Hirano, \& Grau, 2004). Insulin-like growth factor has also been implicated in immune functions. Decreased insulin-like growth factor expression has been reported during infection with vibriosis (Deane \& Woo, 2005) and Edwardsiella ictaluri (Saera-Vila, Calduch-Giner, Prunet, \& Perez-Sanchez, 2009). This marker may therefore be useful in addressing exposure to EDCs, assessing immune related responses and general growth and reproductive disturbances. Thyroid hormones have important roles in development, growth, reproduction and osmoregulation and function through the binding of thyroid hormone receptors (THR). These receptors are hormone-inducible transcription factors which regulate the expression of genes in the hypothalamus-pituitary-thyroid axis (HPT). Teleosts possess two thyroid hormone receptors, known as thyroid hormone receptor $\alpha$ and thyroid hormone receptor $\beta$. Numerous studies have been performed on model species in laboratory settings and have identified a number of contaminants including PCBs, dioxin, pesticides, PBDEs and heavy metals as disruptors of thyroid hormone receptor expression (Adams, Cyr, \& Eales, 2000; Li et al., 2014a, 2014b; L. Yu, Chen, Liu, Gui, \& Zhu, 2013). Increasing evidence for thyroid disruption in wild caught fish is also becoming available. Altered thyroid hormone levels have been reported in shiner 
surfperch (Cymatogaster aggregata) and Pacific staghorn sculpin (Leptocottus armatus) from the San Francisco Bay (Brar, Waggoner, Reyes, Fairey, \& Kelley, 2010) as well as wild sea bass (Dicentrarchus labrax) from European coasts (Schnitzler, Klaren, Bouquegneau, \& Das, 2012). During the metamorphosis of tadpoles, increased thyroid hormone receptor $\beta$ was reported following exposure to waste water effluent known to contain a variety of anthropogenic contaminants (Searcy et al., 2012). Evaluation of expression of thyroid hormone receptors will therefore provide further information on potential modes of action following contaminant exposure.

Iodothyronine deiodinases are enzymes essential to the first step in thyroid hormone action and catalyze the removal of iodine atoms from thyroid hormones in order to cause their activation or deactivation. In teleosts, three types of iodothyronine deiodinase enzymes (type I, II, and III) are expressed. In this study type I and II will be evaluated. In fish, both iodothyronine deiodinase 1 and iodothyronine deiodinase 2 function in hormone biotransformation by converting thyroid hormone T4 to thyroid hormone T3. Despite their importance in thyroid hormone biotransformation, iodothyronine deiodinases are not commonly used markers of contaminant exposure as no specific patterns of iodothyronine deiodinase expression and exposure have been established. Although both types function similarly, differences have been noted in their expression. Particularly in the liver, iodothyronine deiodinase 2 has shown higher sensitivity in response to internal and external stimulants (Sambroni et al., 2001). Similarly, wild caught walleye exposed to EDCs showed up-regulation of iodothyronine deiodinase 2 but not iodothyronine deiodinase 1 in contaminated versus references sites (Picard-Aitken, Fournier, Pariseau, Marcogliese, \& Cyr, 2007). Evaluation of 
the expression of these genes will therefore contribute significantly to existing knowledge of their regulation following exposure to contaminants.

\section{Management Implications}

The evaluation of gene expression markers identified above can be used to assist both fisheries managers and ecotoxicologists. Modulation of gene expression endpoints are among the first measurable changes following exposure to environmental stressors. Synthesis of data from gene expression endpoints, water and sediment chemical analysis and organismal level responses, including tumor and intersex prevalence, provides a comprehensive evaluation of the biological effects of stressors at Great Lakes AOCs on resident organisms. The linkage of molecular initiation events to adverse outcomes at higher levels of biological organization produces information that can be used to inform risk assessment and subsequent management and remediation efforts. The data collected by this study represents the most comprehensive dataset collected with regards to the health of resident fishes at Great Lakes AOCs. The information provided by this study will significantly increase our understanding and ability to mitigate anthropogenic threats facing this region.

\section{References}

Adams, B. A., Cyr, D. G., \& Eales, J. G. (2000). Thyroid hormone deiodination in tissues of American plaice, Hippoglossoides platessoides: characterization and short-term responses to polychlorinated biphenyls (PCBs) 77 and 126. Comp Biochem Physiol C Toxicol Pharmacol, 127(3), 367-378.

Airaksinen, S., Rabergh, C. M., Lahti, A., Kaatrasalo, A., Sistonen, L., \& Nikinmaa, M. (2003). Stressordependent regulation of the heat shock response in zebrafish, Danio rerio. Comp Biochem Physiol A Mol Integr Physiol, 134(4), 839-846.

Aliza, D., Ismail, I. S., Kuah, M. K., Shu-Chien, A. C., \& Tengku Muhammad, T. S. (2008). Identification of Wap65, a human homologue of hemopexin as a copper-inducible gene in swordtail fish, Xiphophorus helleri. Fish Physiology and Biochemistry, 34(2), 129-138. 
Aluru, N., Jorgensen, E. H., Maule, A. G., \& Vijayan, M. M. (2004). PCB disruption of the hypothalamus-pituitary-interrenal axis involves brain glucocorticoid receptor downregulation in anadromous Arctic charr. Am J Physiol Regul Integr Comp Physiol, 287(4), R787-793. doi: 10.1152/ajpregu.00091.2004

Amiard, J. C., Amiard-Triquet, C., Barka, S., Pellerin, J., \& Rainbow, P. S. (2006). Metallothioneins in aquatic invertebrates: Their role in metal detoxification and their use as biomarkers. Aquat Toxicol, 76(2), 160-202. doi: http://dx.doi.org/10.1016/j.aquatox.2005.08.015

An, L.-h., Lei, K., \& Zheng, B.-h. (2014). Use of heat shock protein mRNA expressions as biomarkers in wild crucian carp for monitoring water quality. Environmental Toxicology and Pharmacology, 37(1), 248-255. doi: http://dx.doi.org/10.1016/j.etap.2013.11.019

Andric, S. A., Kostic, T. S., Stojilkovic, S. S., \& Zovaceciv, R. Z. (2000). Inhibtion of Rat Testicular Endrogenesis by a Polychlorinated Biphenyl Mixture Aroclor 1248. Biology of Reproduction, 62(6), 1882-1888.

Ankley, G. T., Bennett, R. S., Erickson, R. J., Hoff, D. J., Hornung, M. W., Johnson, R. D., . . . Villeneuve, D. L. (2010). Adverse outcome pathways: A conceptual framework to support ecotoxicology research and risk assessment. Environmental Toxicology and Chemistry, 29(3), 730-741. doi: 10.1002/etc.34

Arukwe, A., Nordtug, T., Kortner, T. M., Mortensen, A. S., \& Brakstad, O. G. (2008). Modulation of steroidogenesis and xenobiotic biotransformation responses in zebrafish (Danio rerio) exposed to water-soluble fraction of crude oil. Environ Res, 107(3), 362-370. doi:

10.1016/j.envres.2008.02.009

Atli, G., Alptekin, Ö., Tükel, S., \& Canli, M. (2006). Response of catalase activity to Ag+, Cd2+, Cr6+, $\mathrm{Cu} 2+$ and $\mathrm{Zn} 2+$ in five tissues of freshwater fish Oreochromis niloticus. Comparative Biochemistry and Physiology Part C: Toxicology \& Pharmacology, 143(2), 218-224. doi: http://dx.doi.org/10.1016/j.cbpc.2006.02.003

Bach, S. J., \& Swaine, D. (1995). The Effect of Arginase on the Retardation of Tumor Growth. British Journal of Cancer, 19(2), 379-386.

Basu, N., Todgham, A. E., Ackerman, P. A., Bibeau, M. R., Nakano, K., Schulte, P. M., \& Iwama, G. K. (2002). Heat shock protein genes and their functional significance in fish. Gene, 295(2), 173-183. doi: http://dx.doi.org/10.1016/S0378-1119(02)00687-X

Bateman, A., \& Bennett, H. P. (1998). Granulins: the structure and function of an emerging family of growth factors. $J$ Endocrinol, 158(2), 145-151.

Baumann, P. C., Smith, I. R., \& Metcalfe, C. D. (1996). Linkages Between Chemical Contaminants and Tumors in Benthic Great Lakes Fish. Journal of Great Lakes Research, 22(2), 131-152. doi: http://dx.doi.org/10.1016/S0380-1330(96)70946-2

Berghmans, S., Murphey, R. D., Wienholds, E., Neuberg, D., Kutok, J. L., Fletcher, C. D., . . Look, A. T. (2005). tp53 mutant zebrafish develop malignant peripheral nerve sheath tumors. Proc Natl Acad Sci U S A, 102(2), 407-412. doi: 10.1073/pnas.0406252102 
Blair, B. D., Crago, J. P., Hedman, C. J., \& Klaper, R. D. (2013). Pharmaceuticals and personal care products found in the Great Lakes above concentrations of environmental concern. Chemosphere, 93, 216-223.

Blazer, V. S., Hoffman, J., Walsh, H. L., Braham, R. P., Hahn, C., Collins, P., . . Ledder, T. (2014). Health of white sucker within the St. Louis River area of concern associated with habitat usage as assessed using stable isotopes. Ecotoxicology, 23(2), 236-251. doi: 10.1007/s10646-013-1167-5

Blazer, V. S., Iwanowicz, D. D., Iwanowicz, L. R., Smith, D. R., Young, J. A., Hedrick, J. D., . . Reeser, S. J. (2007). Intersex (Testicular Oocytes) in Smallmouth Bass Micropterus dolomieu from the Potomac River and Selected Nearby Drainages. J Aquat Anim Health, 19, 242-253.

Blazer, V. S., Iwanowicz, D. D., Walsh, H. L., Sperry, A. J., Iwanowicz, L. R., Alvarez, D. A., . . Manning, R. (2014). Reproductive health indicators of fishes from Pennsylvania watersheds: association with chemicals of emerging concern. Environ Monit Assess, 186(10), 6471-6491. doi: $10.1007 / \mathrm{s} 10661-014-3868-5$

Blazer, V. S., Iwanowicz, L. R., Henderson, H., Mazik, P. M., Jenkins, J. A., Alvarez, D. A., \& Young, J. A. (2012). Reproductive endocrine disruption in smallmouth bass (Micropterus dolomieu) in the Potomac River basin: spatial and temporal comparisons of biological effects. Environ Monit Assess, 184(7), 4309-4334. doi: 10.1007/s10661-011-2266-5

Blazer, V. S., Rafferty, S. D., Baumman, P. C., Smith, S. B., \& Obert, E. C. (2009a). Assessment of the "fish tumors or other deformities" beneficial use impairment in brown bullhead (Ameiurus nebulosus): I. Orocutaneous tumors. Journal of Great Lakes Research, 35(4), 517-526. doi: http://dx.doi.org/10.1016/j.jglr.2009.08.005

Blazer, V. S., Rafferty, S. D., Baumman, P. C., Smith, S. B., \& Obert, E. C. (2009b). Assessment of the "fish tumors or other deformities" beneficial use impairment in brown bullhead (Ameiurus nebulosus): II. Liver neoplasia. Journal of Great Lakes Research, 35(4), 527-537. doi: 10.1016/j.jglr.2009.08.011

Brar, N. K., Waggoner, C., Reyes, J. A., Fairey, R., \& Kelley, K. M. (2010). Evidence for thyroid endocrine disruption in wild fish in San Francisco Bay, California, USA. Relationships to contaminant exposures. Aquat Toxicol, 96(3), 203-215. doi:

http://dx.doi.org/10.1016/j.aquatox.2009.10.023

Bresolin, T., de Freitas Rebelo, M., \& Celso Dias Bainy, A. (2005). Expression of PXR, CYP3A and MDR1 genes in liver of zebrafish. Comparative Biochemistry and Physiology Part C: Toxicology \& Pharmacology, 140(3-4), 403-407. doi: http://dx.doi.org/10.1016/j.cca.2005.04.003

Caseras, A., Metón, I., Fernández, F., \& Baanante, I. V. (2000). Glucokinase gene expression is nutritionally regulated in liver of gilthead sea bream (Sparus aurata). Biochimica et Biophysica Acta (BBA) - Gene Structure and Expression, 1493(1-2), 135-141. doi: http://dx.doi.org/10.1016/S0167-4781(00)00173-1

Castro, L. F. C., Rocha, M. J., Lobo-da-Cunha, A., Batista-Pinto, C., Machado, A., \& Rocha, E. (2009). The 17ß-hydroxysteroid dehydrogenase 4: Gender-specific and seasonal gene expression in the liver of brown trout (Salmo trutta f. fario). Comparative Biochemistry and Physiology Part B:

Biochemistry and Molecular Biology, 153(2), 157-164. doi: http://dx.doi.org/10.1016/j.cbpb.2009.02.015 
Cheek, A. O., Brouwer, T. H., Carroll, S., Manning, S., McLachlan, J. A., \& Brouwer, M. (2001). Experimental evaluation of vitellogenin as a predictive biomarker for reproductive disruption. Environ Health Perspect, 109(7), 681-690.

Chen, Y.-M., Kuo, C.-E., Chen, G.-R., Kao, Y.-T., Zou, J., Secombes, C. J., \& Chen, T.-Y. (2014). Functional analysis of an orange-spotted grouper (Epinephelus coioides) interferon gene and characterisation of its expression in response to nodavirus infection. Developmental \& Comparative Immunology, 46(2), 117-128. doi: http://dx.doi.org/10.1016/j.dci.2014.04.004

Cheng, P. N. M., Leung, Y. C., Lo, W. H., Tsui, S. M., \& Lam, K. C. (2005). Remission of hepatocellular carcinoma with arginine depletion induced by systemic release of endogenous hepatic arginase due to transhepatic arterial embolisation, augmented by high-dose insulin: arginase as a potential drug candidate for hepatocellular carcinoma. Cancer Letters, 224(1), 67-80. doi: http://dx.doi.org/10.1016/j.canlet.2004.10.050

Cheshenko, K., Pakdel, F., Segner, H., Kah, O., \& Eggen, R. I. (2008). Interference of endocrine disrupting chemicals with aromatase CYP19 expression or activity, and consequences for reproduction of teleost fish. Gen Comp Endocrinol, 155(1), 31-62. doi: 10.1016/j.ygcen.2007.03.005

Cocci, P., Mosconi, G., \& Palermo, F. A. (2013). Effects of 4-nonylphenol on hepatic gene expression of peroxisome proliferator-activated receptors and cytochrome P450 isoforms (CYP1A1 and CYP3A4) in juvenile sole (Solea solea). Chemosphere, 93(6), 1176-1181. doi: http://dx.doi.org/10.1016/j.chemosphere.2013.06.058

Collier, T. K., Singh, S. V., Awasthi, Y. C., \& Varanasi, U. (1992). Hepatic xenobiotic metabolizing enzymes in two species of benthic fish showing different prevalences of contaminant-associated liver neoplasms. Toxicology and Applied Pharmacology, 113(2), 319-324. doi: http://dx.doi.org/10.1016/0041-008X(92)90131-B

Concha, M. I., Molina, S. a., Oyarzún, C., Villanueva, J., \& Amthauer, R. (2003). Local expression of apolipoprotein A-I gene and a possible role for HDL in primary defence in the carp skin. Fish Shellfish Immunol, 14(3), 259-273. doi: http://dx.doi.org/10.1006/fsim.2002.0435

Concha, M. I., Smith, V. J., Castro, K., Bastías, A., Romero, A., \& Amthauer, R. J. (2004). Apolipoproteins A-I and A-II are potentially important effectors of innate immunity in the teleost fish Cyprinus carpio. European Journal of Biochemistry, 271(14), 2984-2990.

Coulombe, P. A., \& Omary, M. B. (2002). 'Hard' and 'soft' principles defining the structure, function and regulation of keratin intermediate filaments. Current Opinion in Cell Biology, 14(1), 110-122. doi: http://dx.doi.org/10.1016/S0955-0674(01)00301-5

Crago, J., Corsi, S. R., Weber, D., Bannerman, R., \& Klaper, R. (2011). Linking biomarkers to reproductive success of caged fathead minnows in streams with increasing urbanization. Chemosphere, 82(11), 1669-1674. doi: 10.1016/j.chemosphere.2010.11.011

Davis, L. K., Pierce, A. L., Hiramatsu, N., Sullivan, C. V., Hirano, T., \& Grau, E. G. (2008). Genderspecific expression of multiple estrogen receptors, growth hormone receptors, insulin-like growth factors and vitellogenins, and effects of $17 \beta$-estradiol in the male tilapia (Oreochromis 
mossambicus). Gen Comp Endocrinol, 156(3), 544-551. doi:

http://dx.doi.org/10.1016/j.ygcen.2008.03.002

Deane, E., \& Woo, N. S. (2011). Advances and perspectives on the regulation and expression of piscine heat shock proteins. Reviews in Fish Biology and Fisheries, 21(2), 153-185. doi: 10.1007/s11160010-9164-8

Deane, E. E., \& Woo, N. Y. (2005). Modulation of beta-actin, insulin-like growth factor 1 and glucose-6phosphate dehydrogenase gene expression during vibriosis of sea bream, Sparus (=Rhabdosargus) sarba Forsskal. J Fish Dis, 28(10), 593-601. doi: 10.1111/j.13652761.2005.00664.x

Deloffre, L. A., Andrade, A., Filipe, A. I., \& Canario, A. V. (2012). Reference genes to quantify gene expression during oogenesis in a teleost fish. Gene, 506(1), 69-75. doi: 10.1016/j.gene.2012.06.047

Denslow, N., Chow, M., Kroll, K., \& Green, L. (1999). Vitellogenin as a Biomarker of Exposure for Estrogen or Estrogen Mimics. Ecotoxicology, 8(5), 385-398. doi: 10.1023/A:1008986522208

Desaulniers, D., Xiao, G. H., \& Cummings-Lorbetskie, C. (2013). Effects of lactational and/or in utero exposure to environmental contaminants on the glucocorticoid stress-response and DNA methylation of the glucocorticoid receptor promoter in male rats. Toxicology, 308(0), 20-33. doi: http://dx.doi.org/10.1016/j.tox.2013.03.006

Dezfuli, B. S., Giari, L., Lorenzoni, M., Manera, M., \& Noga, E. J. (2014). Perch liver reaction to Triaenophorus nodulosus plerocercoids with an emphasis on piscidins 3, 4 and proliferative cell nuclear antigen (PCNA) expression. Veterinary Parasitology, 200(1-2), 104-110. doi: http://dx.doi.org/10.1016/j.vetpar.2013.11.023

Ding, Y., He, F., Wen, H., Li, J., Ni, M., Chi, M., . . Zhao, J. (2013). DNA methylation status of cyp17II gene correlated with its expression pattern and reproductive endocrinology during ovarian development stages of Japanese flounder (Paralichthys olivaceus). Gene, 527(1), 82-88. doi: http://dx.doi.org/10.1016/j.gene.2013.05.037

Dorval, J., Leblond, V., Deblois, C., \& Hontela, A. (2005). Oxidative stress and endocrine endpoints in white sucker (Catostomus commersoni) from a river impacted by agricultural chemicals. Environmental Toxicology and Chemistry, 24(5), 1273-1280. doi: 10.1897/03-523.1

Douard, V., Robinson-Rechavi, M., Laudet, V., \& Guiguen, Y. (2003). Molecular evolution of angrogen receptors in fish. Fish Physiology and Biochemistry, 28(1-4), 207-208. doi: 10.1023/B:FISH.0000030529.13263.df

Filby, A. L., Thorpe, K. L., \& Tyler, C. R. (2006). Multiple molecular effect pathways of an environmental oestrogen in fish. J Mol Endocrinol, 37(1), 121-134. doi: 10.1677/jme.1.01997

Filby, A. L., \& Tyler, C. R. (2007). Appropriate 'housekeeping' genes for use in expression profiling the effects of environmental estrogens in fish. BMC Mol Biol, 8, 10. doi: 10.1186/1471-2199-8-10

Fogarty, G. B., Conus, N. M., Chu, J., \& McArthur, G. (2007). Characterization of the expression and activation of the epidermal growth factor receptor in squamous cell carcinoma of the skin. $\mathrm{Br} J$ Dermatol, 156(1), 92-98. doi: 10.1111/j.1365-2133.2006.07603.x 
Garcia-Reyero, N., Tingaud-Sequeira, A., Cao, M., Zhu, Z., Perkins, E. J., \& Hu, W. (2014). Endocrinology: advances through omics and related technologies. Gen Comp Endocrinol, 203, 262-273. doi: 10.1016/j.ygcen.2014.03.042

Gehringer, D., Finkelstein, M., Coale, K., Stephenson, M., \& Geller, J. (2013). Assessing Mercury Exposure and Biomarkers in Largemouth Bass (Micropterus Salmoides) from a Contaminated River System in California. Archives of Environmental Contamination and Toxicology, 64(3), 484-493. doi: 10.1007/s00244-012-9838-4

Gibson, L., Lavoie, R., Bissegger, S., Campbell, L., \& Langlois, V. (2014). A positive correlation between mercury and oxidative stress-related gene expression (GPX3 and GSTM3) is measured in female Double-crested Cormorant blood. Ecotoxicology, 1-11. doi: 10.1007/s10646-014-12435

Goessling, W., North, T. E., Lord, A. M., Ceol, C., Lee, S., Weidinger, G., . . Zon, L. I. (2008). APC mutant zebrafish uncover a changing temporal requirement for wnt signaling in liver development. Developmental Biology, 320(1), 161-174. doi: http://dx.doi.org/10.1016/j.ydbio.2008.05.526

Gracey, A. Y., Troll, J. V., \& Somero, G. N. (2001). Hypoxia-induced Gene Expression Profiling in the Euryoxic Fish Gillichthys mirabilis. Proc Natl Acad Sci U S A, 98(4), 1993-1998. doi: $10.2307 / 3054989$

Gradin, K., McGuire, J., Wenger, R. H., Kvietikova, I., fhitelaw, M. L., Toftgard, R., . . Poellinger, L. (1996). Functional interference between hypoxia and dioxin signal transduction pathways: competition for recruitment of the Arnt transcription factor. Mol Cell Biol, 16(10), 5221-5231.

Gräns, J., Wassmur, B., Fernández-Santoscoy, M., Zanette, J., Woodin, B. R., Karchner, S. I., . . . Celander, M. C. (2015). Regulation of pregnane-X-receptor, CYP3A and P-glycoprotein genes in the PCB-resistant killifish (Fundulus heteroclitus) population from New Bedford Harbor. Aquat Toxicol, 159, 198-207. doi: http://dx.doi.org/10.1016/j.aquatox.2014.12.010

Great Lakes Water Quality Agreement. (2012). doi: http://binational.net/wpcontent/uploads/2014/05/1094_Canada-USA-GLWQA-_e.pdf

Hall, E. A., Ren, S., Hylemon, P. B., Rodriguez-Agudo, D., Redford, K., Marques, D., . . Pandak, W. M. (2005). Detection of the steroidogenic acute regulatory protein, StAR, in human liver cells. Biochimica et Biophysica Acta (BBA) - Molecular and Cell Biology of Lipids, 1733(2-3), 111119. doi: http://dx.doi.org/10.1016/j.bbalip.2005.01.004

Halm, S., Martínez-Rodríguez, G., Rodríguez, L., Prat, F., Mylonas, C. C., Carrillo, M., \& Zanuy, S. (2004). Cloning, characterisation, and expression of three oestrogen receptors (ER $\alpha, E R \beta 1$ and ER 32 ) in the European sea bass, Dicentrarchus labrax. Mol Cell Endocrinol, 223(1-2), 63-75. doi: http://dx.doi.org/10.1016/j.mce.2004.05.009

Hamilton, S. J., \& Mehrle, P. M. (1986). Metallothionein in fish: review of its importance in assessing stress from metal contaminants. Transactions of the American Fisheries Society, 115, 596-609.

Handy, R. D., Sims, D. W., Giles, A., Campbell, H. A., \& Musonda, M. M. (1999). Metabolic trade-off between locomotion and detoxification for maintenance of blood chemistry and growth 
parameters by rainbow trout (Oncorhynchus mykiss) during chronic dietary exposure to copper. Aquat Toxicol, 47(1), 23-41. doi: http://dx.doi.org/10.1016/S0166-445X(99)00004-1

Hansen, P. D., Dizer, H., Hock, B., Marx, A., Sherry, J., McMaster, M., \& Blaise, C. (1998). Vitellogenin - a biomarker for endocrine disruptors. TrAC Trends in Analytical Chemistry, 17(7), 448-451. doi: http://dx.doi.org/10.1016/S0165-9936(98)00020-X

Hassan, H. M. (1988). Biosynthesis and regulation of superoxide dismutases. Free Radic Biol Med, 5(56), 377-385.

Hassanein, H. M. A., Banhawy, M. A., Soliman, F. M., Abdel-Rehim, S. A., Müller, W. E. G., \& Schröder, H. C. (1999). Induction of Hsp70 by the Herbicide Oxyfluorfen (Goal) in the Egyptian Nile Fish, Oreochromis niloticus. Archives of Environmental Contamination and Toxicology, 37(1), 78-84. doi: 10.1007/s002449900492

Hasspieler, B. M., Behar, J. V., \& Digiulio, R. T. (1994). Glutathione-Dependent Defense in Channel Catfish (Ictalurus punctatus) and Brown Bullhead (Ameriurus nebulosus). Ecotoxicology and Environmental Safety, 28(1), 82-90. doi: http://dx.doi.org/10.1006/eesa.1994.1036

Hayes, M. A., Smith, I. R., Rushmore, T. H., Crane, T. L., Thorn, C., Kocal, T. E., \& Ferguson, H. W. (1990). Pathogenesis of skin and liver neoplasms in white suckers from industrially polluted areas in Lake Ontario. Sci Total Environ, 94(1-2), 105-123.

Heikkila, J. J., Schultz, G. A., Iatrou, K., \& Gedamu, L. (1982). Expression of a set of fish genes following heat or metal ion exposure. J Biol Chem, 257(20), 12000-12005.

Hellou, J., Ross, N. W., \& Moon, T. W. (2012). Glutathione, glutathione S-transferase, and glutathione conjugates, complementary markers of oxidative stress in aquatic biota. Environ Sci Pollut Res Int, 19(6), 2007-2023. doi: 10.1007/s11356-012-0909-x

Hinck, J. E., Blazer, V. S., Denslow, N. D., Echols, K. R., R.W., G., May, T. W., . . Tillitt, D. E. (2007). Biomonitoring of Environmental Status and Trends (BEST) Program: Enviornmental Contaminants, Health Indicators, and Reproductive Biomarkers in Fish from the Mobile, Apalachicola-Chattahoochee-Flint, Savannah, and Pee Dee River Basins. U.S. Geological Survey Scientific Investigations Report 2007-5176, 114.

Hinck, J. E., Blazer, V. S., Schmitt, C. J., Papoulias, D. M., \& Tillitt, D. E. (2009). Widespread occurrence of intersex in black basses (Micropterus spp.) from U.S. rivers, 1995-2004. Aquat Toxicol, 95(1), 60-70. doi: 10.1016/j.aquatox.2009.08.001

Hodson, P. V. (1988). The effect of metal metabolism on uptake, disposition and toxicity in fish. Aquat Toxicol, 11(1-2), 3-18. doi: http://dx.doi.org/10.1016/0166-445X(88)90003-3

Hogstrand, C., \& Haux, C. (1990). Metallothionein as an indicator of heavy-metal exposure in two subtropical fish species. Journal of Experimental Marine Biology and Ecology, 138(1-2), 69-84. doi: http://dx.doi.org/10.1016/0022-0981(90)90177-E

Holth, T. F., Nourizadeh-Lillabadi, R., Blaesbjerg, M., Grung, M., Holbech, H., Petersen, G. I., . . . Hylland, K. (2008). Differential gene expression and biomarkers in zebrafish (Danio rerio) following exposure to produced water components. Aquat Toxicol, 90(4), 277-291. doi: http://dx.doi.org/10.1016/j.aquatox.2008.08.020 
Hu, X., Camus, A. C., Aono, S., Morrison, E. E., Dennis, J., Nusbaum, K. E., . . Shi, J. (2007). Channel catfish hepcidin expression in infection and anemia. Comp Immunol Microbiol Infect Dis, 30(1), 55-69. doi: 10.1016/j.cimid.2006.10.004

Hyllner, S. J., Andersson, T., Haux, C., \& Olsson, P.-E. (1989). Cortisol induction of metallothionein in primary culture of rainbow trout hepatocytes. Journal of Cellular Physiology, 139(1), 24-28. doi: $10.1002 / j c p .1041390105$

IJC. (1991). Commission approves list/delist criteria for Great Lakes Areas of Concern. International Joint Commission Activites, 16, 1-5.

IJC. (2009). Great Lakes Water Quality Agreement Priorities 2007-09 Series. Windsor, Ontario, Canada.

Iwanowicz, L. R., Blazer, V. S., Guy, C. P., Pinkney, A. E., Mullican, J. E., \& Alvarez, D. A. (2009). Reproductive health of bass in the Potomac, U.S.A., drainage: part 1. Exploring the effects of proximity to wastewater treatment plant discharge. Environ Toxicol Chem, 28(5), 1072-1083. doi: $10.1897 / 08-433.1$

Iwanowicz, L. R., Blazer, V. S., Pikney, A. E., Guy, C. P., Major, A. M., Munney, K., . . Sperry, A. (2016). Evidence of estrogenic endocrine disruption in smallmouth and largemouth bass inhabiting Northeast U.S. national wildlife refuge water: A reconnaissance study. Ecotoxicology and Environmental Safety, 124, 50-59.

Janz, D. M., McMaster, M. E., Munkittrick, K. R., \& Van Der Kraak, G. (1997). Elevated Ovarian Follicular Apoptosis and Heat Shock Protein-70 Expression in White Sucker Exposed to Bleached Kraft Pulp Mill Effluent. Toxicology and Applied Pharmacology, 147(2), 391-398. doi: http://dx.doi.org/10.1006/taap.1997.8283

Jin, C., Li, C., Su, X., \& Li, T. (2011). Identification and characterization of a Tegillarca granosa ferritin regulated by iron ion exposure and thermal stress. Dev Comp Immunol, 35(7), 745-751. doi: 10.1016/j.dci.2011.02.006

Johnston, L. D., Brown, G., Gauthier, D., Reece, K., Kator, H., \& Van Veld, P. (2008). Apolipoprotein AI from striped bass (Morone saxatilis) demonstrates antibacterial activity in vitro. Comparative Biochemistry and Physiology Part B: Biochemistry and Molecular Biology, 151(2), 167-175. doi: http://dx.doi.org/10.1016/j.cbpb.2008.06.011

Karaca, M., Varışl1, L., Korkmaz, K., Özaydın, O., Perçin, F., \& Orhan, H. (2014). Organochlorine pesticides and antioxidant enzymes are inversely correlated with liver enzyme gene expression in Cyprinus carpio. Toxicology Letters(0). doi: http://dx.doi.org/10.1016/j.toxlet.2014.02.013

Karnoub, A. E., \& Weinberg, R. A. (2008). Ras oncogenes: split personalities. Nature reviews. Molecular cell biology, 9(7), 517.

Keller, H., Givel, F., Perroud, M., \& Wahli, W. (1995). Signaling cross-talk between peroxisome proliferator-activated receptor/retinoid $\mathrm{X}$ receptor and estrogen receptor through estrogen response elements. Mol Endocrinol, 9(7), 794-804. doi: 10.1210/mend.9.7.7476963 
Kikuchi, K., Watabe, S., \& Aida, K. (1997). The Wap65 gene expression of goldfish (Carassius auratus) in association with warm water temperature as well as bacterial lipopolysaccharide (LPS). Fish Physiology and Biochemistry, 17(1-6), 423-432.

Kikuchi, K., Yamashita, M., Watabe, S., \& Aida, K. (1995). The warm temperature acclimation-related 65-kDa protein, Wap65, in goldfish and its gene expression. Journal of Biological Chemistry, 270(29), 17087-17092.

Klaper, R., \& Welch, L. C. (2011). Emerging contaminant threats and the Great Lakes: Existing science, existing science, estimating relative risk and determining policy. from www.greatlakes.org/Document.Doc?id=1072

Klecka, G., Persoon, C., \& Currie, R. (2010). Chemicals of emerging concern in the Great Lakes Basin: an analysis of environmental exposures. Reviews of Enviornmental Contamination and Toxicology, 207, 1-93.

Kodama, K., Saydur Rahman, M., Horiguchi, T., \& Thomas, P. (2012). Upregulation of hypoxiainducible factor (HIF)-1 $\alpha$ and HIF- $2 \alpha$ mRNA levels in dragonet Callionymus valenciennei exposed to environmental hypoxia in Tokyo Bay. Marine Pollution Bulletin, 64(7), 1339-1347. doi: http://dx.doi.org/10.1016/j.marpolbul.2012.05.002

Köhler, A., Bahns, S., \& Van Noorden, C. J. F. (1998). Determination of kinetic properties of G6PDH and PGDH and the expression of PCNA during liver carcinogenesis in coastal flounder. Mar Environ Res, 46(1-5), 179-183.

Kondo, S., Carr, B. I., Takagi, K., Huang, T. H., Chou, Y. M., Yokoyama, K., \& Itakura, K. (1990). Expression of rat microsomal epoxide hydrolase gene during liver chemical carcinogenesis. Cancer Res, 50(19), 6222-6228.

Lee, K. E., Langer, S. K., Menheer, M. A., Foreman, W. T., Furlong, E. T., \& Smith, S. G. (2012). Chemicals of emerging concern in water and bottom sediment in Great Lakes areas of concern, 2010 to 2011-Collection methods, analyses methods, quality assurance and data. Reston, VA: U.S. Geological Survey Retrieved from http://pubs.er.usgs.gov/publication/ds723.

Lee, K. E., Langer, S. K., Menheer, M. A., Hansen, D. S., Foreman, W. T., Furlong, E. T., . . . Gefell, D. J. (2015). Chemicals of emerging concern in water and bottom sediment in the Great Lakes Basin, 2012: collection methods, analytical methods, quality assurance, and study data Data Series (pp. 14-). Reston, VA.

Lee, Y.-M., Rhee, J.-S., Hwang, D.-S., Kim, I.-C., Raisuddin, S., \& Lee, J.-S. (2008). p53 gene expression is modulated by endocrine disrupting chemicals in the hermaphroditic fish, Kryptolebias marmoratus. Comparative Biochemistry and Physiology Part C: Toxicology \& Pharmacology, 147(2), 150-157. doi: http://dx.doi.org/10.1016/j.cbpc.2007.09.005

Li, H., Helm, P. A., \& Metcalfe, C. D. (2010). Sampling in the Great Lakes for pharmaceuticals, personal care products, and endocrine-disrupting substances using the passive polar organic chemical integrative sampler. Environ Toxicol Chem, 29(4), 751-762. doi: 10.1002/etc.104

Li, H., Zhang, F., Guo, H., Zhu, Y., Yuan, J., Yang, G., \& An, L. (2013). Molecular characterization of hepcidin gene in common carp (Cyprinus carpio L.) and its expression pattern responding to 
bacterial challenge. Fish Shellfish Immunol, 35(3), 1030-1038. doi:

http://dx.doi.org/10.1016/j.fsi.2013.07.001

Li, M. O., Wan, Y. Y., Sanjabi, S., Robertson, A. K., \& Flavell, R. A. (2006). Transforming growth factor-beta regulation of immune responses. Anпu Rev Immunol, 24, 99-146. doi: 10.1146/annurev.immunol.24.021605.090737

Li, Z.-H., Chen, L., Wu, Y.-H., Li, P., Li, Y.-F., \& Ni, Z.-H. (2014a). Alteration of thyroid hormone levels and related gene expression in Chinese rare minnow larvae exposed to mercury chloride. Environmental Toxicology and Pharmacology, 38(1), 325-331. doi: http://dx.doi.org/10.1016/j.etap.2014.07.002

Li, Z.-H., Chen, L., Wu, Y.-H., Li, P., Li, Y.-F., \& Ni, Z.-H. (2014b). Effects of waterborne cadmium on thyroid hormone levels and related gene expression in Chinese rare minnow larvae. Comparative Biochemistry and Physiology Part C: Toxicology \& Pharmacology, 161(0), 53-57. doi: http://dx.doi.org/10.1016/j.cbpc.2014.02.001

Liu, S., Wang, L., Qin, F., Zheng, Y., Li, M., Zhang, Y., . . Wang, Z. (2014). Gonadal development and transcript profiling of steroidogenic enzymes in response to $17 \alpha$-methyltestosterone in the rare minnow Gobiocypris rarus. The Journal of Steroid Biochemistry and Molecular Biology, 143(0), 223-232. doi: http://dx.doi.org/10.1016/j.jsbmb.2014.03.001

Lu, M., Chang, Z., Bae, M.-J., Oh, S. M., Chung, K.-H., \& Park, J.-S. (2013). Molecular characterization of the aryl hydrocarbon receptor (AhR) pathway in goldfish (Carassius auratus) exposure to TCDD: The mRNA and protein levels. Fish Shellfish Immunol, 35(2), 469-475. doi: http://dx.doi.org/10.1016/j.fsi.2013.05.002

Luccio-Camelo, D. C., \& Prins, G. S. (2011). Disruption of androgen receptor signaling in males by environmental chemicals. The Journal of Steroid Biochemistry and Molecular Biology, 127(1-2), 74-82. doi: http://dx.doi.org/10.1016/j.jsbmb.2011.04.004

Machado, S. P., Cunha, V., Reis-Henriques, M. A., \& Ferreira, M. (2014). Histopathological lesions, Pglycoprotein and PCNA expression in zebrafish (Danio rerio) liver after a single exposure to diethylnitrosamine. Environmental Toxicology and Pharmacology, 38(3), 720-732. doi: http://dx.doi.org/10.1016/j.etap.2014.09.002

Mager, E. M., Wintz, H., Vulpe, C. D., Brix, K. V., \& Grosell, M. (2008). Toxicogenomics of water chemistry influence on chronic lead exposure to the fathead minnow (Pimephales promelas). Aquat Toxicol, 87(3), 200-209. doi: 10.1016/j.aquatox.2008.02.001

Marlatt, V. L., Martyniuk, C. J., Zhang, D., Xiong, H., Watt, J., Xia, X., . . Trudeau, V. L. (2008). Autoregulation of estrogen receptor subtypes and gene expression profiling of $17 \beta$-estradiol action in the neuroendocrine axis of male goldfish. Mol Cell Endocrinol, 283(1-2), 38-48. doi: http://dx.doi.org/10.1016/j.mce.2007.10.013

Martyniuk, C. J., Spade, D. J., Blum, J. L., Kroll, K. J., \& Denslow, N. D. (2011). Methoxychlor affects multiple hormone signaling pathways in the largemouth bass (Micropterus salmoides) liver. Aquat Toxicol, 101(3-4), 483-492. doi: http://dx.doi.org/10.1016/j.aquatox.2010.12.002

McBeath, A. J. A., Snow, M., Secombes, C. J., Ellis, A. E., \& Collet, B. (2007). Expression kinetics of interferon and interferon-induced genes in Atlantic salmon (Salmo salar) following infection with 
infectious pancreatic necrosis virus and infectious salmon anaemia virus. Fish Shellfish Immunol, 22(3), 230-241. doi: http://dx.doi.org/10.1016/j.fsi.2006.05.004

McCartney-Francis, N. L., \& Wahl, S. M. (1994). Transforming growth factor beta: a matter of life and death. J Leukoc Biol, 55(3), 401-409.

McFarland, V. A., Inouye, L. S., Lutz, C. H., Jarvis, A. S., Clarke, J. U., \& McCant, D. D. (1999). Biomarkers of Oxidative Stress and Genotoxicity in Livers of Field-Collected Brown Bullhead, Ameiurus nebulosus. Archives of Environmental Contamination and Toxicology, 37(2), 236-241. doi: $10.1007 / \mathrm{s} 002449900510$

Mehinto, A. C., Prucha, M. S., Colli-Dula, R. C., Kroll, K. J., Lavelle, C. M., Barber, D. S., .. . Denslow, N. D. (2014). Gene networks and toxicity pathways induced by acute cadmium exposure in adult largemouth bass (Micropterus salmoides). Aquat Toxicol(0). doi: http://dx.doi.org/10.1016/j.aquatox.2014.04.004

Metcalfe, C. D., Miao, X. S., Koenig, B. G., \& Struger, J. (2003). Distribution of acidic and neutral drugs in surface waters near sewage treatment plants in the lower Great Lakes, Canada. Environ Toxicol Chem, 22(12), 2881-2889.

Meucci, V., \& Arukwe, A. (2006). The xenoestrogen 4-nonylphenol modulates hepatic gene expression of pregnane $\mathrm{X}$ receptor, aryl hydrocarbon receptor, CYP3A and CYP1A1 in juvenile Atlantic salmon (Salmo salar). Comparative Biochemistry and Physiology Part C: Toxicology \& Pharmacology, 142(1-2), 142-150. doi: http://dx.doi.org/10.1016/j.cbpc.2005.11.011

Meyer, J. N., Wassenberg, D. M., Karchner, S. I., Hahn, M. E., \& Di Giulio, R. T. (2003). Expression and inducibility of aryl hydrocarbon receptor pathway genes in wild-caught killifish (Fundulus heteroclitus) with different contaminant-exposure histories. Environ Toxicol Chem, 22(10), $2337-$ 2343.

Midorikawa, Y., Tsutsumi, S., Taniguchi, H., Ishii, M., Kobune, Y., Kodama, T., . . Aburatani, H. (2002). Identification of Genes Associated with Dedifferentiation of Hepatocellular Carcinoma with Expression Profiling Analysis. Cancer Science, 93(6), 636-643. doi: 10.1111/j.13497006.2002.tb01301.x

Miller, D. H., Jensen, K. M., Villeneuve, D. L., Kahl, M. D., Makynen, E. A., Durhan, E. J., \& Ankley, G. T. (2007). Linkage of biochemical responses to population-level effects: a case study with vitellogenin in the fathead minnow (Pimephales promelas). Environ Toxicol Chem, 26(3), 521527.

Min, J., Lee, S. K., \& Gu, M. B. (2003). Effects of endocrine disrupting chemicals on distinct expression patterns of estrogen receptor, cytochrome $\mathrm{P} 450$ aromatase and p53 genes in Oryzias latipes liver. J Biochem Mol Toxicol, 17(5), 272-277. doi: 10.1002/jbt.10089

Mu, W., Yao, J., Zhang, J., Liu, S., Wen, H., Feng, J., \& Liu, Z. (2015). Expression of tumor suppressor genes in channel catfish after bacterial infections. Developmental \& Comparative Immunology(0). doi: http://dx.doi.org/10.1016/j.dci.2014.10.004

Munkittrick, K. R., McMaster, M. E., McCarthy, L. H., Servos, M. R., \& Van Der Kraak, G. J. (1998). An overview of recent studies on the potential of pulp-mill effluents to alter reproductive 
parameters in fish. J Toxicol Environ Health B Crit Rev, 1(4), 347-371. doi:

$10.1080 / 10937409809524558$

Nakamura, I., Kusakabe, M., \& Young, G. (2009). Differential suppressive effects of low physiological doses of estradiol-17 $\beta$ in vivo on levels of mRNAs encoding steroidogenic acute regulatory protein and three steroidogenic enzymes in previtellogenic ovarian follicles of rainbow trout. Gen Comp Endocrinol, 163(3), 318-323. doi: http://dx.doi.org/10.1016/j.ygcen.2009.04.031

Nebert, D. W., Roe, A. L., Dieter, M. Z., Solis, W. A., Yang, Y., \& Dalton, T. P. (2000). Role of the aromatic hydrocarbon receptor and $[\mathrm{Ah}]$ gene battery in the oxidative stress response, cell cycle control, and apoptosis. Biochemical Pharmacology, 59(1), 65-85. doi: http://dx.doi.org/10.1016/S0006-2952(99)00310-X

Nejak-Bowen, K. N., \& Monga, S. P. S. (2011). Beta-catenin signaling, liver regeneration and hepatocellular cancer: Sorting the good from the bad. Seminars in Cancer Biology, 21(1), 44-58. doi: http://dx.doi.org/10.1016/j.semcancer.2010.12.010

Neves, J. V., Wilson, J. M., \& Rodrigues, P. N. S. (2009). Transferrin and ferritin response to bacterial infection: The role of the liver and brain in fish. Developmental \& Comparative Immunology, 33(7), 848-857. doi: http://dx.doi.org/10.1016/j.dci.2009.02.001

Nguyen, A. T., Emelyanov, A., Koh, C. H., Spitsbergen, J. M., Lam, S. H., Mathavan, S., . . Gong, Z. (2011). A high level of liver-specific expression of oncogenic Kras(V12) drives robust liver tumorigenesis in transgenic zebrafish. Dis Model Mech, 4(6), 801-813. doi: 10.1242/dmm.007831

Nikinmaa, M., \& Rees, B. B. (2005). Oxygen-dependent gene expression in fishes. Am J Physiol Regul Integr Comp Physiol, 288(5), R1079-1090. doi: 10.1152/ajpregu.00626.2004

Nunez, S. B., Medin, J. A., Braissant, O., Kemp, L., Wahli, W., Ozato, K., \& Segars, J. H. (1997). Retinoid X receptor and peroxisome proliferator-activated receptor activate an estrogen responsive gene independent of the estrogen receptor. Mol Cell Endocrinol, 127(1), 27-40.

Olsson, P. E., Zafarullah, M., \& Gedamu, L. (1989). A role of metallothionein in zinc regulation after oestradiol induction of vitellogenin synthesis in rainbow trout, Salmo gairdneri. Biochem J, 257(2), 555-559.

Omary, M. B., Ku, N. O., Strnad, P., \& Hanada, S. (2009). Toward unraveling the complexity of simple epithelial keratins in human disease. J Clin Invest, 119(7), 1794-1805. doi: 10.1172/jci37762

Orino, K., Lehman, L., Tsuji, Y., Ayaki, H., Torti, S. V., \& Torti, F. M. (2001). Ferritin and the response to oxidative stress. Biochem J, 357(Pt 1), 241-247.

Ortiz-Zarragoitia, M., \& Cajaraville, M. P. (2005). Effects of selected xenoestrogens on liver peroxisomes, vitellogenin levels and spermatogenic cell proliferation in male zebrafish. Comp Biochem and Physiol, Part C(141), 131-144.

Otto, D. M. E., \& Moon, T. W. (1996). Phase I and II enzymes and antioxidant responses in different tissues of brown bullheads from relatively polluted and non-polluted systems. Archives of Environmental Contamination and Toxicology, 31(1), 141-147. doi: 10.1007/BF00203918 
Pandak, W. M., Ren, S., Marques, D., Hall, E., Redford, K., Mallonee, D., . . Hylemon, P. (2002). Transport of cholesterol into mitochondria is rate-limiting for bile acid synthesis via the alternative pathway in primary rat hepatocytes. J Biol Chem, 277(50), 48158-48164. doi: 10.1074/jbc.M205244200

Parihar, M. S., Dubey, A. K., Javeri, T., \& Prakash, P. (1996). Changes in lipid peroxidation, superoxide dismutase activity, ascorbic acid and phospholipid content in liver of freshwater catfish Heteropneustes fossilis exposed to elevated temperature. Journal of Thermal Biology, 21(5-6), 323-330. doi: http://dx.doi.org/10.1016/S0306-4565(96)00016-2

Picard-Aitken, M., Fournier, H., Pariseau, R., Marcogliese, D. J., \& Cyr, D. G. (2007). Thyroid disruption in walleye (Sander vitreus) exposed to environmental contaminants: Cloning and use of iodothyronine deiodinases as molecular biomarkers. Aquat Toxicol, 83(3), 200-211. doi: http://dx.doi.org/10.1016/j.aquatox.2007.04.004

Picard, D. J., \& Schulte, P. M. (2004). Variation in gene expression in response to stress in two populations of Fundulus heteroclitus. Comparative Biochemistry and Physiology Part A: Molecular \& Integrative Physiology, 137(1), 205-216. doi: http://dx.doi.org/10.1016/S10956433(03)00292-7

Pinkney, A. E., Harshbarger, J. C., Karouna-Renier, N. K., Jenko, K., Balk, L., Skarphéðinsdóttir, H., . . . Rutter, M. A. (2011). Tumor prevalence and biomarkers of genotoxicity in brown bullhead (Ameiurus nebulosus) in Chesapeake Bay tributaries. Science of The Total Environment, 410 411, 248-257. doi: http://dx.doi.org/10.1016/j.scitotenv.2011.09.035

Podok, P., Wang, H., Xu, L., Xu, D., \& Lu, L. (2014). Characterization of myeloid-specific peroxidase, keratin 8 , and dual specificity phosphatase 1 as innate immune genes involved in the resistance of crucian carp (Carassius auratus gibelio) to Cyprinid herpesvirus 2 infection. Fish Shellfish Immunol, 41(2), 531-540. doi: http://dx.doi.org/10.1016/j.fsi.2014.10.001

Pradhan, A., Kharlyngdoh, J. B., Asnake, S., \& Olsson, P.-E. (2013). The brominated flame retardant TBECH activates the zebrafish (Danio rerio) androgen receptor, alters gene transcription and causes developmental disturbances. Aquat Toxicol, 142-143(0), 63-72. doi: http://dx.doi.org/10.1016/j.aquatox.2013.07.018

Premdas, P. D., Metcalfe, T. L., Bailey, M. E., \& Metcalfe, C. D. (1995). The Prevalence and Histological Appearance of Lip Papillomas in White Suckers (Catostomus commersoni) from Two Sites in Central Ontario, Canada. Journal of Great Lakes Research, 21(2), 207-218. doi: http://dx.doi.org/10.1016/S0380-1330(95)71032-2

Pyron, M., Obert, E. C., \& Wellington, R. (2001). Tumor Rates and Population Estimates of Brown Bullhead (Ameiurus nebulosus) in Presque Isle Bay, Lake Erie. Journal of Great Lakes Research, 27(2), 185-190. doi: http://dx.doi.org/10.1016/S0380-1330(01)70631-4

Rafferty, S. D., Blazer, V. S., Pinkney, A. E., Grazio, J. L., Obert, E. C., \& Boughton, L. (2009). A historical perspective on the "fish tumors or other deformities" beneficial use impairment at Great Lakes Areas of Concern. Journal of Great Lakes Research, 35(4), 496-506. doi: 10.1016/j.jglr.2009.07.005

Rasheeda, M. K., Kagawa, H., Kirubagaran, R., Dutta-Gupta, A., \& Senthilkumaran, B. (2010). Cloning, expression and enzyme activity analysis of testicular $11 \beta$-hydroxysteroid dehydrogenase during 
seasonal cycle and after hCG induction in air-breathing catfish Clarias gariepinus. The Journal of Steroid Biochemistry and Molecular Biology, 120(1), 1-10. doi:

http://dx.doi.org/10.1016/j.jsbmb.2010.02.014

Riley, L. G., Hirano, T., \& Grau, E. G. (2004). Estradiol-17beta and dihydrotestosterone differentially regulate vitellogenin and insulin-like growth factor-I production in primary hepatocytes of the tilapia Oreochromis mossambicus. Comp Biochem Physiol C Toxicol Pharmacol, 138(2), 177186. doi: 10.1016/j.cca.2004.07.009

Robertson, L. S., Iwanowicz, L. R., \& Marranca, J. M. (2009). Identification of centrarchid hepcidins and evidence that $17 \beta$-estradiol disrupts constitutive expression of hepcidin-1 and inducible expression of hepcidin-2 in largemouth bass (Micropterus salmoides). Fish Shellfish Immunol, 26(6), 898-907. doi: http://dx.doi.org/10.1016/j.fsi.2009.03.023

Roch, M., \& McCarter, J. A. (1984). Hepatic metallothionein production and resistance to heavy metals by rainbow trout (Salmo gairdneri)--II. Held in a series of contaminated lakes. Comp Biochem Physiol C, 77(1), 77-82.

Sabo-Attwood, T., Kroll, K. J., \& Denslow, N. D. (2004). Differential expression of largemouth bass (Micropterus salmoides) estrogen receptor isotypes alpha, beta, and gamma by estradiol. Mol Cell Endocrinol, 218(1-2), 107-118. doi: http://dx.doi.org/10.1016/j.mce.2003.12.007

Saera-Vila, A., Calduch-Giner, J. A., Prunet, P., \& Perez-Sanchez, J. (2009). Dynamics of liver GH/IGF axis and selected stress markers in juvenile gilthead sea bream (Sparus aurata) exposed to acute confinement: differential stress response of growth hormone receptors. Comp Biochem Physiol A Mol Integr Physiol, 154(2), 197-203. doi: 10.1016/j.cbpa.2009.06.004

Salinas-Clarot, K., Gutiérrez, A. P., Núñez-Acuña, G., \& Gallardo-Escárate, C. (2011). Molecular characterization and gene expression of ferritin in red abalone (Haliotis rufescens). Fish Shellfish Immunol, 30(1), 430-433. doi: http://dx.doi.org/10.1016/j.fsi.2010.09.009

Sambroni, E., Gutieres, S., Cauty, C., Guiguen, Y., Breton, B., \& Lareyre, J. J. (2001). Type II iodothyronine deiodinase is preferentially expressed in rainbow trout (Oncorhynchus mykiss) liver and gonads. Mol Reprod Dev, 60(3), 338-350. doi: 10.1002/mrd.1096

Sanders, B. M., Nguyen, J., Martin, L. S., Howe, S. R., \& Coventry, S. (1995). Induction and subcellular localization of two major stress proteins in response to copper in the fathead minnow Pimephales promelas. Comp Biochem Physiol C Pharmacol Toxicol Endocrinol, 112(3), 335-343.

Sathiyaa, R., \& Vijayan, M. M. (2003). Autoregulation of glucocorticoid receptor by cortisol in rainbow trout hepatocytes. Am J Physiol Cell Physiol, 284(6), C1508-1515. doi: 10.1152/ajpcell.00448.2002

Schnitzler, J. G., Klaren, P. H. M., Bouquegneau, J.-M., \& Das, K. (2012). Environmental factors affecting thyroid function of wild sea bass (Dicentrarchus labrax) from European coasts. Chemosphere, 87(9), 1009-1017. doi: http://dx.doi.org/10.1016/j.chemosphere.2011.11.039

Searcy, B. T., Beckstrom-Sternberg, S. M., Beckstrom-Sternberg, J. S., Stafford, P., Schwendiman, A. L., Soto-Pena, J., . . Propper, C. R. (2012). Thyroid hormone-dependent development in Xenopus laevis: A sensitive screen of thyroid hormone signaling disruption by municipal wastewater 
treatment plant effluent. Gen Comp Endocrinol, 176(3), 481-492. doi:

http://dx.doi.org/10.1016/j.ygcen.2011.12.036

Sepulveda, M. S., Johnson, W. E., Higman, J. C., Denslow, N. D., Schoeb, T. R., \& Gross, T. S. (2002). An evaluation of biomarkers of reproductive function and potential contaminant effects in Florida largemouth bass (Micropterus salmoides floridanus) sampled from the St. Johns River. Sci Total Environ, 289(1-3), 133-144.

Sha, Z., Xu, P., Takano, T., Liu, H., Terhune, J., \& Liu, Z. (2008). The warm temperature acclimation protein Wap65 as an immune response gene: Its duplicates are differentially regulated by temperature and bacterial infections. Molecular Immunology, 45(5), 1458-1469. doi: http://dx.doi.org/10.1016/j.molimm.2007.08.012

Shi, Y. H., Chen, J., Li, C. H., \& Li, M. Y. (2010). Molecular cloning of liver Wap65 cDNA in ayu (Plecoglossus altivelis) and mRNA expression changes following Listonella anguillarum infection. Molecular Biology Reports, 37(3), 1523-1529.

Shike, H., Lauth, X., Westerman, M. E., Ostland, V. E., Carlberg, J. M., Van Olst, J. C., . . Burns, J. C. (2002). Bass hepcidin is a novel antimicrobial peptide induced by bacterial challenge. Eur J Biochem, 269(8), 2232-2237.

Shved, N., Berishvili, G., Mazel, P., Baroiller, J. F., \& Eppler, E. (2011). Growth hormone (GH) treatment acts on the endocrine and autocrine/paracrine GH/IGF-axis and on TNF- $\alpha$ expression in bony fish pituitary and immune organs. Fish Shellfish Immunol, 31(6), 944-952. doi: http://dx.doi.org/10.1016/j.fsi.2011.08.012

Sikstrom, C. B., Metner, D. A., \& Lockhart, W. L. (1975). Hermaphroditism in a White Sucker (Catostomus commersoni) from the Athabasca River, Alberta. Transactions of the American Fisheries Society, 104(2), 413-413. doi: 10.1577/1548-8659(1975)104<413:HIAWSC>2.0.CO;2

Smith, I. R., Ferguson, H. W., \& Hayes, M. A. (1989). Histopathology and prevalence of epidermal papillomas epidemic in brown bullhead, Ictalurus nebulosus (Lesueur), and white sucker, Catostomus commersoni (Lacépède), populations from Ontario, Canada. Journal of Fish Diseases, 12(4), 373-388. doi: 10.1111/j.1365-2761.1989.tb00326.x

Sripa, B., Brindley, P. J., Mulvenna, J., Laha, T., Smout, M. J., Mairiang, E., . . Loukas, A. (2012). The tumorigenic liver fluke Opisthorchis viverrini - multiple pathways to cancer. Trends in Parasitology, 28(10), 395-407. doi: http://dx.doi.org/10.1016/j.pt.2012.07.006

Sripa, B., Kaewkes, S., Sithithaworn, P., Mairiang, E., Laha, T., Smout, M., . . Brindley, P. J. (2007). Liver Fluke Induces Cholangiocarcinoma. PLoS Med, 4(7), e201. doi: 10.1371/journal.pmed.0040201

Srivastava, S., \& Ratha, B. K. (2010). Does fish represent an intermediate stage in the evolution of ureotelic cytosolic arginase I? Biochemical and Biophysical Research Communications, 391(1), 1-5. doi: http://dx.doi.org/10.1016/j.bbrc.2009.11.018

Stalker, M. J., Kirby, G. M., Kocal, T. E., Smith, I. R., \& Hayes, M. A. (1991). Loss of glutathione Stransferases in pollution-associated liver neoplasms in thite suckers (Catostomus commersoni) from Lake Ontario. Carcinogenesis, 12(12), 2221-2226. doi: 10.1093/carcin/12.12.2221 
Strnad, P., Zhou, Q., Hanada, S., Lazzeroni, L. C., Zhong, B. H., So, P., . . Omary, M. B. (2010). Keratin variants predispose to acute liver failure and adverse outcome: race and ethnic associations. Gastroenterology, 139(3), 828-835, 835.e821-823. doi: 10.1053/j.gastro.2010.06.007

Sumpter, J. P., \& Jobling, S. (1995). Vitellogenesis as a biomarker for estrogenic contamination of the aquatic environment. Environmental Health Perspectives, 103(Suppl 7), 173-178.

Sun, Z., Yu, X., Wu, W., Jia, D., Chen, Y., Ji, L., . . Zhang, S. (2012). Fibroblast growth factor 7 inhibits cholesterol $7 \alpha$-hydroxylase gene expression in hepatocytes. Biochemical and Biophysical Research Communications, 423(4), 775-780. doi: http://dx.doi.org/10.1016/j.bbrc.2012.06.035

Sung, T.-I., Wang, Y.-J., Chen, C.-Y., Hung, T.-L., \& Guo, H.-R. (2012). Increased serum level of epidermal growth factor receptor in liver cancer patients and its association with exposure to arsenic. Science of The Total Environment, 424(0), 74-78. doi: http://dx.doi.org/10.1016/j.scitotenv.2012.02.079

Tetreault, G. R., Bennett, C. J., Shires, K., Knight, B., Servos, M. R., \& McMaster, M. E. (2011). Intersex and reproductive impairment of wild fish exposed to multiple municipal wastewater discharges. Aquat Toxicol, 104(3-4), 278-290. doi: http://dx.doi.org/10.1016/j.aquatox.2011.05.008

Teven, C. M., Farina, E. M., Rivas, J., \& Reid, R. R. Fibroblast growth factor (FGF) signaling in development and skeletal diseases. Genes \& Diseases $(0)$. doi: http://dx.doi.org/10.1016/j.gendis.2014.09.005

Thomas, P., \& Rahman, M. S. (2009). Biomarkers of hypoxia exposure and reproductive function in Atlantic croaker: A review with some preliminary findings from the northern Gulf of Mexico hypoxic zone. Journal of Experimental Marine Biology and Ecology, 381, Supplement, S38-S50. doi: http://dx.doi.org/10.1016/j.jembe.2009.07.008

Thomas, P., Rahman, M. S., Khan, I. A., \& Kummer, J. A. (2007). Widespread endocrine disruption and reproductive impairment in an estuarine fish population exposed to seasonal hypoxia. Proc Biol Sci, 274(1626), 2693-2701. doi: 10.1098/rspb.2007.0921

Tseng, H.-P., Hseu, T.-H., Buhler, D. R., Wang, W.-D., \& Hu, C.-H. (2005). Constitutive and xenobiotics-induced expression of a novel CYP3A gene from zebrafish larva. Toxicology and Applied Pharmacology, 205(3), 247-258. doi: http://dx.doi.org/10.1016/j.taap.2004.10.019

Turner, N., \& Grose, R. (2010). Fibroblast growth factor signalling: from development to cancer. Nat Rev Cancer, 10(2), 116-129. doi: 10.1038/nrc2780

Tyler, C. R., Lange, A., Paull, G. C., Katsu, Y., \& Iguchi, T. (2007). The roach (Rutilus rutilus) as a sentinel for assessing endocrine disruption. Environ Sci, 14(5), 235-253.

Vandesompele, J., De Preter, K., Pattyn, F., Poppe, B., Van Roy, N., De Paepe, A., \& Speleman, F. (2002). Accurate normalization of real-time quantitative RT-PCR data by geometric averaging of multiple internal control genes. Genome Biol, 3(7), Research0034.

Vijayan, M. M., Pereira, C., Kruzynski, G., \& Iwama, G. K. (1998). Sublethal concentrations of contaminant induce the expression of hepatic heat shock protein 70 in two salmonids. Aquat Toxicol, 40(2-3), 101-108. doi: http://dx.doi.org/10.1016/S0166-445X(97)00057-X 
Vijayan, M. M., Prunet, P., \& Boone, A. N. (2005). Chapter 13 Xenobiotic impact on corticosteroid signaling. In T. P. Mommsen \& T. W. Moon (Eds.), Biochemistry and Molecular Biology of Fishes (Vol. 6, pp. 365-394): Elsevier.

Vijayan, M. M., Raptis, S., \& Sathiyaa, R. (2003). Cortisol treatment affects glucocorticoid receptor and glucocorticoid-responsive genes in the liver of rainbow trout. Gen Comp Endocrinol, 132(2), 256-263. doi: http://dx.doi.org/10.1016/S0016-6480(03)00092-3

Vincendeau, P., Gobert, A. P., Daulouede, S., Moynet, D., \& Mossalayi, M. D. (2003). Arginases in parasitic diseases. Trends Parasitol, 19(1), 9-12.

Wahl, S. M. (1994). Transforming growth factor beta: the good, the bad, and the ugly. J Exp Med, 180(5), 1587-1590.

Wang, J., Wei, Y., Li, X., Cao, H., Xu, M., \& Dai, J. (2007). The identification of heat shock protein genes in goldfish (Carassius auratus) and their expression in a complex environment in Gaobeidian Lake, Beijing, China. Comp Biochem Physiol C Toxicol Pharmacol, 145(3), 350-362. doi: 10.1016/j.cbpc.2007.01.018

Wang, K.-J., Bo, J., Yang, M., Hong, H.-S., Wang, X.-H., Chen, F.-Y., \& Yuan, J.-J. (2009). Hepcidin gene expression induced in the developmental stages of fish upon exposure to Benzo[a]pyrene (BaP). Mar Environ Res, 67(3), 159-165. doi: http://dx.doi.org/10.1016/j.marenvres.2008.12.008

Watabe, S., Kikuchi, K., \& Aida, K. (1993). Cold-and Warm-temperature Acclimation Induces Specific Cytosolic Proteins in Goldfish and Carp. NIPPON SUISAN GAKKAISHI, 59(1), 151-156. doi: $10.2331 /$ suisan.59.151

Weiskirchen, R., \& Gunther, K. (2003). The CRP/MLP/TLP family of LIM domain proteins: acting by connecting. BioEssays, 25(2), 152-162.

Wheatley, D. N., \& Campbell, E. (2002). Arginine catabolism, liver extracts and cancer. Pathol Oncol Res, 8(1), 18-25.

Wheeler, J. R., Gimeno, S., Crane, M., Lopez-Juez, E., \& Morritt, D. (2005). Vitellogenin: a review of analytical methods to detect (anti) estrogenic activity in fish. Toxicol Mech Methods, 15(4), 293306. doi: 10.1080/15376520590968789

Whyte, J. J., Jung, R. E., Schmitt, C. J., \& Tillitt, D. E. (2000). Ethoxyresorufin-O-deethylase (EROD) Activity in Fish as Biomarker of Chemical Exposure. Critical Reviews in Toxicology, 30(4), 347570.

Williams, R., \& Hubberstey, A. V. (2014). Benzo(a)pyrene exposure causes adaptive changes in p53 and CYP1A gene expression in Brown bullhead (Ameiurus nebulosus). Aquat Toxicol, 156(0), 201210. doi: http://dx.doi.org/10.1016/j.aquatox.2014.09.001

Wood, A. W., Duan, C., \& Bern, H. A. (2005). Insulin-Like Growth Factor Signaling in Fish International Review of Cytology (Vol. Volume 243, pp. 215-285): Academic Press.

Woodling, J. D., Lopez, E. M., Maldonado, T. A., Norris, D. O., \& Vajda, A. M. (2006). Intersex and other reproductive disruption of fish in wastewater effluent dominated Colorado streams. Comp Biochem Physiol C Toxicol Pharmacol, 144(1), 10-15. doi: 10.1016/j.cbpc.2006.04.019 
Wu, F., Lin, L., Qiu, J.-W., Chen, H., Weng, S., \& Luan, T. (2014). Complex effects of two presumably antagonistic endocrine disrupting compounds on the goldfish Carassius aumtus: A comprehensive study with multiple toxicological endpoints. Aquat Toxicol, 155(0), 43-51. doi: http://dx.doi.org/10.1016/j.aquatox.2014.06.003

Yamaguchi, A., Ishibashi, H., Kohra, S., Arizono, K., \& Tominaga, N. (2005). Short-term effects of endocrine-disrupting chemicals on the expression of estrogen-responsive genes in male medaka (Oryzias latipes). Aquat Toxicol, 72(3), 239-249. doi: 10.1016/j.aquatox.2004.12.011

Yang, L., Zha, J., Zhang, X., Li, W., Li, Z., \& Wang, Z. (2010). Alterations in mRNA expression of steroid receptors and heat shock proteins in the liver of rare minnow (Grobiocypris rarus) exposed to atrazine and p,p'-DDE. Aquat Toxicol, 98(4), 381-387. doi: http://dx.doi.org/10.1016/j.aquatox.2010.03.010

Yu, L., Chen, M., Liu, Y., Gui, W., \& Zhu, G. (2013). Thyroid endocrine disruption in zebrafish larvae following exposure to hexaconazole and tebuconazole. Aquat Toxicol, 138-139(0), 35-42. doi: http://dx.doi.org/10.1016/j.aquatox.2013.04.001

Yu, R. M., Wong, M. M., Kong, R. Y., Wu, R. S., \& Cheng, S. H. (2006). Induction of hepatic choriogenin mRNA expression in male marine medaka: a highly sensitive biomarker for environmental estrogens. Aquat Toxicol, 77(4), 348-358. doi: 10.1016/j.aquatox.2006.01.003

Yu, R. M. K., Ng, P. K. S., Tan, T., Chu, D. L. H., Wu, R. S. S., \& Kong, R. Y. C. (2008). Enhancement of hypoxia-induced gene expression in fish liver by the aryl hydrocarbon receptor (AhR) ligand, benzo[a]pyrene (BaP). Aquat Toxicol, 90(3), 235-242. doi: http://dx.doi.org/10.1016/j.aquatox.2008.09.004

Zhang, J., Li, F., Wang, Z., Zhang, X., Zhou, Q., \& Xiang, J. (2006). Cloning, expression and identification of ferritin from Chinese shrimp, Fenneropenaeus chinensis. J Biotechnol, 125(2), 173-184. doi: 10.1016/j.jbiotec.2006.03.010

Zhang, L., Sun, W., Cai, W., Zhang, Z., Gu, Y., Chen, H., . . Jia, X. (2013). Differential response of two ferritin subunit genes (VpFer1 and VpFer2) from Venerupis philippinarum following pathogen and heavy metals challenge. Fish Shellfish Immunol, 35(5), 1658-1662. doi:

http://dx.doi.org/10.1016/j.fsi.2013.07.030

Zhang, Y., Gao, J., Xu, P., Yuan, C., Qin, F., Liu, S., . . Wang, Z. (2014). Low-dose bisphenol A disrupts gonad development and steroidogenic genes expression in adult female rare minnow Gobiocypris rarus. Chemosphere, 112(0), 435-442. doi: http://dx.doi.org/10.1016/j.chemosphere.2014.04.089

Zhou, B. S., Wu, R. S. S., Randall, D. J., Lam, P. K. S., Ip, Y. K., \& Chew, S. F. (2000). Metabolic adjustments in the common carp during prolonged hypoxia. Journal of Fish Biology, 57(5), 11601171. doi: 10.1111/j.1095-8649.2000.tb00478.x 


\section{Figures}

Figure 1. Great Lakes AOCs sampled for this study between the fall of 2010 and spring of 2012.

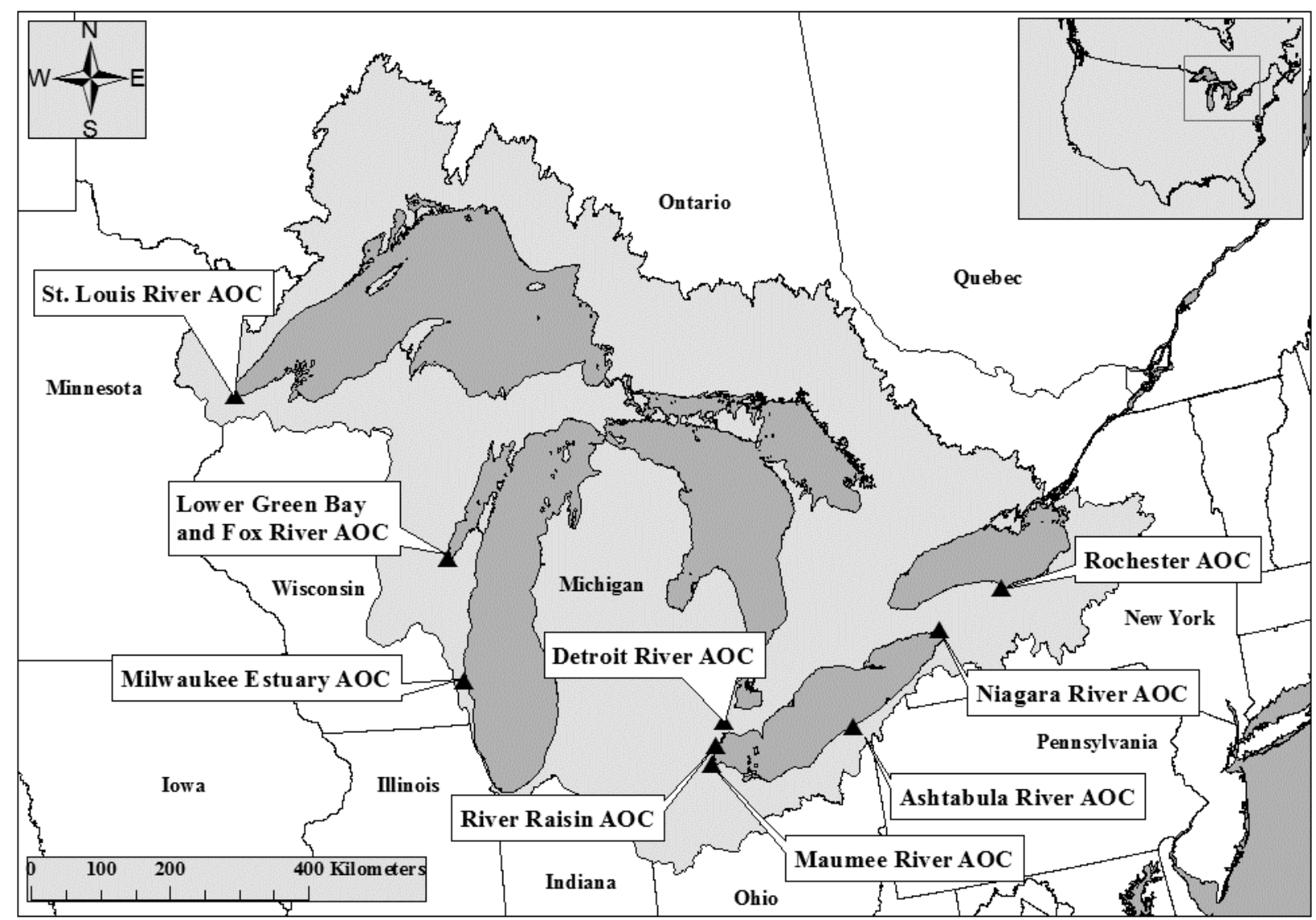




\title{
Chapter Two: Transcriptome Discovery in Non-Model Wild Fish Species for the Development of Quantitative Gene Expression Assays.
}

\begin{abstract}
Environmental studies increasingly identify the presence of both contaminants of emerging concern (CECs) and legacy contaminants in aquatic environments; however, the biological effects of these compounds on resident fishes remain largely unknown. High throughput methodologies were employed to establish partial transcriptomes for three wildcaught, non-model fish species; smallmouth bass (Micropterus dolomieu), white sucker (Catostomus commersonii) and brown bullhead (Ameiurus nebulosus). Sequences from these transcriptome databases were utilized in the development of a custom nCounter CodeSet that allowed for direct multiplexed measurement of 50 gene expression endpoints in liver tissue. Sequence information was also utilized in the development of quantitative real-time PCR (qPCR) primers. Cross-species hybridization allowed the smallmouth bass nCounter CodeSet to be used for quantitative gene expression analysis of an additional non-model species, largemouth bass (Micropterus salmoides). We validated the nCounter analysis data system with qPCR for a subset of genes and confirmed concordant results. Changes in gene expression biomarkers between sexes and seasons were evaluated to provide baseline data on gene modulation for each species of interest.
\end{abstract}




\section{Introduction}

Chemicals of emerging concern (CECs) are increasingly detected in aquatic environments worldwide (Birch et al., 2015; Blair et al., 2013; Lee et al., 2012; Li et al., 2010; Lopez et al., 2015; Nilsen et al., 2014; Stuart et al., 2012). These contaminants can be defined as synthetic or naturally occurring chemicals that are newly recognized, not commonly monitored, but have the potential to enter the environment and cause known or suspected adverse ecological and/or human health effects. This group includes current use pesticides, personal care products, pharmaceuticals, detergents, plasticizers, brominated flame retardants, and biogenic hormones, both human and animal (Klaper and Welch, 2011; Klecka et al., 2010). These compounds are defined not only for their potential detrimental effects on the environment, but by the lack of regulation pertaining to their release into air, water and sediment. In most cases, CECs are present as complex mixtures which may also include legacy contaminants such as heavy metals, polycyclic aromatic hydrocarbons (PAHs) and polychlorinated biphenyls (PCBs). Despite widespread detection in aquatic environments, little information is available regarding the biological effects of exposure to these complex mixtures.

Resident fish species are ideal bioindicators and integrators of chemical mixture effects as they are continually exposed to CECs and legacy contaminants and serve as a model for the evaluation of the impacts in aquatic ecosystems. Contaminant monitoring studies have identified indications of reproductive endocrine disruption, such as intersex (testicular oocytes), in the pelagic smallmouth bass Micropterus dolomieu and largemouth bass M. salmoides (Blazer et al., 2007; Blazer et al., 2012; Hinck et al., 2009; Iwanowicz et al., 2009; Sepulveda et al., 2002; Tetreault et al., 2011). Benthic species, including the brown bullhead Ameiurus nebulosus and white sucker Catostomus commersonii, have been widely used in ecotoxicological studies 
evaluating the presence of liver and skin tumors and other adverse effects (Baumann et al., 1996; Blazer et al., 2014; Blazer et al., 2009a, b; Hayes et al., 1990; Pinkney et al., 2011; Premdas et al., 1995; Pyron et al., 2001; Rafferty et al., 2009; Smith et al., 1989) and in the case of white sucker, reproductive endocrine disruption as well (McMaster, 2001; Woodling et al., 2006). These types of organismal level effects are often indicative of long term exposure to contaminants; therefore, bioindicators at the molecular level, which assess current and/or recent environmental conditions, can be incorporated to improve upon these assessments (GarciaReyero et al., 2008; Garcia-Reyero et al., 2014). Ankley et al. (2010) introduced the concept and use of adverse outcome pathways (AOPs) to accurately and efficiently assess the ecological risks of complex chemical mixtures through the integration and synthesis of data from many levels of biological organization. The linkage of molecular initiation events to adverse outcomes at higher levels of biological organization produces information that can be used for risk assessment by ecotoxicologists.

Unfortunately, much of the information available on adverse outcome pathways relates to model species such as fathead minnow (Pimephales promelas), zebrafish (Danio rerio) and medaka (Oryzias latipes). While this information has greatly contributed to our understanding of mechanisms, similar information for wild fish species is lacking. Hence, following the AOP framework, our objectives were to develop gene expression endpoints for non-model, but environmentally relevant, species to be utilized in conjunction with organismal level indicators. Genes to be included in assay development were determined by literature review of commonly modulated genes in model species exposed to CECs and legacy contaminants. High throughput sequencing technology was employed to establish partial transcriptomes for smallmouth bass, white sucker and brown bullhead. This nucleotide database was then used in the development of 
custom nCounter analysis assays for the evaluation of differential gene expression in liver tissue of wild-caught fishes. We present baseline data on gene expression differences between sexes, seasons and species.

\section{Methods}

\subsection{Transcriptome sequencing}

The initial databases for brown bullhead (BBH) and smallmouth bass (SMB) were created using wild caught individuals from multiple geographic areas and laboratory fish that had been exposed to estradiol in a previous study (Robertson et al., 2009). Liver, gonad, anterior kidney and spleen tissue were pooled. Total RNA was extracted using an E.N.Z.A. ${ }^{\circledR}$ Total RNA Kit (Omega Biotek, Norcross, GA). Total RNA was sent to Cofactor Genomics (St. Louis, MO) for library construction and sequencing on an Illumnia GAIIx (San Diego, CA). Additional sequencing was performed on a 454 GS FLX instrument (Roche, Branford, CT) at Duke Institute for Genome Science and Policy (Durham, NC). For each species, Illumina 60-bp paired-end reads were quality and adapter trimmed with CLC Genomics Workbench (v5). Reads were then assembled de novo with that software using three different kmer lengths $(35,43,51)$ and other settings at default values. These three initial assemblies were merged with a secondary assembly using automatic kmer selection and other default parameters. The 454 runs were assembled with MIRA3 (Chevreux et al., 2004) using the following quick switches: "denovo, est, normal, 454". Finally, the SMB 454 and Illumina contigs were merged with CAP3 (Huang and Madan, 1999) using an overlap length of 60 and percent identity of 90, whereas the BBH 454 and Illumina contigs were merged with CLC Genomics (v5) using default de novo assembly parameters.

White sucker (WHS) transcriptome sequencing was performed using tissue composites from male and female wild fish collected from the Great Lakes region (Hahn et al., 2015). Total 
RNA was isolated from skin and liver samples using an E.N.Z.A. ® RNA Kit (Omega Biotek, Norcross, GA) from nine individuals, pooled and enriched for non-ribosomal RNA using a RiboZero rRNA removal kit (Epicentre, Madison, WI). The resulting RNA preparation was sequenced as 100-bp paired-end reads on an Illumina HiSeq2000 (San Diego, CA) operated by the Institute for Genome Sciences (Baltimore, MD). Additional sequencing was performed on a 454 GS Junior (Roche, Branford, CT) at Duke Institute for Genome Science and Policy (Durham, NC). Illumina sequences were then assembled de novo into contigs using CLC workbench (v6) using the multi-kmer approach as above, but with five values $(21,31,41,51$ and 61). The 454 reads were also assembled with CLC Genomics (v6) using automatic kmer selection and default parameters. The final merging of these six initial assemblies was also performed with CLC Genomics (v6) using automatic kmer selection and default parameters. These assembly approaches were selected from a variety of iterations performed with multiple programs, and were chosen based on assembly N50, number of BLASTx hits to the proteome of Danio rerio (version Zv9; accession GCF_000002035.4), and low apparent redundancy (proportion of unique kmers of length 21).

The Blast2GO plugin (v2.8) for CLC Genomics Workbench (v8) was used for functional annotation of sequence data. First, sequences were used as queries in blastx searches against the uniprot databases for medaka and zebrafish applying the BLOSUM62 matrix and setting the lower threshold at an e-value of $1 \mathrm{xe}^{-6}$. We retained the top 10 alignments for each sequence. Next, functional information for all blast hits was retrieved from the Gene Ontology database and annotated using default parameters in Blast2GO. GO-Slim reduction was performed using default parameters in Blast2GO in order to restrict ontology content to broad functional categories. 


\subsection{Wild fish sampling}

We attempted to collect 20 mature (defined as greater than $250 \mathrm{~mm}$ in length) fish of each species at each sampling site and season. Fish were collected using a variety of collection methods including electrofishing, fyke nets and trap nets. Each species was collected during both the fall (late September to early October) and the spring (mid-April to early May) from sites within the Great Lakes region (Figure 1). Smallmouth bass (SMB) were collected from the St. Louis River (Duluth, MN) in the fall of $2010(n=7)$ and spring of $2011(n=6)$. Largemouth bass (LMB) were collected from the Ashtabula River (Ashtabula, $\mathrm{OH})$ in the fall $(\mathrm{n}=20)$ and spring of $2011(n=20)$. White sucker (WHS) were collected from Swan Creek, a tributary of the Maumee River (Toledo, OH) in the fall of $2010(n=18)$ and spring of $2011(n=20)$. Brown bullhead $(\mathrm{BBH})$ were collected in the fall $(\mathrm{n}=20)$ and spring $(\mathrm{n}=20)$ of 2011 from Conneaut Creek (Conneaut, $\mathrm{OH}$ ). Fish were anesthetized in a holding tank containing a lethal dose of tricaine methanesulfonate (MS-222, Argent Labs, Redmond, WA). A comprehensive necropsy-based assessment was conducted on each fish collected. Small sections of liver were collected and preserved in RNA later® (Life Technologies, Grand Island, NY) for gene expression analysis.

\subsection{Gene expression analysis}

Transcriptome shotgun assembly sequence databases (SRX156704, SRX199239, SRX1436666, SRX1339139, SRX199312, SRX148685) were searched by BLASTx to identify $a$ priori genes of interest. Genes of interest can be broadly assigned to categories and include those with suspected modulation in response to CECs including endocrine disrupting compounds, environmental stressors, as well as genes associated with neoplasia and other risk factors (presence of parasites or viruses). In each species 50 genes including, 5-7 housekeeping genes were chosen for analysis. Annotated sequence data for each gene was orientated and 
trimmed to correspond to coding regions using results from BLASTx searches. Custom CodeSets were designed by Nanostring Technologies (Seattle, WA). CodeSet details for each species are provided in Table 1. Liver samples collected for gene expression analysis were prepared for nCounter ${ }^{\circledR}$ analysis (NanoString Technologies, Seattle, WA). In short, approximately $17-23 \mathrm{mg}$ of liver tissue was homogenized in $400 \mu \mathrm{l}$ of TRK lysis buffer (Omega Biotech, Norcross, GA) in a tissue lyser (Qiagen, Valencia, CA) with $5 \mathrm{~mm}$ stainless steel balls (Boca Bearings, Boynton Beach, FL) at $30 \mathrm{~Hz}$ for 8 minutes. Samples were centrifuged at 16,100 RCF for 10 minutes and the supernatant was removed. Clarified homogenates were stored at $-80^{\circ} \mathrm{C}$ until shipment. Tissue lysate was sent to the University of Pittsburgh Genomics and Proteomics Core Laboratory (Pittsburgh, PA) for mRNA expression analysis on the nCounter analysis system. CodeSets for appropriate species were utilized in the nCounter analysis system workflow as per the manufacturer and core lab protocols. The RCC files generated during analysis were utilized for quantitative interrogation.

\subsection{Cross-species probe hybridization}

The CodeSets utilized for quantitative gene expression target mRNA molecules via hybridization; therefore we investigated the feasibility of utilizing the SMB CodeSet for crossspecies hybridization with the LMB. At the time of probe development publically available largemouth bass sequence data was scarce. On May 8, 2012, LMB and SMB were collected from a site at the Raisin River (Monroe, MI). Clarified liver homogenates from six LMB (3 males and 3 females) were included in nCounter analysis with the SMB CodeSet in tandem with homogenate from SMB. Data from these individuals, which represent similar environmental conditions, were used for regression analysis of all probes between species in SigmaPlot (v13.0, Systat Software, San Jose, CA). 
Following completion of our nCounter analysis of LMB using the CodeSet for SMB, a short read archive database (SRX547137) that included Illumina RNA-seq data from mixed LMB tissue became available. This presented the opportunity to compare sequence identity in the CodeSet binding regions for this species. We imported these short reads into CLC Genomics Workbench (v8) and assembled 100 bp contigs specific for the nCounter CodeSet target regions via the map to target algorithm. The contigs were then aligned using default settings in MUSCLE (Edgar, 2004) with those from the SMB CodeSet to determine \% identity.

\subsection{Comparison of nCounter analysis with quantitative real-time PCR}

Quantitative PCR is the gold standard for gene expression analysis. In order to evaluate the relationship between gene expression values measured by nCounter analysis and those from quantitative real-time PCR (qPCR), total RNA was isolated from the same tissue lysates used for nCounter analysis. Total RNA was extracted using the E.N.Z.A. ${ }^{\circledR}$ Total RNA Kit (Omega Biotek, Norcross, GA). Extracted RNA was synthesized into cDNA using a high capacity cDNA reverse transcription kit (Life Technologies, Grand Island, NY). Primers were designed against Nanostring probe target sequences for a subset of gene targets using Integrated DNA Technologies Real-Time qPCR Assay design tool. Target genes included vitellogenin (VTG), choriogenin (CHG), warm temperature acclimation protein 65 (WAP65) and glucokinase (GLK) genes. GoTaq qPCR Mastermix (Promega, Madison, WI) was used to amplify cDNA samples on a Rotor-Gene Q (QIAgen, Valencia, CA) in duplicate. Primer sequences and qPCR conditions are given in Supplemental Table 1. Correlation between relative expression patterns for nCounter and qPCR data were tested on raw, non-normalized data using SigmaPlot. 


\subsection{Normalization of $n$ Counter gene expression data}

We used nSolver Analysis Software (v2.0) for quality control of gene expression data. Negative controls, as included by Nanostring quality control protocol, with high average counts (values ranging from 7-37) were removed. The geometric mean plus three standard deviations of negative control probes was subtracted from each sample to account for background signal. To eliminate genes with low count data this value was defined as the reporting limit of this assay and genes with expression data below this calculated value were removed from subsequent analysis. Next, the average geometric mean of positive spike-in RNA control samples across all lanes was used to calculate a scaling factor which was applied to all samples. Normalization was performed using reference (housekeeper) genes. Housekeeping genes differed between species as necessary to account for variation in each custom CodeSet. Housekeeping genes were selected for inclusion in analysis based on literature of previous studies (Filby and Tyler, 2007) and searches using the RefGenes tool (Hruz et al., 2011). Housekeeping genes were selected to span average counts (low, medium and highly expressed) and \%CV values of all data collected and included RNA binding motif protein X-linked 2 (RBMX2), ribosomal protein L8 (RPL8), phosphoenolpyruvate carboxykinase (PEPCK), TATA box binding protein (TBP), elongation translation initiation factor 3D (ET1F3D), $\beta$-actin ( $\beta A C T)$, elongation factor $1 \alpha(E F 1 \alpha)$, MUS81, hypoxanthine phosphoribosyltransferase 1 (HPRT1). These genes were assessed for correlation with one another as well as their stability (range $0.145-0.846$ ) across the data set using NormFinder (Anderson et al., 2004). Specific genes used for each species are denoted in Table 1. The geometric mean of the housekeeping genes was used to calculate a scaling factor which was applied to all data. 


\subsection{Statistical analysis}

Bioconductor edgeR package (Robinson et al., 2010) was used to assess differential expression of genes. This package was originally written for the analysis of RNA-seq data, but is appropriate for digital gene expression analysis in general when normalization procedures are omitted. Because edgeR uses empirical Bayes estimation and exact tests with BenjaminiHochberg correction for multiple testing based on the negative binomial distribution, we found that it was more appropriate for nCounter analysis data than the traditional Student's t-test (Anders and Huber, 2010; Brumbaugh et al., 2011; Robinson et al., 2010). Data for each species were grouped by season of collection to allow for the assessment of differential gene expression between sexes without temporal influence. To eliminate the influence of sex, genes determined as differentially expressed between males and females were then removed for subsequent analysis of differential expression between seasons. Gene expression was considered biologically significant when $\log _{2}$ fold changes were $\geq 2$ and $p$-values and false discovery rates were reported at $<0.05$.

\section{Results}

\subsection{Transcriptome sequencing}

Sequencing metrics are summarized in Supplemental Table 2. Transcriptome sequencing identified a high amount of functional diversity in each species (Supplemental Figure 1).

\subsection{Cross-species probe hybridization}

Regression analyses of nCounter data between Micropterus species were performed separately for males and females. In females, there was a strong linear relationship between

nCounter and qPCR data for LMB and SMB (adj. $\left.\mathrm{R}^{2}=0.87\right)$ with only three genes, hepcidin 2 
(HEP2), GLK, and WAP65 outside of the 95\% prediction band (Figure 2A). A similar relationship also occurred in male bass (adj. $\left.\mathrm{R}^{2}=0.90\right)$ with four genes, HEP2, VTG, type 1 iodothyronine deiodinases (DOI1) and metallothionein (MT) outside of the 95\% prediction band (Figure 2B).

All target sequence data from the LMB transcriptome contigs were mapped successfully to the SMB CodeSet. A total of 28 of 50 genes showed $100 \%$ identity between SMB and LMB. The lowest \% identity values were identified in PEPCK (81\%), heat shock protein 70 (HSP70; 84\%) and ferritin (FRT; 87\%; Table 2).

\subsection{Validation of nCounter codeSet with real-time PCR}

The relative expression of the WAP65, GLK, CHG and VTG genes as measured by nCounter and qPCR data was significantly correlated $\left(\mathrm{R}^{2}=0.40,0.73 .0 .74\right.$ and 0.77 , respectively). This positive linear relationship was consistent for genes that are expressed at both low and high levels (Figure 3).

\subsection{Sex-related differences in gene expression}

A number of genes were identified as differentially expressed in males and females (Figure 4). The greatest number of differentially expressed genes between males and females was observed in the Micropterus species. In spring collections, five genes (VTG, estrogen receptor $\alpha(\mathrm{ER} \alpha), \mathrm{CHG}, \mathrm{WAP} 65, \mathrm{MT})$ in SMB, five genes (VTG, CHG, transforming growth factor $\beta R 1$ (TGFßR1), AR (androgen receptor), GLK) in LMB and four genes (ER $\alpha$, catalase (CAT), proliferating cell nuclear antigen (PCNA), WAP65) in BBH were identified as differentially expressed (Table 3). In fall collections, five genes (VTG, CHG, ER $\alpha$, HEP2, TGF $\beta$ ) in SMB, two genes (CHG, VTG) in LMB and one gene (ER $\alpha)$ in BBH were identified as differentially expressed between the sexes (Table 3). In WHS, there was no clear effect of 
season on gene expression between the sexes with the exception of VTG expression, which was higher in females than males in both seasons (Table 3).

\subsection{Seasonal variation in gene expression}

Differentially expressed genes between spring and fall varied between species (Figure 5). In males, six genes (HEP2, VTG, CHG, MT, WAP65, ER $\alpha$ ) in SMB, four genes (DOI1, CHG, GLK, VTG) in LMB, eight genes (cytochrome c oxidase (COI), granulin B (GRNB), $17 \beta$ hydroxysteroid dehydrogenase (17ßHD), CAT, glutathione peroxidase 1 (GPX1), WAP65, estrogen receptor $\beta$ (ERß), Zschokkella sp. 18S ribosomal RNA gene (MYXO)) in BBH and three genes (11ß hydroxysteroid dehydrogenase (11ßHD), VTG, PCNA) in WHS were reported with differential expression between seasons. In females, one gene (HEP2) in SMB, four genes (arginase (ARG), DOI1, androgen receptor $\beta$ (AR $\beta)$, VTG) in LMB, two genes (MYXO, (GPX4) in $\mathrm{BBH}$ and one gene (GPX) in WHS were reported with differential expression between seasons (Table 4).

\section{Discussion}

\subsection{Transcriptome sequencing}

The development of gene expression assays to support biomarker research requires a comprehensive nucleotide database. These resources did not exist for species native to the aquatic environments of research concern. Transcriptome shotgun assembly databases were generated for three species commonly used in environmental health assessment in the midcentral and eastern regions of the United States and Canada. These were used to create custom CodeSets for gene expression analysis with the nCounter system. The quantitative measurement of a collection of genes was preferred to facilitate the assessment of the effects of contaminants 
across a range of aquatic environments which may be influenced by individual compounds or complex chemical mixtures. Previous studies have established transcriptional changes associated with compounds suspected to occur in the habitats of our species of interest that may result in endocrine disruption, tumor formation, immune modulation and/or induction of general stress responses (Brinkmann et al., 2016; Christiansen et al., 2014; Houde et al., 2014; McElroy et al., 2015; Yamaguchi et al., 2005). The nCounter system was advantageous for this purpose as it allowed for the evaluation of numerous genes, with a similar sensitivity as qPCR, but a reduction in both time and cost. A strong linear relationship was observed between a subset of genes (WAP65, GLK, CHG and VTG) tested with qPCR and the data generated through nCounter analysis (Figure 3). These results are similar to those reported in previous comparisons of the nCounter system with qPCR that identified some discrepancies in transcription of genes attributed to differences in the two platforms (Geiss et al., 2008). The nCounter analysis approach utilizes solution-hybridization kinetics and directly measures mRNA molecules, while qPCR includes a reverse transcription step followed by the amplification of sections of cDNA with specific primers. The calculated concentration of gene targets may therefore vary between these two approaches. Analysis by nCounter analysis is also more robust to degraded RNA (Stricker et al., 2014); therefore degradation of samples would lead to lower estimation by qPCR. Given these differences, as well as the difference in starting material used in our assays, we found the nCounter assay to be a reliable alternative to qPCR.

We also tested the feasibility of utilizing the SMB nCounter CodeSet for the measurement of gene expression in the closely related LMB. At the inception of this project, nucleotide sequences in publicly available databases were limited. The development of a CodeSet suitable for both bass species was desirable as both are commonly used in 
environmental health studies (Goodbred et al., 2015; Kolpin et al., 2013; Mierzejewski et al., 2014). These species have divergent movement patterns and are rarely found cohabitating (Carter et al., 2012; Iwanowicz et al., 2016) causing flexibility with regard to species of collection to expand the potential to collect appropriate sample sizes in aquatic environments affected by contaminants. Regression analysis of gene expression endpoints found strong relationships in gene expression between species in both males and females. In both cases, most probes were found within the $95 \%$ prediction band (Figure 2), illustrating high conservation of selected genes between these closely related species. This was well supported by $\%$ identity values between LMB and SMB which ranged from $81 \%$ to $100 \%$ (Table 2). Regression analysis identified several genes which appear to be differentially expressed between species in males including HEP2, VTG, DOI1 and MT and in females, HEP2, GLK, and WAP65 as indicated by nCounter analysis. Count values for these probes fall within the calculated detection limit of the assay with high \% identity between species (99-100\%), therefore we believe these genes may represent physiological differences between the species and do not reflect inefficient hybridization of gene expression probes. Though we identified differences between these species, the utilization of the CodeSet for within species comparisons provides the opportunity for use in ecological assessment of the effects of contaminants in various localities.

\subsection{Baseline differences in gene expression between sexes and seasons}

Establishing a baseline for the natural variation in expression of mRNA markers between sexes and temporal collections for each of these resident species of interest will aid in the ability to assess and interpret fluctuations in gene expression (Wang et al., 2014). We utilized sites from the Great Lakes region in an attempt to establish baseline gene expression metrics between sexes and seasons and make inferences regarding varying species sensitivities. The most common 
genes reported with variable expression between males and females of all species were those involved in reproduction including VTG, CHG and ER $\alpha$. Estrogen receptors (ERs) are transcription factors which control the expression of genes involved in metabolism, development, reproduction and homeostasis. Generally, ERs are activated upon the binding of hormonal molecules, either natural or synthetic, resulting in the synthesis of a number of estrogen response genes. VTG and CHG syntheses are mediated through the ER pathway and occur in the liver following the stimulation of ovarian estrogens. The presence of VTG or CHG in male fish is a well-established biomarker of exposure to estrogenic compounds (Sumpter and Jobling, 1995; Yu et al., 2006). In all cases, these genes were up-regulated in females relative to males (Figure 4). In general, levels of these genes are expected to be high in females and absent or relatively low in males and therefore this relationship is reflective of natural physiological differences between sexes as well as seasonal spawning behavior.

Though similarities in the up-regulation of these genes were found, differences between species were also observed. In pelagic species, SMB consistently show up-regulation of all three of these genes in females, while LMB showed only up-regulation of VTG and CHG. The benthic BBH and WHS each exhibited up-regulation of one gene, ER $\alpha$ or VTG, respectively. It is possible that the collection of these fishes from various sites contributed to the differences seen between species in the regulation of genes in females. However, it is also likely that these differences are related to the varying physiological processes and life history strategies of each species. The timing of spawning varies between these species with WHS spawning first, when water temperatures are between $6-12^{\circ} \mathrm{C}$ (Manny et al., 2010), followed by SMB and LMB which begin spawning when water temperatures reach approximately 14 or $15^{\circ} \mathrm{C}$ (Dufour et al., 2015; Ridgway et al., 1991) and lastly BBH which spawn in water temperatures between $21-25^{\circ} \mathrm{C}$ 
(Sakaris et al., 2005). Sampling for this study targeted the collection of bass species pre-spawn, hence the various species may have been at different stages within the reproductive cycle.

Evaluation of temporal variation in gene expression revealed modulated expression between fall and spring sampling seasons in all species. The VTG gene was most often associated with differences between fall and spring collection periods (Figure 6). Differences in this gene were found in male SMB, LMB, and WHS and female LMB. In bass, VTG was consistently reported as down-regulated, while in WHS it was up-regulated, in the fall relative to the spring. Similar results were observed for $\mathrm{CGH}$, which was also down-regulated in both male bass species with no statistically significant modulation occurring in BBH or WHS. Temporal modulation of gene expression endpoints varied between sexes, with more divergent gene expression between seasons in males than females. This pattern was consistent across all species, though the genes which were modulated within each sex and the number of genes identified as modulated in each species were not necessarily similar. These differences may be influenced by seasonal events, such as snowmelt and/or runoff events, which are likely to vary by site.

Analyses of baseline variation in gene expression endpoints between males and females and temporally using nCounter probes determined a majority of our chosen endpoints to be relatively stable between sexes and seasons. Genes that were identified with modulations between sex or seasons were those we expected to vary as a result of physiological processes. The overall lack of modulation found in the gene expression biomarkers we evaluated will allow for the assessment of biological effects related to contaminants; however, the need to consider sex, season and species as independent statistical units is emphasized. The ability of these biomarkers to detect small fluctuations in these natural processes will presumably allow for easy 
detection of modulated gene expression resulting from other environmental stimuli including exposure to CECs. Concurrent collections of water and sediment chemical parameters and other biological endpoints, including gonadosomatic and hepatosomatic indices, plasma hormones, and histopathology can then be linked to provide a sequential series of effects and establish AOPs to be applied in these non-model species.

\section{Acknowledgements}

This research was funded through a Great Lakes Restoration Initiative grant to the U.S. Fish and Wildlife Service, and by the U.S. Geological Survey's Environmental Health (Contaminant Biology), Ecosystems (Fisheries) and Cooperative Units Programs. We thank JoAnn Banda, Steven Choy, Daniel Gefell, Zachary Jorgenson, and Jeremy Moore for fish collections; Ryan Braham, Heather Walsh, and Adam Sperry for assistance with fish collections and tissue processing; and Tim King for assistance with 454 sequencing of the smallmouth bass. Any use of trade, firm or product names is for descriptive purposes only and does not imply endorsement by the U.S. Government.

\section{References}

Anders, S., Huber, W., 2010. Differential expression analysis for sequence count data. Genome Biology 11, R106.

Anderson, C.L., Ledet-Jensen, J., Orntoft, T., 2004. Normalization of real-time quantitative RTPCR data: a model based variance estimation approach to identify genes suited for normalization - applied to bladder - and colon-cancer data-sets. Cancer Research 64, 5245-5250.

Ankley, G.T., Bennett, R.S., Erickson, R.J., Hoff, D.J., Hornung, M.W., Johnson, R.D., Mount, D.R., Nichols, J.W., Russom, C.L., Schmieder, P.K., Serrrano, J.A., Tietge, J.E., Villeneuve, D.L., 2010. Adverse outcome pathways: A conceptual framework to support ecotoxicology research and risk assessment. Environmental Toxicology and Chemistry 29, 730-741.

Baumann, P.C., Smith, I.R., Metcalfe, C.D., 1996. Linkages between chemical contaminants and tumors in benthic Great Lakes fish. Journal of Great Lakes Research 22, 131-152. 
Birch, G.F., Drage, D.S., Thompson, K., Eaglesham, G., Mueller, J.F., 2015. Emerging contaminants (pharmaceuticals, personal care products, a food additive and pesticides) in waters of Sydney estuary, Australia. Marine Pollution Bulletin 97, 56-66.

Blair, B.D., Crago, J.P., Hedman, C.J., Klaper, R.D., 2013. Pharmaceuticals and personal care products found in the Great Lakes above concentrations of enviornmental concern. Chemosphere 93, 216-223.

Blazer, V.S., Hoffman, J., Walsh, H.L., Braham, R.P., Hahn, C., Collins, P., Jorgenson, Z., Ledder, T., 2014. Health of white sucker within the St. Louis River area of concern associated with habitat usage as assessed using stable isotopes. Ecotoxicology 23, 236-251.

Blazer, V.S., Iwanowicz, D.D., Iwanowicz, L.R., Smith, D.R., Young, J.A., Hedrick, J.D., Foster, S.W., Reeser, S.J., 2007. Intersex (testicular oocytes) in smallmouth bass Micropterus dolomieu from the Potomac River and selected nearby drainages. Journal of Aquatic Animal Health 19, 242-253.

Blazer, V.S., Iwanowicz, L.R., Henderson, H., Mazik, P.M., Jenkins, J.A., Alvarez, D.A., Young, J.A., 2012. Reproductive endocrine disruption in smallmouth bass (Micropterus dolomieu) in the Potomac River basin: spatial and temporal comparisons of biological effects. Environmental Monitoring and Assessment 184, 4309-4334.

Blazer, V.S., Rafferty, S.D., Baumman, P.C., Smith, S.B., Obert, E.C., 2009a. Assessment of the "fish tumors or other deformities" beneficial use impairment in brown bullhead (Ameiurus nebulosus): I. Orocutaneous tumors. Journal of Great Lakes Research 35, 517-526.

Blazer, V.S., Rafferty, S.D., Baumman, P.C., Smith, S.B., Obert, E.C., 2009b. Assessment of the "fish tumors or other deformities" beneficial use impairment in brown bullhead (Ameiurus nebulosus): II. Liver neoplasia. Journal of Great Lakes Research 35, 527-537.

Brinkmann, M., Koglin, S., Eisner, B., Wiseman, S., Hecker, M., Eichbaum, K., Thalmann, B., Buchinger, S., Reifferscheid, G., Hollert, H., 2016. Characterisation of transcriptional responses to dioxins and dioxin-like contaminants in roach (Rutilus rutilus) using whole transcriptome analysis. Science of the Total Environment 541, 412-423.

Brumbaugh, C.D., Kim, H.J., Giovacchini, M., Pourmand, N., 2011. NanoStriDE: normalization and differential expression analysis of NanoString nCounter data. BMC Bioinformatics 12, 479.

Carter, M.W., Weber, M.J., Dettmers, J.M., Wahl, D.H., 2012. Movement patterns of smallmouth and largemouth bass in and around a Lake Michigan harbor: The importance of water temperature. Journal of Great Lakes Research 38, 396-401.

Christiansen, H.E., Mehinto, A.C., Yu, F., Perry, R.W., Denslow, N.D., Maule, A.G., Mesa, M.G., 2014. Correlation of gene expression and contaminant concentrations in wild largescale suckers: a field-based study. Science of the Total Environment 484, 379-389. 
Dufour, K., Gutowsky, L.F.G., Algera, D., Zolderdo, A., Magel, J.M.T., Pleizier, N., Dick, M., Cooke, S.J., 2015. An experimental test of in-season homing mechanisms used by nest-guarding male largemouth bass following displacement. Behavioural Processes 120, 87-93.

Edgar, R., 2004. MUSCLE: multiple sequence alignment with high accuracy and high throughput. Nucleic Acid Research 32, 1792-1797.

Filby, A., Tyler, C.R. 2007. Appropriate 'housekeeping' genes for use in expression profiling the effects of enviornmental estrogens in fish. BMC Moleuclar Biology 8:10, 1-13.

Garcia-Reyero, N., Griffitt, L., Kroll, K.J., Farmerie, W.G., Barber, D.S., Denslow, N.D., 2008. Construction of a robust microarray from a non-model species largemouth bass, Micropterus salmoides (Lacepede), using pyrosequencing technology. Journal of Fish Biology 72, 2354-2376.

Garcia-Reyero, N., Tingaud-Sequeira, A., Cao, M., Zhu, Z., Perkins, E.J., Hu, W., 2014. Endocrinology: advances through omics and related technologies. General and Comparative Endocrinology 203, 262-273.

Geiss, G.K., Bumgarner, R.E., Birditt, B., Dahl, T., Dowidar, N., Dunaway, D.L., Fell, H.P., Ferree, S., George, R.D., Grogan, T., James, J.J., Maysuria, M., Mitton, J.D., Oliveri, P., Osborn, J.L., Peng, T., Ratcliffe, A.L., Webster, P.J., Davidson, E.H., Hood, L., Dimitrov, K., 2008. Direct multiplexed measurement of gene expression with color-coded probe pairs. Nature Biotechnology 26, 317-325.

Goodbred, S.L., Patiño, R., Torres, L., Echols, K.R., Jenkins, J.A., Rosen, M.R., Orsak, E., 2015. Are endocrine and reproductive biomarkers altered in contaminant-exposed wild male largemouth bass (Micropterus salmoides) of Lake Mead, Nevada/Arizona, USA? General and Comparative Endocrinology 219, 125-135.

Hahn, C.M., Iwanowicz, L.R., Cornman, R.S., Conway, C.M., Winton, J.R., Blazer, V.S., 2015. Characterization of a novel Hepadnavirus in the white sucker (Catostomus commersonii) from the Great Lakes region of the United States. Journal of Virology 89, 11801-11811.

Hayes, M.A., Smith, I.R., Rushmore, T.H., Crane, T.L., Thorn, C., Kocal, T.E., Ferguson, H.W., 1990. Pathogenesis of skin and liver neoplasms in white suckers from industrially polluted areas in Lake Ontario. Science of the Total Environment 94, 105-123.

Hinck, J.E., Blazer, V.S., Schmitt, C.J., Papoulias, D.M., Tillitt, D.E., 2009. Widespread occurrence of intersex in black basses (Micropterus spp.) from U.S. rivers, 1995-2004. Aquatic Toxicology 95, 60-70.

Houde, M., Giraudo, M., Douville, M., Bougas, B., Couture, P., De Silva, A.O., Spencer, C., Lair, S., Verreault, J., Bernatchez, L., Gagnon, C., 2014. A multi-level biological approach to evaluate impacts of a major municipal effluent in wild St. Lawrence River yellow perch (Perca flavescens). Science of the Total Environment 497-498, 307-318. 
Hruz, T., Wyss, M., Docquier, M., Pfaffl, M.W., Masanetz, S., Borghi, L., Verbrugge. P., Kalaydjieva, L., Bleuler, S., Laule, O., Descombes, P., Gruissem, W. and P. Zimmermann. 2011. RefGenes: identification of reliable and condition specific reference genes for RT-qPCR data normalization. BMC Genomics 12:156.

Iwanowicz, L.R., Blazer, V.S., Guy, C.P., Pinkney, A.E., Mullican, J.E., Alvarez, D.A., 2009. Reproductive health of bass in the Potomac, U.S.A., drainage: part 1. Exploring the effects of proximity to wastewater treatment plant discharge. Environmental Toxicology and Chemistry 28, 1072-1083.

Iwanowicz, L.R., Blazer, V.S., Pikney, A.E., Guy, C.P., Major, A.M., Munney, K., Mierzykowski, S., Lingenfelser, S., Secord, A., Patnode, K., Kubiak, T.J., Stern, C., Hahn, C.M., Iwanowicz, D.D., Walsh, H.L., Sperry, A., 2016. Evidence of estrogenic endocrine disruption in smallmouth and largemouth bass inhabiting Northeast U.S. national wildlife refuge water: A reconnaissance study. Ecotoxicology and Environmental Safety 124, 50-59.

Klaper, R., Welch, L.C., 2011. Emerging contaminant threats and the Great Lakes: Existing science, existing science, estimating relative risk and determining policy. Alliance for the Great Lakes, accessed January 5, 2016 at http://www.greatlakes.org/Document.Doc?id=1072.

Klecka, G., Persoon, C., Currie, R., 2010. Chemicals of emerging concern in the Great Lakes Basin: an analysis of environmental exposures. Reviews of Enviornmental Contamination and Toxicology 207, 1-93.

Kolpin, D.W., Blazer, V.S., Gray, J.L., Focazio, M.J., Young, J.A., Alvarez, D.A., Iwanowicz, L.R., Foreman, W.T., Furlong, E.T., Speiran, G.K., Zaugg, S.D., Hubbard, L.E., Meyer, M.T., Sandstrom, M.W., Barber, L.B., 2013. Chemical contaminants in water and sediment near fish nesting sites in the Potomac River basin: Determining potential exposures to smallmouth bass (Micropterus dolomieu). Science of the Total Environment 443, 700-716.

Lee, K.E., Langer, S.K., Menheer, M.A., Foreman, W.T., Furlong, E.T., Smith, S.G., 2012. Chemicals of emerging concern in water and bottom sediment in Great Lakes areas of concern, 2010 to 2011-Collection methods, analyses methods, quality assurance and data. U.S. Geological Survey Data Series 723, 26 p.

Li, H., Helm, P.A., Metcalfe, C.D., 2010. Sampling in the Great Lakes for pharmaceuticals, personal care products, and endocrine-disrupting substances using the passive polar organic chemical integrative sampler. Environmental Toxicology and Chemistry 29, 751-762.

Lopez, B., Ollivier, P., Togola, A., Baran, N., Ghestem, J.-P., 2015. Screening of French groundwater for regulated and emerging contaminants. Science of the Total Environment 518$519,562-573$.

Manny, B.A., Kennedy, G.W., Boase, J.C., Allen, J.D., Roseman, E.F., 2010. Spawning by walleye (Sander vitreus) and white sucker (Catostomus commersonii) in the Detroit River: Implications for spawning habitat enhancement. Journal of Great Lakes Research 36, 490-496. 
McElroy, A.E., Hice, L.A., Frisk, M.G., Purcell, S.L., Phillips, N.C., Fast, M.D., 2015. Spatial patterns in markers of contaminant exposure, glucose and glycogen metabolism, and immunological response in juvenile winter flounder (Pseudoplueronectes americanus). Comparative Biochemistry and Physiology, Part D, Genomics \& Proteomics 14, 53-65.

McMaster, M.E., 2001. A review of the evidence for endocrine disruption in Canadian aquatic ecosystems. Water Quality Research Journal of Canada 36, 215-231.

Mierzejewski, J., Haney, D.C., van den Hurk, P., 2014. Biomarker responses in sunfish species and largemouth bass from the Saluda River, South Carolina. Ecotoxicology and Environmental Safety 110, 8-15.

Nilsen, E., Zaugg, S., Alvarez, D., Morace, J., Waite, I., Counihan, T., Hardiman, J., Torres, L., Patiño, R., Mesa, M., Grove, R., 2014. Contaminants of legacy and emerging concern in largescale suckers (Catostomus macrocheilus) and the foodweb in the lower Columbia River, Oregon and Washington, USA. Science of the Total Environment 484, 344-352.

Pinkney, A.E., Harshbarger, J.C., Karouna-Renier, N.K., Jenko, K., Balk, L., Skarphéðinsdóttir, H., Liewenborg, B., Rutter, M.A., 2011. Tumor prevalence and biomarkers of genotoxicity in brown bullhead (Ameiurus nebulosus) in Chesapeake Bay tributaries. Science of the Total Environment 410-411, 248-257.

Premdas, P.D., Metcalfe, T.L., Bailey, M.E., Metcalfe, C.D., 1995. The prevalence and histological appearance of lip papillomas in white suckers (Catostomus commersonii) from two sites in Central Ontario, Canada. Journal of Great Lakes Research 21, 207-218.

Pyron, M., Obert, E.C., Wellington, R., 2001. Tumor rates and population estimates of brown bullhead (Ameiurus nebulosus) in Presque Isle Bay, Lake Erie. Journal of Great Lakes Research 27, 185-190.

Rafferty, S.D., Blazer, V.S., Pinkney, A.E., Grazio, J.L., Obert, E.C., Boughton, L., 2009. A historical perspective on the "fish tumors or other deformities" beneficial use impairment at Great Lakes Areas of Concern. Journal of Great Lakes Research 35, 496-506.

Ridgway, M.S., Shuter, B.J., Post, E.E., 1991. The relative influence of body size and territorial behaviour on nesting asynchrony in male smallmouth bass, Micropterus dolomieui (Pisces: Centrarchidae). Journal of Animal Ecology 60, 665-681.

Robertson, L.S., Iwanowicz, L.R., Marranca, J.M., 2009. Identification of centrarchid hepcidins and evidence that $17 \beta$-estradiol disrupts constitutive expression of hepcidin- 1 and inducible expression of hepcidin-2 in largemouth bass (Micropterus salmoides). Fish and Shellfish Immunology 26, 898-907.

Robinson, M.D., McCarthy, D.J., Smyth, G.K., 2010. edgeR: a Bioconductor package for differential expression analysis of digital gene expression data. Bioinformatics 26, 139-140. 
Sakaris, P.C., Jesien, R.V., Pinkney, A.E., 2005. Brown bullhead as an indicator species: Seasonal movement patterns and home ranges within the Anacostia River, Washington, D.C. Transactions of the American Fisheries Society 134, 1262-1270.

Sepulveda, M.S., Johnson, W.E., Higman, J.C., Denslow, N.D., Schoeb, T.R., Gross, T.S., 2002. An evaluation of biomarkers of reproductive function and potential contaminant effects in Florida largemouth bass (Micropterus salmoides floridanus) sampled from the St. Johns River. Science of the Total Environment 289, 133-144.

Smith, I.R., Ferguson, H.W., Hayes, M.A., 1989. Histopathology and prevalence of epidermal papillomas epidemic in brown bullhead, Ictalurus nebulosus (Lesueur), and white sucker, Catostomus commersonii (Lacépède), populations from Ontario, Canada. Journal of Fish Diseases 12, 373-388.

Stricker, T.P., Morales La Madrid, A., Chlenski, A., Guerrero, L., Salwen, H.R., Gosiengfiao, Y., Perlman, E.J., Furman, W., Bahrami, A., Shohet, J.M., Zage, P.E., Hicks, M.J., Shimada, H., Suganuma, R., Park, J.R., So, S., London, W.B., Pytel, P., Maclean, K.H., Cohn, S.L., 2014. Validation of a prognostic multi-gene signature in high-risk neuroblastoma using the high throughput digital NanoString nCounter ${ }^{\mathrm{TM}}$ system. Molecular Oncology 8, 669-678.

Stuart, M., Lapworth, D., Crane, E., Hart, A., 2012. Review of risk from potential emerging contaminants in UK groundwater. Science of the Total Environment 416, 1-21.

Sumpter, J.P., Jobling, S., 1995. Vitellogenesis as a biomarker for estrogenic contamination of the aquatic environment. Environmental Health Perspectives 103, 173-178.

Tetreault, G.R., Bennett, C.J., Shires, K., Knight, B., Servos, M.R., McMaster, M.E., 2011. Intersex and reproductive impairment of wild fish exposed to multiple municipal wastewater discharges. Aquatic Toxicology 104, 278-290.

Wang, R.-L., Bencic, D.C., Garcia-Reyero, N., Perkins, E.J., Villeneuve, D.L., Ankley, G.T., Biales, A.D., 2014. Natural variation in fish transcriptomes: Comparative analysis of the fathead minnow (Pimephales promelas) and zebrafish (Danio rerio). PloS one 9, e114178.

Woodling, J.D., Lopez, E.M., Maldonado, T.A., Norris, D.O., Vajda, A.M., 2006. Intersex and other reproductive disruption of fish in wastewater effluent dominated Colorado streams. Comparative biochemistry and physiology. Comparative Biochemistry and Physiology, Part C Toxicology and Pharmacology 144, 10-15.

Yamaguchi, A., Ishibashi, H., Kohra, S., Arizono, K., Tominaga, N., 2005. Short-term effects of endocrine-disrupting chemicals on the expression of estrogen-responsive genes in male medaka (Oryzias latipes). Aquatic Toxicology 72, 239-249. 
Yu, R.M., Wong, M.M., Kong, R.Y., Wu, R.S., Cheng, S.H., 2006. Induction of hepatic choriogenin mRNA expression in male marine medaka: a highly sensitive biomarker for environmental estrogens. Aquatic Toxicology 77, 348-358. 


\section{Figures}

Figure 1. Great Lakes Area of Concern Sampling Sites. Sites sampled included St Louis River (Duluth, MN), Swan Creek (Maumee, OH), Ashtabula River (Ashtabula, OH) and Conneaut Creek $(\mathrm{OH})$.

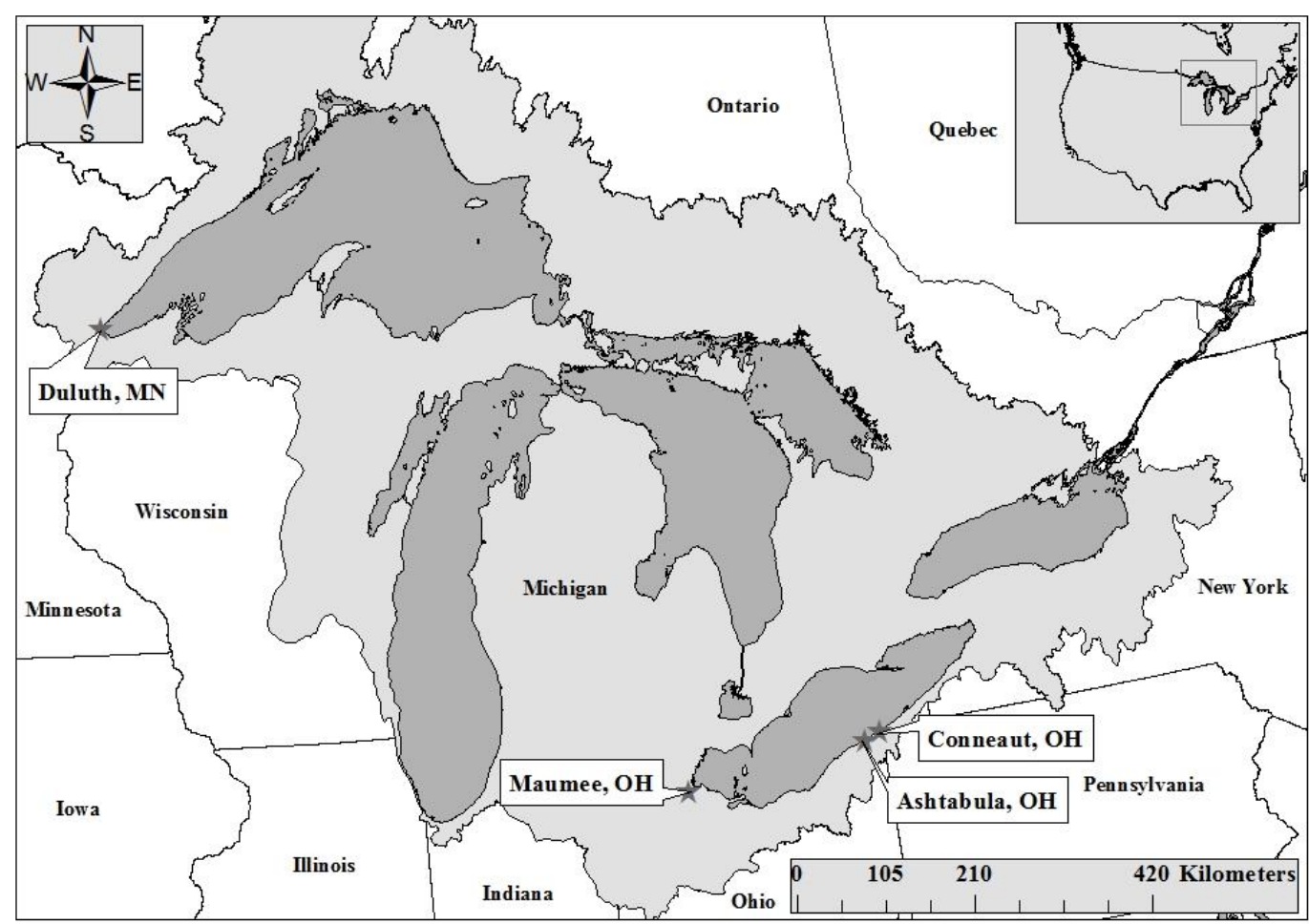


Figure 2. Regression analysis of female $\left(A, R^{2}=0.87\right)$ and male $\left(B, R^{2}=0.90\right)$ and $L M B$ and SMB. Dashed line represents $95 \%$ prediction bands.

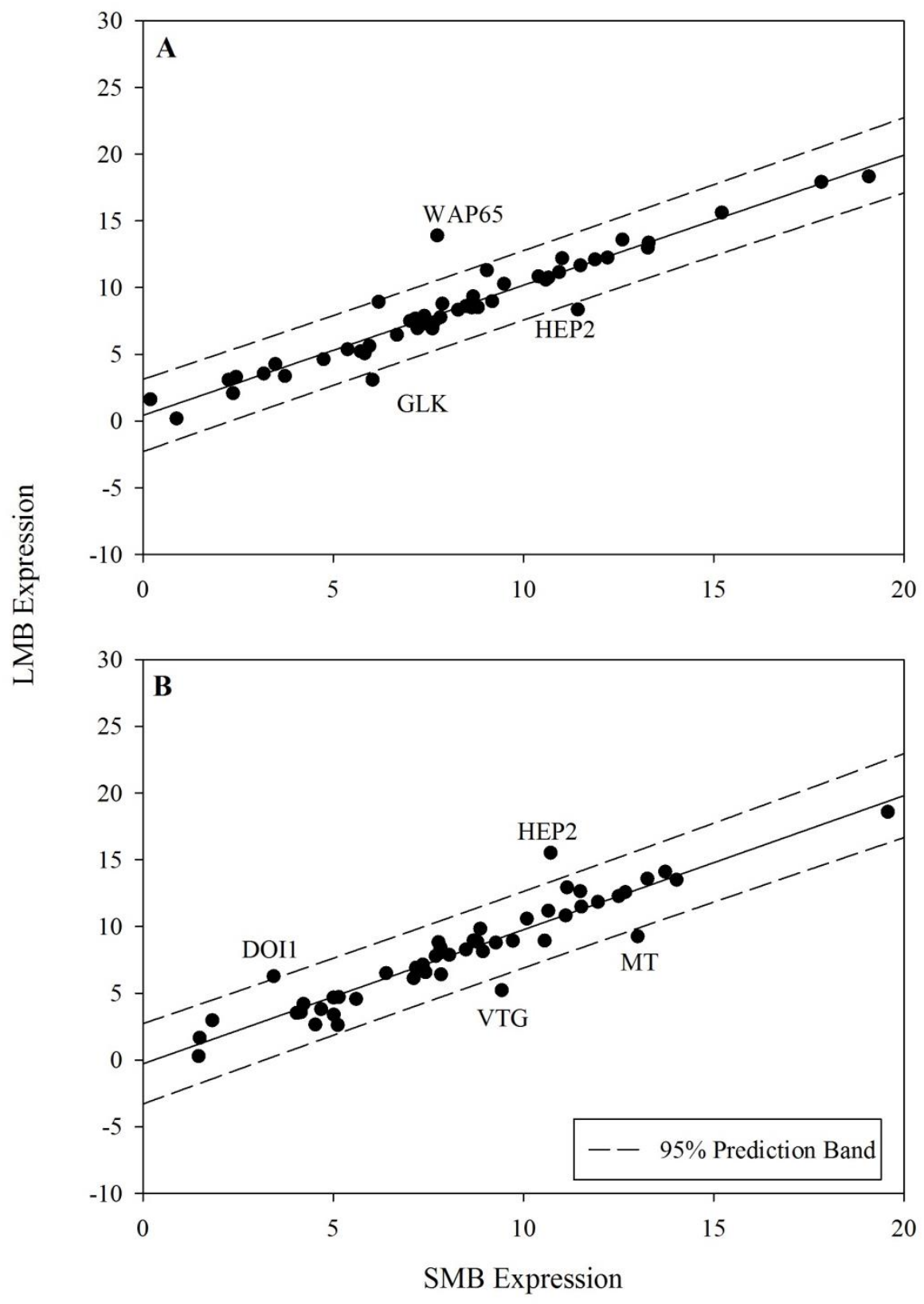


Figure 3. Regression analysis of Nanostring and qPCR results for WAP65 $\left(A, \mathrm{R}^{2}=0.40\right)$, GLK $\left(B, R^{2}=0.73\right), C H G\left(C, R^{2}=0.74\right)$ and VTG $\left(D, R^{2}=0.77\right)$. Dashed line represents $95 \%$ prediction bands.

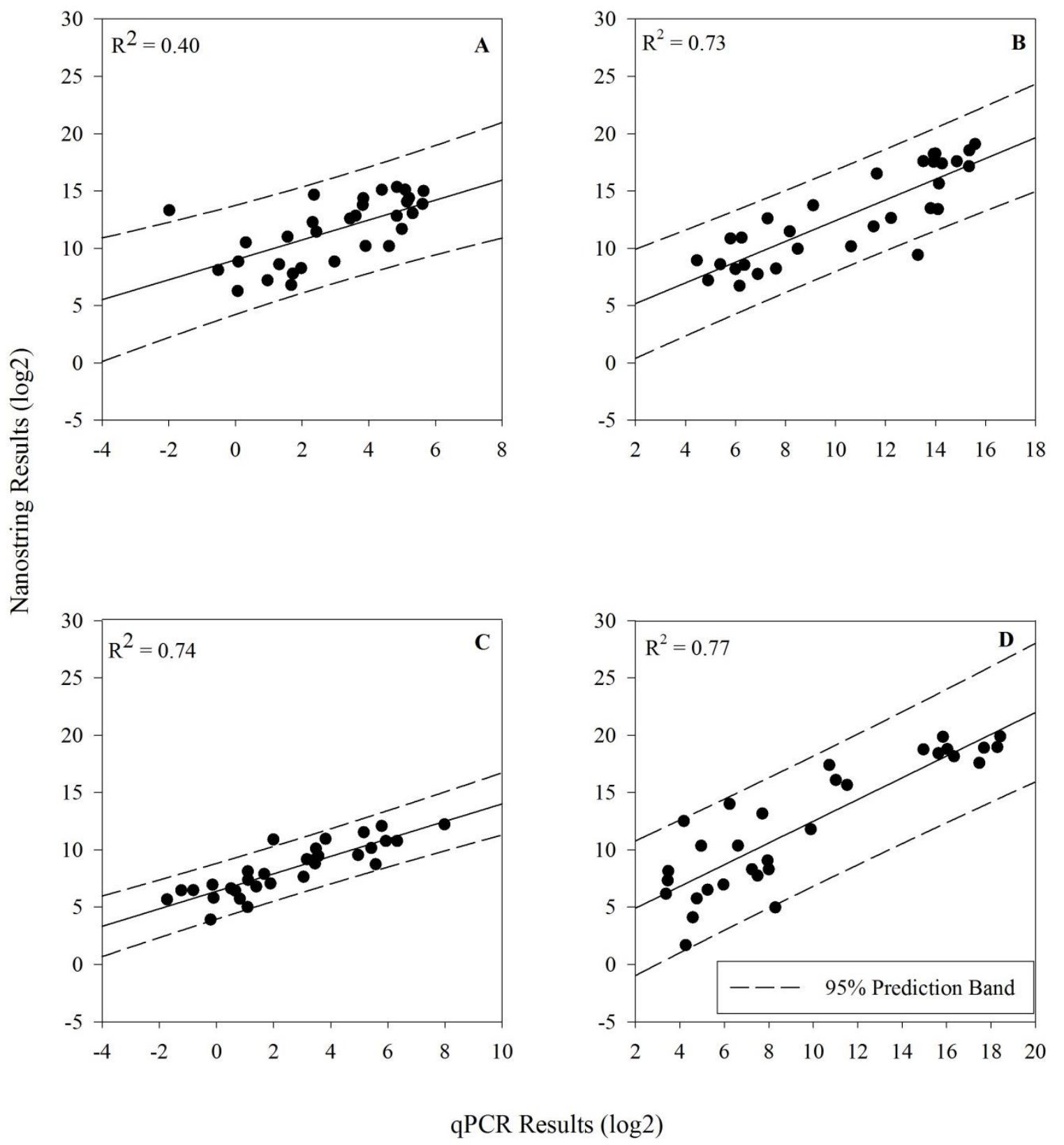


Figure 4. Fold change $(\log 2)$ of genes reported with differential expression between males and females during (A) spring and (B) fall. Dashes indicated species in which no significant modulation of a gene was observed.

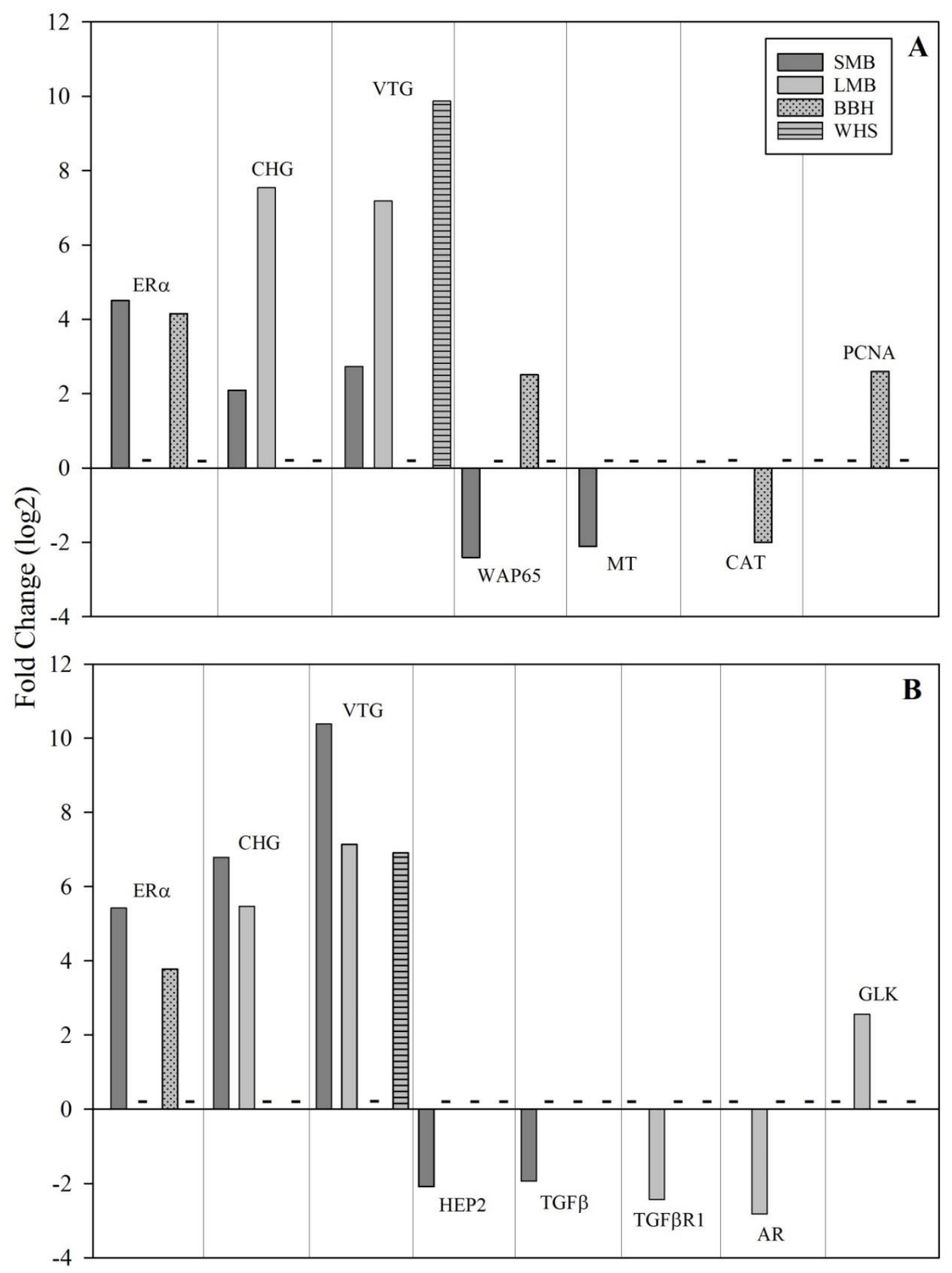


Figure 5. Fold change $(\log 2)$ of genes reported with differential expression between each season in (A) females and (B) males. Dashes indicated species in which no significant modulation of a gene was observed.

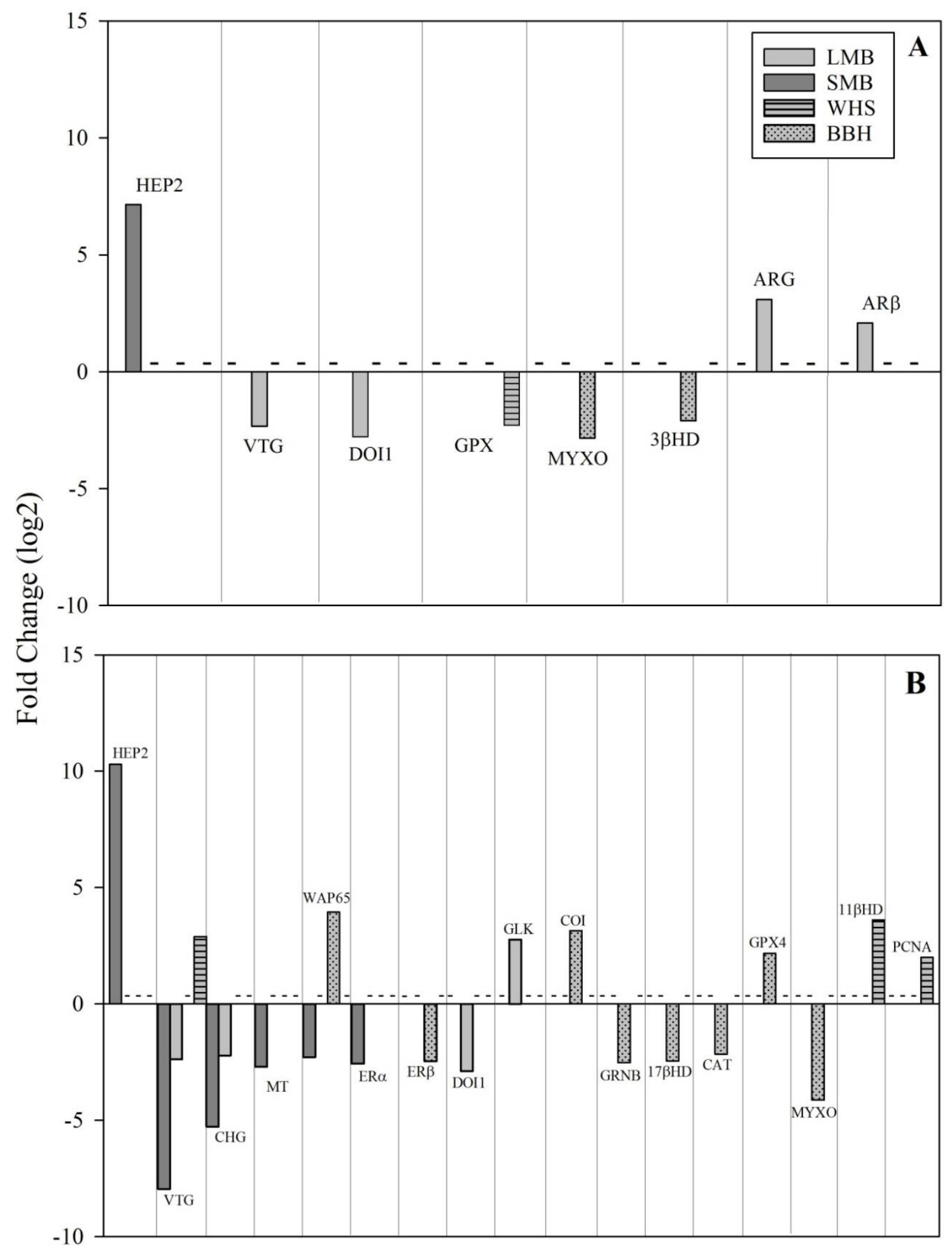


Supplemental Figure 1. GO-slim terms for each transcriptome database (A) smallmouth bass, (B) brown bullhead and (C) white sucker.

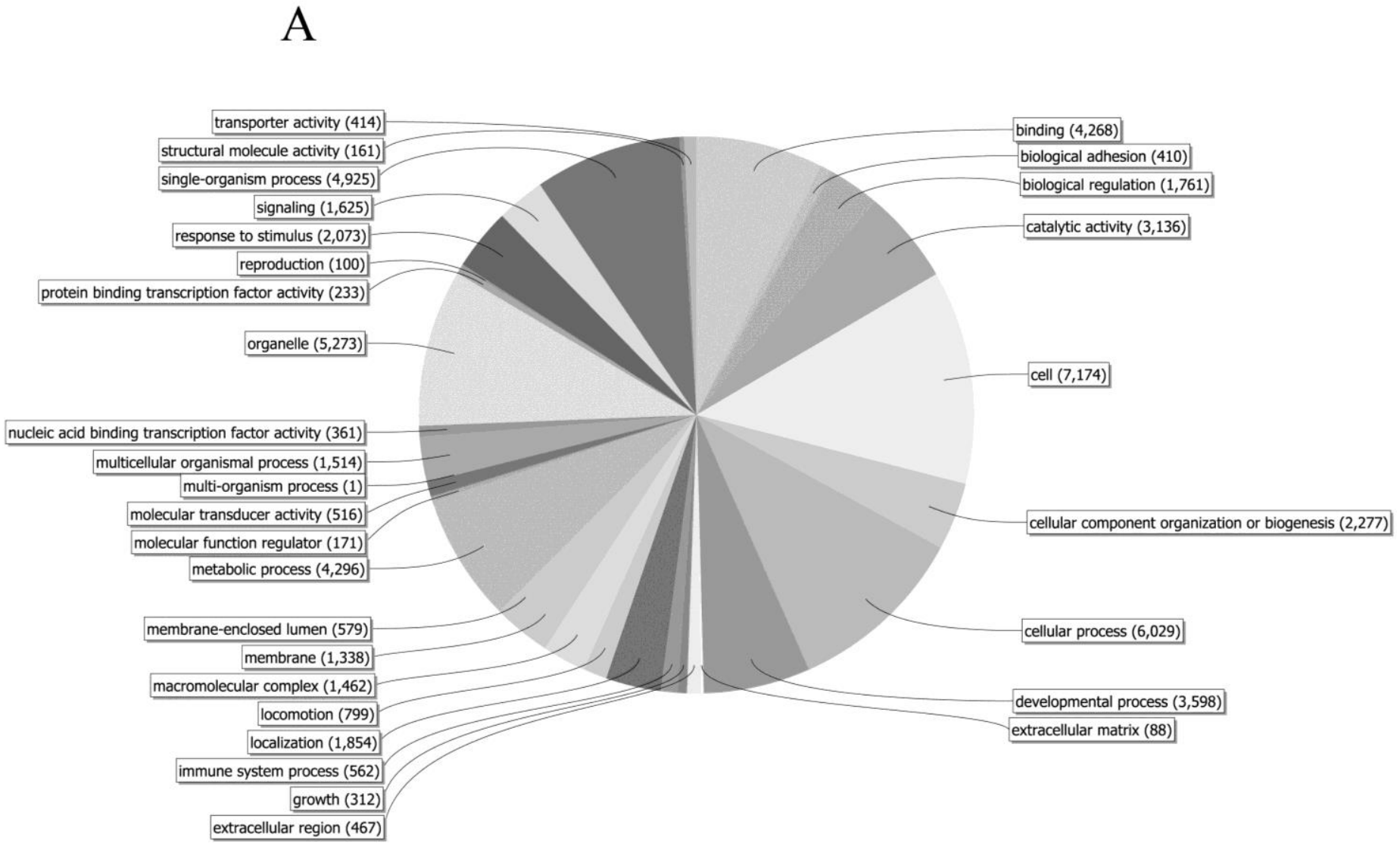



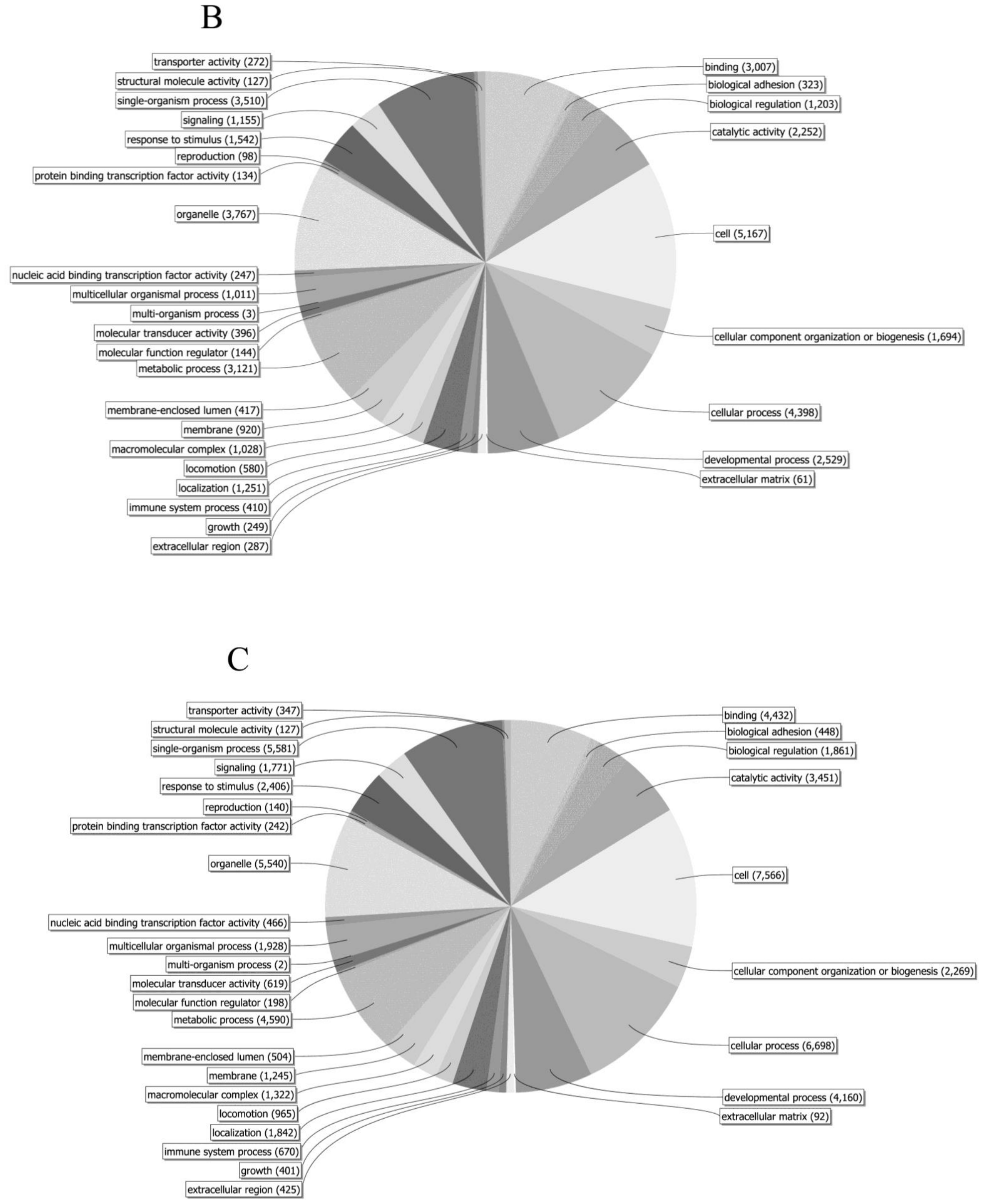


\section{Tables}

Table 1. Genes of interest. Target sequences which was used in the Nanostring nCounter CodeSet for each species. Tm CP indicated melting temperature of capture probe. Tm RP indicates melting temperature of reporter probe. $*$ denotes housekeeping genes.

\begin{tabular}{|c|c|c|c|}
\hline Micropterus species & $\begin{array}{l}\text { Tm } \\
\text { CP }\end{array}$ & $\begin{array}{l}\mathbf{T m} \\
\mathbf{R P}\end{array}$ & Target Sequence \\
\hline $\begin{array}{c}03 \beta \text { Hydroxysteroid } \\
\text { Dehydrogenase (3ßHD) }\end{array}$ & 83 & 79 & $\begin{array}{l}\text { AACTTTTAACTAGAGTCTGGAGGACTGTAGAGGCG } \\
\text { ACACAAAGTTGAATGTTTTCGAGGGCGACATCAGA } \\
\text { GACGGTGATTTCCTGAGAAAACTTGTCGTG }\end{array}$ \\
\hline $\begin{array}{c}17 \beta \text { Hydroxysteroid } \\
\text { Dehydrogenase (17ßHD) }\end{array}$ & 83 & 84 & $\begin{array}{l}\text { CATCCTCAACATCTCGTCTGCCAGTGGGATGTACC } \\
\text { CTGTTCCTCTCCTCACTGTCTACTCTGCCTCCAAGG } \\
\text { CGTTTGTGGACTTCTTCTCCCGAGGACTG }\end{array}$ \\
\hline $\operatorname{Actin} \beta(\beta \mathrm{ACT})$ & 86 & 85 & $\begin{array}{l}\text { GTACGTTGCCATCCAGGCTGTGCTGTCCCTGTATG } \\
\text { CCTCTGGTCGTACCACTGGTATCGTCATGGACTCC } \\
\text { GGTGATGGTGTGACCCACACAGTGCCCATC }\end{array}$ \\
\hline Androgen Receptor $\beta$ (AR $\beta)$ & 82 & 85 & $\begin{array}{l}\text { TCGATAAGCTAAGAAGAAAGAACTGTCCGTCGTGT } \\
\text { CGGCTGAAAAAGTGTTTTGAAGCTGGAATGACTCT } \\
\text { CGGAGCACGCAAACTGAAGAAGATTGGACA }\end{array}$ \\
\hline Apolipoprotein A1 (APA1) & 79 & 84 & $\begin{array}{l}\text { TTTAGCCGCTGAAATCAAGGATAAGTTCCAAGCTA } \\
\text { TCTTCGAGGCCATCGCTGCTACCGTCACCAAGAGC } \\
\text { TAAATCCTCTCCACCCTGTCCCTGTAATTA }\end{array}$ \\
\hline Arginase (ARG) & 85 & 85 & $\begin{array}{l}\text { TGAGGGATATTGACAGACTGGGCATTCAAAGGGTC } \\
\text { ATGGAAGTCACTCTTGACCATCTCCTGGCAAGAAA } \\
\text { ACAGCGACCGATCCACTTGAGCTTTGACAT }\end{array}$ \\
\hline $\begin{array}{l}\text { Aryl Hydrocarbon Receptor } \\
\text { (AHR) }\end{array}$ & 85 & 83 & $\begin{array}{l}\text { CGCCGCCTCAGCTCGCCCTGTTCGCCATCGCCACA } \\
\text { CCCCTCCAGCCTCCAGCCATCCTTGAAATCAGGAC } \\
\text { GAGGAACATGATTTTCAGGACCAAACACAA }\end{array}$ \\
\hline Catalase (CAT) & 84 & 82 & $\begin{array}{l}\text { GCCCAGCTCTTCATCCAGAAACGCATGGTCGAGAA } \\
\text { TTTGAAGGCTGTCCATCCACACTATGGAAACCGAG } \\
\text { TTCAGGCTCTTCTTGACAAGTACAATGTGG }\end{array}$ \\
\hline Catenin $\beta$ ( $\beta \mathrm{CAT})$ & 85 & 84 & $\begin{array}{l}\text { TGCTCAACGATGAGGACCAGGTTGTCGTGAATAAA } \\
\text { GCAGCTGTAATGGTGCATCAGTTGTCAAAGAAGGA } \\
\text { GGCATCGCGCCACGCCCTAATGCGCTCTCC }\end{array}$ \\
\hline Choriogenin (CHG) & 84 & 80 & $\begin{array}{l}\text { GAAAGCAAAAATGTGAGCAGCCTTCCTCTTGACCC } \\
\text { TCTATGGGTCCCATTTTCTGCGGTTAAGGTGGCTG } \\
\text { AGGAATTCTTATACTTCACCCTGAAACTCA }\end{array}$ \\
\hline CYP17 & 85 & 85 & $\begin{array}{l}\text { AGCATCGGGGACTTCACCGTGAGGAAAGGTACTC } \\
\text { GAGTCATCATCAACCTGTGGTCTCTGCACCATGAT } \\
\text { AAGAAGGAATGGAAAAACCCTGAGCTCTTTG }\end{array}$ \\
\hline CYP19A1A (Aromatase) & 85 & 85 & $\begin{array}{l}\text { GCTGGAGATGGTGATCGCAGCACCAGACACTCTGT } \\
\text { CCATCAGCCTCTTCTTCATGCTGCTGCTCCTCAAAC } \\
\text { AAAATCCAGATGTGGAGCTGAAGCTGCTA }\end{array}$ \\
\hline CYP1A & 83 & 78 & $\begin{array}{l}\text { CAGCTCAACACTGTTATGAAGGCTGAAGGCAGTTT } \\
\text { CGACCCATTCCGCTACATCGTTGTCTCTGTTGCTAA } \\
\text { TGTGATCTGTGCCATGTGCTTTGGCCGAC }\end{array}$ \\
\hline
\end{tabular}




\begin{tabular}{|c|c|c|c|}
\hline CYP3A & 79 & 82 & $\begin{array}{l}\text { TTCGGCACTATGCTGGCATATAAAAAGGGATTCAT } \\
\text { GCACTTTGATTCGGAGTGCTTCAAGAAATATGGGA } \\
\text { AAACATGGGGCATTTTTGATGGCCGTCAGC }\end{array}$ \\
\hline Cystenin-Rich Protein (CRP) & 85 & 85 & $\begin{array}{l}\text { CCATGGGACAGTTTACCACGCCGAGGAAGTGCAGT } \\
\text { GTGACGGGAAGAGTTTCCACAAATGCTGTTTTCTC } \\
\text { TGCATGGTCTGCAGGAAGGGCTTAGACAGC }\end{array}$ \\
\hline Elongation Factor $1 \alpha(\mathrm{EF} 1 \mathrm{a})^{*}$ & 85 & 85 & $\begin{array}{l}\text { AGATCAACGCAGGTTACGCACCTGTGCTGGATTGC } \\
\text { CACACAGCTCACATTGCCTGCAAGTTCAAGGAGCT } \\
\text { CATCGAGAAGATCGACCGTCGTTCTGGCAA }\end{array}$ \\
\hline $\begin{array}{l}\text { Epidermal Growth Factor } \\
\text { Receptor (EGFR) }\end{array}$ & 86 & 84 & $\begin{array}{l}\text { GGTCTGTGGGTTCCAGAAGGAGAGGATGTGAAGA } \\
\text { TCCCAGTGGCCATCAAAGTTTTGAGAGAGGCCACA } \\
\text { TCACCAAAAGCAAACAAAGAGATCTTGGACG }\end{array}$ \\
\hline Epoxide Hydrolase 1 (EH1) & 83 & 84 & $\begin{array}{l}\text { GATAGACCAGACTCGCCCTGTCCCTTCACTAGAGG } \\
\text { ATAGCCAGTTTAATTATGGCTTCAATTCCCAGTAC } \\
\text { CTGCAGAAGGTGGTCTCTTACTGGAGAAAT }\end{array}$ \\
\hline Estrogen Receptors $\alpha(E R \alpha)$ & 85 & 85 & $\begin{array}{l}\text { CTCTCCCACCATCAGGCACATGAGCGAACAAAGGT } \\
\text { AATGGAGCATCTCTACAGCATGAAGTGCAAGAAC } \\
\text { AAAGTGCCTCTGTACGACCTTCTGCTGGAGA }\end{array}$ \\
\hline Estrogen Receptors $\beta 1$ (ER $\beta 1)$ & 85 & 85 & $\begin{array}{l}\text { GCCTGAGCAGAGAAGAGGGGAGCTGTGTCCAGGG } \\
\text { CTTCGCAGAGATCTTTGATATGCTGATAGCTGCCA } \\
\text { CGTCCAGGGTGAGAGAGCTCAAGCTCCAGAG }\end{array}$ \\
\hline Estrogen Receptors $\beta 2$ (ER $\beta 2)$ & 85 & 86 & $\begin{array}{l}\text { CTGCAGCTCCATCCTCGGTTGTAACAAGCCGCTGG } \\
\text { GGAAGAGATTAGAGGAAGGAGTGGAAGGCGTGAA } \\
\text { CTCCTCCTTGTGTTCTTCTGCGGTAGGGAAA }\end{array}$ \\
\hline $\begin{array}{c}\text { Eukaryotic Translation Initiation } \\
\text { Factor 3D (ETIF3D)* }\end{array}$ & 85 & 84 & $\begin{array}{l}\text { ACATGACTCAGTTCAACATGCAGACGCTACCTAAG } \\
\text { AGCGCCAAGCAAAAGGAGAGGGATCGTATGCGCC } \\
\text { TGCAGAAGAAGTTCCAAAAGCAGTTTGGTGT }\end{array}$ \\
\hline Ferritin (FRT) & 84 & 83 & $\begin{array}{l}\text { CCATCAACCGGCAAATCAACCTGGAGTTGTATGCC } \\
\text { TCCTATGTCTACCTGTCCATGTCATACTAATTTGAC } \\
\text { AGAGACGACCAGGCTCTGCACAACTTTGC }\end{array}$ \\
\hline Fibroblast Growth Factor (FGF) & 85 & 85 & $\begin{array}{l}\text { CCGCGGTGGTTCTCCTGGGCTTTCTGCTGGGGATC } \\
\text { GTGTCAGCGTACCCTTTACCGAGCAGCAGGACAAA } \\
\text { TGCAACTTTACTGGAGAAACGATGGGAGAC }\end{array}$ \\
\hline $\begin{array}{l}\text { Follicle Stimulating Hormone } \\
\text { Receptor (FSHR) }\end{array}$ & 86 & 86 & $\begin{array}{l}\text { TCAGCTCCCTTCCGGACTACATCCTCGGTGGACTC } \\
\text { CAGAGGCTGATCGCAGAGTCCGCCTTCCACCTGAA } \\
\text { AGAACTTCCTCCTCTGCAGCTCTTCACCAA }\end{array}$ \\
\hline Glucocorticoid Receptor (GR) & 82 & 84 & $\begin{array}{l}\text { GCAGATGCTGAAGATCTGTAATGAGTTTGTCAGAC } \\
\text { TGCAGGTGTCCTATGATGAGTACCTGTGCATGAAG } \\
\text { GTCCTGTTACTGCTCAGTACAGTACCGAAA }\end{array}$ \\
\hline Glucokinase (GLK) & 83 & 81 & $\begin{array}{l}\text { TACTCTATTCCTGAAGATGCCATGACAGGCACTGC } \\
\text { CGAAATGCTATTTGATTACATAGCAGAGTGCATGT } \\
\text { CAGACTTCTTGGACAAACATCATCTCAAGC }\end{array}$ \\
\hline Glutathione Peroxidase 1 (GPX1) & 83 & 83 & $\begin{array}{l}\text { GAACGAGCTTCACAGTCGTTACACTGCCAAGGGAC } \\
\text { TCGTTATTCTGGGTGTGCCCTGCAATCAGTTTGGAC } \\
\text { ATCAGGAGAACTGCAAGAATGATGAAATT }\end{array}$ \\
\hline Glutathione S-Transferase (GST) & 84 & 83 & $\begin{array}{l}\text { CCTGCTGGAGGCGAAATTCCTGCAGAACAAACCGT } \\
\text { TTATCATCGGCGACAAAATCTCTCTGGCTGATCTG } \\
\text { GTGGCTATAGTTGAGATCATGCAGCCTGTT }\end{array}$ \\
\hline
\end{tabular}




\begin{tabular}{|c|c|c|c|}
\hline Heat Shock Proteins 70 (HSP70) & 82 & 85 & $\begin{array}{l}\text { GATCGATTCTCTGTTTGAGGGCGTCGACTTCTACA } \\
\text { CCTCCATCACCAGGGCTCGCTTTGAGGAGCTGTGC } \\
\text { TCCGACCTGTTCAGGGGAACGTTGGAGCCC }\end{array}$ \\
\hline Heat Shock Proteins 71 (HSP71) & 80 & 84 & $\begin{array}{l}\text { TCATTGCATTGTTTGCGACACAACTGAGGAGCAAC } \\
\text { TTGTTGGCACAGTTGAGCTGTCAGTTCACATGTAA } \\
\text { AGTGTCTGGTATACTGAGAGGTCACTGCCT }\end{array}$ \\
\hline $\begin{array}{l}\text { Heat Shock Proteins } 90 \beta \\
\text { (HSP90 } \beta \text { ) }\end{array}$ & 81 & 84 & $\begin{array}{l}\text { ACATCAAGCTGTATGTCAGGAGGGTCTTTATTATG } \\
\text { GACAACTGTGAAGAGCTCATTCCAGAGTACCTGAA } \\
\text { CTTTGTCCGTGGTGTGGTGGACTCTGAGGA }\end{array}$ \\
\hline Hepcidins 1 (HEP1) & 82 & 80 & $\begin{array}{l}\text { TCTCATGGGTGTCAGGCCACCAAAAGAGCACCACA } \\
\text { ATATCTTCACTTTATTCTTCAGCTCTAACGATGGAT } \\
\text { GGCGATTGTCTGGGCAAGTGGATTTCTTC }\end{array}$ \\
\hline Hepcidins 2 (HEP2) & 85 & 81 & $\begin{array}{l}\text { ACTCAGAGGAGCTGACAAGAGTCACCAAAGAGTC } \\
\text { AAAGGATTGAACAACTTAAACCTCTCAAACCCTTC } \\
\text { TAAGATGAAGACACTCAGTGTTGCAGTTGCA }\end{array}$ \\
\hline $\begin{array}{c}\text { Hypoxanthine } \\
\text { Phosphoribosyltransferase } 1 \\
\text { (HPRT1)* }\end{array}$ & 83 & 83 & $\begin{array}{l}\text { ACTTCATTCGCCTCAAGAGCTACTGTAACGACCAG } \\
\text { TCGACAGGTGAAATCAAAGTAATCGGTGGGGATG } \\
\text { ACCTGTGTACGTTGACAGGCAAGAATGTCTT }\end{array}$ \\
\hline $\begin{array}{l}\text { Insulin-like Growth Factor } 1 \\
\text { (IGF1) }\end{array}$ & 83 & 84 & $\begin{array}{l}\text { CGGAGACCCGTGGGGATGTCTAGCGCTCTCTCCTT } \\
\text { TCAGTGGCATTTATGTGATGTCTTCAAGAGTGCGA } \\
\text { TGTGCTGTATCTCCTGTAGCCACACCCTCT }\end{array}$ \\
\hline Metallothionein (MT) & 85 & 75 & $\begin{array}{l}\text { CAGCGCTCTACTGCCCTTGTGATGGCGCCTGTGTG } \\
\text { AACAACTAATGACTAACTGCACATGTCTACATAAA } \\
\text { ATGTATTTTGTACTCGTCTCAGCGTTGCAG }\end{array}$ \\
\hline $\begin{array}{c}\text { Phosphoenolpyruvate } \\
\text { Carboxykinase (PEPCK)* }\end{array}$ & 81 & 83 & $\begin{array}{l}\text { CATGGCAGGTCGAACCATGTATGTGATTCCCTTCA } \\
\text { GTATGGGTCCTGTAGGCTCGACTCTGAGTAAATAT } \\
\text { GGTGTCCAGGTGACAGACTCTCCATACGTT }\end{array}$ \\
\hline $\begin{array}{l}\text { RNA binding motif protein X- } \\
\text { linked } 2(\text { RBMX } 2)^{*}\end{array}$ & 83 & 85 & $\begin{array}{l}\text { CTTCTCTCAGTATGGAGAGATCGTAAACATCAACC } \\
\text { TGGTGCGCGACAAGAAGACGGGGAAGTCCAAAGG } \\
\text { TTTCTGCTTCATCTGCTACGAGGACCAGAGG }\end{array}$ \\
\hline Ribosomal Protein L8 (RPL8)* & 85 & 85 & $\begin{array}{l}\text { TTCTCCTCTGCAAACAGAGCTGTTGTTGGTGTGGT } \\
\text { AGCTGGAGGTGGTCGTATTGACAAGCCCATCCTGA } \\
\text { AGGCTGGTCGTGCCTACCATAAGTACAAGG }\end{array}$ \\
\hline Superoxide Dismutase (SOD) & 79 & 83 & $\begin{array}{l}\text { ATGGTGTTTAAAGCTGTTTGTGTTTTAAAAGGAGC } \\
\text { CGGAGAGACCACCGGGACCGTTTATTTTGAGCAGG } \\
\text { AGGGCGATTCAGACCCTGTGAAGGTGACAG }\end{array}$ \\
\hline Tata Box Binding Protein (TBP)* & 82 & 84 & $\begin{array}{l}\text { GTTAGCTGCCAGAAAATACGCTCGTGTGGTGCAGA } \\
\text { AGCTCGGTTTTCCTGCAAAGTTCCTGGACTTCAAG } \\
\text { ATTCAGAACATGGTGGGAAGCTGCGACGTG }\end{array}$ \\
\hline $\begin{array}{l}\text { Transforming Growth Factor } \beta \\
\text { Receptor } 1 \text { (TGF } \beta \text { R } 1)\end{array}$ & 85 & 82 & $\begin{array}{l}\text { CATTGCTGCTGATAACAAAGATAACGGAACGTGG } \\
\text { ACTCAGCTGTGGCTAGTGTCTGATTACCATGAACA } \\
\text { CGGTTCCCTGTTTGACTACCTGAACCGCTAC }\end{array}$ \\
\hline $\begin{array}{l}\text { Transforming Growth Factor } \beta \\
\text { (TGF } \beta)\end{array}$ & 83 & 84 & $\begin{array}{l}\text { AATAACACAGAGAACACCAAGACCTCCAAAAGCA } \\
\text { TCCCGATGTTCTTCAGCATCTCTAACATACGGGAA } \\
\text { AGTGTGGGGGATTCCAGTTTGCTGACCAGTG }\end{array}$ \\
\hline $\begin{array}{c}\text { Thyroid Hormone Receptor } \beta \\
\text { (THR } \beta \text { ) }\end{array}$ & 83 & 84 & $\begin{array}{l}\text { TGCATTACCTGTGAAGGTTGCAAGGGTTTCTTCAG } \\
\text { GCGGACGATCCAGAAGAATCTCAACCCTACCTACG } \\
\text { CCTGTAAGTATGAGGCGAAATGCGTCATCG }\end{array}$ \\
\hline
\end{tabular}




\begin{tabular}{|c|c|c|c|}
\hline $\begin{array}{l}\text { Thyroid Hormone Receptor } \alpha \\
\text { (THR } \alpha)\end{array}$ & 80 & 85 & $\begin{array}{l}\text { GGAGAGTCCTCTCGGCAGGAATCTGCATTTCTCCG } \\
\text { ACATTTACAGTATGTGGTTTAAAAACTGGAACCAA } \\
\text { CAGTAACAGAAACGACACACCAGCAACAGG }\end{array}$ \\
\hline Type I Deiodinase (DIO1) & 79 & 75 & $\begin{array}{l}\text { GCTGTGAAATTGTGAGTTCACCACCAAGGAGCAAG } \\
\text { CATGTTTTTGCAAAGACTGATGGTCTATTTATCGAC } \\
\text { AGTATGCCTGTTTTGCTATATGATAGGAC }\end{array}$ \\
\hline Type II Deiodinase (DIO2) & 86 & 85 & $\begin{array}{l}\text { ACTGTCTGGAGCAGTCCACAGTGCAGAATACAAAC } \\
\text { TATGAGTAGGACGACTGAGACCGACGATGCAGCG } \\
\text { TTGTGCGTAATGAAGGGTAGTCTGGAATAAA }\end{array}$ \\
\hline Vitellogenin (VTG) & 80 & 84 & $\begin{array}{l}\text { CATTGGTAATCATGTTGCGCTGAGGTTCATCAAGG } \\
\text { AGCACTTCCTCGCTGGTGAGCTATCTTTTGCTGAA } \\
\text { ACTGCTCAAGCCCTGCTGGCATCTGTTCAC }\end{array}$ \\
\hline $\begin{array}{l}\text { Warm Temperature Acclimation } \\
\text { Protein } 65 \text { (WAP65) }\end{array}$ & 82 & 83 & $\begin{array}{l}\text { TGGATGCTGTTGCAGTGAACGAAGAGGGAATCCC } \\
\text { GTACTTTTTCAAGGGTGACCATCTGTTCAAGGGCT } \\
\text { TCCATGGCAAAGCAGAGCTGTCCAATAATTC }\end{array}$ \\
\hline Catostomus commersonii & $\begin{array}{l}\text { Tm } \\
\text { CP }\end{array}$ & $\begin{array}{l}\mathbf{T m} \\
\mathbf{R P}\end{array}$ & Target Sequence \\
\hline $\begin{array}{c}11 \beta \text { Hydroxysteroid } \\
\text { Dehydrogenase (11BHD) }\end{array}$ & 81 & 82 & $\begin{array}{l}\text { GGGAGCAATGTGTCTGTGACCATATGTATACTCGG } \\
\text { CCTTATCGACACAGAGGCCGCCATGGAAAAAATC } \\
\text { AAAGGTTATATCAATATGACAGCCTACCCTG }\end{array}$ \\
\hline $\begin{array}{c}17 \beta \text { Hydroxysteroid } \\
\text { Dehydrogenase (17ßHD) }\end{array}$ & 80 & 79 & $\begin{array}{l}\text { ATCCCTACCCTGAGTTCTTCCTGCACATCCCTGATC } \\
\text { TGGAAAATTTCATCAACACCATGATTAATGTCAAC } \\
\text { ATTACCTCAGTGTGCCAAATGACTCGTCT }\end{array}$ \\
\hline Androgen Receptor (AR) & 84 & 84 & $\begin{array}{l}\text { CCGTGCAGACATGGGGTTGCATCGGGGCGCCGAAT } \\
\text { CAGGATGGAAATGCAGCGGTGCCGCTGAAGTTCTG } \\
\text { TCACGCGAGTTGGGTTTGAGTCGTGACGCA }\end{array}$ \\
\hline Apolipoprotein A1 (APA1) & 79 & 82 & $\begin{array}{l}\text { TCACTGTTCCAAAACTGAACCTGGAGAGTTATAAG } \\
\text { ATTACCATGTTGCCGATCCCTGAAGTCAAGCTCCC } \\
\text { TCAAATCCCAATGGAACCATGTTTACCAGC }\end{array}$ \\
\hline $\begin{array}{l}\text { Aryl Hydrocarbon Receptor } \\
\text { (AHR) }\end{array}$ & 78 & 80 & $\begin{array}{l}\text { AGTACTTTCAATGGGATGTAACCACTGGCACCATG } \\
\text { TGTACAGAATAATTTTTGAAGGAAGTCTAGAGCTT } \\
\text { CAGAGGTTCACAGATGTTCTGGATGAATAT }\end{array}$ \\
\hline Catalase (CAT) & 82 & 85 & $\begin{array}{l}\text { TCACACGTTATTGCAAAGCCAAACTGTTTGAGCAT } \\
\text { GTGGGAAAAAGGACACCCATCGCTGTTCGCTTTTC } \\
\text { CACTGTGGCTGGGGAGTCTGGGTCAGCAGA }\end{array}$ \\
\hline Catenin $\beta$ ( $\beta$ CAT) & 87 & 88 & $\begin{array}{l}\text { AGTATCCAGTGGAGGGACTGCCTGACTTGGGTCAC } \\
\text { GCTCAGGACCTGATGGACGGCTTGCCACCCACAGA } \\
\text { CTCAAATCAGCTGGCCTGGTTCGACACAGA }\end{array}$ \\
\hline CYP11C1 & 85 & 85 & $\begin{array}{l}\text { GAGTTCAGGAGGGGCGTTCCGCTCTCTGGCGTTTG } \\
\text { GGTTCGGCTCCAGACAGTGTGTGGGACGAAGAATC } \\
\text { GCAGAGAACGAGATGCAGCTGCTGCTGTTG }\end{array}$ \\
\hline CYP1B2 & 85 & 78 & $\begin{array}{l}\text { TAGGGAAGCGCAGGTGCATTGGAGAGGACTTGTCT } \\
\text { AAAATCCAGCTCTTCCTCTCTACCTCGTTGCTAGTC } \\
\text { CATCAGTGTAATTTCACAGTAGATAGGAC }\end{array}$ \\
\hline CYP3A & 82 & 81 & $\begin{array}{l}\text { ACTCCGCTGTGTCTAACGACACACTTGACCGGTGG } \\
\text { AAATATCCACAATATAACAGCCTCTACTTCTTGGA } \\
\text { TACGTCCAGTCACGAATCACAGAAATCTGA }\end{array}$ \\
\hline
\end{tabular}




\begin{tabular}{|c|c|c|c|}
\hline Elongation Factor $1 \alpha(\mathrm{EF} 1 \mathrm{a})^{*}$ & 84 & 84 & $\begin{array}{l}\text { AGTCAACCACCACTGGTCATCTGATCTACAGATAC } \\
\text { TGGACAAAGGGGAGCAGCAGCCGAGGAGTGATCT } \\
\text { CTCAACACTGAAACCAATCAATCATGGGGAA }\end{array}$ \\
\hline $\begin{array}{l}\text { Epidermal Growth Factor } \\
\text { Receptor (EGFR) }\end{array}$ & 82 & 79 & $\begin{array}{l}\text { ATCATCAGTGGACTGCGAGAACTGCCTCTTAGAAA } \\
\text { ACTAACAGAAATTCTCAAAGGTGGGGTTATAATAG } \\
\text { ATGATAATCCTTTGCTGTGCAATGTGGAGA }\end{array}$ \\
\hline Epoxide Hydrolase (EH) & 84 & 82 & $\begin{array}{l}\text { CAGAGGCAGAAATGGAGAAAAACCTTGAGCGAAC } \\
\text { CTTTAAACTGATGATCTTTGCAAGTCACGAGACTG } \\
\text { ATGCACATCCTAAGTTTAGTACTGCTGGGGT }\end{array}$ \\
\hline Estrogen Receptors $\alpha(E R \alpha)$ & 77 & 84 & $\begin{array}{l}\text { CTTTATGCATGCCTTCAGAGCATGTGCTGGTGTTAC } \\
\text { TTTTAGGTGCTGAGCCACCAGCTCTCTGCTCGCGA } \\
\text { CAGAAACAAAACCGCCCATACACCGAGAT }\end{array}$ \\
\hline Estrogen Receptors $\beta 1$ (ER $\beta 1)$ & 83 & 80 & $\begin{array}{l}\text { CAATGGAAACGAGGTTGTTACCGTGGCGTTAAGCC } \\
\text { CAGAGGAACTAATAGCTCGCATCATAGATGCAGA } \\
\text { GCCACCACAGATTTACCTTATGAAAGATATG }\end{array}$ \\
\hline $\begin{array}{l}\text { Eukaryotic Translation Initation } \\
\text { Factor 3D (ETIF3D)** }\end{array}$ & 82 & 82 & $\begin{array}{l}\text { CGGAGGTGGAAGCTTGGGGAAGATATTGACCTCAT } \\
\text { TGTTCGCTGCGAGCATGATGGAGTGATGACTGGAG } \\
\text { CAAACGGAGAAGTGTCTTTCATCAACGTGA }\end{array}$ \\
\hline Ferritin (FRT) & 85 & 86 & $\begin{array}{l}\text { GAAACTGATGAAGTTTCAGAACCAGAGGGGAGGG } \\
\text { AAGATCTTTCTGCAGGATGTGAAAAAACCAGAGA } \\
\text { AGGATGAGTGGGGAAGTGGTTTGGAAGCTCTT }\end{array}$ \\
\hline Fibroblast Growth Factor (FGF) & 82 & 80 & $\begin{array}{l}\text { ACTCGGTTCACATTGAATCACAGATGAAATGAGCG } \\
\text { GCTCTCTCCTGTCCGGTCTCTAAGCGCACAAGTTTT } \\
\text { CCTCGTCATGGCAGAGGTGACTGGATTTC }\end{array}$ \\
\hline $\begin{array}{l}\text { Follicle Stimulating Hormone } \\
\text { Receptor (FSHR) }\end{array}$ & 78 & 84 & $\begin{array}{l}\text { TTCTTCACTGTATTCTCCAGCGAACTATCAGTCTAT } \\
\text { ACACTGACTGCCATCACACTTGAGCGCTGGTACAC } \\
\text { CATCACTTACGCCATGGAGCTGGAACGCC }\end{array}$ \\
\hline Glucocorticoid Receptor (GR) & 83 & 85 & $\begin{array}{l}\text { AAATGCTCGCAGAGATCATCAGCAACCAGTTACCA } \\
\text { AAATTCAAAGCTGGGAGTGTCAAACCGCTACTCTT } \\
\text { TCATCAGAAGTGAAGCTCCTCCCTGCAGCA }\end{array}$ \\
\hline Glutathione Peroxidase (GPX) & 83 & 79 & $\begin{array}{l}\text { CAAGATAGAGACCATAAGCTGCCGTCCATTGCCTA } \\
\text { TCACATGTAACCAGAGTAACTGAGATAAGATTGTT } \\
\text { GTTTGATTCAGGCCGACTGTGCAGACATGG }\end{array}$ \\
\hline Glutathione S-Transferase (GST) & 79 & 83 & $\begin{array}{l}\text { AGGATGGTGACCTGGTCCTGTATCAGTCCAATACT } \\
\text { ATGTTAAGACATTTGGGTCGCAAACATGGTGCATA } \\
\text { TGGGAAAAATGACTCTGAGGCTTCTCTTAT }\end{array}$ \\
\hline Granulin (GRN) & 82 & 82 & $\begin{array}{l}\text { AAATTACTACTGCCCTCAACCAAATGACTACACCA } \\
\text { TCCAGTGCATTCTCTGTGGATTCCGACTATAATGTT } \\
\text { CCCTGCAATGACACTGCAGCATGTCCAGA }\end{array}$ \\
\hline Heat Shock Proteins 70 (HSP70) & 80 & 78 & $\begin{array}{l}\text { GACGATTGGAAATGCTGGGAAGAGCCAGATAATA } \\
\text { ACTAATTTTAAGAACACAGTTCACGGCTTTAAGAA } \\
\text { GTTGCATGGTCGCACATTCGATGACCCTTAC }\end{array}$ \\
\hline Heat Shock Proteins 90 (HSP90) & 86 & 82 & $\begin{array}{l}\text { AGGTCATCCGCAAGAACATCGTCAAGAAGTGCCTG } \\
\text { GAACTCTTCGCTGAGCTGGCAGAGGACAATGACA } \\
\text { ACTACAAGAAGTTCTATGATGCGTTCTCAAA }\end{array}$ \\
\hline Hepatitis B PreC Antigen & 80 & 80 & $\begin{array}{l}\text { ACTGTTTAATGTGGGGTGAATCACAAACTGCAGAA } \\
\text { TATACTGCTAAACTTAGAAGTTGGCTTATGACTCC } \\
\text { AACGTCATATCGCAATCAATATGCACCAAC }\end{array}$ \\
\hline
\end{tabular}




\begin{tabular}{|c|c|c|c|}
\hline Hepcidin (HEP) & 84 & 81 & $\begin{array}{l}\text { TATTACTGAAGAGAAAATGAAGTGCACACACGTC } \\
\text { ACTCTTGCTGCTGCAGTCCTCATTGCATGTGTTTGC } \\
\text { CTCCTCCAAACGGCTGCTGTTCCAGTCACA }\end{array}$ \\
\hline Hypoxia-inducible factor (HIF) & 83 & 81 & $\begin{array}{l}\text { CCTGGACTTGGTTCCTCAGGGCCCAACTGTCCTAT } \\
\text { GGATTACTGTTTCCAAATGGACTCCGATATCAGTT } \\
\text { CTGAATTTAAACTGGACCTGGTCGAGAAAC }\end{array}$ \\
\hline Insulin-Like Growth Factor (IGF) & 80 & 83 & $\begin{array}{l}\text { GCCTCTCAGAGTGAAATATTCCAAATATGAAGTGT } \\
\text { GGCAAAGAAAGTCTGTCCAAAGGTTAAGGAGAGG } \\
\text { GGTCCCTTCCATCCTACTTGCCAGAAAGTTT }\end{array}$ \\
\hline Keratin 8 (KRT8) & 83 & 78 & $\begin{array}{l}\text { TTTGAGGAGATGCAGACATCTGCCAACAAATATGG } \\
\text { TGATGACCTTAGATCAACAAAGACAGAGATTGCA } \\
\text { AATTTTAACCGAATGATTCAGAGACTGCAGT }\end{array}$ \\
\hline $\mathrm{v}-\mathrm{K}-\mathrm{ras} 2$ & 84 & 79 & $\begin{array}{l}\text { CAAGGAAGGCAAGAAGAAGAAAAAGAAATCCAA } \\
\text { GACAAAATGTGTACTAATGTGAATAAGTCCTCCCT } \\
\text { GTCATTATAGACTCGAAGTTCCACAACTGCAT }\end{array}$ \\
\hline Metallothionein (MT) & 85 & 76 & $\begin{array}{l}\text { TACACGAACAGTTAGTGCACTTGCAGGTGGCACCA } \\
\text { CAGTTGCAAGTTCCAGTCTTGGAGCAATCACAAGG } \\
\text { ATCCATTTTCCCTCAAAATATCCTTAAAGG }\end{array}$ \\
\hline MUS81* & 85 & 85 & $\begin{array}{l}\text { AAGCATTACCACGGCTCTCACTGTGAACCAGGCCA } \\
\text { AGAATCTTGACCCTGTGTCAGATGCTACAGGAAAA } \\
\text { TCCCAGGCTTTAGAGACTGGGAAAACAGCA }\end{array}$ \\
\hline $\begin{array}{l}\text { Peroxisome proliferator-activated } \\
\text { receptor (PPAR) }\end{array}$ & 82 & 85 & $\begin{array}{l}\text { CTTGATGACAGCGACCTTGCTCTGTTTGTGGCAAC } \\
\text { TGTCATACTGTGTGGAGATCGTCCTGGACTGATGA } \\
\text { ACGTGAAACAGGTAGAGCAGATCCAGGATG }\end{array}$ \\
\hline $\begin{array}{c}\text { Phosphoenolpyruvate } \\
\text { Carboxykinase (PEPCK)* }\end{array}$ & 85 & 85 & $\begin{array}{l}\text { GTTGGGGCCCGGTCCCTCTCCTCCATCCCCTCTTTG } \\
\text { CCTCCATCTGTGGCTGAGTTTGTGTCAGGGGCCGC } \\
\text { ATCTGAGTGTAAACCTGCCAAAGTGCACT }\end{array}$ \\
\hline $\begin{array}{l}\text { Proliferating cell nuclear antigen } \\
\text { (PCNA) }\end{array}$ & 84 & 82 & $\begin{array}{l}\text { AAGATGCCTTCTGGTGAATTTGCCCGAATCTGCAG } \\
\text { AGACCTGTCACAGATTGGTGACGCTGTCATGATTT } \\
\text { CCTGTGCCAAAGATGGAGTGAAGTTCTCTG }\end{array}$ \\
\hline $\begin{array}{l}\text { RNA binding motif protein X- } \\
\text { linked } 2(\text { RBMX2)* }\end{array}$ & 84 & 80 & $\begin{array}{l}\text { GGCAGAATAGCAGAAGGTAAACGCTGGTTTATAA } \\
\text { TGGACTAATGCAGGATATGAAGTGTATGGCGTTAT } \\
\text { CCAAATTGGCCTACACGTAGAGATCAATGAG }\end{array}$ \\
\hline Ribosomal Protein L8 (RPL8)* & 84 & 80 & $\begin{array}{l}\text { CACAACCCTGAGACCAAAAAGTCCAGAGTTAAGC } \\
\text { TTCCATCTGGATCCAAAAAGGTTGTCTCTTCCTCAA } \\
\text { ACAGAGCTGTAGTTGGTGTCGTTGCTGGTG }\end{array}$ \\
\hline $\begin{array}{l}\text { Steroidogenic acute regulatory } \\
\text { protein (STAR) }\end{array}$ & 85 & 78 & $\begin{array}{l}\text { GCTCCTTCTTCGGATGTGGTGAATCCAAGCACTGG } \\
\text { GTCCAGGTCCAGAAATCTTGTTCAGCTCATGGTGG } \\
\text { ATTGCGATCATGGCGTTCTTCCTCAAACCT }\end{array}$ \\
\hline Superoxide Dismutase (SOD) & 84 & 85 & $\begin{array}{l}\text { CAAAATTCAGAGAGGCAGCATGGAACCAAAAAGG } \\
\text { GCTGTTTGTGTGCTCAAAGGCACAGGGGAAGTGAC } \\
\text { CGGAACAGTCTATTTCGACCAAGCGGATGAC }\end{array}$ \\
\hline $\begin{array}{l}\text { Thyroid Hormone Receptor } \alpha \\
\text { (THR } \alpha)\end{array}$ & 78 & 80 & $\begin{array}{l}\text { ACCAACACCTTAGTTATAGACACAGTATATACATA } \\
\text { TATACACACACACATTCTTATAAGTGTGCTTACAG } \\
\text { ATGCAGTACTTACTGTGCGACACGTAACCT }\end{array}$ \\
\hline $\begin{array}{c}\text { Thyroid Hormone Receptor } \beta \\
\text { (THR } \beta \text { ) }\end{array}$ & 80 & 83 & $\begin{array}{l}\text { CTGGATGATTCGGAGGTGGCATTACTGCAAGCCAT } \\
\text { TATTCTCCTCTCATCCGATCGTCCAGGTTTAACGAG } \\
\text { CGTGGACCGGATCGAGCGCTGTCAGGAGG }\end{array}$ \\
\hline
\end{tabular}




\begin{tabular}{|c|c|c|c|}
\hline Tumor Necrosis Factor (TNF) & 80 & 85 & $\begin{array}{l}\text { GATTGCAGTCCTTTTCAGGCACAATCGGTTCAGTG } \\
\text { ATGAGGAGCTAAAGTTGGCTCAGACCTTCAAAAA } \\
\text { GAAACTGCACCAGGGAGCCATGACAGCCATC }\end{array}$ \\
\hline Tumor Protein p53 (TP53) & 85 & 83 & $\begin{array}{l}\text { TGAGGAAGAGAATCTAAAGAAGATTACTGGGGAG } \\
\text { AAGTCTACTGGGACAAAGAGAAAACGTCAGCTTC } \\
\text { AGGATCAGTTGAAAGAGCATCCTATACCTGAT }\end{array}$ \\
\hline $\begin{array}{l}\text { Transforming Growth Factor } \beta \\
\text { (TGF } \beta)\end{array}$ & 89 & 79 & $\begin{array}{l}\text { ATTTGCATAGTGACCACACACCCTGTGGGAGGCCC } \\
\text { AAAGTGCCCATCGTCCACCGAGATCTAAAGAGTTC } \\
\text { CAACATACTGGTGAAGAATGATCTTTCCTG }\end{array}$ \\
\hline $\begin{array}{l}\text { Transforming Growth Factor } \beta \\
\text { Receptor } 1 \text { (TGF } \beta \text { R } 1 \text { ) }\end{array}$ & 79 & 79 & $\begin{array}{l}\text { GTTTGATGTGAAGAAGTCAATCACAGAATGGCTGC } \\
\text { AAAGTTCAGAAGATGAAGTGAGTTTAGATTTGAGG } \\
\text { TTATACTGTGGCTGTAAAACCGGCAAAGAC }\end{array}$ \\
\hline Trypsin (TRY) & 83 & 80 & $\begin{array}{l}\text { GGTTCTCTGATCAACAACCTCTGGGTCGTGTCTGC } \\
\text { CGCTCACTGTTACAAGTCCCGTGTCCAGGTGCGTC } \\
\text { TTGGTGAGCATAATATTGATGTTAACGAGG }\end{array}$ \\
\hline Type II Deiodinase (DIO2) & 77 & 80 & $\begin{array}{l}\text { GTACAATTGAGAGAAAAGTAGAGCAAGGTGCTTT } \\
\text { CAGAAACTGTTTAAAGGAGGCTCCGGGGGAGACT } \\
\text { CTTGGGCTGTGTTCCAAGTCCATTTTTTTAAT }\end{array}$ \\
\hline Vitellogenin (VTG) & 84 & 84 & $\begin{array}{l}\text { TATGCTGGTGACCGTTCCTCTGAGAACACTGATCC } \\
\text { TGAAAGGCCTGCTGTGAGAACTGCTACTCCATTCC } \\
\text { ACAAGACCCTCTGTCTTGATGTCCCATACA }\end{array}$ \\
\hline ZSH & 86 & 82 & $\begin{array}{l}\text { CTGGGAGGTGGTGACGAGAAATACCAGGTCGTTCC } \\
\text { CAAAAGGATTCGACACTGGAATGAGTACAGAATA } \\
\text { AATACTTGTTCGAGTAACAACTGGAGGGCAA }\end{array}$ \\
\hline Ameiurus nebulosus & $\begin{array}{l}\text { Tm } \\
\mathbf{C P}\end{array}$ & $\begin{array}{l}\text { Tm } \\
\mathbf{R P}\end{array}$ & Target Sequence \\
\hline $\begin{array}{c}03 \beta \text { Hydroxysteroid } \\
\text { Dehydrogenase (3ßHD) }\end{array}$ & 82 & 84 & $\begin{array}{l}\text { GTTCTACATGATGGGTGTTCGTACAGGCGGCTGGC } \\
\text { TCATTAAAGGAGTTCCACCGGACACCGAGCACGG } \\
\text { GCGCGTTTACGCAGGTATACGAGTTTAAAGT }\end{array}$ \\
\hline $\begin{array}{l}17 \beta \text { Hydroxysteroid } \\
\text { Dehydrogenase (17ßHD) }\end{array}$ & 85 & 86 & $\begin{array}{l}\text { GATGGGCACCGAGGAGGAAAGTGGACTCATCGCT } \\
\text { CTCTTCCTGGCCGCTGATGCCACCTTCTGCACCGG } \\
\text { AGTAGACCTGCTCCTGAGCGGAGGAGCCGAG }\end{array}$ \\
\hline Androgen Receptor (AR) & 83 & 83 & $\begin{array}{l}\text { ATGGCCGTGATGGTCTTCGCTCTCGGGTGGAGATC } \\
\text { GTACAAAAACGTCAACGCTCGCATGCTGTACTTCG } \\
\text { CTCCTGACCTGGTCTTCAACGAGTCAGTGT }\end{array}$ \\
\hline Apolipoprotein A1 (APA1) & 86 & 85 & $\begin{array}{l}\text { CAGCTGCGTGCCAAGATAGCTGTCAACGTGGAGG } \\
\text { AGACCAAGACCGCCATGATGCCCATTGTGGAGGGT } \\
\text { GTGCGTGAGAAGCTCTCTGAGCGTCTGGAGA }\end{array}$ \\
\hline Arginase (ARG) & 82 & 84 & $\begin{array}{l}\text { TGGTTGGTCTTGCCAACAAACAAGTTGCTGATGCT } \\
\text { GTGCAGAGAATTAAGAATGATGGTCACACCTGCGT } \\
\text { GATGCTTGGAGGAGATCACAGTTTAGCAAT }\end{array}$ \\
\hline $\begin{array}{l}\text { Aryl Hydrocarbon Receptor } \\
\text { (AHR) }\end{array}$ & 86 & 86 & $\begin{array}{l}\text { CTCCAAGCTCACTGTTGAGCTCCATGCTGAAGCAG } \\
\text { GATGAATCCGTCTACCAGGCCAACGGCAATCCCAA } \\
\text { CGCTCAGTTCTGCCTGGAAAAGGCATTTCG }\end{array}$ \\
\hline Catalase (CAT) & 86 & 85 & $\begin{array}{l}\text { TTCTTCACCGCTGTCCTGAACGAGGCTGAGCGCGA } \\
\text { GCGTCTCTGCCGAAACATGGCAGGACATCTGAAAG } \\
\text { GAGCTCAGCTCTTCATTCAGAAGCGCATGG }\end{array}$ \\
\hline
\end{tabular}




\begin{tabular}{|c|c|c|c|}
\hline Catenin $\beta(\beta \mathrm{CAT})$ & 77 & 85 & $\begin{array}{l}\text { CACAACAGAATTGTTATCCGAGGACTCAACACCAT } \\
\text { CCCTCTGTTTGTTCAGTTGCTGTACTCTCCAATCGA } \\
\text { AAACATCCAGCGTGTGGCAGCCCGCGTGA }\end{array}$ \\
\hline CYP17 & 85 & 81 & $\begin{array}{l}\text { ATTTGGTGCTGGAGTGCGTGTGTGTCTCGGTGAAG } \\
\text { GTCTGGCCAAGTTGGAGCTCTTCCTCTTCCTATCAT } \\
\text { GGATTCTGCAAAGGTTCACTCTGGAGGTG }\end{array}$ \\
\hline CYP19A1A (Aromatase) & 83 & 85 & $\begin{array}{l}\text { TAATTACTATAATGAGAAGTACGGAGACATGGTGC } \\
\text { GCGTGTGGATCAGCGGAGAGGAGACACTCGTCCTC } \\
\text { AGCAGGTAGATAAACACTAATCCCACGTCC }\end{array}$ \\
\hline CYP1A & 84 & 82 & $\begin{array}{l}\text { CGAAACCTCTCCCTTTGATTGGAAATGTGCTGGAA } \\
\text { TTGGGACGCAACCCACACCTGAGTTTGACGGCGAT } \\
\text { GAGCAAGCATTACGGCCCGGTTTTCCAGAT }\end{array}$ \\
\hline CYP3A & 79 & 82 & $\begin{array}{l}\text { GACTGATTTCTTTTACGCCTCCCTGCAAAAGATCA } \\
\text { AGTCTGAACGTGTGGCCCAAGATCATAAGAAACG } \\
\text { AGTGGACTTCATGCAGCTGATGATCGATTCC }\end{array}$ \\
\hline Cytochrome C Oxidase (COI) & 79 & 83 & $\begin{array}{l}\text { CTCTCCCAGTCTTAGCGGCTGGTATTACAATACTTC } \\
\text { TAACTGATCGAAACTTAAACACCACATTCTTTGAC } \\
\text { CCGGCAGGAGGAGGGGACCCCATTTTATA }\end{array}$ \\
\hline Elongation Factor $1 \alpha($ EF1a)* & 84 & 84 & $\begin{array}{l}\text { AAGTACTACATCACCATCATTGATGCCCCTGGACA } \\
\text { CAGAGACTTCATCAAGAACATGATCACTGGTACCT } \\
\text { CACAGGCTGATTGTGCTGTGCTGATCGTTG }\end{array}$ \\
\hline $\begin{array}{l}\text { Epidermal Growth Factor } \\
\text { Receptor (EGFR) }\end{array}$ & 85 & 85 & $\begin{array}{l}\text { AGGGACATCTTCCTGAAGACGGGACTGCCTTCTGC } \\
\text { CACACTTGCTCGCATATGGGAGCTATGTGACATTG } \\
\text { GAGATATTGGGAAACTGACTAGAGAGCAGT }\end{array}$ \\
\hline Epoxide Hydrolase (EH) & 82 & 85 & $\begin{array}{l}\text { AGTATGGCTTTAACTCCACTTATCTCCAAAAAGTG } \\
\text { GCTCGATACTGGAGGCACGAATTTAGCTGGGAGA } \\
\text { AACAGGTTAAGGTGCTCAACAAGTACCCACA }\end{array}$ \\
\hline Estrogen Receptors $\alpha(E R \alpha)$ & 86 & 84 & $\begin{array}{l}\text { CAACAGAAGGCAGAGTGGACTCAAGGAGCGGGAG } \\
\text { CGAGGTTATAGCAAAGCCCAGAGCGGTTCTGATGT } \\
\text { GAGAGAAGCGCCTCCACAGGACGGGCAGAGC }\end{array}$ \\
\hline Estrogen Receptors $\beta 1$ (ER $\beta)$ & 82 & 84 & $\begin{array}{l}\text { GTGTGTGTACGTGTGTTCGGGGTTTGTACCTGTAC } \\
\text { GCACGTGCAGTGACCGACTGGTCTCGGTCTTCCCA } \\
\text { GTGATCTGAGCTATGTCAATCAAGCATGCT }\end{array}$ \\
\hline $\begin{array}{c}\text { Eukaryotic Translation Initiation } \\
\text { Factor 3D (ETIF3D)* }\end{array}$ & 86 & 85 & $\begin{array}{l}\text { CGGAGTACCTCAAACTGGGTTACGTGTCCCGCTAC } \\
\text { CACGTGAAGGACTCTGCGCGTCATGTGATCCTGGG } \\
\text { CACGCAGCAGTTCAAGCCCAACGAGTTTGC }\end{array}$ \\
\hline Ferritin (FRT) & 85 & 84 & $\begin{array}{l}\text { CATCAAGAAGCTGGGCGACCACATTAGCAACCTCA } \\
\text { CCCGCATGGACGCCAACACCAACAAGATGGCAGA } \\
\text { GTACCTGTTTGACAAGCACACCCTGGAGGGC }\end{array}$ \\
\hline Fibroblast Growth Factor (FGF) & 85 & 82 & $\begin{array}{l}\text { AGGCTTCTGCAAAATCCGGCTAAACTAGCCAACCA } \\
\text { GCTTCTGTTCCAGATACCGCCAGATCGACAGGCCA } \\
\text { TGCTGATCGAAAGATATTATGCGTTCGATG }\end{array}$ \\
\hline $\begin{array}{l}\text { Follicle Stimulating Hormone } \\
\text { Receptor (FSHR) }\end{array}$ & 85 & 82 & $\begin{array}{l}\text { CATGGCGCCCATCTCGTTCTTCGCCATCTCTGCAGC } \\
\text { TCTCAGGCAACCGCTCATCACCGTGTCACATGCCA } \\
\text { AGGTGCTGCTTGTGCTCTTCTACCCTATT }\end{array}$ \\
\hline Glutathione S-Transferase (GST) & 83 & 80 & $\begin{array}{l}\text { CATACATCAAGGACCTGCCGAACCACCTCTGTAAG } \\
\text { TTTGAGGCTGTTCTGGCGAAGAACAAAAGTGGTTT } \\
\text { CCTCGTCGGTGACTCGATCTCCTTTGCAGA }\end{array}$ \\
\hline
\end{tabular}




\begin{tabular}{|c|c|c|c|}
\hline Glucocorticoid Receptor (GR) & 83 & 85 & $\begin{array}{l}\text { CGTTTGTGAATAAGTCCCTGAGCGTGGAGTTCCCC } \\
\text { GACATGCTCGCCGAGGTCATCAGCAACCAACTACC } \\
\text { AAAAATCAAAGCCGGGAGCGTCAAGCCGCT }\end{array}$ \\
\hline Glucokinase (GLK) & 85 & 85 & $\begin{array}{l}\text { TTCAGACATGCTGAAGACACGGGGCAGCTTCGAG } \\
\text { ACTCGCTTTGTCTCCCAGATTGAGAGTGACACTGG } \\
\text { AGACAGGAAACAAATCTACAACATCCTGAGC }\end{array}$ \\
\hline Glutathione Peroxidase (GPX4) & 82 & 81 & $\begin{array}{l}\text { AATTCTCCGCCATAGACATAGATGGGAACGAGGA } \\
\text { GTCTTTGGAAAAATACAGAGGTTTTGTATGCATCA } \\
\text { TCACGAACGTAGCCTCTAAATGAGGCAAGAC }\end{array}$ \\
\hline Granulin 1 (GRN1) & 84 & 84 & $\begin{array}{l}\text { TCTGTGGTTCACTGTGACAACATCTATACCTGCCCT } \\
\text { GATGGTACAACGTGCTGCAGGTCTCCTTTTGGGCA } \\
\text { ATGGTCATGCTGCATATACAGTGTGGGTC }\end{array}$ \\
\hline Granulin Precursor b (GRNb) & 85 & 86 & $\begin{array}{l}\text { CACACACTCTGGAGTGGGTGATGAGAGTCTCTGCC } \\
\text { AAGCAGACCTCCTTACCTCAGGCAGTGGTGTGTCC } \\
\text { TGACCAGGAGTCCGAATGTCCTGATGGCAC }\end{array}$ \\
\hline Heat Shock Proteins 70 (HSP70) & 83 & 84 & $\begin{array}{l}\text { GATGGTGTAAGTGAATGTGAGGTGTTCCCAAAGAA } \\
\text { CCATGCAGCTCCATTCTCCAAAGTGCTTACCTTCTA } \\
\text { CCGGAAAGAGCCCTTCTCACTGGAAGCTT }\end{array}$ \\
\hline Heat Shock Proteins 90 (HSP90) & 85 & 80 & $\begin{array}{l}\text { CATGAAGGACAACCAGAAATCCATTTACTACATCA } \\
\text { CTGGTGAGAGCAAGGACCAGGTGGCTAACTCTGC } \\
\text { ATTTGTTGAGCGTGTTCGTAAGCGTGGCTTT }\end{array}$ \\
\hline Hepcidin (HEP) & 85 & 86 & $\begin{array}{l}\text { GGTGCTGTTCAGGACGAAGCGTCAGAGTCACCTCT } \\
\text { CTCTGTGCCGATACTGCTGCAACTGCTGTAAGAAT } \\
\text { AAAGGCTGTGGGTTCTGCTGCAGGTTCTAA }\end{array}$ \\
\hline $\begin{array}{c}\text { Hypoxanthine } \\
\text { Phosphoribosyltransferase } 1 \\
\text { (HPRT1)* }\end{array}$ & 84 & 82 & $\begin{array}{l}\text { GGGTACGCACTGTGCCTCTTTTGTATACCCAGACA } \\
\text { CTACGAAGAAGACTTGGACAGTGTTCTTATTCCCA } \\
\text { ATGGTCTCATAAAGGATAGGACCGAGCGCA }\end{array}$ \\
\hline Hypoxia-inducible factor (HIF) & 83 & 84 & $\begin{array}{l}\text { CTTCTTCCTTCGCATGAAGTGCACACTCACTAGTA } \\
\text { GAGGACGCACTGTCAACATCAAGTCTGCCACATGG } \\
\text { AAAGTTCTTCACTGCACAGGACATGTGCGT }\end{array}$ \\
\hline Insulin-Like Growth Factor (IGF) & 79 & 85 & $\begin{array}{l}\text { GTTTCAGAGAGTTTGAGCGAGTGTTCTTTCTGTGC } \\
\text { AGGCTGCAGGATCTGACCCTGTATAACCCTGAAAG } \\
\text { GACCATTACAGTGAAAGGTGCTATTGAGGC }\end{array}$ \\
\hline Interferon (IFN) & 82 & 82 & $\begin{array}{l}\text { GTATTCAGTTGTGTAAGCCGGTGAAACCTGGAACC } \\
\text { TCCCAGTGTAGATATCGTTTGTGCTGTCAGGGCCA } \\
\text { ATTTCCACTTCATAACCCGAGCAGTCAGGC }\end{array}$ \\
\hline Interleukin (IL) & 79 & 82 & $\begin{array}{l}\text { TGCTGGAAAGGTTCTTTGACAGTGACTGTGGATTT } \\
\text { GATTCAGATGACATGGATTTTGATGAGCTGGACTG } \\
\text { TTCTGATCCTTTGGCCATGAGCGGCAGATG }\end{array}$ \\
\hline MYXO Parasite (MYXO) & 86 & 83 & $\begin{array}{l}\text { CACTGGGAGGTGGTGACGAGAAATACCAGGTCGT } \\
\text { TCCCAAAAGGATTCGACACTGGAATGAGTACAGA } \\
\text { ATAAATACTTGTTCGAGTAACAACTGGAGGGC }\end{array}$ \\
\hline $\begin{array}{l}\text { Peroxisome proliferator-activated } \\
\text { receptor (PPAR) }\end{array}$ & 83 & 86 & $\begin{array}{l}\text { AAATCCAAAAGAAGAACCGGAACAAGTGCCAATA } \\
\text { CTGCCGCTTTCAAAAGTGCCTAGCTGTGGGCATGT } \\
\text { CCCACAATGCCATCCGATTTGGCCGAATGCC }\end{array}$ \\
\hline $\begin{array}{l}\text { Proliferating cell nuclear antigen } \\
\text { (PCNA) }\end{array}$ & 79 & 83 & $\begin{array}{l}\text { TCGAGATGAATGAACCTGTCCAGCTCATTTTTGCT } \\
\text { CTGAACTACTTGAACTTCTTCACTAAGGCCACTCCT } \\
\text { CTATCCAAGACGGTCACTCTCAGCATGTC }\end{array}$ \\
\hline
\end{tabular}




\begin{tabular}{|c|c|c|c|}
\hline $\begin{array}{l}\text { RNA binding motif protein X- } \\
\text { linked } 2(\text { RBMX2)* }\end{array}$ & 81 & 83 & $\begin{array}{l}\text { AGTTCTGTTGATGAAGGATCGTGAGACGAATAAGT } \\
\text { CCAGAGGGTTCGCGTTCGTGACCTTTGAGAATCCT } \\
\text { AGTGATGCAAAAGATGCTGCGAGGGAATTG }\end{array}$ \\
\hline Ribosomal Protein L8 (RPL8)* & 85 & 85 & $\begin{array}{l}\text { CAGGCCGTGCCTACCACAAATATAAGGTTAAGAG } \\
\text { GAACTGCTGGCCTCGTGTCCGTGGTGTGGCTATGA } \\
\text { ACCCTGTTGAGCATCCCTTCGGTGGTGGTAA }\end{array}$ \\
\hline $\begin{array}{l}\text { Transforming Growth Factor } \beta 1 \\
\text { (TGF } \beta 1)\end{array}$ & 85 & 86 & $\begin{array}{l}\text { TGCCTGATGGGATGTGTGGGATACTGTGGCACCTT } \\
\text { GTCAACCTGCAAACCCCTGAACCTGGAGCTGGTGA } \\
\text { AAAGGAAGCGCATCGAGGCTATCCGTGGAC }\end{array}$ \\
\hline $\begin{array}{l}\text { Thyroid Hormone Receptor } \alpha \\
\text { (THR } \alpha)\end{array}$ & 87 & 87 & $\begin{array}{l}\text { GTCTCTCTCTGTGCAGTGGTTCTGGACGAGGCGAA } \\
\text { GCGAGTGGCCAAGAGGCGTCTCATCGAGGAGAAC } \\
\text { CGGGAGAAGAGGAAGAAGGAGGAGATGGTGA }\end{array}$ \\
\hline $\begin{array}{l}\text { Thyroid Hormone Receptor } \beta \\
\text { (THR } \beta)\end{array}$ & 79 & 86 & $\begin{array}{l}\text { TAAATGAATCAATCGATCCACCTTTCTCTCCCTTCA } \\
\text { GTGGTGCTGGATGACAGCAAGCGTATGGCCAAAC } \\
\text { GGAAGTTGATTGAGGAGAACCGAGAGCGGC }\end{array}$ \\
\hline Tumor Protein & 86 & 84 & $\begin{array}{l}\text { GAAGAGGAGATGTACTACATCCCAGTACGAGGCA } \\
\text { GGGAGAACTTTGACATCCTGATGAAGATAAAGGA } \\
\text { CAGTTTAGAGTTAGTGGAGCTGGTGCCACAGC }\end{array}$ \\
\hline Tumor Protein p53 (TP53) & 84 & 83 & $\begin{array}{l}\text { CTCCACTCTCGGGTCTCTGAGTCTGAAGAGGATGA } \\
\text { GGATATGGATGTTATGTCATCCCAGGATGATATGT } \\
\text { TTGACGGAGAGAGGAATGGCTCTAAGGTTG }\end{array}$ \\
\hline Superoxide Dismutase (SOD) & 81 & 84 & $\begin{array}{l}\text { GAGATCTGGGTAATGTGACTGCTGATTCCAAAGGA } \\
\text { ATTGCTGATTTCACCATTGTGGACAAACAGTTGTC } \\
\text { ACTGACCGGGCAACACTCGATCATTAGGCA }\end{array}$ \\
\hline $\mathrm{v}$-K-ras & 77 & 85 & $\begin{array}{l}\text { AGAGGGCTTCCTCTGTGTCTTTGCCATTAATAATAC } \\
\text { CAAATCCTTTGAGGACATACACCACTACAGAGAGC } \\
\text { AAATTAAGAGAGTGAAAGACTCCGAGGAT }\end{array}$ \\
\hline Vitellogenin (VTG) & 83 & 85 & $\begin{array}{l}\text { CTGAGACTGGTGTCGTGGGTCAAGAGCCGGCATTC } \\
\text { CGCTTGAAGATTTCTTGGGACAAACTTCCAAAATG } \\
\text { CATGAAGCGCTACGCTAAGGAGCTTTCTAG }\end{array}$ \\
\hline $\begin{array}{l}\text { Warm Temperature Acclimation } \\
\text { Protein } 65 \text { (WAP65) }\end{array}$ & 84 & 84 & $\begin{array}{l}\text { AAGACCGAAGCTCCACTGCCCTTCTCTAAAATTGA } \\
\text { TGCTGCTACATGTCACACTGATGGTGTGAAAGTGT } \\
\text { TTGTTGGCGGGGAATACTACCTGTACCAGA }\end{array}$ \\
\hline
\end{tabular}


Table 2. Results of mapping smallmouth bass nCounter analysis target sequences to available RNA-seq contigs (SRX547137) for largemouth bass.

\begin{tabular}{|c|c|c|c|c|}
\hline Name & $\begin{array}{l}\text { Consensus } \\
\text { Length }\end{array}$ & $\begin{array}{l}\text { Total Read } \\
\text { Count }\end{array}$ & $\begin{array}{l}\text { Coverage } \\
\text { (mean) }\end{array}$ & $\begin{array}{c}\% \\
\text { Identity }\end{array}$ \\
\hline $03 \beta$ Hydroxysteroid Dehydrogenase (3ßHD) & 97 & 139 & 93 & 96 \\
\hline $17 \beta$ Hydroxysteroid Dehydrogenase (17ßHD) & 100 & 585 & 393 & 99 \\
\hline Androgen Receptor (AR) & 100 & 121 & 71 & 100 \\
\hline Apolipoprotein A1 (APA1) & 100 & 96912 & 64702 & 97 \\
\hline Arginase (ARG) & 100 & 579 & 374 & 100 \\
\hline Aryl Hyrdrocarbon Receptor (AHR) & 100 & 31 & 12 & 100 \\
\hline Catenin $\beta(\beta \mathrm{CAT})$ & 100 & 577 & 352 & 94 \\
\hline $\operatorname{Actin} \beta(\beta \mathrm{ACT})$ & 100 & 14881 & 9822 & 100 \\
\hline Catalase (CAT) & 100 & 837 & 558 & 99 \\
\hline Choriogenin $(\mathrm{CHG})$ & 99 & 645 & 434 & 99 \\
\hline CYP17 & 100 & 8 & 5 & 100 \\
\hline CYP19A1A (Aromatase) & 98 & 65 & 17 & 98 \\
\hline CYP1A & 100 & 233 & 159 & 100 \\
\hline CYP3A & 100 & 515 & 349 & 100 \\
\hline Cystenin-Rich Protein (CRP) & 100 & 274 & 158 & 100 \\
\hline Elongation Factor $1 \alpha(\mathrm{EF} 1 \alpha)^{*}$ & 100 & 24849 & 16911 & 100 \\
\hline Epidermal Growth Factor Receptor (EGFR) & 100 & 94 & 62 & 92 \\
\hline Epoxide Hydrolase 1 (EH1) & 100 & 159 & 98 & 98 \\
\hline Estrogen Receptors $\alpha(\mathrm{ER} \alpha)$ & 97 & 351 & 70 & 97 \\
\hline Estrogen Receptors $\beta 1$ (ER $\beta 1)$ & 100 & 149 & 94 & 100 \\
\hline Estrogen Receptors $\beta 2$ (ER $\beta 2)$ & 98 & 67 & 43 & 97 \\
\hline $\begin{array}{l}\text { Eukaryotic Translation Initation Factor 3D } \\
\text { (ETIF3D)* }\end{array}$ & 100 & 937 & 638 & 100 \\
\hline Ferritin (FRT) & 98 & 8 & 4 & 87 \\
\hline Fibroblast Growth Factor (FGF) & 96 & 8 & 3 & 100 \\
\hline Follicle Stimulating Hormone Receptor (FSHR) & 100 & 28 & 11 & 100 \\
\hline Glucocorticoid Receptor (GR) & 100 & 123 & 77 & 100 \\
\hline Glucokinase (GLK) & 100 & 72 & 43 & 100 \\
\hline Glutathione Peroxidase 1 (GPX1) & 100 & 289 & 186 & 100 \\
\hline Glutathione S-Transferase (GST) & 100 & 4451 & 2943 & 100 \\
\hline Hepcidins 1 (HEP1) & 100 & 18438 & 13725 & 100 \\
\hline Hepcidins 2 (HEP2) & 100 & 11044 & 7627 & 99 \\
\hline Heat Shock Proteins 70 (HSP70) & 100 & 2293 & 1374 & 84 \\
\hline Heat Shock Proteins 71 (HSP71) & 100 & 4095 & 2601 & 100 \\
\hline Heat Shock Proteins 90 $\beta$ (HSP90 $\beta$ ) & 100 & 7374 & 4951 & 98 \\
\hline
\end{tabular}




\begin{tabular}{|c|c|c|c|c|}
\hline $\begin{array}{l}\text { Hypoxanthine Phosphoribosyltransferase } 1 \\
\text { (HPRT1)* }\end{array}$ & 100 & 900 & 580 & 100 \\
\hline Insulin-like Growth Factor 1 (IGF1) & 100 & 145 & 87 & 100 \\
\hline Metallothionein (MT) & 100 & 23360 & 15160 & 99 \\
\hline Phosphoenolpyruvate Carboxykinase (PEPCK)* & 100 & 1825 & 1205 & 81 \\
\hline $\begin{array}{l}\text { RNA binding motif protein X-linked } 2 \\
(\mathrm{RBMX} 2)^{*}\end{array}$ & 100 & 131 & 78 & 100 \\
\hline Ribosomal Protein L8 (RPL8)* & 99 & 10678 & 6800 & 99 \\
\hline Superoxide Dismutase (SOD) & 100 & 2125 & 1422 & 98 \\
\hline Tata Box Binding Protein (TBP)* & 100 & 221 & 132 & 100 \\
\hline Transforming Growth Factor $\beta$ Receptor 1 (TGF $\beta$ R1) & 100 & 130 & 80 & 98 \\
\hline Transforming Growth Factor $\beta$ (TGF $\beta$ ) & 100 & 107 & 70 & 99 \\
\hline Thyroid Hormone Receptor $\alpha$ & 100 & 22 & 11 & 100 \\
\hline Thyroid Hormone Receptor $\beta$ & 100 & 89 & 47 & 100 \\
\hline Type I Deiodinase (DIO1) & 91 & 20 & 10 & 99 \\
\hline Type II Deiodinase (DIO2) & 100 & 129 & 79 & 100 \\
\hline Vitellogenin (VTG) & 100 & 11 & 5 & 100 \\
\hline Warm Temperature Acclimation Protein 65 (WAP65) & 100 & 1997 & 1342 & 100 \\
\hline
\end{tabular}


Table 3. Raw count data for genes with statistically significant $(\mathrm{p}<0.05)$ differences between males and females of each species separated by season. Range is defined as the minimum expression value of the gene subtracted from the maximum expression value of the gene. Mean differences in parenthesis represent negative values.

\begin{tabular}{|c|c|c|c|c|c|c|c|}
\hline \multicolumn{8}{|c|}{ Male vs Female } \\
\hline \multirow{2}{*}{ Species } & \multirow{2}{*}{ Season } & \multirow{2}{*}{ Gene } & \multicolumn{2}{|c|}{ Male } & \multicolumn{2}{|c|}{ Female } & \multirow{2}{*}{ Difference (Mean) } \\
\hline & & & Mean & Range & Mean & Range & \\
\hline \multirow{5}{*}{ BBH } & \multirow{4}{*}{ Spring } & ER $\alpha$ & 88 & 94 & 1,315 & 1,553 & $(1,227)$ \\
\hline & & CAT & 6,118 & 8,284 & 1,339 & 3,116 & 4,779 \\
\hline & & PCNA & 141 & 779 & 830 & 3,605 & $(689)$ \\
\hline & & WAP65 & 3,026 & 11,887 & 19,922 & 139,951 & $(16,897)$ \\
\hline & Fall & ER $\alpha$ & 72 & 146 & 858 & 1,573 & (786) \\
\hline \multirow{7}{*}{ LMB } & \multirow{2}{*}{ Spring } & CHG & 355 & 1,332 & 28,453 & 46,317 & $(28,098)$ \\
\hline & & VTG & 1,924 & 8,034 & 552,830 & 995,847 & $(550,905)$ \\
\hline & \multirow{5}{*}{ Fall } & CHG & 52 & 131 & 10,929 & 20,106 & $(10,877)$ \\
\hline & & VTG & 273 & 1,279 & 51,238 & 187,818 & $(50,965)$ \\
\hline & & AR & 386 & 482 & 395 & 483 & (8) \\
\hline & & TGFßR1 & 1,039 & 780 & 746 & 1,125 & 293 \\
\hline & & GLK & 469 & 1,693 & 237 & 863 & 232 \\
\hline \multirow{10}{*}{ SMB } & \multirow{5}{*}{ Spring } & CHG & 7,772 & 17,732 & 46,912 & 40,942 & $(39,140)$ \\
\hline & & $\mathrm{ER} \alpha$ & 90 & 219 & 2,632 & 912 & $(2,542)$ \\
\hline & & MT & 7,604 & 12,858 & 2,485 & 4,224 & 5,119 \\
\hline & & VTG & 66,724 & 195,992 & 609,672 & 619,120 & $(542,948)$ \\
\hline & & WAP65 & 2,721 & 2,672 & 646 & 582 & 2,076 \\
\hline & \multirow{5}{*}{ Fall } & CHG & 172 & 219 & 26,379 & 4,261 & $(26,208)$ \\
\hline & & $\mathrm{ER} \alpha$ & 13 & 15 & 762 & 213 & (749) \\
\hline & & HEP2 & 19,880 & 78,702 & 5,713 & 16,870 & 14,167 \\
\hline & & VTG & 244 & 530 & 410,880 & 198,283 & $(410,637)$ \\
\hline & & TGF $\beta$ & 202 & 191 & 74 & 18 & 127 \\
\hline \multirow{2}{*}{ WHS } & Spring & VTG & 56 & 192 & 127,280 & 388,672 & $(127,224)$ \\
\hline & Fall & VTG & 415 & 1,716 & 102,888 & 296,473 & $(102,473)$ \\
\hline
\end{tabular}


Table 4. Raw count data for genes with statistically significant $(\mathrm{p}<0.05)$ differences between seasons of each species separated by sex. Range is defined as the minimum expression value of the gene subtracted from the maximum expression value of the gene. Mean differences in parenthesis represent negative values.

\begin{tabular}{|c|c|c|c|c|c|c|c|}
\hline \multicolumn{8}{|c|}{ Spring vs Fall } \\
\hline \multirow[b]{2}{*}{ Species } & \multirow[b]{2}{*}{ Sex } & \multirow[b]{2}{*}{ Gene } & \multicolumn{2}{|c|}{ Fall } & \multicolumn{2}{|c|}{ Spring } & \multirow[b]{2}{*}{ Difference (Mean) } \\
\hline & & & Mean & Range & Mean & Range & \\
\hline \multirow{10}{*}{ ВBH } & \multirow{8}{*}{$\mathbf{M}$} & $17 \beta \mathrm{HD}$ & 713 & 1,001 & 2,852 & 7,127 & $(2,139)$ \\
\hline & & $\mathrm{COI}$ & 95,335 & 87,463 & 7,051 & 25,887 & 88,284 \\
\hline & & CAT & 1,880 & 3,326 & 6,118 & 8,284 & $(4,238)$ \\
\hline & & GRNB & 63 & 46 & 270 & 729 & (206) \\
\hline & & GPX4 & 3,087 & 3,556 & 438 & 1,126 & 2,650 \\
\hline & & WAP65 & 78,052 & 329,270 & 2,740 & 11,904 & 75,312 \\
\hline & & ER $\beta$ & 555 & 1,392 & 2,255 & 4,224 & $(1,700)$ \\
\hline & & MYXO & 26 & 54 & 341.6 & 2655 & (316) \\
\hline & \multirow{2}{*}{$\mathbf{F}$} & GPX4 & 3,000 & 3,920 & 1,233 & 1,364 & 1,767 \\
\hline & & MYXO & 30 & 116 & 128 & 412 & (98) \\
\hline \multirow{8}{*}{ LMB } & \multirow{4}{*}{$\mathbf{M}$} & DOI1 & 14 & 31 & 154 & 353 & (139) \\
\hline & & CHG & 52 & 131 & 355 & 1,332 & (303) \\
\hline & & GLK & 469 & 1,693 & 104 & 354 & 365 \\
\hline & & VTG & 273 & 1,279 & 1,924 & 8,034 & $(1,651)$ \\
\hline & \multirow{4}{*}{$\mathbf{F}$} & ARG & 464 & 489 & 91 & 79 & 373 \\
\hline & & DOI1 & 2,508 & 1,623 & 2,410 & 2,382 & 98 \\
\hline & & $\mathrm{AR}$ & 395 & 483 & 140 & 143 & 254 \\
\hline & & VTG & 51,238 & 187,818 & 552,830 & 995,847 & $(501,591)$ \\
\hline \multirow{7}{*}{ SMB } & \multirow{6}{*}{$\mathbf{M}$} & HEP2 & 19,880 & 78,702 & 18 & 16 & 19,863 \\
\hline & & VTG & 244 & 530 & 66,724 & 195,992 & $(66,480)$ \\
\hline & & CHG & 172 & 219 & 7,772 & 17,732 & $(7,600)$ \\
\hline & & $\mathrm{ER} \alpha$ & 13 & 15 & 90 & 219 & (77) \\
\hline & & MT & 1,126 & 1,091 & 7,604 & 12,858 & $(6,478)$ \\
\hline & & WAP65 & 483 & 532 & 2,721 & 2,672 & $(2,238)$ \\
\hline & $\mathbf{F}$ & HEP2 & 5,713 & 16,870 & 57 & 99 & 5,656 \\
\hline \multirow{4}{*}{ WHS } & \multirow{3}{*}{$\mathbf{M}$} & $11 \beta \mathrm{HD}$ & 516 & 1,092 & 64 & 117 & 452 \\
\hline & & VTG & 448 & 1,496 & 89 & 294 & 359 \\
\hline & & PCNA & 83 & 173 & 35 & 65 & 48 \\
\hline & $\mathbf{F}$ & GPX & 1,110 & 2,323 & 5,355 & 7,184 & $(4,245)$ \\
\hline
\end{tabular}


Supplemental Table 1. Primer sequences utilized in real-time PCR. PCR cycling conditions were: $95^{\circ} \mathrm{C}$ for $10 \mathrm{~min}$ and then 35 cycles of $95^{\circ} \mathrm{C}$ for $10 \mathrm{~s}, 54^{\circ} \mathrm{C}$ for $15 \mathrm{~s}, 72^{\circ} \mathrm{C}$ for $20 \mathrm{~s}$.

\begin{tabular}{|c|c|l|}
\hline \multirow{2}{*}{ Gene } & Orientation & \multicolumn{1}{c|}{ Primer Sequence } \\
\hline \multirow{2}{*}{ Vitellogenin (VTG) } & Forward & GTGTGGCCAGATATGAGAGTATT \\
\cline { 2 - 3 } & Reverse & ATTACCAATGGCAGGGACAG \\
\hline \multirow{2}{*}{ Choriogenin (CHG) } & Forward & GCCTTCCTCTTGACCCTCTAT \\
\cline { 2 - 3 } & Reverse & CTCACTTTGCCAGTCATCAGTC \\
\hline $\begin{array}{c}\text { Warm Temperature Acclimation } \\
\text { Protein 65 (WAP65) }\end{array}$ & Forward & GCTGTCCTTGACCGTTGTAA \\
\cline { 2 - 3 } Glucokinase (GLK) & Reverse & TGGAAGCCCTTGAACAGATG \\
\hline & Forward & CACTCACCGCAAACCTAGAA \\
\cline { 2 - 3 } & Reverse & GCTACAAGGCATCTTCACAATC \\
\hline
\end{tabular}


Supplemental Table 2. Transcriptome sequencing results by species.

\begin{tabular}{|c|c|c|c|}
\hline Species & Platform & SRA Experiment \# & $\begin{array}{c}\text { Total \# } \\
\text { Contigs }\end{array}$ \\
\hline \multirow{2}{*}{ Micropterus dolomieu } & Illumina & SRR199239 & \multirow{2}{*}{573,805} \\
\cline { 2 - 3 } & 454 & SRX156704 & \\
\hline \multirow{2}{*}{$\begin{array}{c}\text { Catostomus } \\
\text { commersonii }\end{array}$} & Illumina & SRX1339167 & \multirow{2}{*}{539,050} \\
\cline { 2 - 3 } Ameiurus nebulosus & Illumina & SRX1436666 & \\
\cline { 2 - 3 } & 454 & SRX199312 & \multirow{2}{*}{340,942} \\
\hline
\end{tabular}




\title{
Chapter Three: Assessing the health of resident largemouth bass (Micropterus salmoides) and brown bullhead (Ameiurus nebulosus) from the Rochester Embayment of Lake Ontario, NY.
}

\begin{abstract}
The Rochester Embayment is an area of concern (AOC) due to the impairment of 12 beneficial uses, including those associated with contaminants. Despite the presence of chemical contaminants, biological effects based monitoring of fishes inhabiting this AOC is currently limited. Gene expression endpoints for largemouth bass (Micropterus salmoides) and brown bullhead (Ameiurus nebulosus) were used to assess differences between species, seasons, sampling sites and endpoints at higher levels of biological organization. Differences in the expression of genes related to reproduction and temperature acclimation in largemouth bass were determined between temporal collections. Analysis of gene expression endpoints between the largemouth bass and brown bullhead revealed differences in the expression of genes associated with oxidative stress and the biotransformation of contaminants. Greater expression of genes associated with contaminant exposure and injury to liver tissue were identified at sampling sites outside of the AOC. Histological endpoints were used to distinguish variation in the expression of genes in diseased and normal liver tissue. This is the first time many of these gene expression biomarkers have been used in these wild, caught resident fish species and provide novel information regarding the potential biological effects of contaminants.
\end{abstract}




\section{Introduction}

In the Laurentian Great Lakes, the International Joint Commission (IJC) has identified 43 contaminated locations known as Areas of Concern (AOCs). These sites are designated as a result of impairment to one or more of 14 beneficial uses. Beneficial use impairments (BUIs) are reference points that are employed during the development of Remedial Action Plans (RAPs) and during the assessment of achievements of restoration efforts. The Rochester Embayment AOC (REAOC) is delineated by a straight line connecting the indentation of Nine Mile Point in Webster, NY and Bogus Point in Parma, NY both located in Monroe County (Figure 1). The southern boundary encompasses $9.6 \mathrm{~km}$ of the Genesee River and extends to the mouth of the Lower Falls (USEPA, 2013). The REAOC was originally listed after the identification of 12 BUIs with contaminants indicated as the potential cause of many of the impairments. The presence of legacy contaminants (polychlorinated biphenyls (PCBs), mirex, dioxins, and phosphorus) in the REAOC has been attributed to historic industrial and agricultural influences as well as failing or inadequate sewer systems (NYS-DEC, 2003). Recently, a new class of compounds known collectively as contaminants of emerging concern (CECs) have also been identified in the REAOC (Lee et al., 2012). Despite the established presence of complex chemical mixtures of legacy and emerging contaminants the biological effects of these compounds on resident species of the REAOC remains largely unknown.

Fish and other aquatic organisms are widely used as sentinels of contaminant exposure (Stein et al., 1992; Stentiford et al., 2003; Stentiford et al., 2014). In the Great Lakes, resident species available as bioindicators of exposure to these compounds include the pelagic largemouth bass (Micropterus salmoides) and the benthic brown bullhead (Ameiurus nebulosus). Largemouth bass have been used previously for environmental monitoring and have shown 
sensitivity to endocrine disrupting compounds (Denslow et al., 2004; Goodbred et al., 2015; Sepulveda et al., 2002) including the presence of testicular oocytes (Hinck et al., 2008; Hinck et al., 2009; Iwanowicz et al., 2016). Brown bullhead have also been a target species for contaminant monitoring (Eufemia et al., 1997; Leadley et al., 1998), particularly in the evaluation of the presence of skin and liver tumors (Baumann et al., 1996; Blazer et al., 2009a, b; Pinkney et al., 2011; Rafferty et al., 2009).

Currently, biological effects based monitoring of fishes inhabiting the REAOC is limited. The "fish tumors and other deformities" BUI was not listed in the stage one RAP completed in 1993 and remained undetermined in the stage two RAP completed in 2012 (NYS-DEC). A tumor survey of brown bullhead from Braddock Bay, located along the western perimeter of the REAOC, was conducted in 2010. No evidence of tumors was found (Haynes and Neuderfer, 2011) however, further data for the inhabitants of the Genesee River was identified as a priority in the determination of this BUI (NYS-DEC, 2011). More recently, data collected at Great Lakes AOCs including the REAOC identified lip and body surface lesions, external neoplasms and liver neoplasms in brown bullhead (Blazer et al., 2014b) and testicular oocytes in largemouth (Blazer et al., 2014; Mazik et al., 2015) sampled from the Genesee River and two sites that border but are not explicitly within the boundaries of the AOC, Irondequoit Bay and Long Pond.

The identification of tumors and testicular oocytes represent organismal levels effects that are often indicative of long term exposure to contaminants. To accurately and efficiently assess the ecological risks of exposure to complex chemicals mixtures, synthesis of data from many levels of biological organization is required (Ankley et al., 2010). Therefore, in conjunction with the analysis of liver and gonad histology performed by Blazer et al., (2014a,b) and Mazik et al. (2015), our objectives were to 1.) Utilize gene expression endpoints developed 
for liver tissue collected from largemouth bass and brown bullhead (Hahn et al., 2016) to evaluate differences between species, seasons and locations within the REAOC and 2.) Assess potential association of these molecular initiation events with endpoints at higher levels of biological organization.

\section{Methods}

\section{Sampling locations}

At each sampling site we attempted to collect 20 mature fish, defined as greater than 250 $\mathrm{mm}$ in length. Fish were collected by elecrofishing or fyke net. In the fall of 2010 largemouth bass were collected from the Genesee River $\left(43^{\circ} 14^{\prime} 02.4^{\prime \prime} \mathrm{N} 77^{\circ} 37^{\prime} 04.8^{\prime \prime} \mathrm{W}\right)$. In the spring of 2011, largemouth bass and brown bullhead were collected at the same location along the Genesee River. In the spring of 2012, largemouth bass and brown bullhead were collected from Irondequoit Bay $\left(43^{\circ} 12^{\prime} 50.8^{\prime \prime} \mathrm{N} 77^{\circ} 32^{\prime} 04.7^{\prime \prime} \mathrm{W}\right)$ while brown bullhead only were collected from

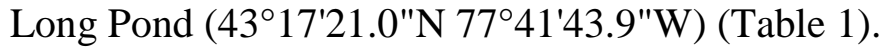

\section{Fish collection}

Fish were euthanized with a lethal dose of tricaine methanesulfonate (MS-222, Finquel, Argent Laboratories, Redmond, WA). Handling and euthanasia protocols were approved by the USGS, Leetown Science Center, Institutional Animal Care and Use Committee. Fish length was measured to the nearest millimeter and weighed to the nearest gram. Blood was collected from the caudal vein or dorsal aorta with a sodium heparinized (Fisher Scientific, Pittsburgh, PA) syringe. We centrifuged blood samples to separate plasma that was then collected and stored at $80^{\circ} \mathrm{C}$ for the analysis of vitellogenin. A comprehensive necropsy-based assessment was then conducted on each fish collected. The liver and gonads were removed, observed for gross 
abnormalities, and weighed in order to calculate hepatosomatic (HSI) and gonadosomatic indices (GSI). Small sections of liver were collected and preserved in RNAlater ${ }^{\circledR}$ for gene expression analysis. Sections of gill, liver, anterior and posterior kidney, spleen, gonad, thyroid, and any gross lesions or abnormalities were fixed in Z-Fix (Anatech Ltd.) for histological analysis. Otoliths were removed for aging.

\section{Microscopic pathology}

Fixed samples for histological analyses which were collected in Z-fix, were trimmed in, paraffin embedded and sectioned at $6 \mathrm{um}$. Sections were stained with hematoxylin and eosin and slides were examined for microscopic abnormalities in the liver including inflammatory, proliferative, preneoplastic and neoplastic lesions following the diagnostic criteria developed for brown bullhead and other fish species (Blazer et al., 2006; Blazer et al., 2007; Boorman et al., 1997; Wolf and Wolfe, 2005). Most observations were scored as absent (0) or present (1).

Commonly identified non-neoplastic lesions include hepatic foci of cellular alteration, necrosis and bile duct proliferation. Hepatic foci of cellular alteration are non-neoplastic, proliferative areas in which cells are not encapsulated or invasive but stain differently the surrounding tissue. These areas have been postulated to be preneoplasic in some fish species (Hendricks et al., 1984; Hinton et al., 1988). Necrosis can be defined as the cell injury resulting in the premature death of cells. Macrophage aggregates (MA) are focal accumulations of macrophages. Variation in the number, size and percent of area occupied by MA has been known to change following exposure to environmental contaminants (Blazer et al., 1987; Fournie et al., 2001). Bile duct proliferation consists of focal or multifocal increase in bile ducts which are well-differentiation but do not cause compression of surrounding tissues. 
Sections of male gonads were examined for intersex, or in this case testicular oocytes (TO) as previously defined by Blazer et al. (2007). Briefly, the severity of TO was recorded using a ranking system on a scale of 1 to 4 . Severity was rated by focusing on the central area of the section however the entire section was scanned for presence of TO at low magnification. A score of 1, (focal distribution) indicates a single oocyte within each microscopic field under a 10X objective. A score of 2, (diffuse distribution) indicated more than one oocyte in the field of view with no physical association with neighboring oocytes. A score of 3, (cluster distribution) was more than one but less than five closely association oocytes and finally a score of 4 (zonal distribution) was more than five closely associated oocytes or numerous clusters in a field of view.

\section{Plasma analyses}

Plasma samples were analyzed for vitellogenin $(v t g)$. Plasma $v t g$ was quantified using an enzyme-linked immunosorbent assay (ELISA) with species specific monoclonal antibodies following previously described methodology (Blazer et al., 2012; Denslow et al., 1996; Iwanowicz et al., 2016).

Aging

Aging of lapillus otoliths was performed using a modification of the multiple-stage process described by Koch \& Quist (2007). Modeling clay was used to fill the caps of plastic 2.0-mL flat-top microcentrifuge tubes (Fisher Scientific, Pittsburgh, Pennsylvania). Their tapered ends were removed to create a cylinder. The "thumb" of single lapilli were placed into the clay such that the ootolith became embedded. Epoxicure brand resin and hardener (Buehler Inc., Lake Bluff, Illinois) was then used to fill the vial and allowed to harden. Microcentrifuge 
tubes were then removed and the otolith sectioned at $7.6 \mathrm{~mm}$ thickness using an Isomet low speed saw (Buehler Inc. Lake Bluff, Illinois). Sections were read using a stereo microscope.

Gene expression analysis

Expression analysis of liver transcripts was performed using nCounter analysis ${ }$ (NanoString Technologies, Seattle, WA). BLASTx searches of partial transcriptome databases for smallmouth bass (SRX156704, SRX199239) and brown bullhead (SRX199312, SRX148685) developed in our lab were used to identify a priori genes of interest. Selected genes were those with suspected modulation in response to contaminants including endocrine disrupting compounds, environmental stressors and genes associated with neoplasia or the presence of parasites. A total of 50 genes for each species were chosen for analysis (Supplemental Table 1). Annotated sequence data for each gene was orientated and trimmed to correspond to coding regions using results from BLASTx searches. Custom CodeSets were designed by Nanostring Technologies (Seattle, WA). Application of the smallmouth bass Codeset for cross-species hybridization with the largemouth bass has been demonstrated elsewhere (Hahn et al., 2016).

Liver samples were sent to the University of Pittsburgh Genomics and Proteomics Core Laboratory (Pittsburgh, PA) for mRNA expression analysis on the Nanostring Technologies platform. Approximately $17-23 \mathrm{mg}$ of liver tissue was combined with $400 \mu \mathrm{l}$ of TRK lysis buffer (Omega Biotech, Norcross, GA) and homogenized on a tissue lyser (Qiagen, Valencia, CA) with $5 \mathrm{~mm}$ stainless steel balls (Boca Bearings, Boynton Beach, FL). Samples were then centrifuged at 16,100 RCF for 10 minutes and the supernatant was removed. Clarified homogenates were stored at $-80^{\circ} \mathrm{C}$ until shipment. CodeSets were utilized in the nCounter analysis system workflow as per the manufacturer and core lab protocols. Generated fills were utilized for quantitative interrogation. 
We used nSolver Analysis Software (v2.0) for quality control and normalization of gene expression data. Negative controls, as included by Nanostring quality control protocol, with high average counts (values ranging from 7-37) were excluded from quality control analysis. The geometric mean plus three standard deviations of negative control probes was subtracted from each sample to account for background signal. To eliminate genes with low count data this value was defined as the reporting limit of this assay and genes with expression data below this calculated value were removed from subsequent analysis. Genes that were removed the analyses because count values were less than the detection limit included are indicated in Supplemental Table 1. Next, we applied a scaling factor to all samples of the average geometric mean of positive spike-in samples across all lanes. Lastly, samples were normalized by tissue mass.

\section{Statistical analysis}

Correlation analyses for plasma vitellogenin (vtg) and hepatic vitellogenin (VTG) were conducted using Spearman rank order correlations. Kruskal Wallis with Mann-Whitney-U posthoc test was used to assess differences in age, HSI, GSI, liver parasites and macrophage aggregate prevalence between sampling locations. These statistical analyses were performed using SigmaPlot 11 (SPSS Inc., Chicago, IL). Statistical comparisons of the differences in the observation of liver lesions including neoplasms, foci of cellular alteration, necrosis and bile duct proliferation were made among site using a Tukey Test with binomial distribution in $\mathrm{R}(\mathrm{R}$ Development Core Team, 2010). All statistical comparisons were considered significant at $\mathrm{p}<$ 0.05 .

Subsequent to normalization procedures, the Bioconductor edgeR package (Robinson et al., 2010) was used to assess differential expression of genes. We first compared males and females to identify gene expression endpoints influenced by sex. Differences in the gene 
expression of largemouth bass from the Genesee River were assessed between seasons. Based on differences noted in these results, we chose to only compare endpoints from fish collected at sites during the same season. Following these criteria we were able to assess site differences in brown bullhead at all three sites during the spring and largemouth bass between the Genesee River and Irondequoit Bay during the spring. We also assessed differences between species collected from Irondequoit Bay and the Genesee River. When sample sizes included 10 or more individuals, we used the results of histological analyses to evaluate differences in gene expression responses in brown bullhead and largemouth bass in normal liver tissue and liver tissue identified with necrosis, bile duct proliferation, altered foci, parasites and macrophage aggregates. Though only five brown bullhead were identified with neoplastic lesions, we also compared gene expression profiles of individuals with neoplastic vs non-neoplastic liver tissue. Fishes were grouped (across sexes, sampling season and sites) and edgeR analysis was used to compare individuals identified as having normal and diseased tissues. In all analyses, genes were defined as statistically significantly different when the $\log 2$ fold change was greater than 1.5 and the false discovery rate was $<0.05$.

\section{Results}

\section{Fish collections}

A total of 59 largemouth bass and 60 brown bullhead were collected between the fall of 2010 and the spring of 2012. Sample size, morphometric data, condition factor and HSI have been summarized previously (Blazer et al., 2014a; Blazer et al., 2014b; Mazik et al., 2015) and are presented here in Table 1. No significant differences were identified in the ages of either largemouth bass or brown bullhead collected between sampling locations. 


\section{Biomarkers of reproductive endocrine disruption}

The prevalence of TO in male largemouth bass collected from these locations is reported elsewhere (Blazer et al., 2014a; Mazik et al., 2015). Briefly, TO prevalence in male largemouth bass collected from the Genesee River, ranged from 0 to $10 \%$ in the fall and spring sampling periods, respectively. In Irondequoit Bay, TO prevalence was $11 \%$. No TOs were identified in collected brown bullhead at any sampling location (Table 2). The low prevalence of intersex made determination of relationships between intersex and other biomarker responses impractical. Plasma $v t g$ was identified in $100 \%$ of collected largemouth bass and brown bullhead. Hepatic VTG mRNA expression was identified in $67-100 \%$ of female and $0-50 \%$ of male largemouth bass (Table 2). No hepatic VTG mRNA expression was identified in brown bullhead. No significant relationships were identified between plasma vtg and hepatic VTG in male largemouth bass. Differences in GSI were assessed in each species between spring sampling sites. There were no significant different between largemouth bass from the Genesee River and Long Pond. Brown bullhead collected from these locations had significant differences in GSI.

\section{Liver pathology}

Summary data for HSI and the presence of microscopic liver lesions of brown bullhead collected from these sites are reported elsewhere (Blazer et al., 2014b; Mazik et al., 2015) and are summarized here in Table 1. Summary data for largemouth bass has previously included HSI (Blazer et al., 2014a; Mazik et al., 2015) but not microscopic liver lesion analyses which are available in Table 1. In brown bullhead, significant differences in HSI were found in fish collected from Long Pond relative to those at other sampling locations. Similarly, HSI in largemouth bass collected from Long Pond were significantly different than those collected from the Genesee River. 
Non-neoplastic, proliferative hepatic lesions identified included macrophage aggregates, foci of cellular alteration, necrosis and bile duct proliferation. Parasites were also observed in the liver. The severity of parasite prevalence was rated on a scale from 0 to 4 . No statistically significant differences were seen in the severity of parasites in the liver between sampling locations. Macrophage aggregates were identified in all sampled fishes. The severity of MA was rated on a scale from 0 to 4 . Average MA severity was 2.9, 3.05, and 1.45 in largemouth bass from the Genesee River in the fall and spring and Long Pond, respectively. Average severity of MA in brown bullhead was 3.6, 3.8, and 3.3 in the Genesee River, Irondequoit Bay, and Long Pond, respectively. Significant differences in the severity of MA were identified in largemouth bass between Long Pond and other sampling locations.

Hepatic foci of cellular alteration were found in $20 \%, 25 \%$ and $10 \%$ of brown bullhead from the Genesee River, Irondequoit Bay and Long Pond, respectively. Foci of cellular alteration were not identified in largemouth bass from any sampling locations. Necrosis was of the liver tissue identified in 15\%, 5\%, and 10\% of largemouth bass from the Genesee River in the fall and spring and Long Pond in the spring, respectively. In brown bullhead, necrosis was identified in 5\% of fish from Irondequoit Bay only.

Bile duct proliferation was identified in $25 \%, 15 \%$ and $35 \%$ of brown bullhead from the Genesee River, Irondequoit Bay and Long Pond, respectively. In largemouth bass, bile duct proliferation was identified in $25 \%, 32 \%$, and $10 \%$ of fish from the Genesee River in the fall and spring and Long Pond, respectively. No statistically significant differences were found in the prevalence of bile duct proliferation, foci of cellular alteration, or necrosis in either species collected from different sites within the REAOC. 
Neoplastic liver lesions identified included cholangioma, hepatic cell adenoma, and cholangiocarcinoma (Table 1). Two fish (10\%) collected from the Genesee River had neoplastic liver lesions. Both cholangiocarcinoma and hepatic cell adenoma were identified in one fish. In Irondequoit Bay, two fish (10\%) had liver neoplasm, identified as cholangiocarcinoma. In Long Pond, one fish (5\%) had a cholangioma. No statistically significant differences were found in the prevalence of cholangioma, hepatic cell adenoma, or cholangiocarcinoma in either species collected from different sites within the REAOC.

\section{Seasonal variation in gene expression}

Temporal differences in mRNA expression were assessed in largemouth bass collected from the Genesee River in September 2010 and May 2011 (Figure 2). In females, 29 were differential expressed between spring and fall $(\mathrm{p}<0.05)$. Of these 29 genes, two (vitellogenin (VTG) and Glucokinase (GLK)) were up-regulated in the spring while the others were more highly expressed in the fall. In males, three of the same genes (VTG, warm temperature acclimation protein 65 (WAP65) and androgen receptor (AR) had statistically significant fold changes between spring and fall. Two of these genes (WAP65 and VTG) were similarly expressed in females while AR was up-regulated in males in the fall but down-regulated in females in the fall. Brown bullhead were only collected in April and May and therefore significant temporal variation in mRNA expression was not assessed.

\section{Variation in gene expression between sites}

Differential expression of gene transcripts between sites was assessed for each species when collection occurred during the same season (Figure 3). In brown bullhead from Irondequoit Bay compared with those from Long Pond, GLK had statistically significant fold changes in females. A gene for a myxobolus parasite (Zschokkella sp. 18S ribosomal RNA gene 
(MYXO)) was also identified with higher expression in female brown bullhead from Irondequoit Bay compared with those from Long Pond. No differences were found in male brown bullhead collected at these locations. In brown bullhead from Long Pond compared with those from the Genesee River, three genes (CYP1A, WAP65 and $3 \beta$ hydroxysteroid dehydrogenase (3ßHD)) in females and one gene (WAP65) in males were identified as statistically significant. In largemouth bass from these same locations, seven genes (hepcidin 2 (HEP2), epidermal growth factor receptor (EGFR), arginase (ARG), GLK, metallothionen (MT), WAP65, RNA binding motif protein X-linked 2 (RBMX2)) in females and one gene in males (ARG) were found to be significantly different. In this case, genes identified as different between sites were not similar between species. In brown bullhead from Irondequoit Bay compared with those collected from the Genesee River, two genes (CYP1A and GLK) in females and two genes (CYP1A and estrogen receptor $\beta(E R \beta)$ ) in males were identified as statistically significant.

\section{Variation in gene expression between species}

At two sites, differences in gene expression between species were assessed (Figure 4). In the spring, female largemouth bass collected from the Genesee River had higher expression of one gene (VTG) and lower expression of 20 genes relative to brown bullhead. Male largemouth bass from this location had higher expression of six genes (VTG, transforming growth factor $\beta$ receptor 1 (TGFßR1), EGFR, GLK, CYP1A and AR) and eight genes with lower expression (epoxide hydrolase (EH), glutathione peroxidase (GP), ERß1, heat shock protein 70 (HSP70), WAP65, ARG, RBMX2, super oxide dismutase (SOD) relative to brown bullhead. In the fall, female largemouth bass collected from Long Pond had higher expression of five genes (VTG, EGFR, hypoxanthine phosphoribosyltransferase 1 (HPRT1), RBMX2, TGFßR1) and lower expression of 12 genes (GP, GLK, SOD, Ribosomal Protein L8 (RPL8), HSP70, EH, HSP90ß, 
elongation factor $1 \alpha(\mathrm{EF} 1 \alpha)$, aryl hydrocarbon receptor (AHR), CYP3A, glutathione-s-

transferase (GST). Male largemouth bass from this location had higher expression of five genes (EGFR, VTG, TGFßR1, HPRT1, and AR) and lower expression of four genes (GP, HSP70, SOD, and EH).

\section{Comparison of histological and gene expression endpoints}

Differences in gene expression in brown bullhead and largemouth bass with different histological conditions were compared (Table 3). Decreased expression of GLK was observed in brown bullhead with bile duct proliferation and foci of cellular alteration. Decreased activity of GLK was also identified in brown bullhead with liver neoplasia, though sample size here was low $(n=5)$. No differential in gene expression was identified in brown bullhead in association with the presence of parasite prevalence. Decreased activity of HEP2 and EGFR were identified in largemouth bass with bile duct proliferation. Decreased activity of ARG was identified in largemouth bass with macrophage aggregate prevalence of 4 , relative to those with a prevalence of 1 . Lower prevalences of macrophage aggregates were not tested due to small sample size. Increased activity of GLK was identified in largemouth bass with a parasite prevalence of 3, relative to those with a prevalence of 2 .

\section{Discussion}

\section{Comparison of plasma and hepatic vitellogenin biomarkers}

Variation in the percentage of fish with protein plasma $v t g$ and hepatic VTG gene transcription were observed in both species. The egg yolk precursor protein VTG is a wellestablished biomarker of exposure to estrogenic compounds in males (Sumpter and Jobling, 1995). Previously, in fathead minnows exposed to $17 \alpha$ - ethinylestradiol, VTG gene 
transcription reached a maximum after several days while plasma vtg protein continued to increase after this time (Flick et al., 2014). The amount of time taken for a species to reach equilibrium has been suggested to be a function of body mass and concentration of exposure. For example, adult male rainbow trout (Oncorhynchus mykiss) took considerably longer, 24 days (Skillman et al., 2006), while zebrafish (Danio rerio) were seen to reach equilibrium after only 5 days of exposure (Rose et al., 2002). Our species were exposed to estrogenic compounds in the environment and therefore exposure duration and concentration is likely to be highly variable across sampled locations and seasons. Vitellogenin transcription responds rapidly to these fluctuations and accordingly gene transcription measurements most accurately address current environmental exposure. Conversely, plasma vtg shows longer response times that could indicate both current exposure and recent but no longer ongoing exposures. The higher percentage of fishes identified with plasma $v t g$ could therefore be indicative of periodic pulses from run-off events resulting in the input of estrogenic compounds from nearby agriculture and/or combined sewer overflows which occurred several days or weeks prior to our collection of fishes. Regardless of the timing of exposure, the results of both vitellogenin endpoints and the histological presence of testicular oocytes in collected bass, indicate exposure to estrogenic endocrine disrupting compounds.

\section{Seasonal variation in gene expression}

Seasonal changes in gene expression endpoints were assessed in largemouth bass. Modulated expression of three genes (WAP65, VTG and AR) was consistent in males and females between seasons. One of these genes, warm temperature acclimation protein 65 , is essential in the acclimation of fishes to changing temperatures and has been previously associated with seasonal fluctuations (Kikuchi et al., 1995; Sha et al., 2008; Watabe et al., 1993). 
Increased activity of VTG was identified in the spring relative to the fall in both males and females. Largemouth bass begin spawning in the spring when water temperatures reach approximately $14-15^{\circ} \mathrm{C}$ (Dufour et al., 2015). The higher expression of VTG in females is indicative of a natural physiological response in preparation for spawning. The similarity of this response in males presents evidence of exposure to exogenous estrogens. As previously mentioned, up-regulation of this gene in males has been associated with exposure to estrogenic compounds. Spring run-off events that result in the influx of estrogenic compounds from agricultural and municipal sources are likely to be a major factor in the response of the VTG gene in male largemouth bass. The steroid-hormone transcription factor androgen receptor (AR) is activated by the binding of androgenic hormones and is essential in sexual differentiation and maturation. We identified decreased AR activity in females and increased AR activity in males between spring and fall sampling periods which, like VTG expression, is likely a reflection of natural physiological responses in preparation for spawning.

\section{Variation in gene expression between sites}

Differentially regulated genes were identified in female largemouth bass between Long Pond and the Genesee River. Genes with the greatest differences in expression between these locations included hepcidin 2 (HEP2), epidermal growth factor receptor (EGFR), and arginase (ARG). These site differences were largely influenced by the expression of these genes in individual fish. Two female fish from Long Pond had unusually high expression of these three genes. As an antimicrobial peptide, HEP is involved in innate immune response. In fish, HEP expression is induced during bacterial infections (Li et al., 2013; Shike et al., 2002) or iron overload (Hu et al., 2007). Epidermal growth factor receptor is a transmembrane tyrosine kinase important to cellular growth, proliferation and apoptosis. Increases in the activity of EGFR can 
result in unregulated cell division and increased expression of EGFR has been associated with tumor progression in epithelial neoplasms of humans (Fogarty et al., 2007). This gene has also been identified as a potential biomarker of arsenic exposure in humans (Sung et al., 2012). Arginase is an enzyme which catalyzes the last step of the urea cycle by converting L-arginine to L-ornithine and urea however the wide distribution of ARG throughout many tissues suggests its importance in functions other than the urea cycle (Srivastava and Ratha, 2010). Arginase may play a vital role in the immune system as it can deplete arginine, which is essential to proliferation and survival of pathogen and host cells (Vincendeau et al., 2003). Requirements for ARG are elevated during acute stress and malignant cell growth and therefore, in many tumors, and particularly in hepatic cancers, arginine demand is beyond its natural supply (Wheatley and Campbell, 2002). Although ARG has been isolated in fishes, to our knowledge no research on its expression or potential role in liver tumors of fish species has been reported. Despite the evidence presented by the up-regulation of these genes, no other indications of neoplasia or increased immune response in these two fish were identified. Given the rapid response of gene expression endpoints to changing environmental conditions and the amount of time required for tumor progression it is possible that these changes represent molecular initiation events which may evolve to higher level effects over time.

In brown bullhead, CYP1A expression differed between sampling locations. A member of the cytochrome P450 family, CYP1A induction is associated with adverse effects including apoptosis, embryonic mortality and the general need for detoxification of the liver (Whyte et al., 2000). Structurally similar contaminants, including polychlorinated dibenzo-p-dioxins (PCDDs), PCBs, polychlorinated bibenzofurans (PCDFs) and PAHs may activate CYP1A expression (Nebert et al., 2000). Brown bullhead from the Irondequoit Bay, had higher CYP1A activity 
than those sampled from the Genesee River. Though only in female brown bullhead, expression of CYP1A was also significantly higher in fish collected from Long Pond than those collected in the Genesee River. Several possible explanations for the higher expression of CYP1A in fish from Long Pond and Irondequoit Bay exist. First, occurrence of contaminants may currently be higher in Long Pond and Irondequoit Bay than in the Genesee River. Historic information, collected between 1981 and 1984, on contaminants at these two locations indicates higher ranges of PCBs, DDT, dieldrin, mirex, and chlordene in tissue of fishes (carp Cyprinus carpio, black crappie Pomoxis nigromaculatus, smallmouth bass Micropterus dolomieu and white sucker Catostomus commersonii) collected in Irondequoit Bay compared to locations along the Genesee River (NYSDEC, 1993). Unfortunately, Long Pond was not included in historic assessment of contaminants in fish tissues. Though this higher level of contaminants was previously reported in Irondequoit Bay, the Genesee River was historically and is currently considered as impaired by the presence of contaminants and the lower activity of CYP1A may be associated with other factors. Lower levels of CYP1A expression in brown bullhead from the Genesee River may be attributed to an adaptive response of brown bullhead following long term exposure to contaminants. Williams and Hubberstey (2014) found low expression of CYP1A in the offspring of brown bullhead collected from contaminated regions which suggests an adaptive molecular change to increase protection to cells and decrease the carcinogens produced during metabolism of contaminants. Additional information on the current contamination of sites in and around the REAOC with compounds known to elicit a response by CYP1A would be useful in the resolution of the effects experienced by brown bullhead and may also aid remediation initiatives to locations where contaminants are most detremential. 
Glucokinase (GLK) phosphorylates glucose and is essential to homeostasis. Little information is available in regards to the expression of this gene in our species of interest. Higher activity of GLK in rainbow trout (Oncorhynchus mykiss) has been identified following food deprivation and subsequent re-feeding (Soengas et al., 2006). Brown bullhead from Irondequoit Bay were found to have higher expression of GLK than those collected at both the Genesee River and Long Pond. Water temperatures during fish collection were also variable with temperatures averaging $6.7^{\circ}, 11.9^{\circ}$, and $10.5^{\circ} \mathrm{C}$ at Irondequoit Bay, the Genesee River and Long Pond, respectively (Lee et al., 2012; Lee et al., 2015). The difference in water temperatures between sites presumably contributes significantly to the GLK modulation identified here. Increased expression of GLK at Irondequoit Bay likely coincides with increasing water temperature and resurgence of metabolism and feeding in brown bullhead.

Warm temperature acclimation protein 65 (WAP65) expression differed between sites and presumably reflects variations in water temperature. Expression of WAP65 was higher in the Genesee River relative to Long Pond in brown bullhead contrary to results identified in largemouth bass where activity of WAP65 was higher at Long Pond relative to the Genesee River. Though the results for each species are inconsistent, it is reasonable to presume that in both localities increased WAP65 activity represents a response to recent seasonal fluctuations in water temperature. Though limited research has been conducted on the expression of WAP65 in wild-caught fishes, previous physiological differences in the expression of WAP65 have been indicated in closely related largemouth bass and smallmouth bass (Hahn et al., 2016). The differences in expression of this temperature related biomarker demonstrate the divergent responses of these species to seasonal fluctuations. 


\section{Variation in gene expression between species}

Differences between largemouth bass and brown bullhead were observed in females and males from both sampling locations. Across both sites and sexes five genes (EH, GP, HSP70, and SOD) had consistently lower activity and one gene (VTG) had consistently higher activity in largemouth bass relative to brown bullhead. All genes with higher observed activity were those closely associated with oxidative stress and/or detoxification following exposure to xenobiotics. Oxidative stress occurs when the balance between the reactive oxidative species (ROS) and the ability of an organism to detoxify reactive intermediates and/or repair the resulting damage is interrupted and often occurs in response to contaminant exposure (Winston and Di Giulio, 1991). Mechanisms to combat the formation of free radicals include antioxidants superoxide dismutase (SOD), which metabolizes superoxide and glutathione peroxidase (GP) which further metabolizes hydrogen peroxide. Components of the biotransform of xenobiotics to less toxic, more water soluble conjugates include heat shock protein 70 (HSP70) and epoxide hydrolase (EH). Heat shock protein 70 is a highly conserved cellular protein which protects and repairs cells against physical, chemical and biological stressors including heat shock, oxidative stress and ultraviolet radiation (Han et al., 2016; Vijayan et al., 1998). Epoxide hydrolase is involved in the biotransformation of xenobiotics through the conversion of epoxides into their corresponding diols (Xu et al., 2015). The induction of ROS and exposure to environmental contaminants has been associated with the formation of cancer (Schumacker, 2006). Elevated frequencies of hepatic tumors are regularly identified in the brown bullhead as demonstrated by this and other studies of contaminated ecosystems (Baumann et al., 1996; Blazer et al., 2009b). Conversely, the largemouth bass infrequently exhibit hepatic tumors in contaminated systems. Brown bullhead are philopatric, benthic species, thus they inhabit a small geographical area throughout 
their lives and spend a considerable amount of time in contact with sediment. In comparison, pelagic largemouth bass live higher in the water column and have been known to move larger distances throughout their lifetime (Carter et al., 2012). These life history differences result in exposure of each species to different classes of contaminants for different lengths of time. To our knowledge, the present study represents the first contrast of antioxidant activity between brown bullhead and largemouth bass. Comparisons of an additional benthic species, the channel catfish (Ictalurus punctatus), have demonstrated lower activity of these important antioxidants in brown bullhead (Hasspieler et al., 1994). The dissimilarity identified here in tumor prevalence, as well as modulation of gene expression endpoints between these species adds to existing knowledge of the divergent biological effects experienced by these species following contaminant exposure.

\section{Comparison of histological and gene expression endpoints}

Comparisons of diseased and normal tissues, as diagnosed by histopathology, identified the modulation of several gene expression endpoints in both species. In the brown bullhead, decreased activity of GLK was identified in neoplastic liver tissue and liver tissue with altered foci. As discussed above, the activity of GLK was higher in brown bullhead collected from the Irondequoit Bay where lower prevalence of altered foci and neoplastic liver lesions were also observed. In addition to the functions of this gene in glucose homeostasis, decreased activity of GLK has been associated with liver tumors which have lower rates of growth in rats (Shonk et al., 1965; Weinhouse et al., 1963). Increased activity of GLK was also identified in largemouth bass as the presence of liver parasites increased from a rating of 2 to 3 . This trend was not identified in other comparisons of parasite prevalence and therefore we cannot draw conclusions regarding the association of GLK expression and parasites. To date, little is known about GLK 
regulation in fish species in general. The findings of the present study represent the first indication that GLK activity may be modulated in association with liver lesions in fish species.

Decreased expression of HEP2 and EGFR was identified in largemouth bass with bile duct proliferation. Site differences in these gene expression endpoints were noted above as driven largely by the high expression of these genes in two fish. Here, because of the increased number of fish per condition the expression of these individual fish does not have a similar influence. The proliferation of bile ducts generally occurs in fish species in response to liver injury. The down-regulation of hepcidin has been previously documented in association with liver injury following obstructed bile flow in mice (Huang et al., 2012). The results of the present study represent the first indication that HEP2 activity may have a similar response in fish species. Largemouth bass with bile duct proliferation also had decreased activity of EGFR. Typically, EGFR is overexpressed in liver regeneration and proliferation of hepatocytes (Sibilia et al., 2007). The low expression of EGFR presented here does not indicate a similar relationship and warrants further investigation on the role of this gene in fish species. A decrease in the activity of ARG was also observed in largemouth bass with macrophage aggregates. Significantly lower prevalence of macrophage aggregates were observed in largemouth bass collected from Long Pond than those collected from the Genesee River in both the spring and the fall. The decrease expression of ARG in fishes with high prevalence of macrophage aggregates may be the result of increase demand for arginine during immune response. This is the first report of the response of ARG in fishes. The results present here justify future research on the role of ARG in the immune response of fishes.

Sample collection may influence the identification of gene expression endpoints associated with histopathology. During the necropsy of individual fishes, multiple, large 
sections of liver tissue, generally several grams, were preserved for histological analyses. In contrast, much smaller amounts ( $\sim 30 \mathrm{mg}$ ) of tissue were preserved for gene expression. Often, tumors and other lesions identified during histopathology are focal and not observed through the entire organ. For these reasons, it is possible for the results of this type of comparison to include bias as there is often no way to grossly verify the health of collected tissues. Future sampling should include techniques which allow for the capture of samples which can be used in both types of analyses in order to eliminate any such biases.

\section{Conclusion}

The development and implementation of gene expression endpoints in non-model, wild caught species allows for finer temporal resolution and comprehensive assessments of the biological effects of contaminants. The modulation of these endpoints provides initial evidence of differences in responses between species and seasons and demonstrates the utility of these markers for the comparison of sites. The evaluation of histological endpoints in conjunction with gene expression makers provides some of the first data available for these species that links conditions at multiple levels of biological organization. As many of the gene expression biomarkers presented in this study have not yet been utilized in the analysis of our species of interest much of this information is novel and should add significantly to our knowledge of the effects of complex chemical mixtures in resident fishes.

\section{References}

Ankley, G.T., Bennett, R.S., Erickson, R.J., Hoff, D.J., Hornung, M.W., Johnson, R.D., Mount, D.R., Nichols, J.W., Russom, C.L., Schmieder, P.K., Serrrano, J.A., Tietge, J.E., Villeneuve, D.L., 2010. Adverse outcome pathways: A conceptual framework to support ecotoxicology research and risk assessment. Environmental Toxicology and Chemistry 29, 730-741.

Baumann, P.C., Smith, I.R., Metcalfe, C.D., 1996. Linkages Between Chemical Contaminants and Tumors in Benthic Great Lakes Fish. Journal of Great Lakes Research 22, 131-152. 
Blazer, V.S., Fournie, J.W., Wolf, J.C., Wolfe, M.J., 2006. Diagnostic criteria for proliferative hepatic lesions in brown bullhead Ameiurus nebulosus. Dis Aquat Organ 72, 19-30.

Blazer, V.S., Fournie, J.W., Wolf, J.C., Wolfe, M.J., 2007. Maunal for the Microscopic Diagnosis of Proliferative Liver and Skin Lesions in the Brown Bullhead (Ameiurus nebulosus). Pennsylvania Sea Great, 1-34.

Blazer, V.S., Iwanowicz, D.D., Iwanowicz, L.R., Smith, D.R., Young, J.A., Hedrick, J.D., Foster, S.W., Reeser, S.J., 2007. Intersex (Testicular Oocytes) in Smallmouth Bass Micropterus dolomieu from the Potomac River and Selected Nearby Drainages. Journal of aquatic animal health 19, 242-253.

Blazer, V.S., Iwanowicz, L.R., Henderson, H., Mazik, P.M., Jenkins, J.A., Alvarez, D.A., Young, J.A., 2012. Reproductive endocrine disruption in smallmouth bass (Micropterus dolomieu) in the Potomac River basin: spatial and temporal comparisons of biological effects. Environmental monitoring and assessment 184, 4309-4334.

Blazer, V.S., Mazik, P.M., Iwanowicz, L.R., Braham, R., Hahn, C., Walsh, H.L., Sperry, A., 2014a. Monitoring of wild fish health at selected site in the Great Lakes basin - methods and preliminary results. U.S. Geological Survey Open-File Report 2014-1027.

Blazer, V.S., Mazik, P.M., Iwanowicz, L.R., Braham, R.P., Hahn, C.M., Walsh, H.L., Sperry, A.J., 2014b. Assessment of the fish tumor beneficial use impairment in brown bullhead (Ameiurus nebulosus) at selected Great Lakes Areas of Concern. U.S. Geological Survey, Reston, VA, p. 28.

Blazer, V.S., Rafferty, S.D., Baumman, P.C., Smith, S.B., Obert, E.C., 2009a. Assessment of the "fish tumors or other deformities" beneficial use impairment in brown bullhead (Ameiurus nebulosus): I. Orocutaneous tumors. Journal of Great Lakes Research 35, 517-526.

Blazer, V.S., Rafferty, S.D., Baumman, P.C., Smith, S.B., Obert, E.C., 2009b. Assessment of the "fish tumors or other deformities" beneficial use impairment in brown bullhead (Ameiurus nebulosus): II. Liver neoplasia. Journal of Great Lakes Research 35, 527-537.

Blazer, V.S., Wolke, R.E., Brown, J., Powell, C.A., 1987. Piscine macrophage aggregate parameters as health monitors: effect of age, sex, relative weight, season and site quality in largemouth bass (Micropterus salmoides). Aquatic toxicology 10, 199-215.

Boorman, G.A., Botts, S., Bunton, T.E., Fournie, J.W., Harshbarger, J.C., Hawkins, W.E., Hinton, D.E., Jokinen, M.P., Okihiro, M.S., Wolfe, M.J., 1997. Diagnostic criteria for degenerative, inflammatory, proliferative nonneoplastic and neoplastic liver lesions in medaka (Oryzias latipes): consensus of a National Toxicology Program Pathology Working Group. Toxicologic pathology 25, 202-210.

Carter, M.W., Weber, M.J., Dettmers, J.M., Wahl, D.H., 2012. Movement patterns of smallmouth and largemouth bass in and around a Lake Michigan harbor: The importance of water temperature. Journal of Great Lakes Research 38, 396-401. 
Denslow, N.D., Chow, M.M., Folmar, L.C., Bonomelli, S.L., Heppell, S.A., Sullivan, C.V., 1996. Development of antibodies to teleost vitellogenins: potential biomarkers for environmental estrogens. ASTM SPECIAL TECHNICAL PUBLICATION 1306, 23-36.

Denslow, N.D., Kocerha, J., Sepulveda, M.S., Gross, T., Holm, S.E., 2004. Gene expression fingerprints of largemouth bass (Micropterus salmoides) exposed to pulp and paper mill effluents. Mutation research 552, 19-34.

Dufour, K., Gutowsky, L.F.G., Algera, D., Zolderdo, A., Magel, J.M.T., Pleizier, N., Dick, M., Cooke, S.J., 2015. An experimental test of in-season homing mechanisms used by nest-guarding male Largemouth Bass following displacement. Behavioural Processes 120, 87-93.

Eufemia, N., Collier, T., Stein, J., Watson, D., Di Giulio, R., 1997. Biochemical responses to sediment-associated contaminants in brown bullhead (Ameriurus nebulosus) from the Niagara River ecosystem. Ecotoxicology 6, 13-34.

Flick, R.W., Bencic, D.C., See, M.J., Biales, A.D., 2014. Sensitivity of the vitellogenin assay to diagnose exposure of fathead minnows to $17 \alpha$-ethynylestradiol. Aquatic toxicology 152, 353360.

Fogarty, G.B., Conus, N.M., Chu, J., McArthur, G., 2007. Characterization of the expression and activation of the epidermal growth factor receptor in squamous cell carcinoma of the skin. The British journal of dermatology 156, 92-98.

Fournie, J.W., Summers, J.K., Courtney, L.A., Engle, V.D., Blazer, V.S., 2001. Utility of Splenic Macrophage Aggregates as an Indicator of Fish Exposure to Degraded Environments. Journal of aquatic animal health 13, 105-116.

Goodbred, S.L., Patiño, R., Torres, L., Echols, K.R., Jenkins, J.A., Rosen, M.R., Orsak, E., 2015. Are endocrine and reproductive biomarkers altered in contaminant-exposed wild male Largemouth Bass (Micropterus salmoides) of Lake Mead, Nevada/Arizona, USA? General and comparative endocrinology 219, 125-135.

Hahn, C.M., Iwanowicz, L.R., Cornman, R.S., Mazik, P.M., Blazer, V.S., 2016. Transcriptome Discovery in Non-Model Wild Fish Species for the Development of Quantitative Gene Expression Assays. Journal of Comparative Biochemistry and Physiology: Part D In review.

Han, Y.-L., Yang, W.-X., Long, L.-L., Sheng, Z., Zhou, Y., Zhao, Y.-Q., Wang, Y.-F., Zhu, J.Q., 2016. Molecular cloning, expression pattern, and chemical analysis of heat shock protein 70 (HSP70) in the mudskipper Boleophthalmus pectinirostris: Evidence for its role in regulating spermatogenesis. Gene 575, 331-338.

Hasspieler, B.M., Behar, J.V., Carlson, D.B., Watson, D.E., Di Giulio, R.T., 1994. Susceptibility of channel catfish (Ictalurus punctatus) and brown bullhead (Ameriurus nebulosus) to oxidative stress: a comparative study. Aquatic toxicology 28, 53-64.

Haynes, J.M., Neuderfer, G.N., 2011. Brown Bullhead Tumors and Deformities in the Rochester Embayment Area of Concern, Project Number GL 97233009-0. USEPA Region 2. 
Hendricks, J.D., Meyers, T.R., Shelton, D.W., 1984. Histological progression of hepatic neoplasia in rainbow trout (Salmo gairdneri). National Cancer Institute monograph 65, 321-336.

Hinck, J.E., Blazer, V.S., Denslow, N.D., Echols, K.R., Gale, R.W., Wieser, C., May, T.W., Ellersieck, M., Coyle, J.J., Tillitt, D.E., 2008. Chemical contaminants, health indicators, and reproductive biomarker responses in fish from rivers in the Southeastern United States. Science of The Total Environment 390, 538-557.

Hinck, J.E., Blazer, V.S., Schmitt, C.J., Papoulias, D.M., Tillitt, D.E., 2009. Widespread occurrence of intersex in black basses (Micropterus spp.) from U.S. rivers, 1995-2004. Aquatic toxicology 95, 60-70.

Hinton, D.E., Couch, J.A., Teh, S.J., Courtney, L.A., 1988. Cytological changes during progression of neoplasia in selected fish species. Aquatic toxicology 11, 77-112.

Hu, X., Camus, A.C., Aono, S., Morrison, E.E., Dennis, J., Nusbaum, K.E., Judd, R.L., Shi, J., 2007. Channel catfish hepcidin expression in infection and anemia. Comparative immunology, microbiology and infectious diseases 30, 55-69.

Huang, Y.-H., Yang, Y.-L., Tiao, M.-M., Kuo, H.-C., Huang, L.-T., Chuang, J.-H., 2012. Hepcidin protects against lipopolysaccharide-induced liver injury in a mouse model of obstructive jaundice. Peptides 35, 212-217.

IJC, 2012. Delisting targets developed by RAP teams. Accessed February 2016. <http://www.ijc.org/rel/boards/annex2/buis.htm>

Iwanowicz, L.R., Blazer, V.S., Pikney, A.E., Guy, C.P., Major, A.M., Munney, K., Mierzykowski, S., Lingenfelser, S., Secord, A., Patnode, K., Kubiak, T.J., Stern, C., Hahn, C.M., Iwanowicz, D.D., Walsh, H.L., Sperry, A., 2016. Evidence of estrogenic endocrine disruption in smallmouth and largemouth bass inhabiting Northeast U.S. national wildlife refuge water: A reconnaissance study. Ecotoxicology and Environmental Safety 124, 50-59.

Kikuchi, K., Yamashita, M., Watabe, S., Aida, K., 1995. The warm temperature acclimationrelated 65-kDa protein, Wap65, in goldfish and its gene expression. Journal of Biological Chemistry 270, 17087-17092.

Leadley, T.A., Balch, G., Metcalfe, C.D., Lazar, R., Mazak, E., Habowsky, J., Haffner, G.D., 1998. Chemical accumulation and toxicological stress in three brown bullhead (Ameiurus nebulosus) populations of the Detroit River, Michigan, USA. Environmental Toxicology and Chemistry 17, 1756-1766.

Lee, K.E., Langer, S.K., Menheer, M.A., Foreman, W.T., Furlong, E.T., Smith, S.G., 2012. Chemicals of emerging concern in water and bottom sediment in Great Lakes areas of concern, 2010 to 2011-Collection methods, analyses methods, quality assurance and data., in: Series, U.N. (Ed.). U.S. Geological Survey, Reston, VA, p. 36.

Lee, K.E., Langer, S.K., Menheer, M.A., Hansen, D.S., Foreman, W.T., Furlong, E.T., Jorgenson, Z.G., Choy, S.J., Moore, J.N., Banda, J., Gefell, D.J., 2015. Chemicals of emerging 
concern in water and bottom sediment in the Great Lakes Basin, 2012: collection methods, analytical methods, quality assurance, and study data, Data Series, Reston, VA, pp. 14-.

Li, H., Zhang, F., Guo, H., Zhu, Y., Yuan, J., Yang, G., An, L., 2013. Molecular characterization of hepcidin gene in common carp (Cyprinus carpio L.) and its expression pattern responding to bacterial challenge. Fish \& shellfish immunology 35, 1030-1038.

Mazik, P.M., Braham, R.P., Hahn, C.M., Blazer, V.S., 2015. Assessment of general health of fishes collected at selected sites within the Great Lakes Basin in 2012. Department of Interior, Fish and Wildlife Service, Cooperator Science Series, FWS.CSS-112-2015, Washington, D.C.

Nebert, D.W., Roe, A.L., Dieter, M.Z., Solis, W.A., Yang, Y., Dalton, T.P., 2000. Role of the aromatic hydrocarbon receptor and $[\mathrm{Ah}]$ gene battery in the oxidative stress response, cell cycle control, and apoptosis. Biochemical Pharmacology 59, 65-85.

NYS-DEC, 2011. December 2011 Addendum to Stage 1 and 2 Remedial Action Plans

Rochester Embayment Area of Concern. Accessed February 2016.

<http://www.dec.ny.gov/docs/water_pdf/rochaocrap2fnl.pdf>

NYS-DEC, 1993. Rochester Embayment Remedial Action Plan, Stage I, Chapter 4: Water Quality Conditions/Problems. New York State Department of Conservation, Great lakes Section, Division of Water, Albany, NY, 9 - 11.

NYS-DEC, 2003. The 2001 Genesee River Basin Waterbody Inventory and Priority Waterbodies List. New York State Department of Environmental Conservation.

Pinkney, A.E., Harshbarger, J.C., Karouna-Renier, N.K., Jenko, K., Balk, L., Skarphéðinsdóttir, H., Liewenborg, B., Rutter, M.A., 2011. Tumor prevalence and biomarkers of genotoxicity in brown bullhead (Ameiurus nebulosus) in Chesapeake Bay tributaries. Science of The Total Environment 410-411, 248-257.

R Development Core Team, 2010. R: A language and environment for statistical computing. R Foundation for Statistical Computing, Vienna, Austria.

Rafferty, S.D., Blazer, V.S., Pinkney, A.E., Grazio, J.L., Obert, E.C., Boughton, L., 2009. A historical perspective on the "fish tumors or other deformities" beneficial use impairment at Great Lakes Areas of Concern. Journal of Great Lakes Research 35, 496-506.

Robinson, M.D., McCarthy, D.J., Smyth, G.K., 2010. edgeR: a Bioconductor package for differential expression analysis of digital gene expression data. Bioinformatics 26 .

Rose, J., Holbech, H., Lindholst, C., Nørum, U., Povlsen, A., Korsgaard, B., Bjerregaard, P., 2002. Vitellogenin induction by $17 \beta$-estradiol and $17 \alpha$-ethinylestradiol in male zebrafish (Danio rerio). Comparative Biochemistry and Physiology Part C: Toxicology \& Pharmacology 131, 531-539.

Schumacker, P.T., 2006. Reactive oxygen species in cancer cells: Live by the sword, die by the sword. Cancer Cell 10, 175-176. 
Sepulveda, M.S., Johnson, W.E., Higman, J.C., Denslow, N.D., Schoeb, T.R., Gross, T.S., 2002. An evaluation of biomarkers of reproductive function and potential contaminant effects in Florida largemouth bass (Micropterus salmoides floridanus) sampled from the St. Johns River. The Science of the total environment 289, 133-144.

Sha, Z., Xu, P., Takano, T., Liu, H., Terhune, J., Liu, Z., 2008. The warm temperature acclimation protein Wap65 as an immune response gene: Its duplicates are differentially regulated by temperature and bacterial infections. Molecular Immunology 45, 1458-1469.

Shike, H., Lauth, X., Westerman, M.E., Ostland, V.E., Carlberg, J.M., Van Olst, J.C., Shimizu, C., Bulet, P., Burns, J.C., 2002. Bass hepcidin is a novel antimicrobial peptide induced by bacterial challenge. European journal of biochemistry / FEBS 269, 2232-2237.

Shonk, C.E., Morris, H.P., Boxer, G.E., 1965. Patterns of Glycolytic Enzymes in Rat Liver and Hepatoma. American Association for Cancern Research 25, 671-676.

Sibilia, M., Kroismayr, R., B.M., L., Natarajan, A., Hecking, M., Holcmann, M., 2007. The epidermal growth factor receptor: from development to tumorigenesis. Differentitation 75, 770787.

Skillman, A.D., Nagler, J.J., Hook, S.E., Small, J.A., Schultz, I.R., 2006. Dynamics of 17 $\alpha-$ Ethynylestradiol Exposure in Rainbow Trout (Oncorhynchus mykiss): Absorption, Tissue Disruption, and Hepatic Gene Expression Pattern. . Environmental toxicology and chemistry / SETAC 25, 2997-3005.

Soengas, J.L., Polakof, S., Chen, X., Sangiao-Alvarellos, S., Moon, T.W., 2006. Glucokinase and hexokinase expression and activities in rainbow trout tissues: changes with food deprivation and refeeding. American Journal of Physiology - Regulatory, Integrative and Comparative Physiology 291, R810-R821.

Srivastava, S., Ratha, B.K., 2010. Does fish represent an intermediate stage in the evolution of ureotelic cytosolic arginase I? Biochemical and Biophysical Research Communications 391, 1-5.

Stein, J.E., Collier, T.K., Reichert, W.L., Casillas, E., Hom, T., Varanasi, U., 1992. Bioindicators of contaminant exposure and sublethal effects: studies with benthic fish in Puget Sound, Washington. Environmental Toxicology and Chemistry 11, 701-714.

Stentiford, G.D., Longshaw, M., Lyons, B.P., Jones, G., Green, M., Feist, S.W., 2003. Histopathological biomarkers in estuarine fish species for the assessment of biological effects of contaminants. Marine environmental research 55, 137-159.

Stentiford, G.D., Massoud, M.S., Al-Mudhhi, S., Al-Sarawi, M.A., Al-Enezi, M., Lyons, B.P., 2014. Histopathological survey of potential biomarkers for the assessment of contaminant related biological effects in species of fish and shellfish collected from Kuwait Bay, Arabian Gulf. Marine environmental research 98, 60-67.

Sumpter, J.P., Jobling, S., 1995. Vitellogenesis as a biomarker for estrogenic contamination of the aquatic environment. Environmental Health Perspectives 103, 173-178. 
Sung, T.-I., Wang, Y.-J., Chen, C.-Y., Hung, T.-L., Guo, H.-R., 2012. Increased serum level of epidermal growth factor receptor in liver cancer patients and its association with exposure to arsenic. Science of The Total Environment 424, 74-78.

USEPA, 2013. Great Lakes Areas of Concern: Rochester Embayment. U.S. Environmental Protection Agency.

Vijayan, M.M., Pereira, C., Kruzynski, G., Iwama, G.K., 1998. Sublethal concentrations of contaminant induce the expression of hepatic heat shock protein 70 in two salmonids. Aquatic toxicology 40, 101-108.

Vincendeau, P., Gobert, A.P., Daulouede, S., Moynet, D., Mossalayi, M.D., 2003. Arginases in parasitic diseases. Trends Parasitol 19, 9-12.

Watabe, S., Kikuchi, K., Aida, K., 1993. Cold-and Warm-temperature Acclimation Induces Specific Cytosolic Proteins in Goldfish and Carp. NIPPON SUISAN GAKKAISHI 59, 151-156.

Weinhouse, S., Cristofalo, V., Sharma, C., Morris, H.P., 1963. Some properties of glucokinase in normal and neoplastic liver. Advances in Enzyme Regulation 1, 363-371.

Wheatley, D.N., Campbell, E., 2002. Arginine catabolism, liver extracts and cancer. Pathology oncology research : POR 8, 18-25.

Whyte, J.J., Jung, R.E., Schmitt, C.J., Tillitt, D.E., 2000. Ethoxyresorufin-O-deethylase (EROD) Activity in Fish as Biomarker of Chemical Exposure. Critical Reviews in Toxicology 30, 347570 .

Williams, R., Hubberstey, A.V., 2014. Benzo(a)pyrene exposure causes adaptive changes in p53 and CYP1A gene expression in Brown bullhead (Ameiurus nebulosus). Aquatic toxicology 156, 201-210.

Winston, G.W., Di Giulio, R.T., 1991. Prooxidant and antioxidant mechanisms in aquatic organisms. Aquatic toxicology 19, 137-161.

Wolf, J.C., Wolfe, M.J., 2005. A brief overview of nonneoplastic hepatic toxicity in fish. Toxicologic pathology 33, 75-85.

Xu, J., Morisseau, C., Yang, J., Mamatha, D.M., Hammock, B.D., 2015. Epoxide hydrolase activities and epoxy fatty acids in the mosquito Culex quinquefasciatus. Insect Biochemistry and Molecular Biology 59, 41-49. 


\section{Figures}

Figure 1. Map of the Rochester Embayment Area of Concern boundaries and fish sampling locations.

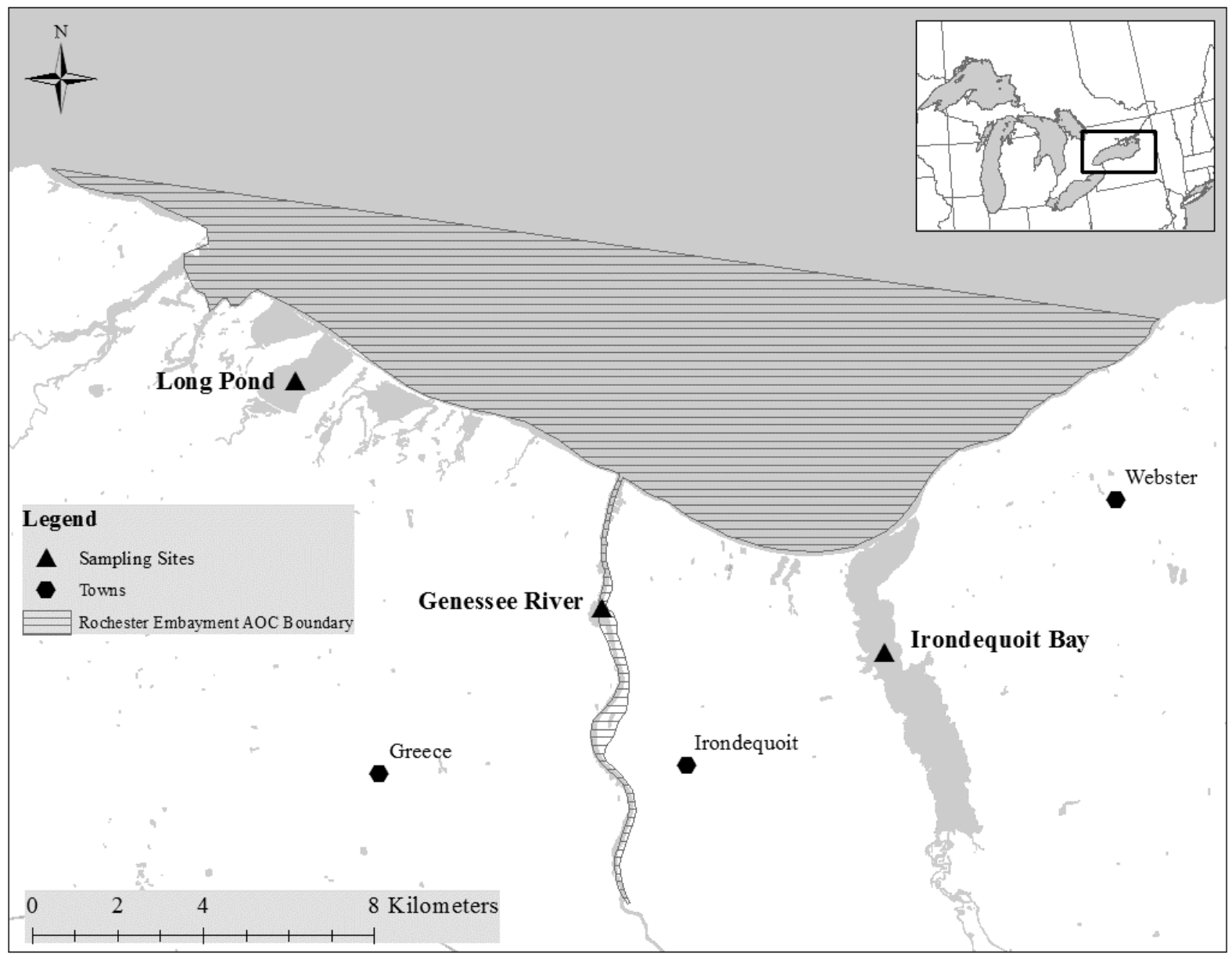


Figure 2. Heatmap of seasonal differences (spring vs fall) of male and female largemouth bass collected in from the Genesee River. Green values represent negative fold changes $(\log 2)$ while red values represent positive fold changes $(\log 2)$.

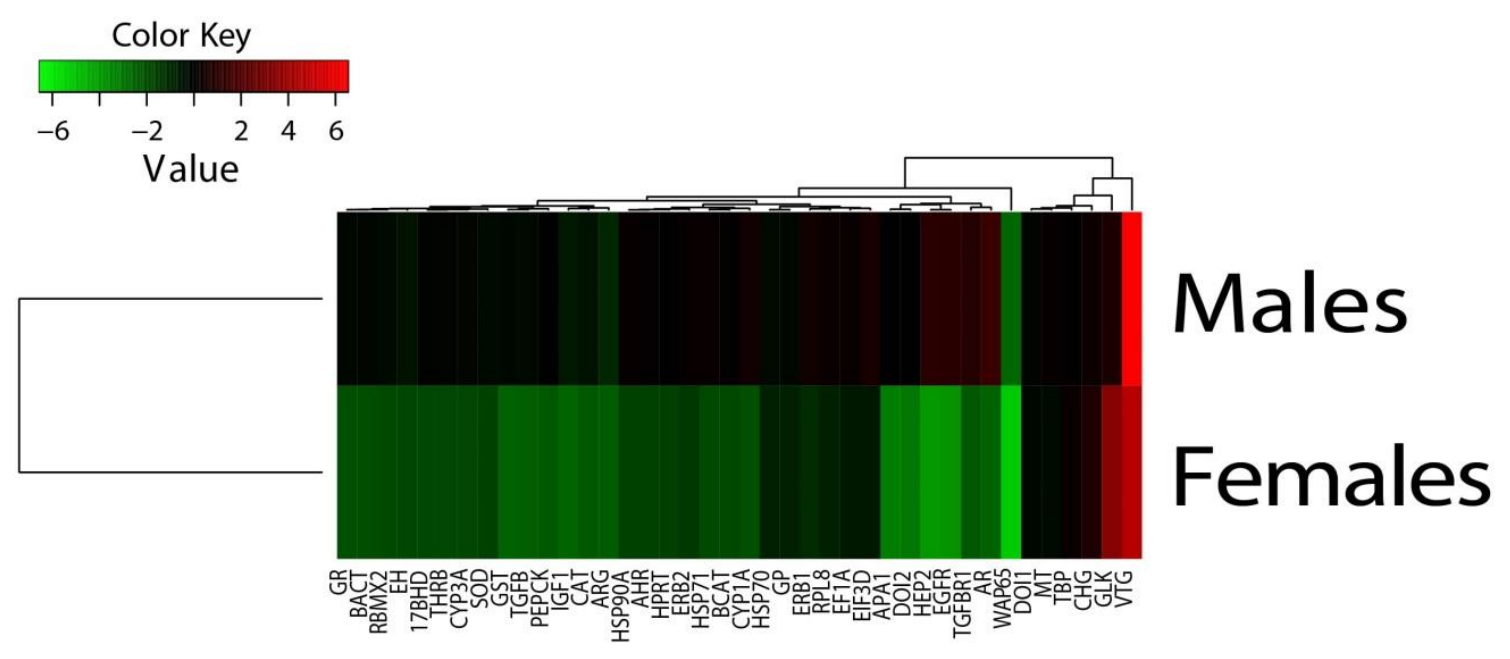


Figure 3. Gene expression differences (fold change) between sampling site locations in largemouth bass and brown bullhead. Light grey bars represent females while dark grey bars represent males.

Long Pond vs Genessee River Largemouth Bass

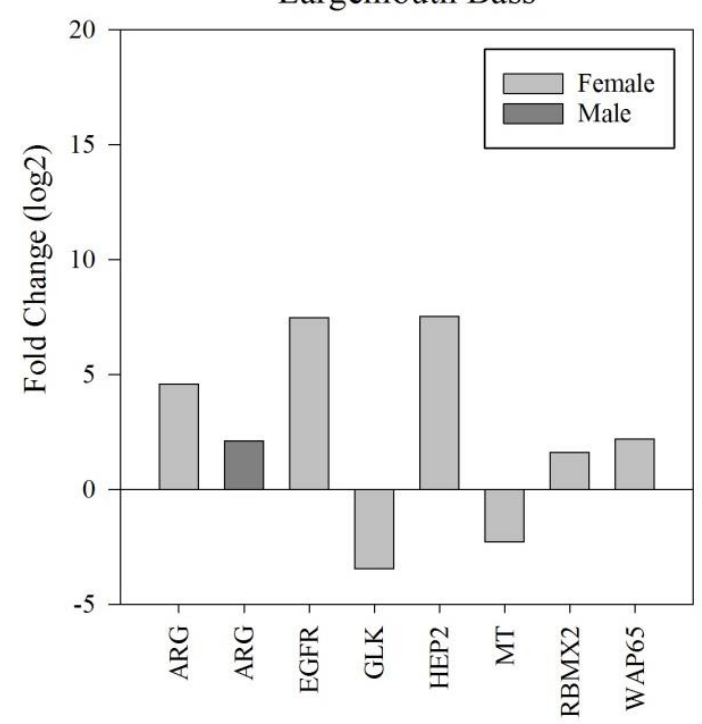

Irondequoit Bay vs Long Pond

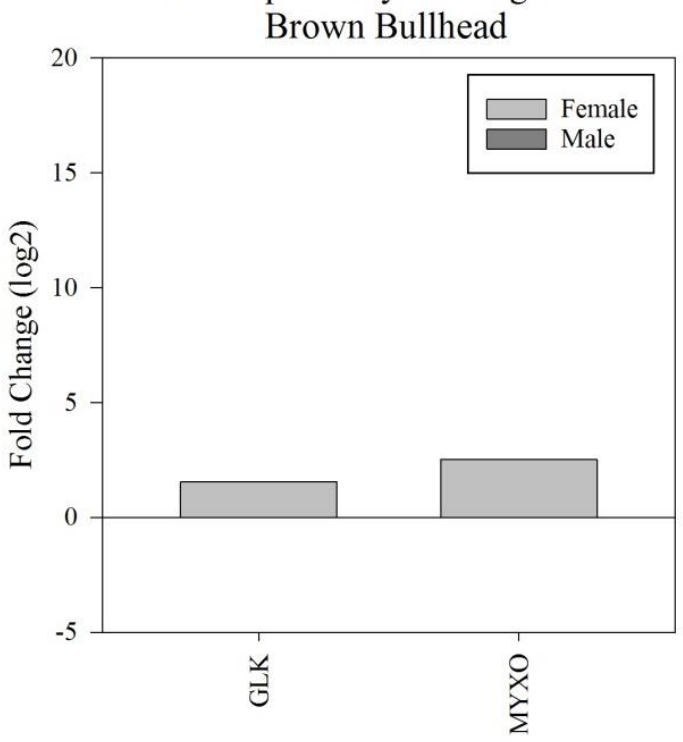

Long Pond vs Genesee River Brown Bullhead

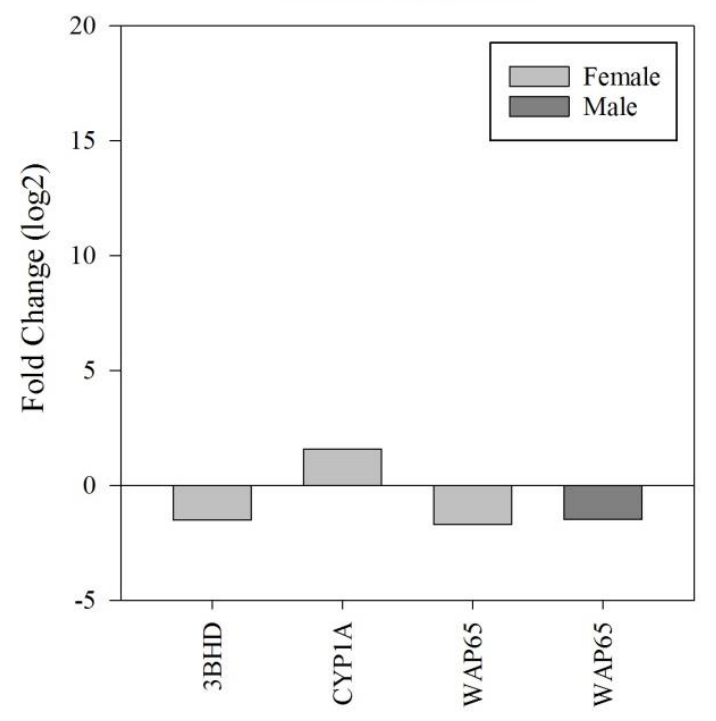

Irondequoit Bay vs Genesee River Brown Bullhead

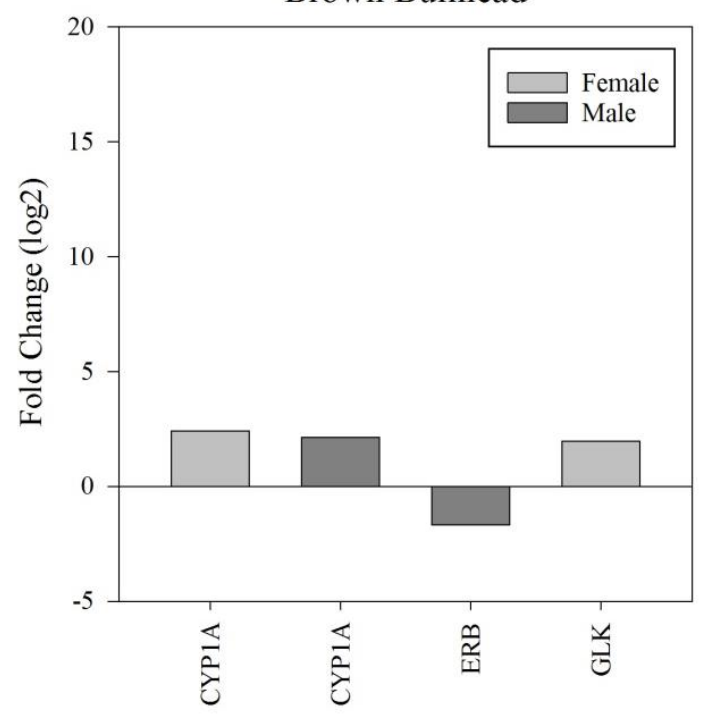


Figure 4. Heatmap of species differences (largemouth bass vs brown bullhead) separated by sampling site location and sex. Green values represent negative fold changes $(\log 2)$ while red values represent positive fold changes $(\log 2)$.

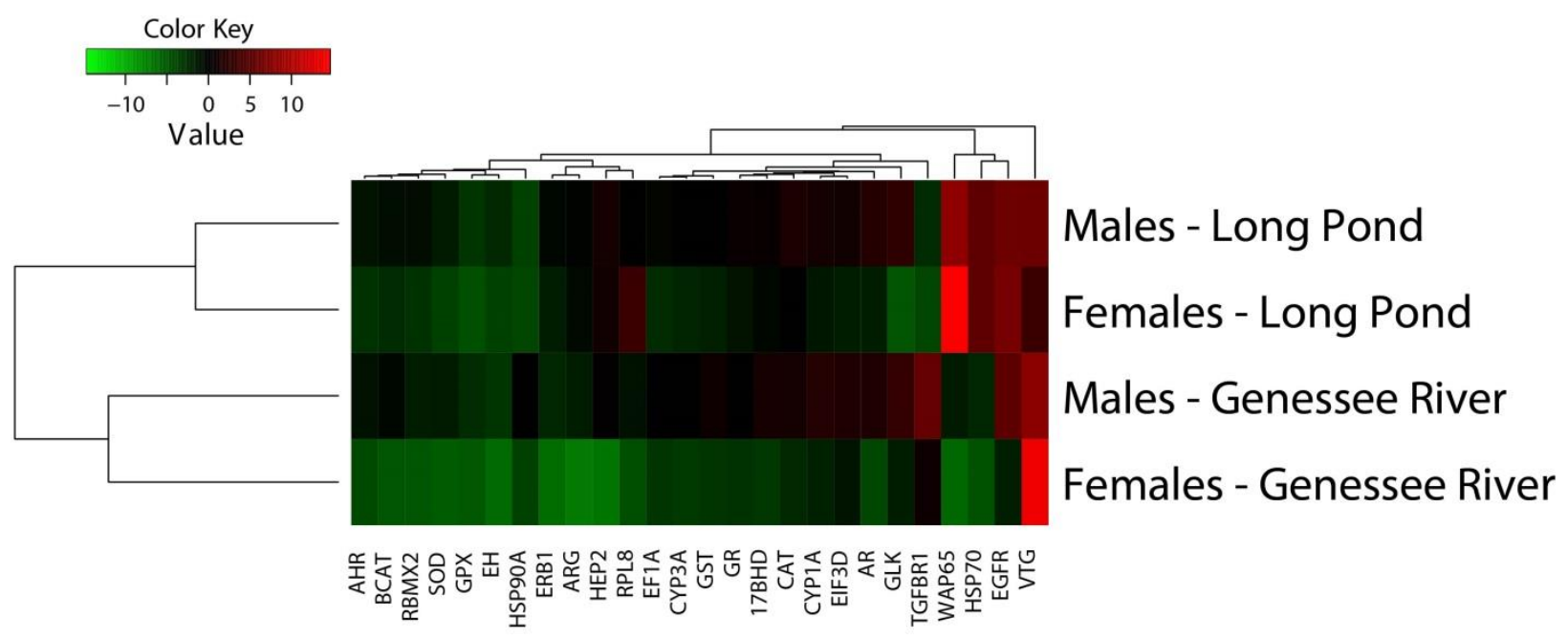




\section{Tables}

Table 1. Collection dates, sites, sample sizes, morphometric data, hepatosomatic index, liver neoplasma and putative preneoplastic liver lesions for largemouth bass and brown bullhead collected at the Rochester Embayment Area of Concern.

\begin{tabular}{|c|c|c|c|c|c|c|}
\hline & \multicolumn{3}{|c|}{ Genesee River } & \multicolumn{2}{|c|}{ Long Pond } & $\begin{array}{c}\text { Irondequoit } \\
\text { Bay }\end{array}$ \\
\hline Latitude & \multicolumn{3}{|c|}{43.23} & \multicolumn{2}{|c|}{43.29} & 43.21 \\
\hline Longitude & \multicolumn{3}{|c|}{-77.62} & \multicolumn{2}{|c|}{-77.70} & -77.53 \\
\hline Species & \multicolumn{2}{|c|}{ Largemouth Bass } & $\begin{array}{l}\text { Brown } \\
\text { Bullhead }\end{array}$ & $\begin{array}{l}\text { Largemouth } \\
\text { Bass }\end{array}$ & $\begin{array}{l}\text { Brown } \\
\text { Bullhead }\end{array}$ & $\begin{array}{l}\text { Brown } \\
\text { Bullhead }\end{array}$ \\
\hline Collection Date & $9 / 21 / 2010$ & \multicolumn{2}{|c|}{$5 / 11 / 2011$} & \multicolumn{2}{|c|}{$4 / 26 / 2012$} & $4 / 25 / 2012$ \\
\hline \multirow{2}{*}{$\mathrm{N}$} & $6 \mathrm{~F}$ & $9 \mathrm{~F}$ & $13 \mathrm{~F}$ & $11 \mathrm{~F}$ & $5 \mathrm{~F}$ & $11 \mathrm{~F}$ \\
\hline & $14 \mathrm{M}$ & $10 \mathrm{M}$ & $7 \mathrm{M}$ & $9 \mathrm{M}$ & $15 \mathrm{M}$ & $9 \mathrm{M}$ \\
\hline Length $^{1}$ & $333 \pm 10.8$ & $368 \pm 10.8$ & $319 \pm 11.0$ & $311.7 \pm 9.6$ & $316 \pm 7.0$ & $306 \pm 5.6$ \\
\hline Weight $^{1}$ & $612 \pm 57.0$ & $906 \pm 95.9$ & $419 \pm 29.8$ & $551.4 \pm 67.1$ & $379 \pm 26.7$ & $402 \pm 31.1$ \\
\hline $\mathrm{Age}^{1}$ & $5.5 \pm 0.1$ & $6.7 \pm 0.4$ & $7.8 \pm 0.6$ & $5.4 \pm 0.2$ & $7.5 \pm 0.3$ & $8.0 \pm 0.6$ \\
\hline Condition Factor $^{2}$ & $1.59 \pm 0.04$ & $1.64 \pm 0.02$ & $1.3 \pm 0.03$ & $1.61 \pm 0.04$ & $1.2 \pm 0.02$ & $1.3 \pm 0.05$ \\
\hline \multicolumn{7}{|c|}{ Liver Lesions } \\
\hline Hepatosomatic Index ${ }^{3}$ & $1.0 \pm 0.1$ & $1.9 \pm 0.1$ & $2.9 \pm 0.2$ & $1.75 \pm 0.1$ & $1.7 \pm 0.08$ & $2.5 \pm 0.1$ \\
\hline Liver neoplasms ${ }^{4}$ & $0 \%$ & $0 \%$ & $10 \%$ & $0 \%$ & $10 \%$ & $5 \%$ \\
\hline $\begin{array}{l}\text { Foci of cellular } \\
\text { alteration }\end{array}$ & $0 \%$ & $0 \%$ & $20 \%$ & $0 \%$ & $25 \%$ & $10 \%$ \\
\hline Necrosis & $15 \%$ & $5 \%$ & $10 \%$ & $0 \%$ & $0 \%$ & $5 \%$ \\
\hline Bile duct proliferation & $25 \%$ & $32 \%$ & $25 \%$ & $10 \%$ & $35 \%$ & $15 \%$ \\
\hline Parasites & $2.2 \pm 1.00$ & $2.21 \pm 1.23$ & $0.42 \pm 0.51$ & $2.15 \pm 1.18$ & $0.30 \pm 0.47$ & $0.25 \pm 0.44$ \\
\hline $\begin{array}{l}\text { Macrophage } \\
\text { aggregates }^{1}\end{array}$ & $2.9 \pm 1.41$ & $3.05 \pm 1.35$ & $3.6 \pm 0.88$ & $1.45 \pm 1.00$ & $3.3 \pm 1.08$ & $3.8 \pm 0.52$ \\
\hline
\end{tabular}

${ }^{1}$ Data are presented as mean \pm standard error.

${ }^{2}$ Condition factor $(\mathrm{KtL})$ is calculated as ((body weight - gonad weight)/length $\left.{ }^{3}\right) \times 10^{5}$

${ }^{3} \mathrm{Hepatosomatic} \mathrm{index} \mathrm{(HSI)} \mathrm{is} \mathrm{calculated} \mathrm{as} \mathrm{(liver} \mathrm{weight/(body} \mathrm{weight-gonad} \mathrm{weight))} \mathrm{X} 10^{2}$

${ }^{4}$ Liver neoplasms included hepatic cell adenoma, hepatic cell carcinoma, cholangioma and cholangiocarcinoma 
Table 2. Plasma vitellogenin, hepatic vitellogenin and testicular oocyte results for largemouth bass and brown bullhead.

\begin{tabular}{|c|c|c|c|c|c|c|}
\hline \multicolumn{7}{|c|}{ Largemouth Bass } \\
\hline Site & Season & $\mathbf{N}$ & GSI & $\begin{array}{l}\text { \% Hepatic } \\
\text { VTG }\end{array}$ & $\begin{array}{c}\text { \% Plasma } \\
\text { VTG }\end{array}$ & $\begin{array}{c}\text { \% Testicular } \\
\text { Oocytes }\end{array}$ \\
\hline \multirow{4}{*}{ Genesee River } & \multirow{2}{*}{ Fall } & $6 \mathrm{~F}$ & $0.95 \pm 0.10$ & 67 & 100 & NA \\
\hline & & $14 \mathrm{M}$ & $0.36 \pm 0.02$ & 0 & 100 & 0 \\
\hline & \multirow{2}{*}{ Spring } & $9 \mathrm{~F}$ & $6.42 \pm 0.10$ & 100 & 100 & NA \\
\hline & & $10 \mathrm{M}$ & $0.44 \pm 0.03$ & 50 & 100 & 10 \\
\hline \multirow{2}{*}{ Long Pond } & \multirow{2}{*}{ Spring } & $11 \mathrm{~F}$ & $5.18 \pm 1.10$ & 100 & 100 & NA \\
\hline & & $9 \mathrm{M}$ & $0.48 \pm 0.11$ & 11 & 100 & 11 \\
\hline \multicolumn{7}{|c|}{ Brown Bullhead } \\
\hline \multirow{2}{*}{ Genesee River } & \multirow{2}{*}{ Spring } & $13 \mathrm{~F}$ & $3.44 \pm 0.37$ & 0 & 100 & NA \\
\hline & & $7 \mathrm{M}$ & $0.30 \pm 0.05$ & 0 & 100 & 0 \\
\hline \multirow{2}{*}{ Long Pond } & \multirow{2}{*}{ Spring } & $5 \mathrm{~F}$ & $2.77 \pm 0.57$ & 0 & 100 & NA \\
\hline & & $15 \mathrm{M}$ & $0.23 \pm 0.04$ & 0 & 100 & 0 \\
\hline \multirow{2}{*}{$\begin{array}{l}\text { Irondequoit } \\
\text { Bay }\end{array}$} & \multirow{2}{*}{ Spring } & $11 \mathrm{~F}$ & $4.33 \pm 0.50$ & 9 & 100 & NA \\
\hline & & $9 \mathrm{M}$ & $0.24 \pm 0.05$ & 0 & 100 & 0 \\
\hline
\end{tabular}


Table 3. Differences in gene expression in brown bullhead and largemouth bass with various histological conditions. In brown bullhead, glucokinase activity was decreased in fish with liver neoplasia and altered foci. In largemouth bass, hepcidin 2 and epidermal growth factor receptor both had decreased activity in fish with bile duct proliferation. Also in largemouth bass, arginase had decreased activity in fish with macrophage aggregate prevalence of 4 when compared to those with a prevalence of 1 and Glucokinase was increased in fish with a parasite prevalence of 3 when compared to those with a prevalence of 2 .

\begin{tabular}{|l|l|r|}
\hline \multicolumn{1}{|c|}{ Species } & \multicolumn{1}{|c|}{ Gene } & Fold Change \\
\hline \multicolumn{3}{|c|}{ Liver Neoplasia } \\
\hline Brown Bullhead & Glucokinase & -2.01 \\
\hline \multicolumn{3}{|c|}{ Biled Foci } \\
\hline Brown Bullhead & Glucokinase & -1.57 \\
\hline \multicolumn{3}{|c|}{ Mepcidin 2 Proliferation } \\
\hline \multirow{2}{*}{ Largemouth Bass } & Epidermal Growth Factor Receptor \\
\hline \multicolumn{2}{|c|}{ Parasite Prevalence (3 vs 2) } \\
\hline Largemouth Bass & Arginase \\
\hline \multicolumn{3}{|c|}{-4.87} \\
\hline Largemouth Bass & Glucokinase \\
\hline
\end{tabular}


Supplemental Table 1. Genes of interest for largemouth bass and brown bullhead $*$ denotes gene below detection limit

\begin{tabular}{|c|c|}
\hline Micropterus salmoides & Ameiurus nebulosus \\
\hline \multicolumn{2}{|c|}{ Gene Name } \\
\hline $03 \beta$ Hydroxysteroid Dehydrogenase (3ßHD)* & $03 \beta$ Hydroxysteroid Dehydrogenase (3ßHD) \\
\hline $17 \beta$ Hydroxysteroid Dehydrogenase (17 $\beta \mathrm{HD})$ & $17 \beta$ Hydroxysteroid Dehydrogenase (17 $\beta \mathrm{HD})$ \\
\hline $\operatorname{Actin} \beta(\beta \mathrm{ACT})$ & Androgen Receptor (AR) \\
\hline Androgen Receptor $\beta(\mathrm{AR} \beta)$ & Apolipoprotein A1 (APA1)* \\
\hline Apolipoprotein A1 (APA1) & Arginase (ARG) \\
\hline Arginase (ARG) & Aryl Hyrdrocarbon Receptor (AHR) \\
\hline Aryl Hyrdrocarbon Receptor (AHR) & Catalase (CAT) \\
\hline Catalase (CAT) & Catenin $\beta$ ( $\beta \mathrm{CAT})$ \\
\hline Catenin $\beta(\beta C A T)$ & CYP17* \\
\hline Choriogenin (CHG) & CYP19A1A (Aromatase)* \\
\hline CYP17* & CYP1A \\
\hline CYP19A1A (Aromatase)* & CYP3A \\
\hline CYP1A & Cytochrome C Oxidase (COI) \\
\hline CYP3A & Elongation Factor $1 \alpha(\mathrm{EF} 1 \mathrm{a})$ \\
\hline Cystenin-Rich Protein (CRP)* & Epidermal Growth Factor Receptor (EGFR) \\
\hline Elongation Factor $1 \alpha($ EF1a) & Epoxide Hydrolase $(\mathrm{EH})$ \\
\hline Epidermal Growth Factor Receptor (EGFR) & Estrogen Receptors $\alpha(E R \alpha)$ \\
\hline Epoxide Hydrolase 1 (EH1) & Estrogen Receptors $\beta 1(\mathrm{ER} \beta)$ \\
\hline Estrogen Receptors $\alpha(\mathrm{ER} \alpha)^{*}$ & $\begin{array}{l}\text { Eukaryotic Translation Initiation Factor 3D } \\
\text { (ETIF3D) }\end{array}$ \\
\hline Estrogen Receptors $\beta 1$ (ER $\beta 1)$ & Ferritin $($ FRT)* \\
\hline Estrogen Receptors $\beta 2$ (ER $\beta 2)$ & Fibroblast Growth Factor (FGF) \\
\hline $\begin{array}{l}\text { Eukaryotic Translation Initation Factor 3D } \\
\text { (ETIF3D) }\end{array}$ & Follicle Stimulating Hormone Receptor (FSHR)* \\
\hline Ferritin $(\mathrm{FRT}) *$ & Glutathione S-Transferase (GST) \\
\hline Fibroblast Growth Factor (FGF)* & Glucocorticoid Receptor (GR) \\
\hline Follicle Stimulating Hormone Receptor (FSHR)* & Glucokinase (GLK) \\
\hline Glucocorticoid Receptor (GR) & Glutathione Peroxidase (GPX4) \\
\hline Glucokinase (GLK) & Granulin 1 (GRN1) \\
\hline Glutathione Peroxidase 1 (GPX1) & Granulin Precursor b (GRNb) \\
\hline Glutathione S-Transferase (GST) & Heat Shock Proteins 70 (HSP70) \\
\hline Heat Shock Proteins 70 (HSP70) & Heat Shock Proteins 90 (HSP90) \\
\hline Heat Shock Proteins 71 (HSP71) & Hepcidin (HEP) \\
\hline Heat Shock Proteins $90 \beta$ (HSP90 $\beta$ ) & $\begin{array}{l}\text { Hypoxanthine Phosphoribosyltransferase } 1 \\
\text { (HPRT1)* }\end{array}$ \\
\hline Hepcidins 1 (HEP1)* & Hypoxia-inducible factor (HIF) \\
\hline Hepcidins 2 (HEP2) & Insulin-Like Growth Factor (IGF)* \\
\hline $\begin{array}{c}\text { Hypoxanthine Phosphoribosyltransferase } 1 \\
\text { (HPRT1) }\end{array}$ & Interferon (IFN) \\
\hline
\end{tabular}




\begin{tabular}{|c|c|}
\hline Insulin-like Growth Factor 1 (IGF1) & Interleukin (IL)* \\
\hline Metallothionein (MT) & MYXO Parasite (MYXO) \\
\hline Phosphoenolpyruvate Carboxykinase (PEPCK) & Peroxisome proliferator-activated receptor (PPAR) \\
\hline RNA binding motif protein X-linked 2 (RBMX2) & Proliferating cell nuclear antigen (PCNA) \\
\hline Ribosomal Protein L8 (RPL8) & RNA binding motif protein X-linked 2 (RBMX2) \\
\hline Superoxide Dismutase (SOD) & Ribosomal Protein L8 (RPL8) \\
\hline Tata Box Binding Protein (TBP) & Transforming Growth Factor $\beta 1$ (TGF $\beta 1)$ \\
\hline Transforming Growth Factor $\beta$ Receptor 1 & Thyroid Hormone Receptor $\alpha$ (THR $\alpha)^{*}$ \\
\hline Transforming Growth Factor $\beta$ (TGF $\beta$ ) & Thyroid Hormone Receptor $\beta$ (THR $\beta)^{*}$ \\
\hline Thyroid Hormone Receptor $\beta($ THR $\beta$ ) & Tumor Protein p73 (TP73)* \\
\hline Thyroid Hormone Receptor $\alpha(\text { THR } \alpha)^{*}$ & Superoxide Dismutase (SOD) \\
\hline Type I Deiodinase (DIO1) & v-K-ras \\
\hline Type II Deiodinase (DIO2) & Vitellogenin (VTG) \\
\hline Vitellogenin (VTG) & Warm Temperature Acclimation Protein 65 \\
\hline (WAP65)
\end{tabular}




\title{
Chapter Four: Effects of environmentally relevant concentrations of tonalide (AHTN) on genotoxic and gene expression biomarkers in brown bullhead (Ameiurus nebulosus)
}

\begin{abstract}
The increasing common use of synthetic musks, including Tonalide (AHTN), in personal care products has resulted in the release of these compounds into aquatic ecosystems. Despite the widespread detection of AHTN, little is known with regards to its potential biological impacts on resident aquatic species. The objectives of this study were to determine the potential of AHTN to alter gene expression and genotoxic endpoints in the brown bullhead, a resident, benthic species commonly used in contaminant monitoring in environments where AHTN is present. Brown bullhead were exposed to either $30 \mu \mathrm{g}$ or $3 \mathrm{ng} / \mathrm{g}$ body weight AHTN by intraperitoneal injection and sampled after 24, 48 and 96 hours. No statistically significant changes in gene expression were identified related to dose of AHTN received. Modulated gene expression was identified in 19 genes in fish receiving the low dose between sampling times 24 and 48. Micronuclei were not observed in any treatment group at any time however, statistically significant differences in nuclear abnormalities both within and among treatment groups were observed. The induction of genes associated with reproduction, oxidative stress and innate immune responses suggests the ability of AHTN to induce damage to a multitude of physiological functions in exposed aquatic species. Further investigation of potential biological effects of synthetic musks is advised to determine both short and long term consequences of exposure on resident aquatic species.
\end{abstract}




\section{Introduction}

Synthetic polycyclic musks, including 7-acetyl-1,1,3,4,4,5-hexamethyl-1,2,3,4-

tetrohydronapthalene (AHTN, trade name Tonalide) are widely used to scent a range of personal care products (PCPs) such as soaps, detergents, cosmetics and creams. Originally introduced in the 1950s as an economical substitute for natural musk fragrances, they have become increasingly common with an estimated production rate of 8,000 tons/year in 1996 (Gatermann et al. 2002). Products utilizing AHTN are largely designed for external application and therefore the compound does not undergo metabolic transformation commonly associated with integrated PCPS. Consequently it may enter the environment essentially unchanged (Ternes et al. 2004). In general, PCPs are often those which are washed down household drains and reach aquatic systems mainly via the effluent of wastewater facilities that are not designed to completely remove them during the treatment processes (Salvito et al. 2004). These factors have resulted in this wide distribution of the compound.

Tonalide is lipophilic, allowing for its bioaccumulation in aquatic organisms including fish species (Reiner and Kannan 2011), fresh water mussels (Parolini et al. 2015), wildlife and humans (Kannan et al. 2005) and raising concern regarding its potential toxic effects. These factors have promoted an increased amount of research on the biological effects of AHTN to aquatic organisms. In teleosts, gene expression responses to AHTN exposure have reported both estrogenic (Yamauchi et al. 2008) and anti-estrogenic (Schreurs et al. 2004) gene regulation as well up-regulation of innate immune response genes (Randelli et al. 2011). These results indicate the capacity of this compound to elicit endocrine disrupting and other effects; however the use of model species (zebrafish, Danio rerio and medaka, Oryzias latipes) may not directly simulate effects experienced by resident, wild populations in watersheds where AHTN exposure is 
ubiquitous. Research on environmentally relevant concentrations of AHTN on non-model fish species is necessary to accurately address the risks of AHTN exposure in wild populations and develop regulatory standards for its release into the environment.

Brown bullhead (Amerius nebulosus) are a widely distributed, benthic species which have been used extensively as an indicator species in contaminant monitoring studies (Baumann et al. 1996; Blazer et al. 2009; Pinkney et al. 2011; Rafferty et al. 2009). AHTN has been previously identified in the tissue of brown bullhead collected from two designated Areas of Concern (AOCs) in the Great Lakes region; Hamilton Harbour (Ontario, CA) and the Detroit River (Detroit, MI) (O'Toole and Metcalfe 2006). A recent reconnaissance study on the health of wild caught fishes, reported higher prevalence of skin neoplasms and tumors, as well as liver tumors, in bullhead at selected AOCs relative to reference locations (Blazer et al. 2014). Concurrent water quality monitoring of these AOCs, reported the presence of AHTN at several locations (Lee et al. 2012). The objectives of this study were to monitor changes in genotoxic and gene expression biomarkers following a short term exposure to AHTN in a controlled laboratory environment in an effort to assess its role in adverse health effects including, tumor promotion and endocrine disruption, in wild caught fishes.

\section{Materials and Methods}

\section{Fish maintenance}

During late October of 2013, 86 juvenile brown bullhead were collected from outdoor research ponds at the National Fish Health Research Laboratory (Leetown, WV). Fish were moved indoors and held in a flow through system at approximately $12^{\circ} \mathrm{C}$ for 5 months under local natural photoperiod. During March of 2014, 12 fish were randomly stocked into each of 
six black circular tanks. Fish were maintained according to approved Animal and Care Safety protocols (USGS, Leetown Science Center).

\section{AHTN exposure}

To investigate the effects of exposure to AHTN on genotoxic and gene expression endpoints, brown bullhead were exposed to a single concentration dose of AHTN by intraperitoneal injection. The low concentration selected was similar to average body burden concentrations of AHTN previously reported in wild caught brown bullhead (O'Toole and Metcalfe 2006). Brown bullheads were anesthetized in $100 \mathrm{ppm}$ tricaine methanesulfonated (MS-222; Finquel; Argent Laboratories, Redmond, WA) and replicate tanks received an intraperitoneal injection (i.p.) of either $30 \mu \mathrm{g}$ or $3 \mathrm{ng} / \mathrm{g}$ body weight of AHTN (Tonalide, purity 97\%, lot no. sc-208446, Santa Cruz Biotechnology, Inc, Dallas, TX) or $100 \mu 1$ vehicle control (corn oil). At this time, four fish were euthanized in approximately $250 \mathrm{ppm}$ tricane methanesulfonate, to control for any effects resulting from i.p. injection alone. All other fish were maintained for a total of 96 hours without feeding. Four fish per replicate tank were then sampled at 24, 48, and 96 hours.

All fish were euthanized in approximately $250 \mathrm{ppm}$ tricaine methanesulfonate and length and weight were recorded (Table 1). Fish were bled via the caudal vein with heparinized capillary tubes (Chase Instruments Corp, Glen Falls, NY). One drop of blood was placed onto each of two pre-cleaned glass slides and blood smears prepared and allowed to dry. Slides were fixed with absolute methanol for 10 minutes within four hours of preparation on slides. Small pieces of liver tissue were removed from each fish and preserved in RNAlater ${ }^{\circledR}$ (Life Technologies, Grand Island, NY) for molecular analysis. 
Gene expression analysis

Approximately $20 \mathrm{mg}$ of liver tissue was combined with $400 \mu \mathrm{l}$ of TRK lysis buffer (Omega Biotech, Norcross, GA) by 5mm stainless steel balls (Boca Bearings, Boynton Beach, FL) in a tissue lyser (Qiagen, Valencia, CA) at $30 \mathrm{Hx}$ for 8 minutes. Lysate was centrifuged at $13,000 \mathrm{G}$ for 10 minutes. Clarified lysate was then stored at $-80^{\circ} \mathrm{C}$ and shipped to the University of Pittsburgh, Genomic and Proteomics Core Laboratory for nCounter ${ }^{\circledR}$ analysis. A custom codeset containing 50 genes of interest (Table 2) was synthesized by Nanostring Technologies (Seattle, WA) for use in this analysis. Genes of interest were those with suspected modulation in response to endocrine disruption, environmental stressors, tumor promotion and innate immune function. Codesets were utilized in the nCounter analysis system workflow as per the manufacturer and core laboratory protocols. Files generated during analysis were utilized for quantitative interrogation.

We used nSolver Analysis Software (v2.0) for quality control of gene expression data. One negative control with high average count value (9.1) was removed. We then subtracted the geometric mean plus three standard deviations of negative controls from each sample to account for background signal. Genes with expression data falling below the mean plus three standard deviations of the negative control were eliminated from subsequent analysis (Table 2). Next, the average geometric mean of positive spike-in RNA control samples across all lanes was used to calculate a scaling factor which was applied to all samples. Finally, count data for each gene was normalized by tissue mass.

\section{Micronuclei and nuclear abnormalities}

Slides were stained in Giemsa solution (Fluka Analytical, Saint Louis, MO), 1:12:2 $(\mathrm{w} / \mathrm{w} / \mathrm{w})$ in glycerol/methanol 5:24 (v/v)) for 45 minutes. They were then rinsed sequentially in 
deionized $\mathrm{H}_{2} \mathrm{O}$ for 45 minutes each. Stained slides were cover-slipped and evaluated via light microscopy at 600x magnification. A minimum of 200 erythrocytes were scored in each of five random stratified locations on each slide such that a minimum of 1000 erythrocytes were evaluated for abnormalities.

Nuclear abnormalities were determined as defined by Carrasco et al. (1990). Briefly, a micronucleus is a round cytoplasmic inclusion having a diameter one-tenth to one-third that of the primary nucleus. Notched nuclei have a distinct slit that extends into the nuclear envelope. Lobed nuclei have large evaginations of the nuclear envelope that have no clear shape or definition. Blebbed nuclei have small evaginations of the nuclear envelope that can resemble a micronucleus, however are attached by a small threadlike stalk. A binucleated cell contains two nuclei that are relatively similar in size and not attached by a stalk. Data are presented as the percentage of fish with micronuclei (MN) or other nuclear abnormalities (NAs, a sum of all other abnormalities). Occurrence was defined as the percentage of fish in each treatment group with NA. Severity was defined as the total number of NAs/total cells for all fish and again for only those fish with NAs present.

\section{Statistical analysis}

All data were initially examined for differences between replicate tanks using the Wilcoxon-Mann-Whitney test. No statistically significant differences were found and subsequent data were analyzed and reported for combined tanks within each treatment group. Multiple Experiment Viewer (v4.8) was used to estimate significance differences in gene expression among samples. A Kruskal-Wallis test, followed by a Wilcoxon rank sum post hoctest with Benjamini-Hochberg correction was performed to identify genes with statistically significant differences between sample times and treatment groups. Similarly, a Kruskal-Wallis 
test, followed by Wilcoxon rank sum post-hoc test, was performed using the $\mathrm{R}$ statistical package (R Development Core Team 2010) to determine statistically significant differences for MN/NA prevalence and severity rates between treatment groups and sampling times. For all tests significance was determined at $\alpha=0.05$.

\section{Results}

\section{Gene expression}

We investigated the effects of exposure to two concentrations of AHTN on gene expression over 96 hours. A high amount of variability in expression was observed between and within treatment groups (Figure 2). Statistically significant changes in gene expression were not identified between fish which received the control injection (corn oil) and those sampled before being administered any type of i.p. injection. No statistically significant gene expression changes occurred between low and high dose fish and controls. Between times 24 and 48 statistically significant modulation of 19 genes occurred in fish receiving the low dose (Figure 3 , Table 3). No other statistically significant gene expression modulation related to time of exposure was found.

\section{Micronucleus assay}

MN were not observed in any treatment group at any time, however statistically significant differences in NAs both within and among treatment groups was observed. The nuclear abnormalities observed were "notched", "lobed", and "blebbed" (Figure 1). No significant differences were seen in the occurrence or severity of NAs in fish of the control group between sampling times (Figure 4). Significantly higher occurrence and severity of NAs was observed in fish receiving the low doses between times 48 and 96 relative to those sampled at 24 
hours. In fish receiving the high dose, significantly higher occurrence was observed after 48 as compared to fish sampled after 96 hours (Figure 5).

After 24 hours, significantly higher occurrence and severity of NA were reported in fish receiving the high dose relative to control and low treatment groups. There was no difference in the low dose fish as compared to control fish. After 48 hours, occurrence and severity significantly higher in both the low and high dose fish relative to the control. After 96 hours, only the low dose occurrence was significantly higher than the control group. This pattern was not observed in the severity of NA.

\section{Discussion}

\section{Gene expression}

AHTN and other polycyclic musks have become ubiquitous in watersheds receiving wastewater effluent (Lee et al. 2012). Despite the distribution of AHTN, little information is available regarding its potential detrimental effects on resident, wild species of contaminated aquatic environments. Previous studies of the biological effects and risks of AHTN in model fish species have demonstrated the ability of AHTN to induce gene expression responses both in vitro (Randelli et al. 2011; Torre et al. 2011) and in vivo (Yamaguchi et al. 2005). We were unable to find induction of hepatic mRNA in brown bullhead related dose of AHTN received however, differences were noted in the expression of 19 genes in fish receiving the low dose between sampling times of 0, 24 and 48 hours. In all cases, these genes are up-regulated at time 24 relative to time 48 (Figure 3). Curiously, we do not see statistically significant differences between control fish and those receiving the low dose; however the data indicates an upregulation of these same 19 genes between fish of these groups. In addition, in all but one gene 
glutathione peroxidase 4 (GPX4), up-regulation was identified between low dose fish sampled after 24 hours relative to time 0 fish which did not receive any type of i.p. injection (Figure 3). Great variability in the response of individual fish from each treatment group was identified and likely contributes to this lack of statistical significance (Figure 2). The data suggests that modulation of these genes occurred rapidly ( $>24$ hours post injection) therefore, our sample scheme may not include the initial response (Figure 3). Consequently, future investigations should consider sampling closer to injection time and more frequently in an effort to identify the length of time between exposure to AHTN and initial response.

Although dose effect responses were not observed, several of the genes with modulated response over time corroborated existing information on the potential biological effects of AHTN as an endocrine disrupting compound. Estrogen receptors alpha and beta (ER $\alpha$ and ER $\beta$ ) were among the genes exhibiting up-regulation. Previously, AHTN has demonstrated weakly agonistic properties on human ER $\alpha$ in vitro (Mori et al. 2007; Seinen et al. 1999). Information regarding the estrogenic effects of synthetic musks in vivo are far more limited however, induction of ER $\alpha$ and vitellogenin (VTG), an egg yolk precursor protein commonly used as a biomarker of exposure to estrogenic compounds in males, has been previously identified in the liver of juvenile male medaka exposed to AHTN (Yamauchi et al. 2008). In the present study, we do not see effects of either concentration of AHTN on VTG. Up-regulation of ER $\beta$ occurred contradictory to previous findings by Yamauchi et al. (2008) in which ER $\beta$ expression remained constant. In environmental studies, expression of hepatic VTG is not typically detected in brown bullhead even when collected from areas where AHTN is known to be ubiquitous and other endocrine disrupting compounds have been detected. Generally, ER $\beta$ differs from ER $\alpha$ in its response to both natural and synthetic estrogens (Paech et al. 1997; Sabo-Attwood et al. 2004) 
however, induction of ER $\beta$ in response to environmental estrogens has been identified (Palermo et al. 2012). Though induction of VTG did not occur in the present study, the induction of both estrogen receptors further suggests AHTN as an endocrine disruptor in aquatic environments.

Several genes with known modulation in gene expression in response to environmental and oxidative stress were identified. Oxidative stress occurs when the balance between the reactive oxygen species (ROS) and the ability of an organism to detoxify reactive intermediates and/or repair the resulting damage is interrupted and can occur as the result of exposure to environmental influences such as pathogens or xenobiotics. In the present study, we identified seven genes including aryl hydrocarbon receptor (AHR), hypoxia-inducible factor (HIF), heat shock protein 70 (HSP70), superoxide dismutase (SOD), glucocorticoid receptor (GR), peroxisome proliferator-activated receptors (PPAR) and GPX4 which appear to be altered by AHTN. The genes identified as modulated in this study are also affected by a variety of contaminants including benzo(a)pyrene (BaP) (Yu et al. 2008), polycyclic aromatic hydrocarbons (PAHs) (Vijayan et al. 1998), polychlorinated biphenyl (PCBs) (McFarland et al. 1999; Otto and Moon 1996), pesticides (Hassanein et al. 1999; Karaca et al. 2014; OrtizZarragoitia and Cajaraville 2005), endocrine disrupting compounds (Cocci et al. 2013; SaboAttwood et al. 2004; Vijayan et al. 2003) and heavy metals (Airaksinen et al. 2003; Heikkila et al. 1982; Liu et al. 2015; Sanders et al. 1995). The effects of AHTN on many of these gene expression endpoints have not been previously explored. Transcriptional changes of SOD, catalase (CAT) and HSP70 have been established in the earthworm (Eisenia fetida) which identified a bell-shaped response over time which closely resembles the results of the present study (Chen et al. 2011). These findings and the results of the present study indicate the potential of AHTN to induce an oxidative stress response in exposed aquatic species however, 
the large amount of variability in the response of these markers should be consider only as a warning sign of potential harmful effects of AHTN and additional evaluation of this response should be conducted.

A subset of genes chosen by this study for use in the assessment of the effects of AHTN, were those which had been previously identified or suspected of involvement in innate immune response and/or dysregulation during tumor promotion and development. Nine of these genes were among those with statistically significant up-regulation between sampling times 24 and 48 in fish receiving the low dose. To our knowledge, only one gene, transforming growth factor beta (TGFß), has previously shown up-regulation in response to AHTN in vitro in fish species (Randelli et al. 2011) and mice (Shi et al. 2013). All other genes, have not be assessed for response to AHTN in aquatic species however, tumor protein p53 (p53), kirsten rat sarcoma viral oncogene homolog (V-Ki-ras), fibroblast growth factor (FGF), epidermal growth factor receptor (EGFR), granulin 1 (GRN1), granulin b (GRNB) and proliferation cell nuclear antigen (PCNA) have all been previously associated with pre-neoplastic or neoplastic changes (Bateman and Bennett 1998; Fogarty et al. 2007; Karnoub and Weinberg 2008; Machado et al. 2014; Turner and Grose 2010) while beta-catenin ( $\beta$-CAT) has been linked to liver development and regeneration (Goessling et al. 2008). The up-regulation of these genes in the liver of BBH exposed to AHTN demonstrates the potential of this compound in the promotion of liver neoplasia. Our chosen species frequently experiences liver and skin neoplasia which is often attributed to contaminant exposure (Pinkney et al. 2009, Baumann et al. 1996). The modulation of these genes may therefore be considered a warning sign of the potential of AHTN to disrupt normal cellular functions in these aquatic species and should be considered for further 
investigation as both an individual compound and as a part of complex chemical mixtures often found in aquatic environments.

\section{Micronucleus assay}

Damage to genetic information can be caused by a number of factors including ROS induced by contaminant exposure. To determine the genotoxicity of AHTN, the micronucleus test (MNT) was employed. No micronuclei were identified in any BBH in the present study however, significant changes in the presence and severity, of nuclear abnormalities were detected. The MNT has previously been used to assess the genotoxcity of AHTN with similar results. In vitro tests of the human lymphocytes and the human hepatoma cell line Hep G2 as well as in vivo tests in mice and zebra mussel (Dreissena polymorpha) have all indicated a lack of genotoxicity following exposure to AHTN (Abramsson-Zetterberg and Slanina 2002;

Kevekordes et al. 1997; Parolini et al. 2015). Though genetic damage has not been identified by the MNT, other biomarkers including the DNA precipitation assay have indicate the potential of AHTN to cause genetic damage (Parolini et al. 2015). In the present study, the identification of nuclear abnormalities which were significantly higher in fish exposed to AHTN provides evidence for the mutagenic ability of this compound. The mechanisms by which nuclear abnormalities form has not been fully explained but a number of studies have indicated that nuclear abnormalities are induced in response to exposure to genotoxic compounds (Ayllon and Garcia-Vazquez 2000; Baršienė et al. 2006; Ergene et al. 2007). After 24 hours, significant changes in the presence of nuclear abnormalities relative to control fish were identified in fish receiving the low dose only. After 48 hours, nuclear abnormalities in both high and low dose fish were significantly different from controls. Finally, after 96 hours, statistically significant differences remained in only those fish receiving the high dose. This bell-shaped response over 
time is similar to the results of gene expression analyses for antioxidant and oxidative stress response biomarkers SOD, CAT and HSP70 and suggests the ability of AHTN to induce mutagenic damage by ROS.

\section{Conclusion}

The present study suggests the ability of synthetic musks, including AHTN, to induce a range of responses including the induction of estrogen receptors and genes involved in both oxidative stress and innate immune responses. The presence of nuclear abnormalities further corroborates the ability of AHTN to induce mutagenic damage by ROS. The ubiquitous detection of AHTN in geographically disperse watersheds (Lee et al. 2012) and the previous identification of AHTN in the tissue of resident species (O'Toole and Metcalfe 2006) insinuates a similar response in wild fishes and other aquatic organisms inhabiting these areas. Further investigation are required to understand both short and long term effects of exposure to synthetic musks in these ecosystems.

\section{References}

Abramsson-Zetterberg L, Slanina P. 2002. Macrocyclic musk compounds-an absence of genotoxicity in the Ames test and the in vivo Micronucleus assay. Toxicology Letters 135(1-2):155-163.

Airaksinen S, Rabergh CM, Lahti A, Kaatrasalo A, Sistonen L, Nikinmaa M. 2003. Stressordependent regulation of the heat shock response in zebrafish, Danio rerio. Comp Biochem Physiol A Mol Integr Physiol 134(4):839-46.

Ayllon F, Garcia-Vazquez E. 2000. Induction of micronuclei and other nuclear abnormalities in European minnow Phoxinus phoxinus and mollie Poecilia latipinna: an assessment of the fish micronucleus test. Mutation Research/Genetic Toxicology and Environmental Mutagenesis 467(2):177-186.

Baršienė J, Dedonytė V, Rybakovas A, Andreikènaitė L, Andersen OK. 2006. Investigation of micronuclei and other nuclear abnormalities in peripheral blood and kidney of marine fish treated with crude oil. Aquatic Toxicology 78, Supplement:S99-S104. 
Bateman A, Bennett HP. 1998. Granulins: the structure and function of an emerging family of growth factors. J Endocrinol 158(2):145-51.

Baumann PC, Smith IR, Metcalfe CD. 1996. Linkages between chemical contaminants and tumors in benthic Great Lakes fish. Journal of Great Lakes Research 22(2):131-152.

Blazer VS, Mazik PM, Iwanowicz LR, Braham RP, Hahn CM, Walsh HL, Sperry AJ. 2014. Assessment of the fish tumor beneficial use impairment in brown bullhead (Ameiurus nebulosus) at selected Great Lakes Areas of Concern. Reston, VA: U.S. Geological Survey. p 28.

Blazer VS, Rafferty SD, Baumman PC, Smith SB, Obert EC. 2009. Assessment of the "fish tumors or other deformities" beneficial use impairment in brown bullhead (Ameiurus nebulosus): I. Orocutaneous tumors. Journal of Great Lakes Research 35(4):517-526.

Carrasco KR, Tilbury KL, Myers MS. 1990. Assessment of the Piscine Micronucleus Teset as an insitu biological indicator of chemical contaminants effects. Canadian Journal of Fisheries Science 47:2123-2136.

Chen C, Zhou Q, Liu S, Xiu Z. 2011. Acute toxicity, biochemical and gene expression responses of the earthworm Eisenia fetida exposed to polycyclic musks. Chemosphere 83(8):114754.

Cocci P, Mosconi G, Palermo FA. 2013. Effects of 4-nonylphenol on hepatic gene expression of peroxisome proliferator-activated receptors and cytochrome P450 isoforms (CYP1A1 and CYP3A4) in juvenile sole (Solea solea). Chemosphere 93(6):1176-1181.

Ergene S, Çavaş T, Çelik A, Köleli N, Kaya F, Karahan A. 2007. Monitoring of nuclear abnormalities in peripheral erythrocytes of three fish species from the Goksu Delta (Turkey): genotoxic damage in relation to water pollution. Ecotoxicology 16(4):385-391.

Fogarty GB, Conus NM, Chu J, McArthur G. 2007. Characterization of the expression and activation of the epidermal growth factor receptor in squamous cell carcinoma of the skin. Br J Dermatol 156(1):92-8.

Gatermann R, Biselli S, Huhnerfuss H, Rimkus GG, Hecker M, Karbe L. 2002. Synthetic musks in the environment. Part 1: Species-dependent bioaccumulation of polycyclic and nitro musk fragrances in freshwater fish and mussels. Arch Environ Contam Toxicol 42(4):437-46.

Goessling W, North TE, Lord AM, Ceol C, Lee S, Weidinger G, Bourque C, Strijbosch R, Haramis A-P, Puder M and others. 2008. APC mutant zebrafish uncover a changing temporal requirement for wnt signaling in liver development. Developmental Biology 320(1):161-174. 
Hassanein HMA, Banhawy MA, Soliman FM, Abdel-Rehim SA, Müller WEG, Schröder HC. 1999. Induction of Hsp70 by the Herbicide Oxyfluorfen (Goal) in the Egyptian Nile Fish, Oreochromis niloticus. Archives of Environmental Contamination and Toxicology 37(1):78-84.

Heikkila JJ, Schultz GA, Iatrou K, Gedamu L. 1982. Expression of a set of fish genes following heat or metal ion exposure. J Biol Chem 257(20):12000-5.

Kannan K, Reiner JL, Yun SH, Perrotta EE, Tao L, Johnson-Restrepo B, Rodan BD. 2005. Polycyclic musk compounds in higher trophic level aquatic organisms and humans from the United States. Chemosphere 61(5):693-700.

Karaca M, Varışlı L, Korkmaz K, Özaydın O, Perçin F, Orhan H. 2014. Organochlorine pesticides and antioxidant enzymes are inversely correlated with liver enzyme gene expression in Cyprinus carpio. Toxicology Letters(0).

Karnoub AE, Weinberg RA. 2008. Ras oncogenes: split personalities. Nature reviews. Molecular cell biology 9(7):517.

Kevekordes S, Mersch-Sundermann V, Diez M, Dunkelberg H. 1997. In vitro genotoxicity of polycyclic musk fragrances in the micronucleus test. Mutation Research/Genetic Toxicology and Environmental Mutagenesis 395(2-3):145-150.

Lee KE, Langer SK, Menheer MA, Foreman WT, Furlong ET, Smith SG. 2012. Chemicals of emerging concern in water and bottom sediment in Great Lakes areas of concern, 2010 to 2011-Collection methods, analyses methods, quality assurance and data. In: Series UN, editor. Reston, VA: U.S. Geological Survey. p 36.

Liu G-D, Sheng Z, Wang Y-F, Han Y-L, Zhou Y, Zhu J-Q. 2015. Glutathione peroxidase 1 expression, malondialdehyde levels and histological alterations in the liver of Acrossocheilus fasciatus exposed to cadmium chloride. Gene.

Machado SP, Cunha V, Reis-Henriques MA, Ferreira M. 2014. Histopathological lesions, Pglycoprotein and PCNA expression in zebrafish (Danio rerio) liver after a single exposure to diethylnitrosamine. Environmental Toxicology and Pharmacology 38(3):720732.

McFarland VA, Inouye LS, Lutz CH, Jarvis AS, Clarke JU, McCant DD. 1999. Biomarkers of Oxidative Stress and Genotoxicity in Livers of Field-Collected Brown Bullhead, Ameiurus nebulosus. Archives of Environmental Contamination and Toxicology 37(2):236-241.

Mori T, Iida M, Ishibashi H, Kohra S, Takao Y, Takemasa T, Arizono K. 2007. Hormonal activity of polycyclic musks evaluated by reporter gene assay. Environ Sci 14(4):195202. 
O'Toole S, Metcalfe C. 2006. Synthetic Musks in Fish from Urbanized Areas of the Lower Great Lakes, Canada. Journal of Great Lakes Research 32(2):361-369.

Ortiz-Zarragoitia M, Cajaraville MP. 2005. Effects of selected xenoestrogens on liver peroxisomes, vitellogenin levels and spermatogenic cell proliferation in male zebrafish. Comp Biochem and Physiol Part C(141):131-144.

Otto DME, Moon TW. 1996. Phase I and II enzymes and antioxidant responses in different tissues of brown bullheads from relatively polluted and non-polluted systems. Archives of Environmental Contamination and Toxicology 31(1):141-147.

Paech K, Webb P, Kuiper GGJM, Nilsson S, Gustafsson J-A, Kushner PJ, Scanlan TS. 1997. Differential Ligand Activation of Estrogen Receptors ERA and ERB at AP1 Sites. Science 277:1508-1510.

Palermo FA, Cocci P, Angeletti M, Polzonetti-Magni A, Mosconi G. 2012. PCR-ELISA detection of estrogen receptor $\beta$ mRNA expression and plasma vitellogenin induction in juvenile sole (Solea solea) exposed to waterborne 4-nonylphenol. Chemosphere 86(9):919-925.

Parolini M, Magni S, Traversi I, Villa S, Finizio A, Binelli A. 2015. Environmentally relevant concentrations of galaxolide (HHCB) and tonalide (AHTN) induced oxidative and genetic damage in Dreissena polymorpha. Journal of Hazardous Materials 285(0):1-10.

Pinkney AE, Harshbarger JC, Karouna-Renier NK, Jenko K, Balk L, Skarphéðinsdóttir H, Liewenborg B, Rutter MA. 2011. Tumor prevalence and biomarkers of genotoxicity in brown bullhead (Ameiurus nebulosus) in Chesapeake Bay tributaries. Science of The Total Environment 410-411:248-257.

R Development Core Team. 2010. R: A language and environment for statistical computing. Vienna, Austria: R Foundation for Statistical Computing.

Rafferty SD, Blazer VS, Pinkney AE, Grazio JL, Obert EC, Boughton L. 2009. A historical perspective on the "fish tumors or other deformities" beneficial use impairment at Great Lakes Areas of Concern. Journal of Great Lakes Research 35(4):496-506.

Randelli E, Rossini V, Corsi I, Focardi S, Fausto AM, Buonocore F, Scapigliati G. 2011. Effects of the polycyclic ketone tonalide (AHTN) on some cell viability parameters and transcription of P450 and immunoregulatory genes in rainbow trout RTG-2 cells. Toxicol In Vitro 25(8):1596-602.

Reiner J, Kannan K. 2011. Polycyclic Musks in Water, Sediment, and Fishes from the Upper Hudson River, New York, USA. Water, Air, \& Soil Pollution 214(1-4):335-342. 
Sabo-Attwood T, Kroll KJ, Denslow ND. 2004. Differential expression of largemouth bass (Micropterus salmoides) estrogen receptor isotypes alpha, beta, and gamma by estradiol. Molecular and Cellular Endocrinology 218(1-2):107-118.

Salvito DT, Vey MGH, Senna RJ. 2004. Fragrance materials and their environmental impact. Flavour and Fragrance Journal 19(2):105-108.

Sanders BM, Nguyen J, Martin LS, Howe SR, Coventry S. 1995. Induction and subcellular localization of two major stress proteins in response to copper in the fathead minnow Pimephales promelas. Comp Biochem Physiol C Pharmacol Toxicol Endocrinol 112(3):335-43.

Schreurs RHMM, Legler J, Artola-Garicano E, Sinnige TL, Lanser PH, Seinen W, Van Der Burg B. 2004. In Vitro and in Vivo Antiestrogenic Effects of Polycyclic Musks in Zebrafish. Environmental Science and Technology 38(4):997-1002.

Seinen W, Lemmen JG, Pieters RHH, Verbruggen EMJ, van der Burg B. 1999. AHTN and HHCB show weak estrogenic - but no uterotrophic activity. Toxicology Letters 111(12):161-168.

Shi J, Li M, Jiao Z, Zhang J, Feng Y, Shao B. 2013. Microarray analysis of gene expression in mouse (strain 129) embryonic stem cells after typical synthetic musk exposure. Bull Environ Contam Toxicol 90(1):17-21.

Ternes TA, Joss A, Siegrist H. 2004. Peer Reviewed: Scrutinizing Pharmaceuticals and Personal Care Products in Wastewater Treatment. Environmental Science \& Technology 38(20):392A-399A.

Turner N, Grose R. 2010. Fibroblast growth factor signalling: from development to cancer. Nat Rev Cancer 10(2):116-29.

Vijayan MM, Pereira C, Kruzynski G, Iwama GK. 1998. Sublethal concentrations of contaminant induce the expression of hepatic heat shock protein 70 in two salmonids. Aquatic Toxicology 40(2-3):101-108.

Vijayan MM, Raptis S, Sathiyaa R. 2003. Cortisol treatment affects glucocorticoid receptor and glucocorticoid-responsive genes in the liver of rainbow trout. General and Comparative Endocrinology 132(2):256-263.

Yamaguchi A, Ishibashi H, Kohra S, Arizono K, Tominaga N. 2005. Short-term effects of endocrine-disrupting chemicals on the expression of estrogen-responsive genes in male medaka (Oryzias latipes). Aquat Toxicol 72(3):239-49.

Yamauchi R, Ishibashi H, Hirano M, Mori T, Kim JW, Arizono K. 2008. Effects of synthetic polycyclic musks on estrogen receptor, vitellogenin, pregnane $\mathrm{X}$ receptor, and 
cytochrome P450 3A gene expression in the livers of male medaka (Oryzias latipes). Aquat Toxicol 90(4):261-8.

Yu RMK, Ng PKS, Tan T, Chu DLH, Wu RSS, Kong RYC. 2008. Enhancement of hypoxiainduced gene expression in fish liver by the aryl hydrocarbon receptor (AhR) ligand, benzo[a]pyrene (BaP). Aquatic Toxicology 90(3):235-242. 


\section{Figures}

Figure 1. Erythrocyte abnormalities. A) Notched nucleus (arrow) B) Lobed nucleus (arrow), note the notched nucleus within the partial erythrocyte at the bottom of the pane C) Blebbed nucleus (arrow). All pictures were taken at 600x magnification.

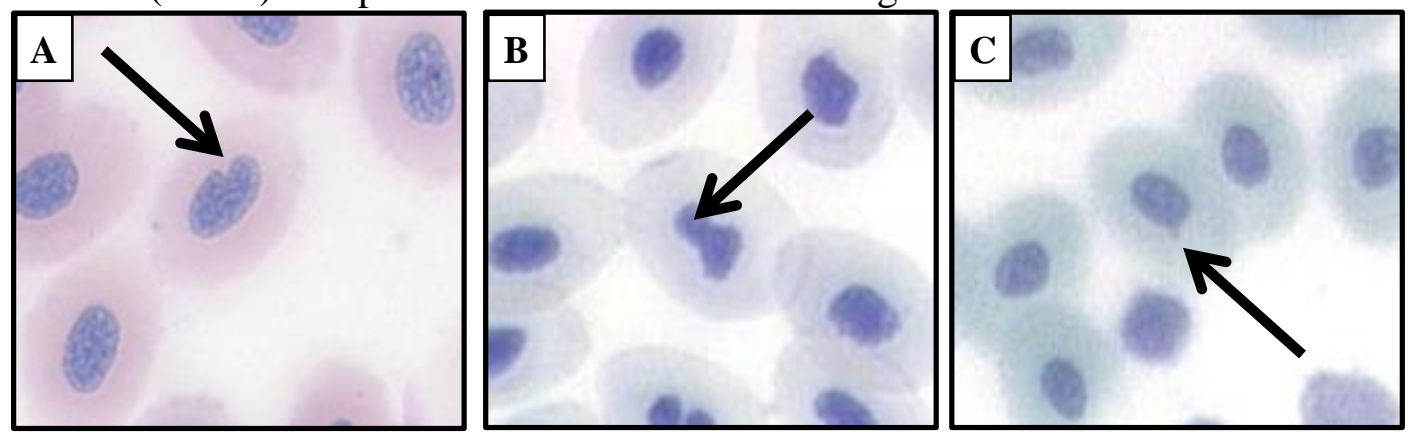


Figure 2. Heat map of all gene expression endpoints across doses and sampling times. Blue boxes represent minimum values in each row while red boxes represent maximum values within each row.

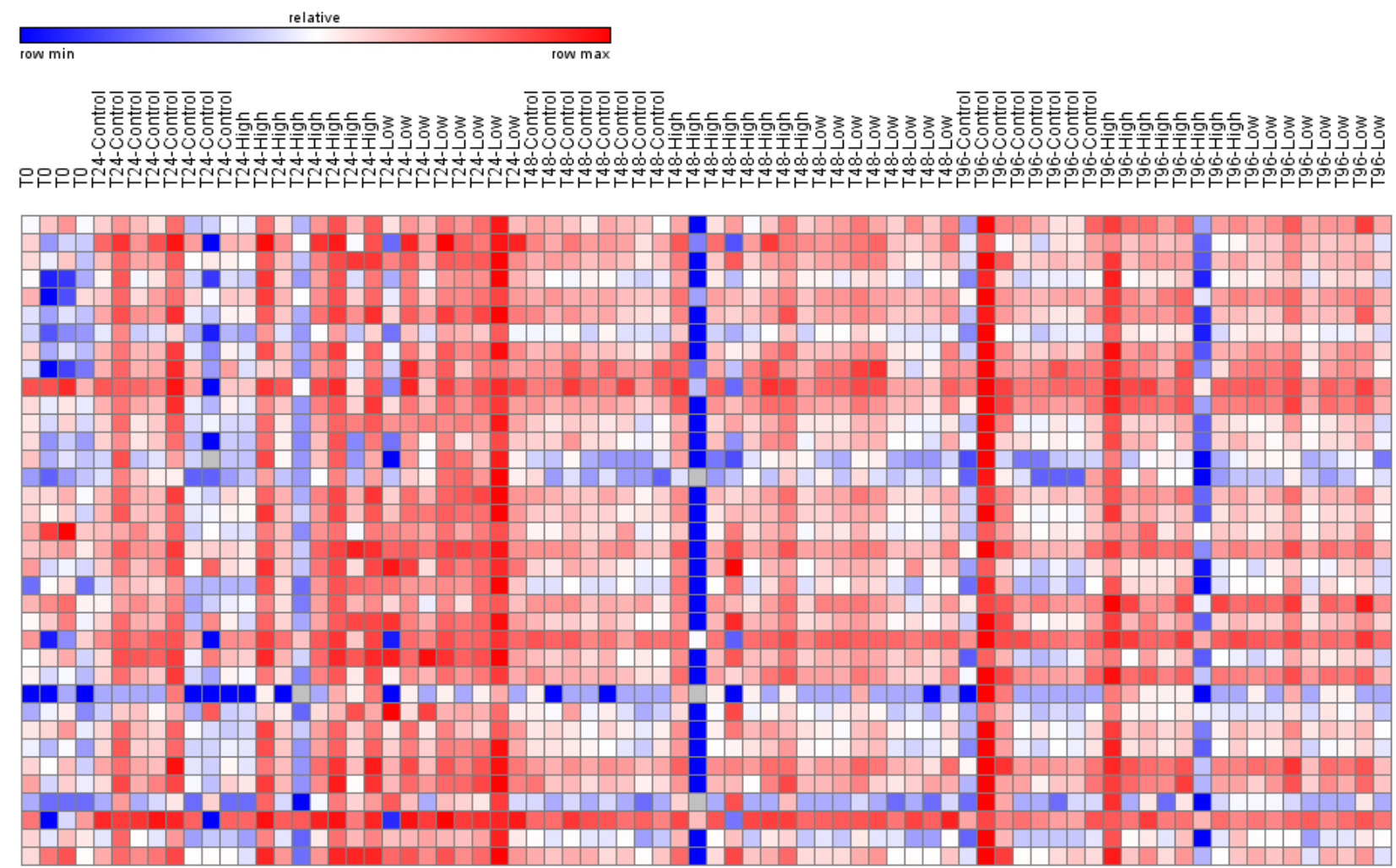

Annotation 
Figure 3. Gene expression endpoints which were identified as significantly different $(p<0.05)$ between sampling times in fish receiving the low dose.

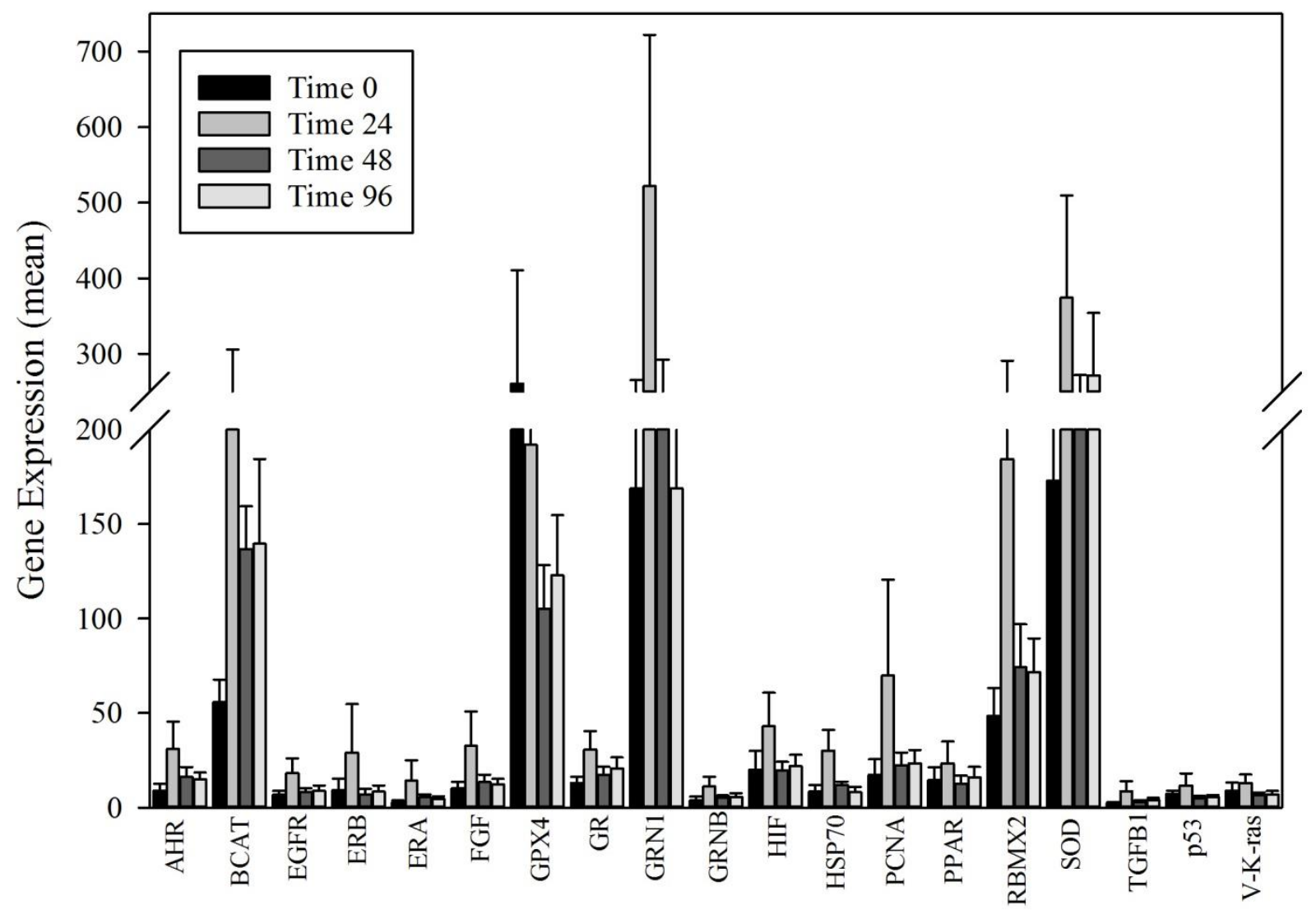


Figure 4. Occurrence of nuclear abnormalities across all time points. D denotes statistically significant differences $(\mathrm{p}<0.05)$ between low or high doses and control fish. T denotes statistically significant differences $(\mathrm{p}<0.05)$ between sampling times within each dose.

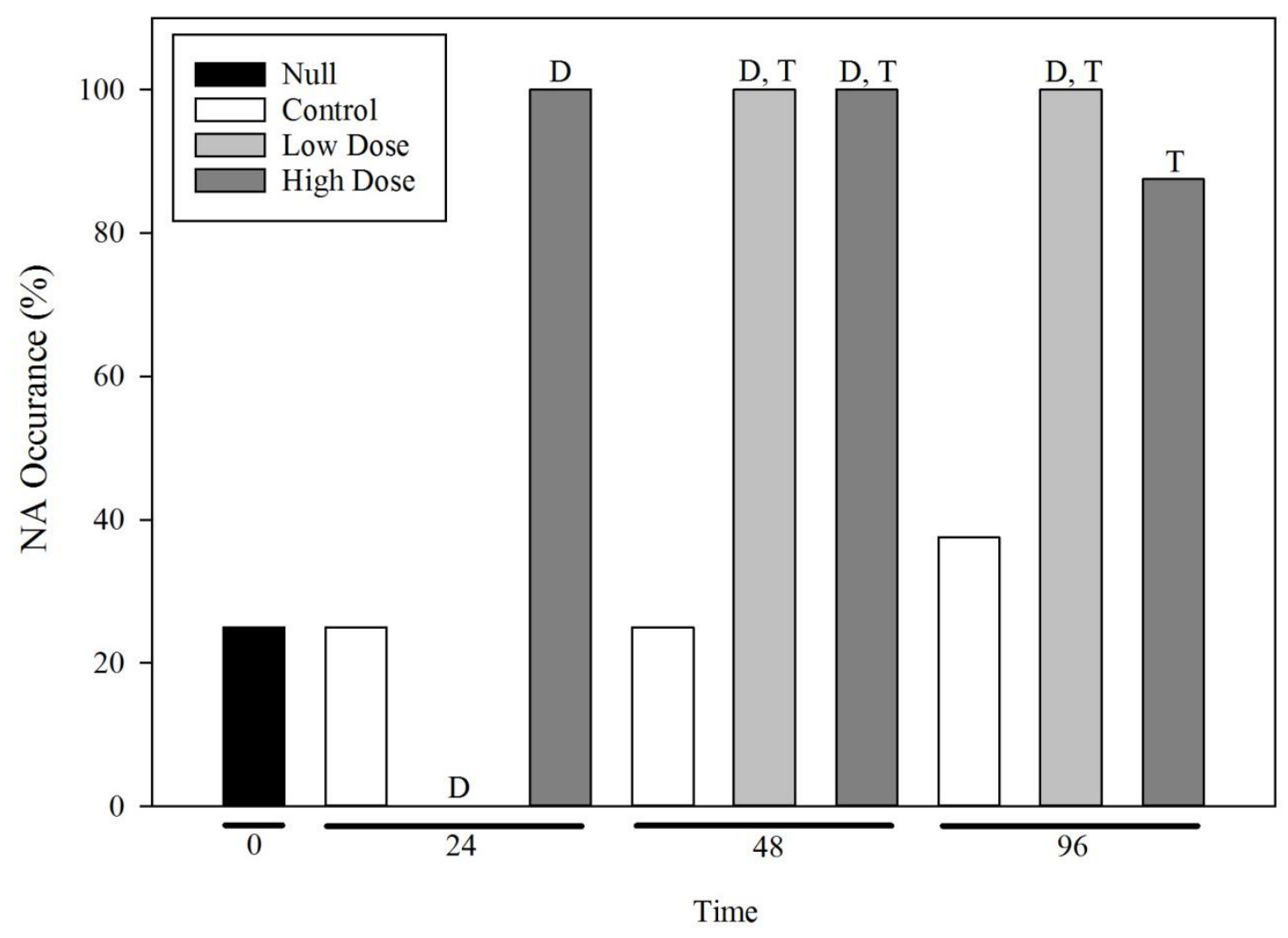


Figure 5. NA Severity of A) all fish and B) only those fish in which NA were detected. D denotes statistically significant differences $(p<0.05)$ between low or high doses and control fish. T denotes statistically significant differences $(\mathrm{p}<0.05)$ between sampling times within each dose.

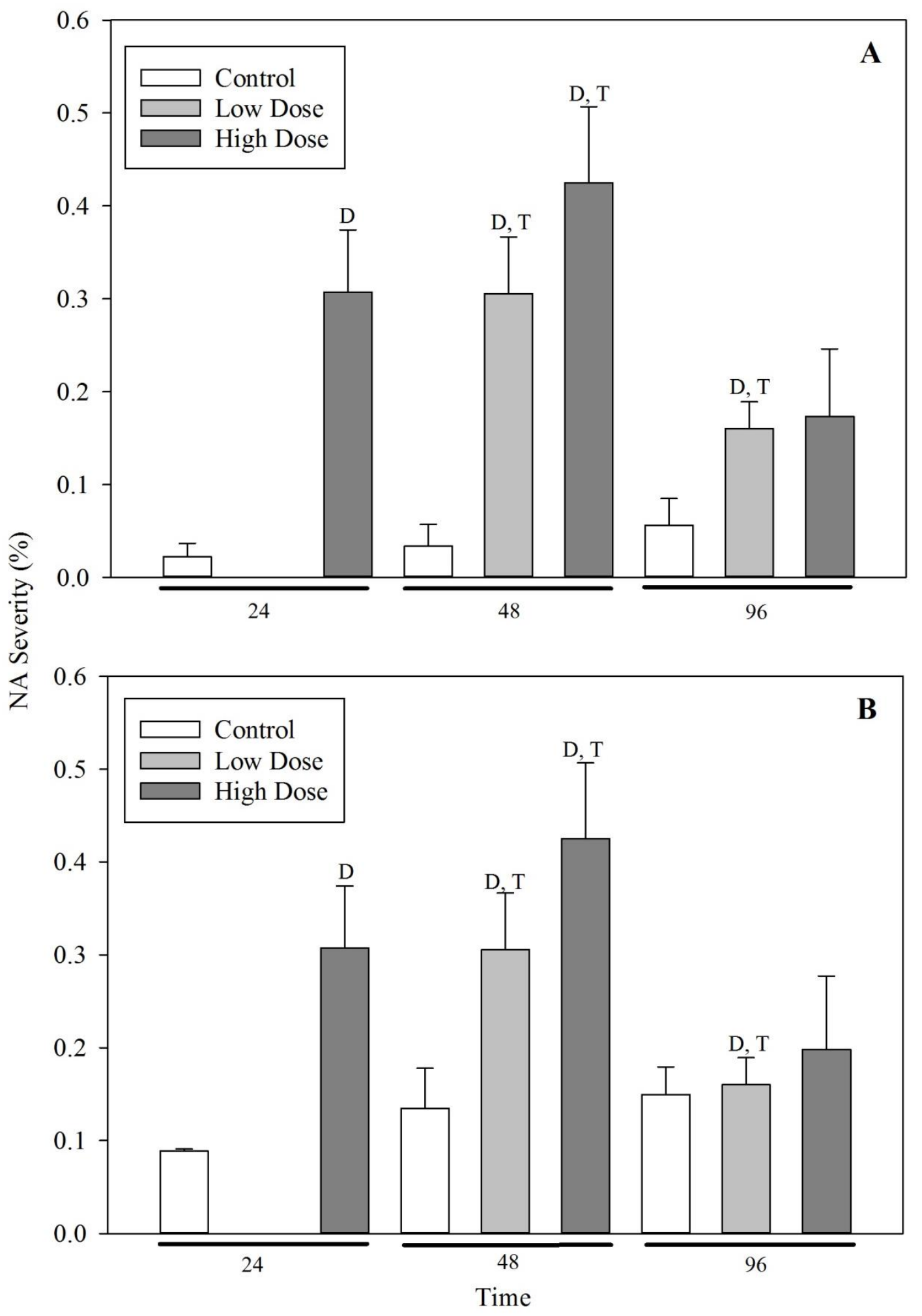


Tables

Table 1. Average length and weight of fish by treatment group.

\begin{tabular}{|c|c|c|c|}
\hline Time & Dose & Weight & Length \\
\hline 0 & Null & $3.69 \pm 0.69$ & $75.25 \pm 6.65$ \\
\hline \multirow{3}{*}{24} & Control & $3.41 \pm 0.95$ & $75 \pm 6.26$ \\
\cline { 2 - 4 } & Low & $3.03 \pm 0.41$ & $70.88 \pm 3.00$ \\
\cline { 2 - 4 } & High & $3.50 \pm 0.48$ & $74.5 \pm 3.59$ \\
\hline \multirow{4}{*}{48} & Control & $2.79 \pm 0.94$ & $69.88 \pm 6.44$ \\
\cline { 2 - 4 } & Low & $2.83 \pm 0.95$ & $69.25 \pm 6.76$ \\
\cline { 2 - 4 } & High & $3.39 \pm 0.77$ & $74.25 \pm 4.50$ \\
\hline \multirow{3}{*}{96} & Control & $3.61 \pm 1.03$ & $75.75 \pm 5.85$ \\
\cline { 2 - 4 } & Low & $3.42 \pm 1.19$ & $74.63 \pm 5.83$ \\
\cline { 2 - 4 } & High & $3.18 \pm 0.89$ & $72.38 \pm 7.17$ \\
\hline
\end{tabular}


Table 2. Gene expression endpoints chosen for analysis with Nanostring nCounter Assay. * denotes housekeeping genes $* *$ denotes gene which fell below the detection limit and were eliminated from analysis

\begin{tabular}{|c|c|c|}
\hline Gene Name and Abbreviation & $\begin{array}{c}\text { Contig or } \\
\text { Accession \# }\end{array}$ & BP Target \\
\hline $03 \beta$ Hydroxysteroid Dehydrogenase (3ßHD) & 5280 & $24-123$ \\
\hline $17 \beta$ Hydroxysteroid Dehydrogenase (17 $\beta \mathrm{HD})$ & 76474 & $164-293$ \\
\hline Androgen Receptor (AR) & 223529 & $110-209$ \\
\hline Apolipoprotein A1 (APA1) ** & 117593 & $72-171$ \\
\hline Arginase (ARG) & 9750 & $247-349$ \\
\hline Aryl Hyrdrocarbon Receptor (AHR) & 13611 & $75-174$ \\
\hline Catalase (CAT) & 53928 & $163-292$ \\
\hline Catenin $\beta(\beta C A T)$ & 74455 & $229-328$ \\
\hline CYP17 & 58698 & $30-129$ \\
\hline CYP19A1A (Aromatase) $* *$ & 24482 & $204-303$ \\
\hline CYP1A & 6644 & $539-638$ \\
\hline CYP3A & 413 & $891-990$ \\
\hline Cytochrome C Oxidase (COX) & 69 & $926-1025$ \\
\hline Elongation Factor $1 \alpha(\mathrm{EF} 1 \mathrm{a})^{*}$ & 224 & $671-770$ \\
\hline Epidermal Growth Factor Receptor (EGFR) & 7917 & $53-152$ \\
\hline Epoxide Hydrolase $(\mathrm{EH})$ & 319319 & $43-142$ \\
\hline Estrogen Receptors $\alpha(\mathrm{ER} \alpha)$ & 135133 & $7-106$ \\
\hline Estrogen Receptors $\beta 1(\mathrm{ER} \beta)$ & 122860 & $47-146$ \\
\hline Eukaryotic Translation Initiation Factor 3D (ETIF3D)* & 55460 & $26-125$ \\
\hline Ferritin (FRT) & 119642 & $85-184$ \\
\hline Fibroblast Growth Factor (FGF) & 3663 & $727-826$ \\
\hline Follicle Stimulating Hormone Receptor (FSHR) $* *$ & 228623 & $70-169$ \\
\hline Glutathione S-Transferase (GST) & 1264 & $825-924$ \\
\hline Glucocorticoid Receptor (GR) & 25729 & $318-417$ \\
\hline Glucokinase (GLK) & 176945 & $65-164$ \\
\hline Glutathione Peroxidase (GPX4) & 3390 & $696-795$ \\
\hline Granulin 1 (GRN1) & 19648 & $273-372$ \\
\hline Granulin Precursor b (GRNb) & 7323 & $355-454$ \\
\hline Heat Shock Proteins 70 (HSP70) & 685 & $592-601$ \\
\hline Heat Shock Proteins 90 (HSP90) & 54 & $1010-1109$ \\
\hline Hepcidin (HEP) & DQ200985 & $1034-1133$ \\
\hline Hypoxanthine Phosphoribosyltransferase 1 (HPRT1)** & 32875 & $102-201$ \\
\hline Hypoxia-inducible factor (HIF) & 120 & $813-912$ \\
\hline Insulin-Like Growth Factor (IGF) & 36969 & $296-395$ \\
\hline Interferon (IFN) & 2030 & $798-897$ \\
\hline Interleukin (IL)** & 3016 & $139-238$ \\
\hline MYXO Parasite (MYXO) & FJ361238 & $424-523$ \\
\hline Peroxisome proliferator-activated receptor (PPAR) & 78007 & $1-100$ \\
\hline
\end{tabular}




\begin{tabular}{|l|c|c|}
\hline Proliferating cell nuclear antigen (PCNA) & 1111 & $813-912$ \\
\hline RBMX $^{*}$ & 60526 & $146-245$ \\
\hline Ribosomal Protein L8 (RPL8)* & 2907 & $193-292$ \\
\hline Transforming Growth Factor $\beta 1$ (TGF $\beta 1)$ & 14811 & $195-294$ \\
\hline Thyroid Hormone Receptor $\alpha(\mathrm{THR} \alpha)$ & 33510 & $92-191$ \\
\hline Thyroid Hormone Receptor $\beta(\mathrm{THR} \beta)$ & 33545 & $3-102$ \\
\hline Tumor Protein p73 (TP73)** & 25765 & $17-116$ \\
\hline Tumor protein p53 (TP53) & 2135 & $608-707$ \\
\hline Superoxide Dismutase (SOD) & 541 & $1327-1426$ \\
\hline v-K-ras & 2549 & $123-222$ \\
\hline Vitellogenin (VTG) & 1986 & $657-756$ \\
\hline Warm Temperature Acclimation Protein 65 (WAP65) & 1320 & $200-299$ \\
\hline
\end{tabular}


Table 3. Mean count values and range of normalized gene expression for genes found with statistically significant modulation between times 24 and 48 in fish receiving the low dose. Range is defined as the minimum expression value of the gene subtracted from the maximum expression value of the gene.

\begin{tabular}{|c|c|c|c|c|}
\hline \multirow{3}{*}{ Gene } & \multicolumn{4}{|c|}{ Time (hours) } \\
\hline & \multicolumn{2}{|c|}{24} & \multicolumn{2}{|c|}{48} \\
\hline & Mean & Range & Mean & Range \\
\hline AHR & 4.8 & 2.1 & 3.9 & 1.4 \\
\hline$\beta C A T$ & 7.7 & 1.9 & 7.1 & 0.6 \\
\hline EGFR & 4.1 & 1.5 & 3.0 & 0.9 \\
\hline ER $\alpha$ & 3.5 & 3.2 & 2.4 & 1.0 \\
\hline$E R \beta$ & 4.1 & 6.4 & 2.6 & 1.6 \\
\hline FGF & 4.9 & 2.3 & 3.7 & 1.2 \\
\hline GP & 7.6 & 0.8 & 6.7 & 0.9 \\
\hline GR & 4.9 & 1.4 & 4.1 & 0.8 \\
\hline GRN1 & 8.9 & 2.0 & 7.8 & 1.1 \\
\hline GRNB & 3.4 & 1.7 & 2.3 & 1.2 \\
\hline HIF & 5.3 & 1.7 & 4.3 & 0.9 \\
\hline HSP70 & 4.8 & 1.7 & 3.6 & 0.7 \\
\hline p53 & 3.4 & 1.9 & 2.2 & 1.2 \\
\hline PCNA & 5.8 & 2.7 & 4.4 & 1.3 \\
\hline PPAR & 4.4 & 1.8 & 3.6 & 1.2 \\
\hline RBMX2 & 7.4 & 2.2 & 6.2 & 1.2 \\
\hline SOD & 8.5 & 1.6 & 7.8 & 0.9 \\
\hline TGF $\beta 1$ & 2.9 & 2.6 & 1.5 & 1.0 \\
\hline v-K-ras & 3.6 & 1.4 & 2.6 & 0.8 \\
\hline
\end{tabular}




\title{
Chapter 5: Characterization of a Novel Hepadnavirus in the White Sucker (Catostomus commersonii) from the Great Lakes Region of the USA
}

\begin{abstract}
The white sucker Catostomus commersonii is a freshwater teleost often utilized as a resident sentinel. Here, we sequenced the full genome of a hepatitis B-like virus that infects white suckers from the Great Lakes Region of the USA. Dideoxysequencing confirmed the white sucker hepatitis B virus (WSHBV) has a circular genome (3542 bp) with the prototypical codon organization of hepadnaviruses. Electron microscopy demonstrated that complete virions of approximately $40 \mathrm{~nm}$ were present in the plasma of infected fish. Compared to avi- and orthohepadnaviruses, sequence conservation of the core, polymerase and surface proteins was low and ranged from $16-27 \%$ at the amino acid level. An X protein homologue common to the orthohepadnaviruses was not present. The WSHBV genome included an atypical, presumptively non-coding region absent in previously described hepadnaviruses. Phylogenetic analyses confirmed WSHBV as distinct from previously documented hepadnaviruses. The level of divergence in protein sequences between WSHBV other hepadnaviruses, and the identification of an HBV-like sequence in an African cichlid provide evidence that a novel genus of the family Hepadnaviridae may need to be established that includes these hepatitis B-like viruses in fishes. Viral transcription was observed in 9.5\% (16 of 169) of white suckers evaluated. The prevalence of hepatic tumors in these fish was $4.9 \%$, of which only $2.4 \%$ were positive for both virus and hepatic tumors. These results are not sufficient to draw inferences regarding the association of WSHBV and carcinogenesis in white sucker.
\end{abstract}




\section{Importance}

We report the first full length genome of a hepadnavirus from fishes. Phylogenetic analysis of this genome indicates divergence from those of previously described hepadnaviruses from mammalian and avian hosts and supports the creation of a novel genus. The discovery of this novel virus may better our understanding of the evolutionary history of hepatitis B-like viruses of other hosts. In fishes, knowledge of this virus may provide insight regarding possible risk factors associated with hepatic neoplasia in the white sucker. This may also offer another model system for mechanistic research.

\section{Introduction}

The white sucker Catostomus commersonii is a freshwater teleost that is endemic to river systems in the Midwestern and Northeastern United States. Their widespread distribution and life-history has made them a target species in numerous contaminant monitoring and effects studies (1-3). The prevalence of tumors in white sucker is currently used as an indicator of exposure to environmental contaminants and is also a criterion used in the assessment and listing or delisting of Areas of Concern (AOCs) throughout the Great Lakes region. Fish tumors or other deformities, specifically in white sucker or brown bullhead, are listed as one of the "beneficial use" impairments at Great Lakes AOCs (4). In 2010, the Great Lakes Restoration Initiative specifically targeted certain priorities, one of which was the evaluation and monitoring of progress in AOCs (5). One component of this program was the assessment of wild populations present at potentially impacted sites. A suite of biomarkers ranging from the molecular to the organismal level was developed for multiple fish species (6). During the development of a hepatic transcriptome for white sucker, we identified the presence of a novel hepatitis B-like virus. 
Hepatitis B virus (HBV) is an enveloped, reverse-transcribing DNA virus of the family Hepadnaviridae. Hepadnaviruses are small ( 42nm), spherical viruses characterized by a compact, circular, partially double stranded DNA genome approximately $3.2 \mathrm{~kb}$ in length. The genome utilizes all three forward frames to encode transcripts from three to four overlapping, canonical open reading frames (ORFs): the "pre $\mathrm{C} / \mathrm{C}$ " ORF, the "pre $\mathrm{S} / \mathrm{S}$ " ORF, the pol ORF and the "X" ORF. These reading frames encode the nucleocapsid protein (core antigen), envelope proteins (surface antigen), polymerase/reverse transcriptase polyprotein, and regulatory transactivating protein, respectively. The life cycle of HBV can be broadly divided into three stages that begin with infectious virions containing circular, partially double-stranded but not covalently closed DNA (relaxed circular; rcDNA). These virions attach to carbohydrate side chains of hepatocyte-associated heparin sulfate proteoglycans on the host cell membrane that initiate a multistep entry process (7). Once within the host cell, rcDNA is converted into covalently closed circular DNA (cccDNA). This serves as a template for the transcription of pregenomic RNA (pgRNA) and mRNA $(8,9)$.

The family Hepadnaviridae is comprised of two recognized genera, Orthohepadnavirus (type species: Hepatitis B virus, HBV) and Avihepadnavirus (type species: Duck hepatitis B virus, DHBV). The orthohepadnaviruses infect humans and other mammals including the Old World great apes (10-13) while the avihepadnaviruses infect avian species (14-19). In general, these viruses have a narrow host range and infection leads to variable presentation and outcomes. These viruses exhibit a tropism for hepatocytes and are typically associated with acute and chronic liver diseases including fibrosis, cirrhosis, cholangiocarcinoma (CC) (20) and hepatocellular carcinoma (HCC) $(21,22)$. It is estimated that 350 million people are chronically infected with HBV (23). Consequently, HCC is the fifth most frequent human cancer (24). In 
birds, liver pathology is less commonly observed with hepadnavirus infections (25). Viral replication is non-cytopathic and tissue pathology is typically associated with the immune response to viral antigens. Current evidence suggests that birds are the ancestral host of the mammalian orthohepadnavirses (26). To date, hepadnaviruses have not been identified in fishes. Here, we report the complete genome of a novel hepadnavirus isolated from the white sucker and present molecular and morphological evidence to support its assignment as the type species of a new genus in the family Hepadnaviridae. We also examine the prevalence of viral transcription in white sucker collected from five rivers of the Great Lakes region and the association of virus with hepatic neoplasia.

\section{Materials and Methods}

\section{Sampling}

We collected liver tissue from wild caught, white sucker $(n=169)$ inhabiting five rivers in the Great Lakes region (Fig 1; Table S1). These samples were preserved in RNAlater (Life Technologies, Grand Island, NY) for a transcriptome assembly project (BioProject \#839157), and quantitative gene expression analyses. A liver sample from a white sucker collected from Michael Brook near Carmel, NY was included for this purpose as well. Tissue was not collected for DNA applications from these fish. In an attempt to collect samples suitable for DNA analysis, we collected white sucker $(n=20)$ from the Root River (Racine, WI) in the spring of 2014. Liver tissue was excised and stored in 90\% ethanol for subsequent DNA extraction. All fish were euthanized with a lethal dose of tricane methanesulfonate (MS-222; Finquel; Argent Laboratories, Redmond, WA) according to approved Animal and Care Safety protocols (USGS, Leetown Science Center). Prior to necropsy, blood was collected using heparinized syringes, transferred to heparinized Vacutainers ${ }^{\circledR}$ and stored on wet ice until centrifuged. Plasma samples 
were stored at $-80^{\circ} \mathrm{C}$ until analyzed. Additional liver tissue was preserved in Z-fix (Anatech LTD, Battle Creek, MI) from all individuals for subsequent histopathological assessment.

\section{High-throughput sequencing}

Total RNA was extracted using an E.N.Z.A. ${ }^{\circledR}$ Total RNA Kit (Omega Biotek, Norcross, GA) from nine individuals, pooled and enriched for non-ribosomal RNA using a Ribo-Zero ${ }^{\mathrm{TM}}$ rRNA removal kit (Epicentre, Maidson, WI). An RNA sequencing library was prepared and paired-end ( 2 x 100) ultra-deep sequencing was carried out at the Institute for Genome Sciences (Baltimore, MD) on an Illuminia HiSeq2000.

Read pairs were quality-screened and adapter-trimmed prior to de novo assembly into contigs with CLC Genomics Workbench v. 7. As part of routine efforts to screen for contaminating sequences, blastx searches identified contigs with sequence similarity to hepadnaviruses, which we then culled from our white sucker transcriptome assembly, which is to be described elsewhere.

\section{Full genome re-sequencing and mapping}

The initial indication that a hepadnavirus was present in our pooled liver sample was based on blastx results of de novo assembled RNA transcripts (Fig 2). To avoid the inclusion of pgRNA or viral mRNA in the genome model, we isolated DNA from an ethanol preserved liver. Re-sequencing was conducted on a single, PCR positive fish collected from the Root River (WSHBV RR173). The DNA was extracted using a DNeasy kit (QIAgen, Valencia, CA) as per manufacturer protocols. Primers were designed to re-sequence the complete genome and confirm a circular architecture. We used Primer3 v2.3.4 (27) to design these primers. Default parameters were modified to amplify $280-797$ bp products (Table S2). Sequence overlap ranged from 19 to $461 \mathrm{bp}$ with a mean overlap of $189 \mathrm{bp}$ (Fig. S1). PCR conditions are noted in 
Table S2. All PCR amplicons were purified using the QIAquick purification kit (QIAgen, Valencia, CA). Dideoxy sequencing was conducted using the BigDye ® Terminator v3.1 chemistry and an ABI 3100 Genetic Analyzer (Applied Biosystems, Forster City, CA). The resulting sequences were assembled into a single circular sequence using Geneious (version R7, Biomatters, Fig. 3).

Per-base coverage of the genome model in Illumina RNA reads was assessed by mapping the reads with bowtie2 (28) using the "end-to-end" and "very-sensitive" quick switches and specifying a maximum fragment length of $700 \mathrm{bp}$. Mapping quality and mismatches/polymorphisms were investigated with the Alignment Summary Metrics package of Picard (Broad Institute, [http://broadinstitute.github.io/picard/]) and with the Tablet alignment viewer (29). In addition we searched for polyadenylated RNA sequences consistent with functional polyadenylation sites. To do this, we re-mapped Illumina reads from the liver cDNA library, using bowtie2 and targeting genomic windows from 100 positions 5 ' to 100 positions $3^{\prime}$ of each candidate site. The bowtie2 mapping mode was "local" rather than "end-to-end" to allow A homopolymers to remain unmapped while allowing templated mRNA upstream of the homopolymer to be mapped. The remaining bowtie 2 parameters were the default values. A total of 16,384 unique fragments (read pairs or singletons) mapped to these seven (partly overlapping) regions.

In addition to re-sequencing, we assessed the presence of WSHBV DNA in all fish collected from the Root River via end-point PCR (primer set and conditions denoted in Table S2). This was also conducted to confirm that the viral sequence was not endogenous. Template DNA from both liver and plasma was used for this screening. DNA was extracted from plasma using the DNeasy kit (QIAgen, Valencia, CA) as per manufacturer protocols. 


\section{Electron microscopy}

Plasma from fish testing positive by PCR were diluted in TNE buffer ( $50 \mathrm{~mm}$ Tris- $\mathrm{HCl}$, $100 \mathrm{~mm} \mathrm{NaCl}, 0.1 \mathrm{~mm}$ EDTA, $\mathrm{pH}$ 7.4) to a volume of $5 \mathrm{~mL}$ and pelleted by ultracentrifugation through a $200 \mathrm{uL}$ cushion of 25\% (w/w) sucrose in TNE (Beckman SW50.1 rotor, 150,000 x g, 1 $\left.\mathrm{h}, 10^{\circ} \mathrm{C}\right)$. The pellet was resuspended in $0.5 \mathrm{~mL}$ TNE and layered onto a gradient composed of $1.5 \mathrm{~mL} \mathrm{30 \% (w/w)} \mathrm{CsCl,} 1.5 \mathrm{~mL} \mathrm{35 \%} \mathrm{(w/w)} \mathrm{CsCl,} \mathrm{and} 1.5 \mathrm{~mL} \mathrm{40 \% (w/w)} \mathrm{CsCl} \mathrm{in} \mathrm{TNE.} \mathrm{After}$ centrifugation to equilibrium for $16 \mathrm{~h}$ (Beckman SW 50.1 rotor, 115,000 x g, $10^{\circ} \mathrm{C}$ ), $250 \mathrm{uL}$ fractions were collected from the gradient and the densities determined using a refractometer. Fractions with a density at or near $1.22 \mathrm{~g} / \mathrm{mL}$ were pooled, diluted with TNE to a volume of 4.5 $\mathrm{mL}$ and the virus pelleted through a $200 \mathrm{uL}$ cushion of $25 \%(\mathrm{~W} / \mathrm{W})$ sucrose (Beckman SW50.1 rotor, $150,000 \mathrm{x} \mathrm{g}, 2 \mathrm{~h}, 10^{\circ} \mathrm{C}$ ). The pellet of gradient-purified virus was dried and diluted in 50uL distilled water. Samples of the virus were adsorbed onto 400-mesh formvar/silicone monoxidecoated copper grids (Electron Microscopy Sciences) for 3 min and negatively stained with either $1 \%$ phosphotungstic acid, $\mathrm{pH} 6.5$ (PTA), or $0.5 \%$ or $1 \%$ uranyl acetate (UA) for 1 min. Grids were sent to the electron microscopy facility at the University of Montana where they were examined using a Hitachi H-7100 transmission electron microscope (Hitachi High Technologies America, Inc.) and photographed digitally.

\section{Survey of hepadnavirus prevalence in white sucker}

In order to assess the general prevalence and geographic distribution of WSHBV in wildcaught white sucker, we targeted WSHBV core protein RNA using a custom Nanostring CodeSet designed for a separate, ongoing study (6). The hybridization CodeSet targeted the RNA sequence in the coding region of the core protein. The hybridization code set was designed by Nanostring Technologies and nCounter analysis was conducted at the University of Pittsburgh, 
Genomics Research Core. This hybridization analysis method specifically targets RNA and not DNA. Liver samples (mass $15-25 \mathrm{mg}$ ) collected from fish inhabiting waters in the Great Lakes Region and preserved in RNA Later were homogenized in TRK lysis buffer (OmegaBiotek, Norcross, GA) using 5mm stainless steel balls in a TissueLyzer (QIAgen, Valencia, CA) at 30 Hz for 8 minutes. Lysate was centrifuged at 13,000G for 10 minutes. The clarified lysate was then frozen at $-80^{\circ} \mathrm{C}$ for subsequent nCounter analysis.

In order to normalize the transcript count data and conservatively filter false positives, we utilized the internal negative control (background) count data output from the analysis. We set the background value to subtract from target counts equal to the mean plus three standard deviations of all negative controls from all sample counts. Data was then normalized to the tissue mass.

\section{Relationship between WSHBV and liver tumor prevalence}

Hepatocellular carcinoma is associated with HBV infection in humans. Hepatic tumors are not uncommon in white sucker inhabiting the Great Lakes regions and prevalence of this pathology is used as an indication of contaminant exposure. Liver tissue preserved in Z-fix (Anatech LTD, Battle Creek, MI) was therefore processed for histopathological observation via graded alcohols, paraffin infiltration and embedding. Tissues were sectioned at $5 \mu \mathrm{m}$, and stained with hematoxylin and eosin. Hepatic tumors included HCC, hepatic adenoma (HA), cholangioma (CO) and cholangiocarcinoma (CC). Tumor and virus data were converted to a binary data set and Jaccard binary dichotomy coefficients were determined to evaluate dissimilarity.

\section{Sequence Comparisons and Phylogenetic Analysis}

Once a complete genome of the WSHBV was constructed we performed additional blastn and blastx searches within the NCBI nucleotide collection (nr/nt). Although hepadnaviruses from 
fish have not been reported previously, we suspected that related sequences may exist in public nucleotide data. We executed tblastn queries in the transcriptome shotgun assembly (restricted to bony fishes; taxid:7898) database using translated gene products from all three predicted ORFs. Additionally, given that hepadnaviruses are integrating viruses and that relic genomes (endogenous viral elements; EVEs) have been identified in avian genomes, we executed tblastx queries against the reference genomic sequences (restricted to bony fishes; taxid:7897) to further assess the possibility of endogenization events of hepadnaviruses in fishes.

Phylogenetic relationships of the white sucker hepatitis B virus (WSHBV) genome and predicted gene products (core, polymerase and surface) were compared to members of the genera Avihepadnavirus and Orthohepadnavirus. We used nucleotide and protein sequences from the duck HBV (DHBV), Ross's goose HBV (RGHBV), sheldgoose HBV (ShHBV), heron HBV (HHBV), parrot HBV (PHBV), snow goose HBV (SGHBV), horseshoe bat HBV (HBHBV), bat HBV (BtHBV), roundleaf bat HBV (RBHBV), tent-making bat HBV (TBHBV), ground squirrel HBV (GSHBV), woodchuck HBV (WHBV) and human HBV (HBV). Accession numbers of included HBV protein or nucleotide sequences are listed in Tables 1 and 2.

Following Cui and Holmes (2012) (30), we aligned the protein sequences using default settings in MUSCLE (31). We then determined the appropriate amino acid substitution model with ProtTest 2.4 (32). Maximum likelihood phylogenetic analyses were executed in PhyML (33) using the LG (core), WAG (polymerase) and JTT(surface) models of amino acid substitution with 1000 bootstrap replicates evaluate to phylogenetic relationships of mammalian, avian and white sucker HBVs. Nucleotide sequences for these ORFs were aligned in MUSCLE as well to determine nucleotide identity. Complete genomes were re-ordinated such that the first nucleotide corresponded to the start codon of the core ORF. We then aligned the sequences using 
MUSCLE and determined the appropriate substitution model with MEGA 6.0 (34).

Phylogenetic relationships were determined with PhyML using the GTR nucleotide substitution model.

\section{Results}

Sequencing the viral genome and ORF organization

De novo assembly of ribosomal-depleted RNA isolated from white sucker included a linear contig of 3,519 bp with blastx similarity to hepadnaviruses. Our finished genome, 2014 WSHBV RR173 (GenBank Accession Number, KR229754), was 3,542 bp. Dideoxysequencing confirmed a circular architecture of the genome (Fig. 3). Re-mapping Illumina reads to the complete genome included 131,080 reads. Genome coverage was high (average coverage, $3184 x$; maximum coverage, $7215 x$ ) with a mismatch frequency of $0.2 \%$ (Fig 4). The genome size of WSHBV was larger than other previously described hepadnaviruses (3542 vs 3377 bp from HBHBV) and included an atypical, presumably non-coding region comprised of $679 \mathrm{bp}$ (nt 2538 - 3214). We confirmed the presence of this region as authentic viral sequence using primerset anchored in the polymerase and core ORFs, or one of these ORFs and the non-coding region (Fig S1, Fig S2, Table S2). This presumably non-coding region terminated with a noncanonical polyadenylation signal (TATAAA; nt 3211 - 3216). Three additional polyadenylation signals were identified at nt 596-601, $1954-1959$ and $3148-4158$. Traditional polyadenylation signals were located at nt $2544-2549,3201-3206$, and $3425-3430$. Local remapping of the short reads identified the non-canonical hexanucleotide polyadenylation signal (TATAAA; nt 3211 - 3216) that terminated the presumptively non-coding region as the single polyadenylation site. The GC content of the complete genome was $42 \%$ while the non-coding region had considerably lower GC content of $34 \%$. 
The genome organization was similar to that of other hepadnaviruses. In silico translation identified three partially or completely overlapping reading frames $(+1,+2$ and +3$)$. These corresponded to the core protein, polymerase protein and surface protein of prototypical hepadnaviruses. A hepatitis B X protein homologue common to orthohepadnaviruses was not present. The numbering of base pairs in the hepadnavirus genome is typically assigned based on a conserved cleavage site for EcoRI. This restriction site is absent from the WSHBV genome. We therefore manually aligned the WSHBV to the genome of the DHBV (NC_001344), such that the start codons of the polymerase protein (nt 176) corresponded.

Open reading frame $1(\mathrm{RF}+1$; nt $3216-3542,1-315)$ encodes the core polyprotein of 213 amino acids with a theoretical average molecular weight of 24255.67 daltons (Table 1). The size of this ORF was in the range of other hepadnaviruses, but was more similar (in size) to that of the orthohepadnaviruses. We identified the hepatitis core antigen conserved domain within this ORF (nt 46-204; Fig 3, Table S3). Pairwise alignment with avian and mammalian hepadnaviruses revealed 16 - 25\% amino acid identity (Fig S3, Table 2). Based on amino acid identity the WSHBV was more similar to avihepadnaviruses. The isoelectric point of this polyprotein was 9.68 and is within the range reported for avian and mammalian hepadnaviruses (pI 9.34 - 10.12). The core ORF of HHBV contains a hydrophobic $\mathrm{N}$ terminal extension of 29 amino acids that forms a signal peptide (35). We identified a similar, but shorter (21 amino acids) hydrophobic $\mathrm{N}$ terminal extension in the WSHBV RR173.

Open reading frame $2(\mathrm{RF}+2 ; \mathrm{nt} 170-2536)$ encodes the viral polymerase protein of 789 amino acids and was similar in size to other hepadnavirus P proteins $(785-902$ amino acids; Table 2). This ORF contains four conserved domains that include viral DNA polymerases and reverse transcriptase (Fig. 3, Table S3). Pairwise alignment with avian and mammalian 
hepadnaviruses identified 23 - 30\% amino acid identity (Fig S4, Table 2). The terminal region of this ORF associated with RNase $\mathrm{H}$ activity had the greatest GC content in the genome (65\%). This ORF partially overlaps ORF 1 (core protein) and completely overlaps ORF 3 (surface protein).

Open reading frame 3 of WSHBV (RF +3; nt $633-1724)$ was homologous to the large surface protein of hepadnaviruses. We identified a conserved domain for major surface antigen from hepadnavirus (vMSA) in this ORF (nt 1281 - 1487; Fig. 3, Table S3). An atypical conserved domain for amelogenin was also identified (nt 834 - 1094). Pairwise alignment with avian and mammalian hepadnaviruses identified 15 - 27\% amino acid identity (Fig S5, Table 2). The EcoRI site typically present in this ORF was not present, as noted above.

\section{Identification of additional fish hepadnavirus sequence}

The best blastn hit for the complete genome of the WSHBV was to the large S gene of HHBV (isolate: Kyoto-LS-2006; AB809504). The E-value of this alignment was 8e-27 with $74 \%$ identity; however, the query coverage was only $6 \%$. A blastx search identified Crane HBV polymerase (CAD29588) as the best match. The E-value was 7e-104 with 35\% identity and 58\% query coverage. The most convincing evidence that we had identified a genome of a novel hepadnavirus was the graphic summary in which conserved domains of HBV were identified in 3 reading frames and in the appropriate genomic organization (Fig. 2).

A tblastn query in the transcriptome shotgun assembly (restricted to bony fishes; taxid:7898) database using the $\mathrm{P}$ protein identified a 2186 bp transcript from a Lake Tanganyika African cichlid (JL559376, Ophthalmotilapia ventralis) liver library. The E-value for this was $4 \mathrm{e}-49$ with $32 \%$ identity and $66 \%$ query coverage. When this contig was used in a blastx query 
the most significant alignment produced was to Stork HBV (E-value $=4 \mathrm{e}-53 ; 34 \%$ identity; $67 \%$ query coverage).

A tblastx search performed using the complete genome of WSHBV against all available reference genomic sequences of bony fishes identified the best matches as Northern pike (NC_025975.1, NW_011545020.1) however both had low query coverage (14\% and 9\%) and Evalue scores $(0.30)$. This cursory paleovirological exploration did not identify evidence of endogenized hepadnaviruses in fish genomes.

\section{Phylogenetic analysis and amino acid conservation}

Phylogenetic analyses of predicted WSHBV proteins to those of previously described hepadnaviruses depict well-supported monophyletic groups comprised of the orthohepadnaviruses (mammals) and avihepadnaviruses (birds) which do not include the WSHBV (Fig. 5). Analysis which included the putative hepadnavirus polymerase protein from African cichlid depicts poorly resolved paraphyletic groups between fish species that are distinct from the known viruses of mammalian and bird hosts (Fig. 5A). Similar tree topology was identified for the nucleotide analysis of the complete genomes (Fig. 6). Multiple alignments of the core, polymerase and surface proteins with subset of mammalian and avian hepadnaviruses identified amino acid conservation within critical conserved domains (Fig. S3, S4 and S5).

\section{Electron microscopy}

Examination of the grids prepared using plasma from fish testing positive by PCR showed two types of typical hepadnavirus-like particles. These included complete particles of approximately 40nm in diameter that were morphologically similar to the "Dane" particles of hepatitis B virus (Fig. 7). These larger particles were greatly outnumbered by smaller particles of approximately 20-25nm thought to be composed of virus surface antigen. 
Survey of hepadnavirus prevalence in white sucker

Core protein RNA was identified in fish sampled from four of five sites in the Great Lakes region (Fig. 8). The highest prevalence was observed in Milwaukee, WI (Milwaukee River) where expression of the core protein gene was noted in $40 \%$ of sampled fish $(n=20)$. At three other sites; Duluth, MN (St. Louis River, n=86), Maumee, OH (Swan Creek, n=37), and Green Bay, WI (Fox River, n=16), core protein RNA was reported in 3-7\% of sampled fish. In Detroit, MI (Detroit River, $\mathrm{n}=10$ ), no core protein RNA was detected.

Assessment of the presence of WSHBV DNA in white sucker from the Root River (Racine, WI) (n=20) via end-point PCR identified a prevalence of $20 \%$ positive. The prevalence of virus was not statistically different than that observed at the geographically proximate Milwaukee River site (Fisher's exact test, $\mathrm{P}=0.3$ ). We detected viral DNA in the plasma samples from the same four positive individuals (data not shown). Absence of amplicons from numerous individuals confirmed that this PCR primer set does not amplify an endogenous viral relic.

Association of WSHBV replication and liver neoplasms

We compared the prevalence of hepatic tumors, $\mathrm{HCC}, \mathrm{CO}, \mathrm{CC}$, and $\mathrm{HA}$ with the prevalence of viral transcription in white suckers sampled throughout the Great Lakes region $(\mathrm{n}=169)$. The multi-site composite prevalence of virus $(9.5 \%)$ and tumors $(4.9 \%)$ was low. The Jaccard similarity coefficient between virus prevalence and tumor prevalence was low $(0.16)$. Fish were identified that were virus positive/tumor negative (6.5\%), tumor positive/virus negative (3.0\%), or positive for both (2.4\%; Table 3). Only one HCC was identified and that fish was virus positive. Four individuals were diagnosed with CC, two of which were also virus positive. 


\section{Discussion}

Here we identify the first complete genome of a hepadnavirus associated with fish. The confirmation of a circular genome, observation of complete virions in fish plasma, and presence of the virus in some, but not all, fish or locations provides strong evidence that the WSHBV sequence reported here is that of an infectious agent and not that of an endogenous virus. Additionally, we have identified a putative hepadnavirus polymerase sequence associated with African cichlid hepatic transcriptome shotgun assembly that provides further evidence that there are other hepadnaviruses that infect fishes. Differences in predicted proteins between WSHBV and hepadnaviruses from mammals and birds are sufficient to support proposing the creation of a novel genus containing WSHBV as the type species. Here, we refrain from suggesting a specific genus name prior to acceptance by the International Committee on Taxonomy of Viruses. Due to the identification of only one viral transcript for the African cichlid hepadnavirus additional information will be needed before its taxonomic status is clear.

The evolutionary origin of hepadnaviruses remains controversial. Until recently, records of endogenization in the genomes of extant avian, rodent and primate hosts were lacking. This forced insights into the evolutionary history of members of the family Hepadnaviridae to be based solely on sequence analysis of extant HBVs. Using this approach, the last common ancestor of Orthohepadnavirus and Avihepadnavirus was dated to 30,000 years (36) or 125,000 (37) years ago. Paleovirological analyses have found HBV endogenous viral elements (EVEs) to be widely distributed in birds (38), including the genome of the zebra finch, a species not documented as an extant host of HBV (39). Phylogenetic analyses of endogenous zebra finch HBV-derived EVEs suggests the common ancestor of viruses in the family Hepadnaviridae infected birds and that the mammalian hepadnaviruses emerged following a bird-mammal host 
switch (26). Suh et al. (2013) suggest that the ancestor of the current members of the family Hepadnaviridae likely infected an amniote ancestor living >324 million years ago, which is significantly earlier than previous estimates. The complete WSHBV genome is $165 \mathrm{bp}$ larger than the longest reported hepadnavirus genome (Roundleaf bat), lacks the X protein (or X-like protein) and contains a large, presumptively non-coding region where the $\mathrm{X}$ protein is located in orthohepadnaviruses. Duck hepatitis B virus contains what has been described as a vestigial X open reading frame (40). It has been suggested that the common ancestor of Hepadnaviridae did not encode a fourth ORF (X or X-like protein) (41) which is the case for the WSHBV. It is possible that the non-coding region of WSHBV is a precursor to the $\mathrm{X}$ open reading frame and that the non-coding region of the WSHBV genome provided non-coding nucleotides as a substrate for overprinting and the emergence of an X protein. Conversely, it is possible that this region devolved from an ancestral $\mathrm{X}$ gene that was not necessary in fish hosts. We suggest that the origin of this virus family may pre-date amniotes. We did not find evidence of endogenization of WSHBV-like viruses in publicly available fish genomes, but few such genomes are presently available for paleovirological investigation.

The prevalence of WSHBV was variable between sampling sites as assessed via WSHBV core protein mRNA transcription. Virus positive individuals were identified from four of five sites representing three of the Great Lakes; Superior, Michigan and Erie. Geographically, fish positive for replicating virus spanned a distance of approximately 1164 nautical $\mathrm{km}$. In humans, HBVs are represented by 8 different genotypes with a cosmopolitan distribution (42). In bats, evidence of different virus strains separated by $430 \mathrm{~km}$ have been reported (43). Therefore, the geographic distribution of our sampled virus may include multiple genotypes. We have evidence that nucleotide 3413 differs between the Root River WSHBV and that from the pool of hepatic 
RNA used for the initial virus discovery. Here, we should emphasize that the prevalence of WSHBV is likely higher at these sites than our estimates given that end-point PCR is less sensitive than qPCR (44), and measuring viral RNA interjects a virus life-cycle bias. Development of a non-lethal, rapid qPCR for future sampling of wild fish is a priority for subsequent assessment of the prevalence of WSHBV as well as investigations into genetic diversity and spatial distribution. These data could facilitate the reconstruction of the evolutionary history of the virus and provide preliminary knowledge of the potential of the virus to be transmitted between localities.

Early investigation of viral replication and antiviral drugs for HBV has relied heavily on animal models, particularly the duck and woodchuck. The discovery of WSHBV and the putative $\mathrm{HBV}$ in Ophthalmotilapia ventralis may provide an opportunity for the development of other model systems. This could assist further investigation of hepadnavirus replication, evolution, drug testing and liver pathogenesis. A hepatitis E virus isolated from the cutthroat trout has provided similar opportunities (45). Fish represent the largest, most diverse group of vertebrates with over 30,000 extant species. Although tumors have been identified in more than 300 species of fish (46), there is no evidence to support oncovirus induction of hepatic neoplasia in these species. Viruses of the family Herpesviridae and Retroviridae are associated with skin neoplasia in a number of fish species $(47,48)$. The tropism of HBV for hepatocytes and known association with acute and chronic liver diseases, many of which have historically been attributed to contaminants in previous studies of white sucker, warrants the investigation of its association with liver pathology. We identified a small percentage (2.4\%; 4 of 169) of fish that were both virus and tumor positive. One of these virus positive fish was diagnosed with a hepatocellular carcinoma. Two additional virus positive fish were diagnosed with cholangiocarcinoma. This 
dataset, however, is not sufficient to infer relationships between virus and carcinogenesis. Initiation of neoplasia by orthohepadnaviruses often requires decades of chronic infection in humans, thus the relationship between viral infection and neoplasia is often not straightforward. Of note, the WSHBV described here lacks the X protein associated with the induction of neoplasia (49). To date, attempts have not been made to isolate and propagate this virus via cell culture. Considerable future research is necessary to investigate a mechanistic relationship of WSHBV with liver pathology including necrosis, inflammation, preneoplastic and neoplastic changes as well as advance our understanding of the molecular biology and immunobiology of hepadnaviruses. Identification of this fish host host and novel hepadnavirus may offer an additional research model system.

\section{Acknowledgements}

The authors thank Dr. Patricia Mazik, Ryan Braham and Rachel Harrison for assistance with fish collections and processing. We also wish to thank Jim Driver at the University of Montana for operation of the electron microscope. The research was funded through a Great Lakes Restoration Initiative grants to the U.S. Fish and Wildlife Service and the Minnesota Pollution Control Board, and by the U.S. Geological Survey's Environmental Health (Contaminant Biology), Ecosystems (Fisheries) and Cooperative Units programs. Any use of trade, firm or product names is for descriptive purposes only and does not imply endorsement by the U.S. Government.

\section{References}

1. Blazer VS, Hoffman J, Walsh HL, Braham RP, Hahn C, Collins P, Jorgenson Z, Ledder T. 2014. Health of white sucker within the St. Louis River area of concern associated with habitat usage as assessed using stable isotopes. Ecotoxicology 23:236251. 
2. Bowron LK, Munkittrick KR, McMaster ME, Tetreault G, Hewitt LM. 2009.

Responses of white sucker (Catostomus commersoni) to 20 years of process and waste treatment changes at a bleached kraft pulp mill, and to mill shutdown. Aquatic toxicology 95:117-132.

3. Munkittrick KR, Dixon DG. 1989. Use of White Sucker (Catostomus commersoni) Populations to Assess the Health of Aquatic Ecosystems Exposed to Low-Level Contaminant Stress. Canadian Journal of Fisheries and Aquatic Sciences 46:1455-1462.

4. Rafferty SD, Blazer VS, Pinkney AE, Grazio JL, Obert EC, Boughton L. 2009. A historical perspective on the "fish tumors or other deformities" beneficial use impairment at Great Lakes Areas of Concern. Journal of Great Lakes Research 35:496-506.

5. 2010, posting date. Great Lakes Restoration Initiative Action Plan. [Online.]

6. Blazer VS, Mazik PM, Iwanowicz LR, Braham R, Hahn C, Walsh HL, Sperry A. 2014. Monitoring of wild fish health at selected site in the Great Lakes basin - methods and preliminary results. U.S. Geological Survey Open-File Report 2014-1027.

7. Schulze A, Gripon P, Urban S. 2007. Hepatitis B virus infection initiates with a large surface protein-dependent binding to heparan sulfate proteoglycans. Hepatology 46:1759-1768.

8. Sai L-T, Yao Y-Y, Guan Y-Y, Shao L-H, Ma R-P, Ma L-Z. 2014. Hepatitis B virus infection and replication in a new cell culture system established by fusing HepG2 cells with primary human hepatocytes. Journal of Microbiology, Immunology and Infection In press, corrected proof.

9. Beck J, Nassal M. 2007. Hepatitis B virus replication. World J Gastroenterol 13:48-64.

10. Marion PL, Oshiro LS, Regnery DC, Scullard GH, Robinson WS. 1980. A virus in Beechey ground squirrels that is related to hepatitis B virus of humans. Proceedings of the National Academy of Sciences of the United States of America 77:2941-2945.

11. Robertson BH, Margolis HS. 2002. Primate hepatitis B viruses - genetic diversity, geography and evolution. Reviews in medical virology 12:133-141.

12. Lanford RE, Chavez D, Brasky KM, Burns RB, Rico-Hesse R. 1998. Isolation of a hepadnavirus from the woolly monkey, a New World primate. Proc Natl Acad Scie 95:5757-5761.

13. Summers J, Smolec JM, Snyder R. 1978. A virus similar to human hepatitis B virus associated with hepatitis and hepatoma in woodchucks. Proceedings of the National Academy of Sciences of the United States of America 75:4533-4537.

14. Mason WS, Seal G, Summers J. 1980. Virus of Pekin ducks with structural and biological relatedness to human hepatitis B virus. Journal of virology 36:829-836.

15. Piasecki T, Kurenbach B, Chrzastek K, Bednarek K, Kraberger S, Martin DP, Varsani A. 2012. Molecular characterisation of an avihepadnavirus isolated from Psittacula krameri (ring-necked parrot). Arch. Virol. 157:585-590.

16. Guo H, Mason WS, Aldrich CE, Saputelli JR, Miller DS, Jilbert AR, Newbold JE. 2005. Identification and characterization of avihepadnaviruses isolated from exotic anseriformes maintained in captivity. Journal of virology 79:2729-2742.

17. Prassolov A, Hohenberg H, Kalinina T, Schneider C, Cova L, Krone O, Frölich K, Will H, Sirma H. 2003. New hepatitis B virus of cranes that has an unexpected broad host range. Journal of virology 77:1964-1976. 
18. Pult I, Netter HJ, Bruns M, Prassolov A, Sirma H, Hohenberg H, Chang SF, Frölich K, Krone O, Kaleta EF, Will H. 2001. Identification and analysis of a new hepadnavirus in white storks. Virology 289:114-128.

19. Chang SF, Netter HJ, Bruns M, Schneider R, Frölich K, Will H. 1999. A new avian hepadnavirus infecting snow geese (Anser caerulescens) produces a significant fraction of virions containing single-stranded DNA. Virology 262:39-54.

20. Li M, Li J, Li P, Li H, Su T, Zhu R, Gong J. 2012. Hepatitis B virus infection increases the risk of cholangiocarcinoma: a meta-analysis and systematic review. J Gastroenterol Hepatol 27:1561-1568.

21. Di Bisceglie AM. 2009. Hepatitis B and hepatocellular carcinoma. Hepatology 49:S56S60.

22. Zhou H, Wang H, Zhou D, Wang H, Wang Q, Zou S, Tu Q, Wu M, Hu H. 2010. Hepatitis B virus-associated intrahepatic cholangiocarcinoma and hepatocellular carcinoma may hold common disease process for carcinogenesis. European journal of cancer (Oxford, England : 1990) 46:1056-1061.

23. Organization WH March 2015 2014, posting date. Hepatitis B. [Online.]

24. de Carvalho Dominguez Souza BF, Drexler JF, de Lima RS, de Oliveira Hughes Veiga do Rosário M, Netto EM. 2014. Theories about evolutionary origins of human hepatitis B virus in primates and humans. The Brazilian Journal of Infectious Diseases 18:535-543.

25. Funk A, Mhamdi M, Will H, Sirma H. 2007. Avian hepatitis B viruses: molecular and cellular biology, phylogenesis, and host tropism. World J Gastroenterol 13:91-103.

26. Suh A, Brosius J, Schmitz J, Kriegs JO. 2013. The genome of a Mesozoic paleovirus reveals the evolution of hepatitis B viruses. Nat Commun 4:1791.

27. Untergrasser A CI, Koressaar T, Ye J, Faircloth BC, Remm M, Rozen SG 2012. Primer3 - new capabilities and interfaces. Nucleic Acids Research 40:e115.

28. Langmead B, Salzberg SL. 2012. Fast gapped-read alignment with Bowtie 2. Nat Meth 9:357-359.

29. Milne I, Bayer M, Cardle L, Shaw P, Stephen G, Wright F, Marshall D. 2010. Tablet - next generation sequence assembly visualization. Bioinformatics 26:401-402.

30. Cui J, Holmes EC. 2012. Endogenous hepadnaviruses in the genome of the budgerigar (Melopsittacus undulatus) and the evolution of avian hepadnaviruses. Journal of virology 86:7688-7691.

31. Edgar R. 2004. MUSCLE: multiple sequence alignment with high accuracy and high throughput. Nucleic Acid Res 32:1792-1797.

32. Abascla F, Zardoya R, Posada D. 2005. ProtTest: Selection of best-fit models of protein evolution. Bioinformatics 21:2104-2105.

33. Guindon S, Dufayard JF, Lefort V, Anisimova M, Hordijk W, Gascuel O. 2010. New Algorithms and Methods to Estimate Maximum-Likelihood Phylogenies: Assessing the Performance of PhyML 3.0. Systematic Biology 59:307-321.

34. Tamura K, Stecher G, Peterson D, Filipski A, Kumar S. 2013. MEGA6: Molecular Evolutionary Genetics Analysis Version 6.0. Molecular Biology and Evolution 30:27252729.

35. Bruss V. 2004. Envelopment of the hepatitis B virus nucleocapsid. Virus Research 106:199-209. 
36. Orito E, Mizokami M, Ina Y, Moriyama EN, Kameshima N, Yamamoto M, Gojobori T. 1989. Host-independent evolution and a genetic classification of the hepadnavirus family based on nucleotide sequences. Proceedings of the National Academy of Sciences of the United States of America 86:7059-7062.

37. van Hemert FJ, van de Klundert MA, Lukashov VV, Kootstra NA, Berkhout B, Zaaijer HL. 2011. Protein X of hepatitis B virus: origin and structure similarity with the central domain of DNA glycosylase. PloS one 6:e23392.

38. Cui J, Zhao W, Huang Z, Jarvis ED, Gilbert MT, Walker PJ, Holmes EC, Zhang G. 2014. Low frequency of paleoviral infiltration across the avian phylogeny. Genome biology 15:539.

39. Gilbert C, Feschotte C. 2010. Genomic fossils calibrate the long-term evolution of hepadnaviruses. PLoS biology 8.

40. Lin B, Anderson DA. 2000. A Vestigial X Open Reading Frame in Duck Hepatitis B Virus. Intervirology 43:185-190.

41. Suh A, Weber CC, KehImaier C, Braun EL, Green RE, Fritz U, Ray DA, Ellegren H. 2014. Early Mesozoic Coexistence of Amniotes and Hepadnaviridae. PLoS Genet 10:e1004559.

42. Saeed U, Waheed Y, Ashraf M. 2014. Hepatitis B and hepatitis C viruses: a review of viral genomes, viral induced host immune responses, genotypic distributions and worldwide epidemiology. Asian Pacific Journal of Tropical Disease 4:88-96.

43. He B, Zhang F, Xia L, Hu T, Chen G, Qiu W, Fan Q, Feng Y, Guo H, Tu C. 2015. Identification of a novel Orthohepadnavirus in pomona roundleaf bats in China. Arch Virol 160:335-337.

44. Abe A, Inoue K, Tanaka T, Kato J, Kajiyama N, Kawaguchi R, Tanaka S, Yoshiba M, Kohara M. 1999. Quantitation of hepatitis B virus genomic DNA by real-time detection PCR. Journal of clinical microbiology 37:2899-2903.

45. Batts W, Yun S, Hedrick R, Winton J. 2011. A novel member of the family Hepeviridae from cutthroat trout (Oncorhynchus clarkii). Virus Research 158:116-123.

46. Anders K, Yoshimizu M. 1994. Role of viruses in the induction of skin tumours and tumour-like proliferations of fish. Diseases of Aquatic Organisms 19:215-232.

47. Quackenbush SL, Casey JM, Bowser PR, al. e. 2010. Cancers induced by piscine retroviruses. Springer, New York, NY.

48. Getchell RG, Casey JW, Bowser PR. 2011. Seasonal Occurrence of Virally Induced Skin Tumors in Wild Fish. Journal of Aquatic Animal ealth 10:191-201.

49. Kew MC. 2011. Hepatitis B virus x protein in the pathogenesis of hepatitis B virusinduced hepatocellular carcinoma. Journal of Gastroenterology and Hepatology 26:144152. 


\section{Figures}

Figure 1. Map of white sucker sample locations. These include the St. Louis River, Green Bay and Lower Fox River, Milwaukee Estuary, Detroit River and Maumee River Areas of Concern and the Root River.

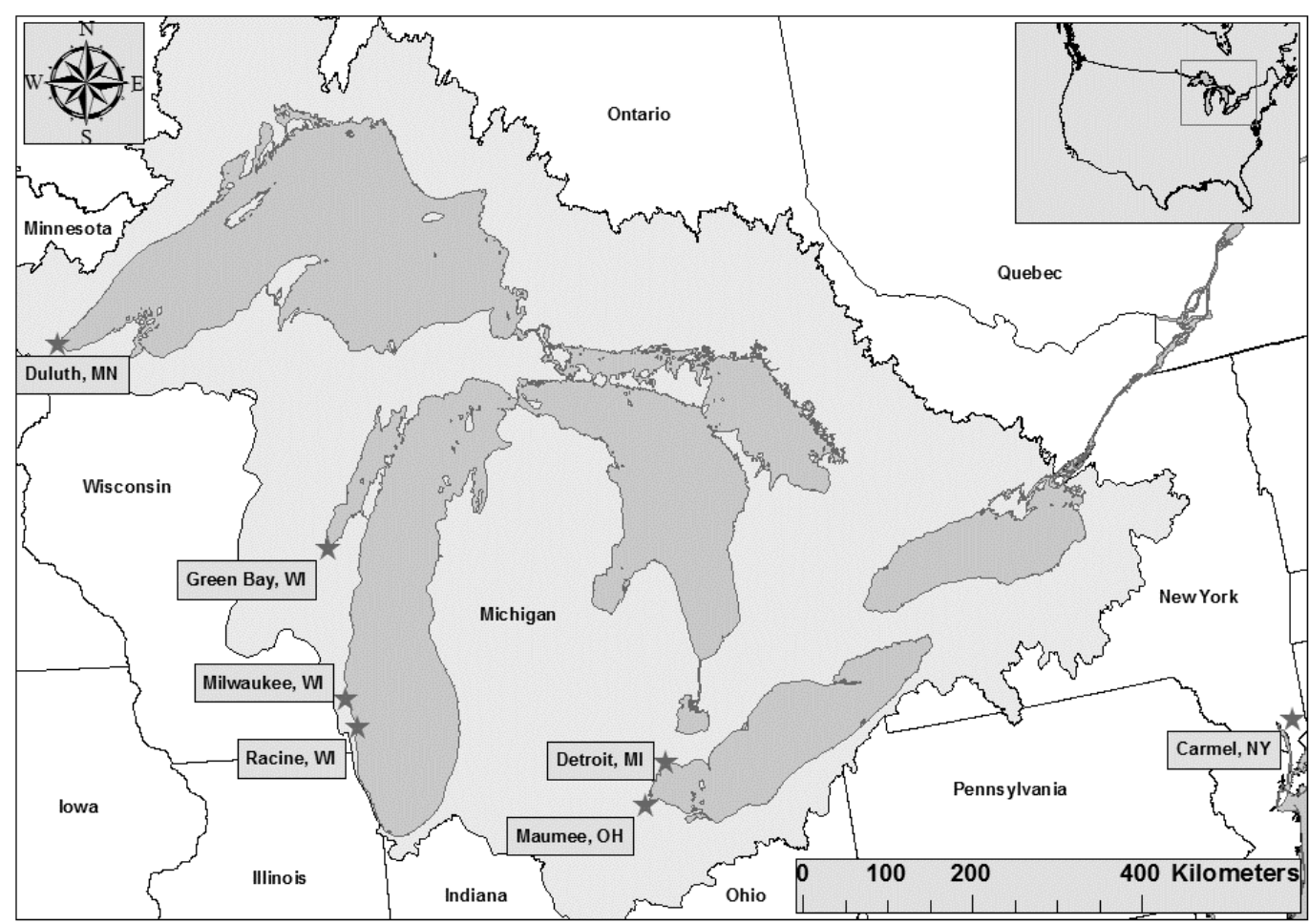


Figure 2. Graphic summary of blastx results identify genomic organization and signature conserved domains consistent with that of hepadnaviruses.

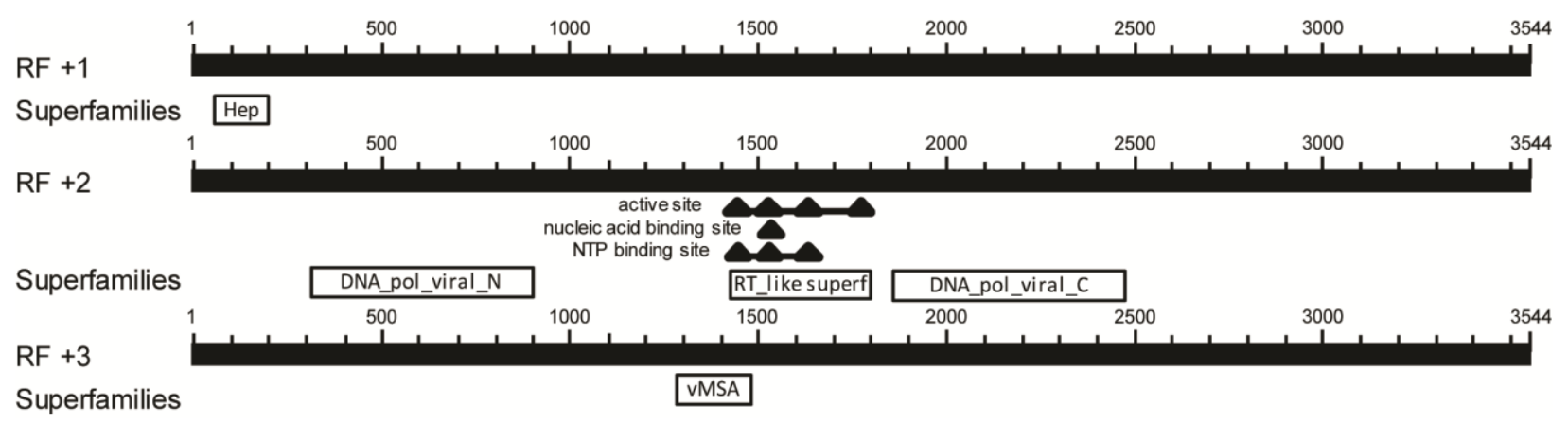


Figure 3. Genome organization of the WSHBV. The complete genome consists of 3542 nucleotides of double-stranded DNA that encode three partially of complete overlapping ORFs $(\mathrm{RF}+1,+2,+3)$. Open reading frames encoding the core, polymerase, and surface proteins are denoted in black. Conserved domains are indicated in gray.

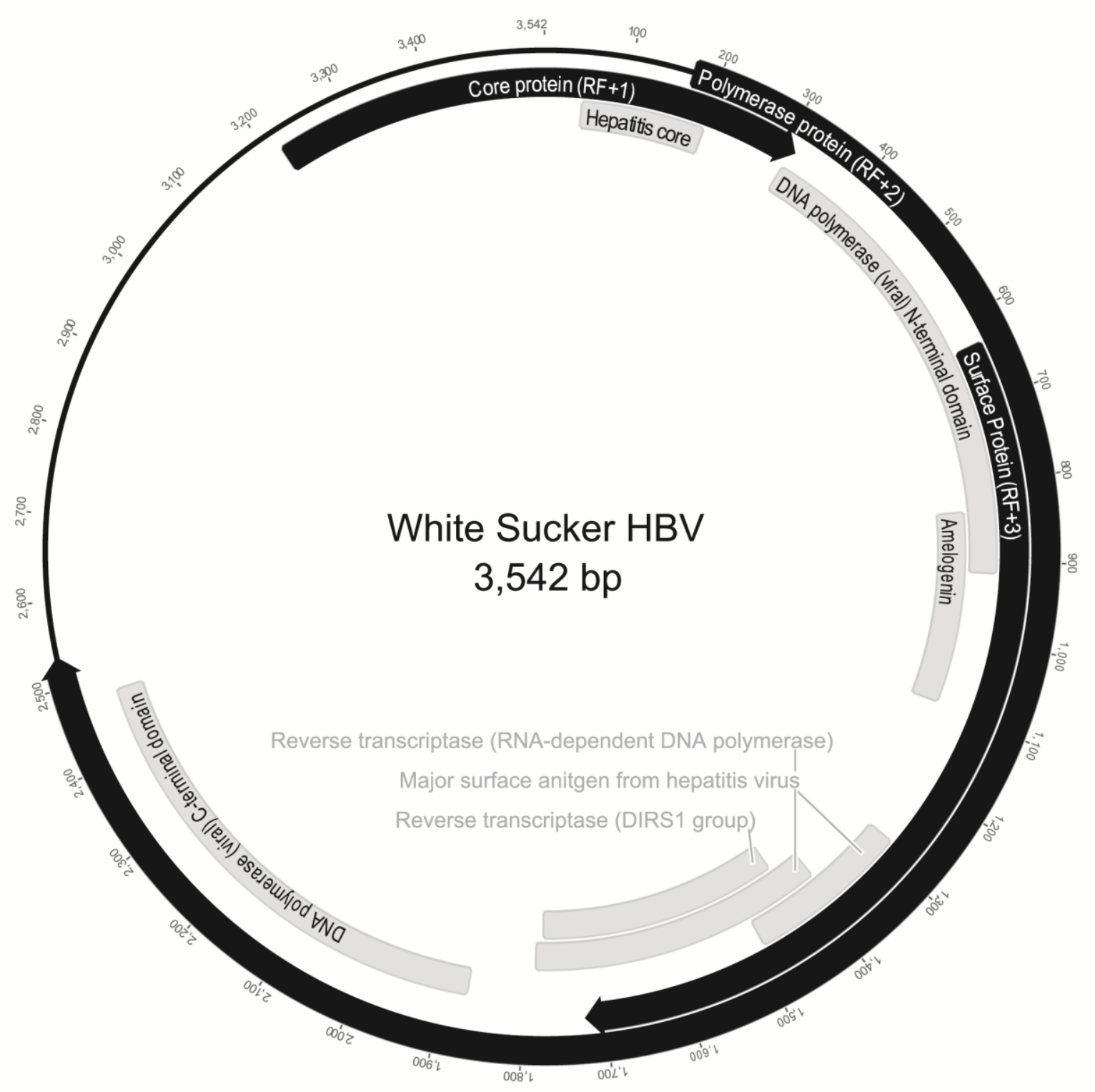


Figure 4. Genome coverage per base of the WSHBV in the pooled liver sample utilized for RNA-seq analysis (131,080 reads). Locations of the open reading frames that encode the core, polymerase, and surface proteins are denoted.

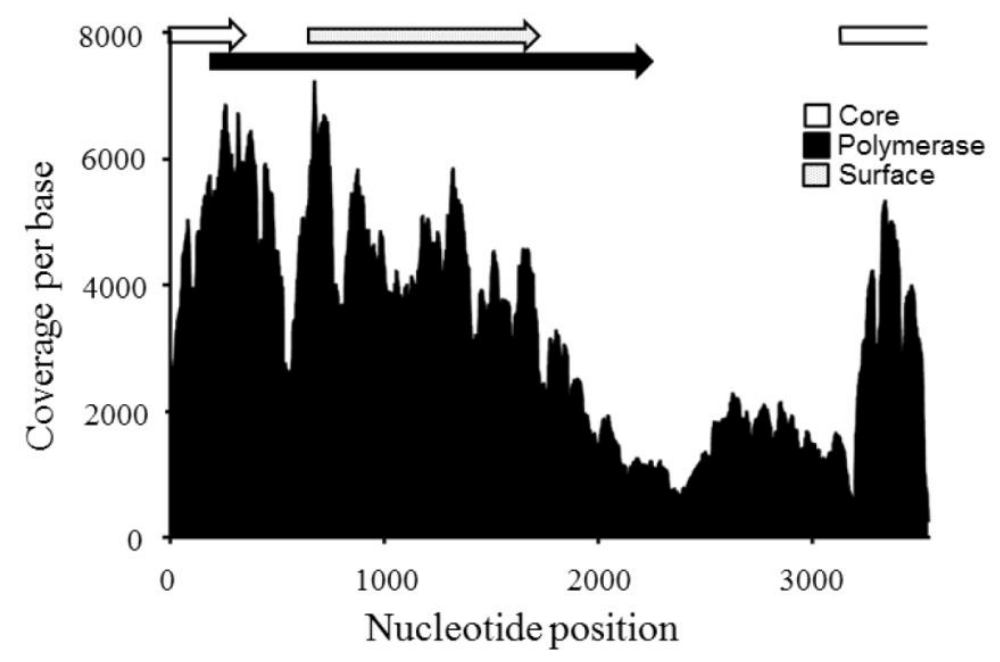


Figure 5. Unrooted phylogram illustrating the phylogenetic relationships of mammalian, avian and fish hepadnavirus proteins: (A) polymerase protein (B) surface protein (C) core proteins. Results of maximum likelihood phylogenetic analysis (PhyML; 1000 replicates). Asterisks denote bootstrap support $100 \%(* * *),>90 \%,(* *)$ or $>70 \%(*)$.

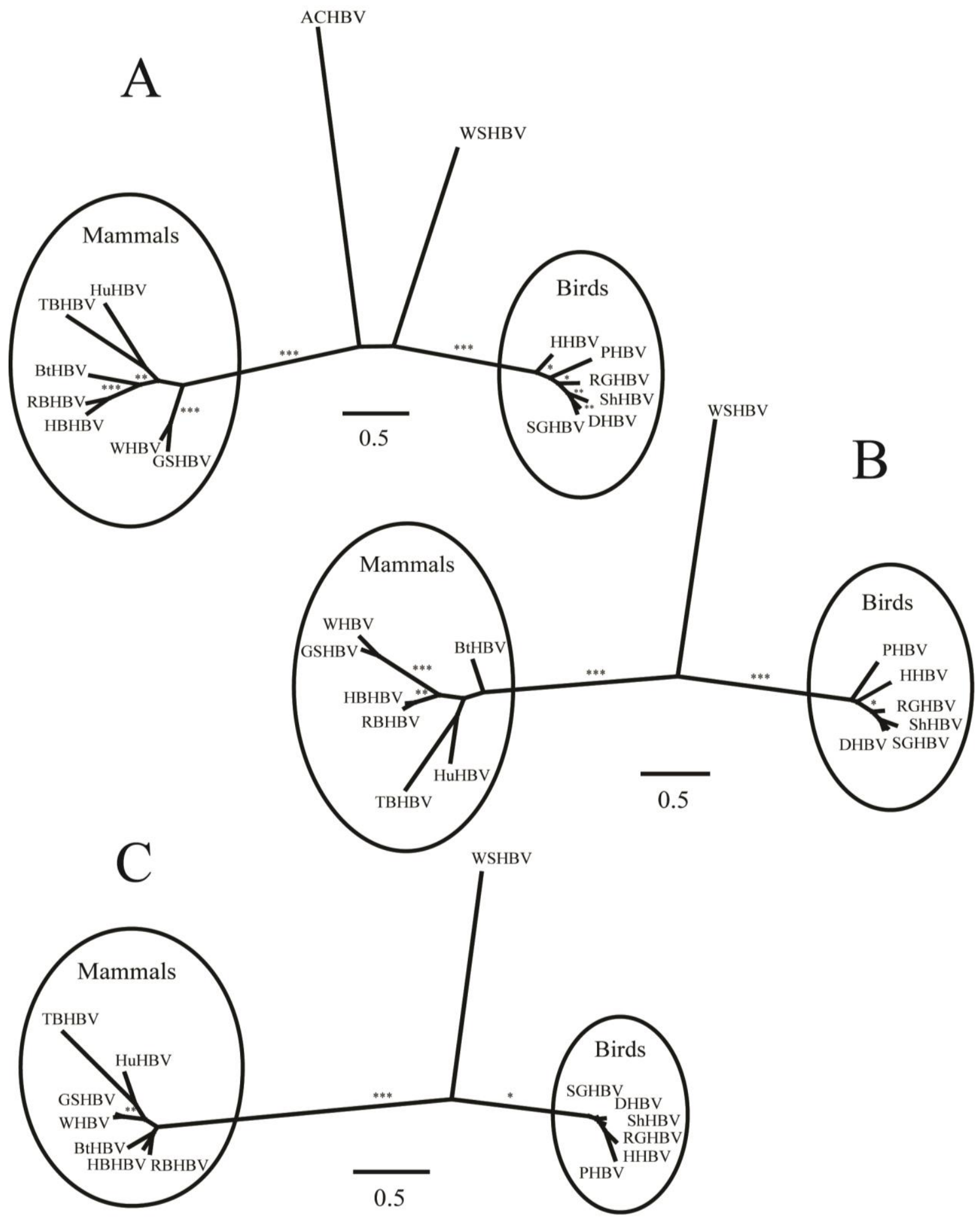


Figure 6. Unrooted phylogram denoting the phylogenetic relationships of mammalian, avian and fish hepadnavirus genomes. Results of maximum likelihood phylogenetic analysis (PhyML; 1000 replicates). Asterisks denote bootstrap support $100 \%(* * *),>90 \%,(* *)$ or $>70 \%(*)$.

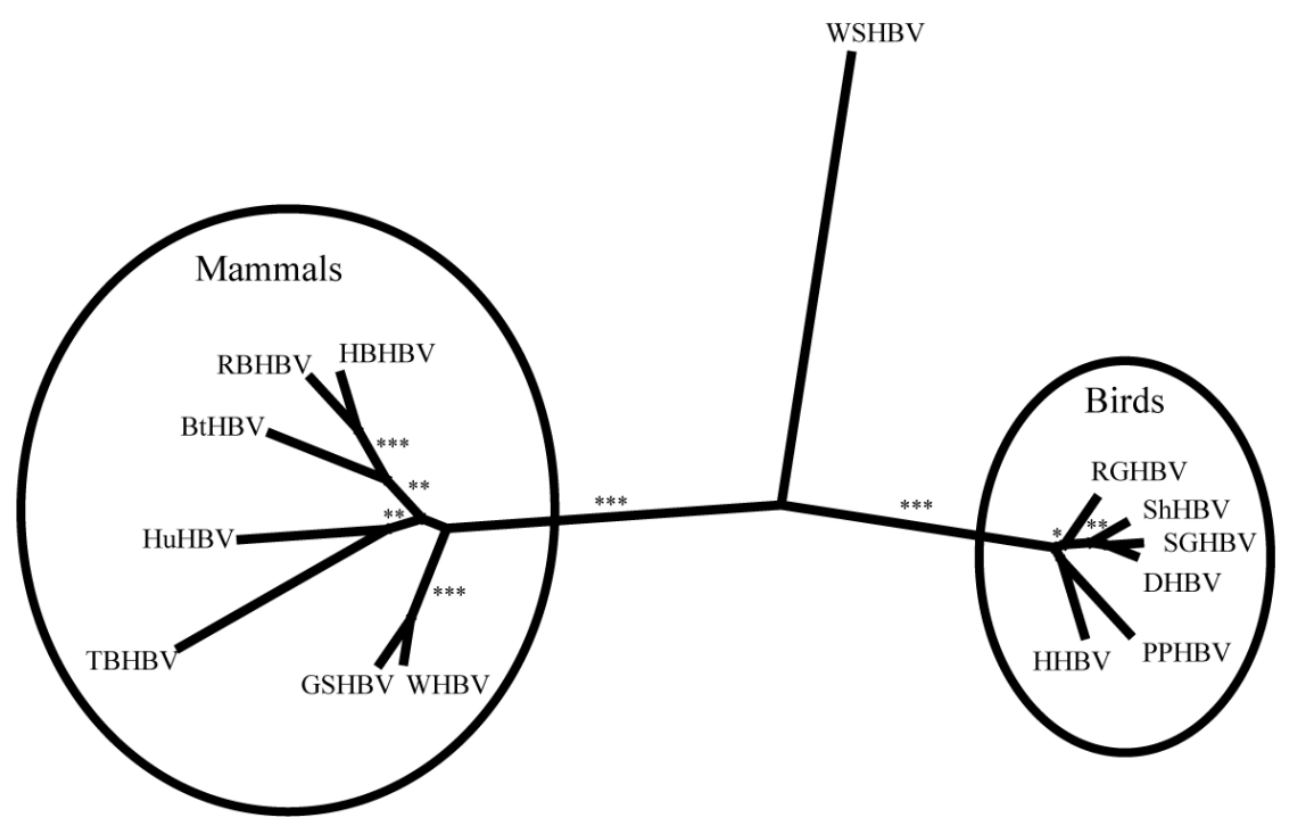

0.4 
Figure 7. Transmission electron micrograph showing both complete virions of approximately 40 $\mathrm{nm}$ in diameter as well as smaller particles assumed to be composed of self-assembled virus surface proteins. The two types of particles from gradient-purified white sucker sera have a strong resemblance to those of other hepatitis B-like viruses from mammals and birds. (A) Virus stained using $1 \%$ phosphotungstic acid and (B) $0.5 \%$ uranyl acetate. Scale bars $=100 \mathrm{~nm}$. Images were processed using Adobe Photoshop and included adjusting the brightness and contrast and application of the unsharp mask filter.

\section{(A)}

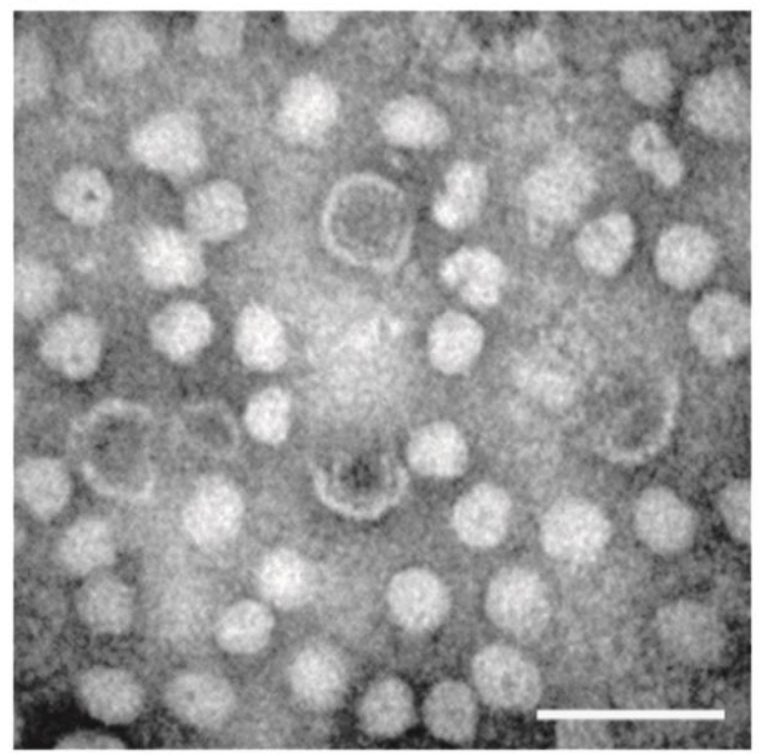

(B)

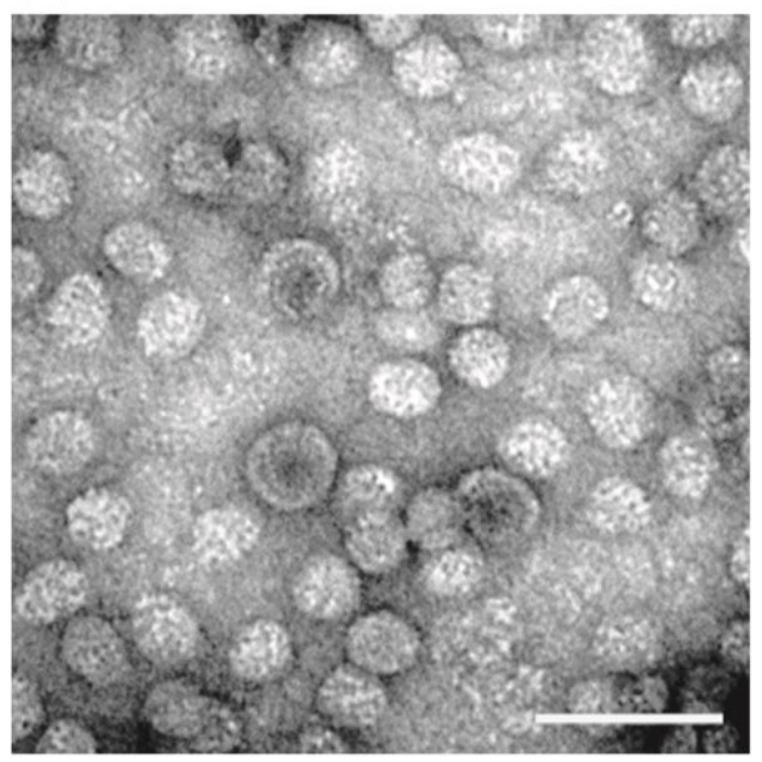


Figure 8. Prevalence of core protein RNA transcription in liver tissue of white sucker collected in the Great Lakes (USA) region. (A) absolute number of fish with detectable transcripts (B) normalized copy number of transcripts.
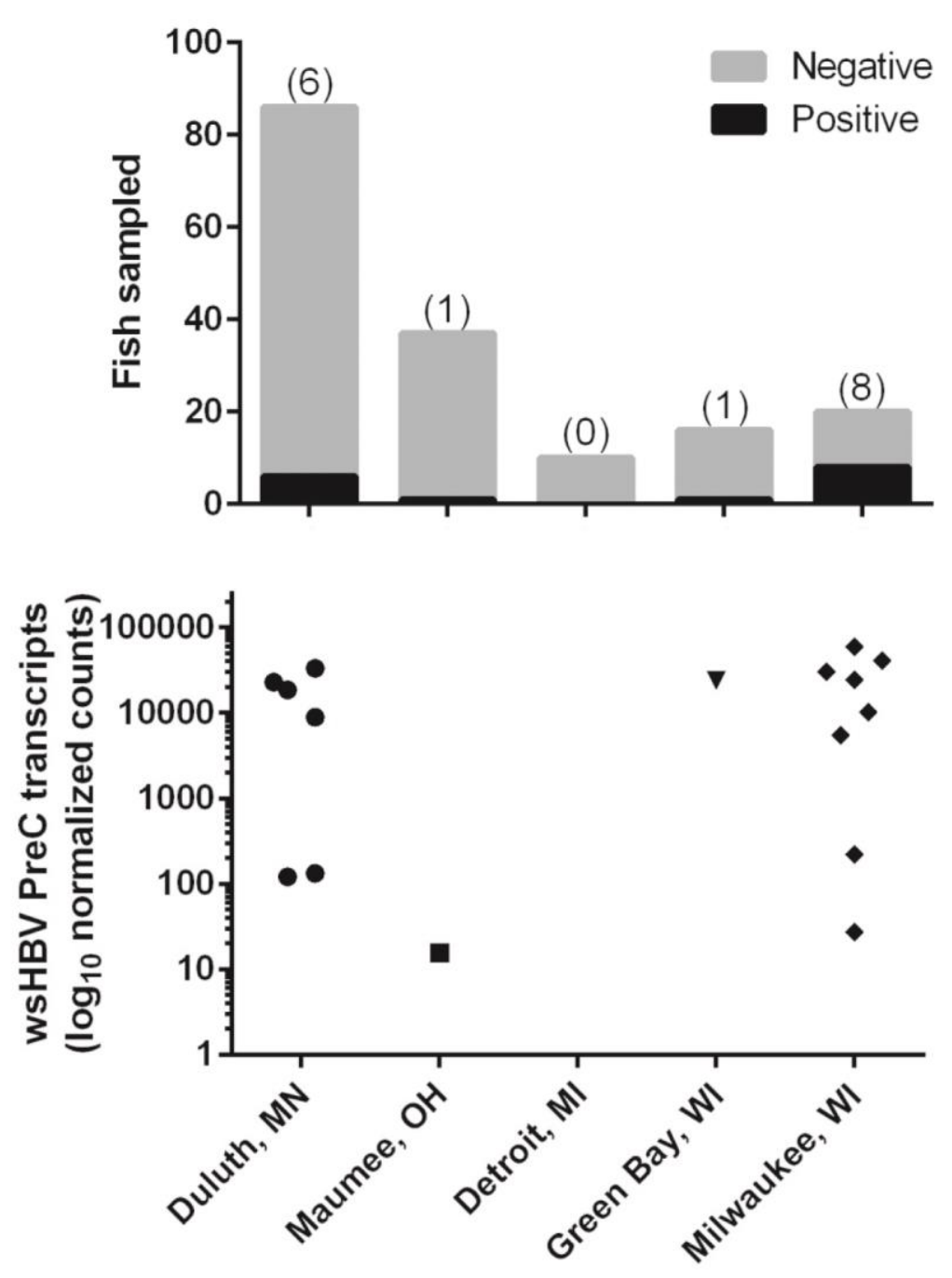


\section{Tables}

Table 1. Size and biochemical properties of predicted hepadnavirus core, polymerase and surface proteins.

\begin{tabular}{|c|c|c|c|c|c|c|c|c|c|c|c|c|}
\hline \multirow[t]{2}{*}{ Virus } & \multicolumn{4}{|c|}{ Polymerase } & \multicolumn{4}{|c|}{ Surface } & \multicolumn{4}{|c|}{ Core } \\
\hline & $\begin{array}{l}\text { GenBank } \\
\text { Accession No. }\end{array}$ & aa & $\mathrm{pI}$ & $\begin{array}{l}\text { Theoretical } \\
\text { MW (kDa) }\end{array}$ & $\begin{array}{l}\text { GenBank } \\
\text { Accession No. }\end{array}$ & aa & $\mathrm{pI}$ & $\begin{array}{l}\text { Theoretical } \\
\text { MW (kDa) }\end{array}$ & $\begin{array}{l}\text { GenBank } \\
\text { Accession No. }\end{array}$ & aa & pI & $\begin{array}{l}\text { Theoretical } \\
\text { MW (kDa) }\end{array}$ \\
\hline WSHBV & - & 789 & 9.76 & 87.3 & - & 346 & 9.65 & 41.5 & - & 213 & 9.68 & 24.3 \\
\hline PHBV & YP_004956864.1 & 795 & 9.77 & 90.3 & YP_04956865.1 & 375 & 9.31 & 41.4 & YP_04956862.1 & 305 & 9.55 & 34.8 \\
\hline HHBV & NP_040998.1 & 788 & 9.93 & 90.0 & NP_040999.1 & 335 & 8.84 & 37.2 & NP_040997.1 & 305 & 9.69 & 34.9 \\
\hline ShHBV & YP_024974.1 & 796 & 9.91 & 90.6 & YP_024975.1 & 338 & 8.88 & 37.8 & YP_024972.1 & 305 & 9.71 & 35.2 \\
\hline SGHBV & YP_031695.1 & 787 & 10.08 & 90.0 & YP_031696.1 & 329 & 9.18 & 36.6 & YP_031693.1 & 305 & 9.49 & 34.9 \\
\hline RGHBV & YP_024968.1 & 785 & 9.91 & 89.4 & YP_024969.1 & 325 & 8.90 & 36.4 & YP_024967.1 & 305 & 9.39 & 35.0 \\
\hline DHBV & NP_039822.1 & 788 & 9.92 & 89.3 & NP_039824.1 & 330 & 8.35 & 37.0 & ADP55743.1 & 262 & 9.85 & 30.2 \\
\hline HBHBV & YP_009045995.1 & 902 & 10.01 & 100.6 & YP_009045996.1 & 224 & 8.41 & 25.4 & YP_009045998.1 & 217 & 9.57 & 24.9 \\
\hline RBHBV & YP_009045991.1 & 899 & 10 & 99.9 & YP_009045992.1 & 224 & 8.41 & 25.4 & YP_009045994.1 & 217 & 9.61 & 25.0 \\
\hline BtHBV & YP_007677999.1 & 853 & 9.91 & 95.2 & YP_007678000.1 & 399 & 7.91 & 44.4 & YP_07678002.1 & 217 & 9.58 & 24.9 \\
\hline TBHBV & YP_009045999.1 & 827 & 9.78 & 93.2 & YP_009046000.1 & 223 & 8.27 & 25.0 & YP_009046002.1 & 188 & 9.35 & 21.7 \\
\hline GSHBV & NP_040994.1 & 881 & 9.57 & 100.0 & NP_040995.1 & 282 & 6.85 & 31.8 & NP_040993.1 & 217 & 9.34 & 25.2 \\
\hline WHBV & NP_671813.1 & 884 & 9.71 & 99.4 & NP_671814.1 & 431 & 8.51 & 48.9 & NP_671816.1 & 188 & 10.12 & 21.7 \\
\hline HuHBV & NP_647604.2 & 843 & 9.83 & 94.6 & YP_355333.1 & 400 & 8.21 & 43.7 & YP_355335.1 & 212 & 9.49 & 24.3 \\
\hline
\end{tabular}


Table 2. Percent nucleotide identity compared to the WSHBV of hepadnaviruses partitioned by open reading frame.

\begin{tabular}{|c|c|c|c|c|c|c|}
\hline \multicolumn{7}{|c|}{ \% Identity at the indicated level } \\
\hline $\begin{array}{c}\text { Virus (GenBank } \\
\text { accession no.) }\end{array}$ & \multicolumn{2}{|c|}{ Polymerase protein } & \multicolumn{2}{c|}{ Surface protein } & \multicolumn{2}{c|}{ Core protein } \\
\hline PHBV (NC_016561) & 40.54 & 29.82 & 40.44 & 22.25 & 33.89 & 22.26 \\
\hline HHBV (NC_001486) & 40.30 & 30.06 & 42.22 & 23.51 & 33.67 & 21.92 \\
\hline RGHBV (NC_005888) & 40.94 & 30.17 & 40.99 & 25.82 & 35.79 & 21.92 \\
\hline SGHBV (NC_005950) & 41.97 & 29.21 & 40.55 & 24.05 & 35.12 & 21.92 \\
\hline ShHBV (NC_005890) & 40.97 & 29.45 & 40.28 & 24.53 & 35.34 & 21.23 \\
\hline DHBV (NC_001344) & 41.59 & 28.97 & 41.24 & 24.86 & 36.72 & 24.50 \\
\hline TBHBV (NC_02445) & 35.55 & 23.79 & 25.00 & 27.07 & 27.16 & 16.82 \\
\hline HuHBV (NC_003977) & 35.63 & 22.85 & 36.25 & 20.00 & 28.05 & 16.31 \\
\hline GSHBV (NC_001484) & 36.12 & 25.52 & 39.69 & 15.33 & 31.17 & 19.31 \\
\hline WHBV (NC_004107) & 37.28 & 26.13 & 36.38 & 18.82 & 28.69 & 20.69 \\
\hline BtHBV (NC_020881) & 36.99 & 25.25 & 33.69 & 18.33 & 29.58 & 21.46 \\
\hline RBHBV (NC_024443) & 36.66 & 25.00 & 44.30 & 16.21 & 29.32 & 16.74 \\
\hline HBHBV (NC_024444) & 36.76 & 24.73 & 43.87 & 15.46 & 29.71 & 17.17 \\
\hline
\end{tabular}


Table 3. Prevalence of viral transcription and tumors in white suckers from each AOC collection site.

\begin{tabular}{lllll}
\hline Site & Sample Size & Virus Only & Tumor Only & Virus/Tumor \\
\hline St. Louis River & 86 & 5 & 2 & 1 \\
Maumee & 37 & 1 & 0 & 0 \\
Detroit River & 10 & 0 & 0 & 0 \\
Fox River & 16 & 0 & 0 & 1 \\
Milwaukee River & 20 & 6 & 3 & 2 \\
\hline
\end{tabular}


Supplemental Table 1. Sampling location, sex and collection data for liver tissue samples which were pooled for Illumnia Sequencing.

\begin{tabular}{llll}
\hline \multicolumn{3}{c}{ White Sucker Liver Tissue for Illumnia Sequencing } \\
\hline Location & River & Sex & Collection Date \\
Duluth, MN & St. Louis River & M & $9 / 28 / 2010$ \\
& St. Louis River & F & $5 / 2 / 2012$ \\
Maumee, OH & Swan Creek & M & $4 / 19 / 2011$ \\
Detroit, MI & Detroit River & M & $10 / 19 / 2010$ \\
Green Bay & Fox River & F & $10 / 14 / 2010$ \\
& Fox River & M & $10 / 14 / 2010$ \\
Milwaukee, WI & Milwaukee River & M & $4 / 12 / 2011$ \\
& Milwaukee River & F & $4 / 12 / 2011$ \\
Fishkill, NY & Hobart & F & $5 / 26 / 2010$ \\
\hline
\end{tabular}


Supplemental Table 2. Primer sequences, range and product size for WSHBV RR173 DNA amplification. PCR cycling conditions were as follows: $95^{\circ} \mathrm{C}$ for $5 \mathrm{~min}$ and then 35 cycles of $95^{\circ} \mathrm{C}$ for $30 \mathrm{~s}, 57^{\circ} \mathrm{C}$ for $30 \mathrm{~s}, 72^{\circ} \mathrm{C}$ for 1 min and a final extension of $72^{\circ} \mathrm{C}$ for 10 min. * denotes primers which were used to assess the presence of WSHBV in fish collected from the Root River via end-point PCR.

${ }^{* *}$ denotes primers which were designed to amplify and confirm the presence the non-coding region of the WSHBV (nt 2538 - 3214 ).

\begin{tabular}{|c|c|c|c|c|}
\hline Name & Orientation & $\begin{array}{c}\text { Nucleotide } \\
\text { Range }\end{array}$ & $\begin{array}{c}\text { Product } \\
\text { Size }\end{array}$ & Sequence \\
\hline WSHBV2 & Forward & \multirow{2}{*}{$2-282$} & \multirow{2}{*}{280} & ACGCTAGAACTGGATTAGCCT \\
\hline WSHBV263 & Reverse & & & TTTGCTAGAGGACCTTGCCC \\
\hline WSHBV192 & Forward & \multirow{2}{*}{$192-898$} & \multirow{2}{*}{706} & TACAAGGACCGTCAAAGCGA \\
\hline WSHBV898 & Reverse & & & GGAGGAACGCTGCCTTGATA \\
\hline WSHBV827 & Forward & \multirow{2}{*}{$827-1265$} & \multirow{2}{*}{438} & AAGTCTACAGTGGCCCAAGC \\
\hline WSHBV1265 & Reverse & & & CACCACCAGTAACACGACGA \\
\hline WSHBV1019 & Forward & \multirow{2}{*}{$1019-1520$} & \multirow{2}{*}{501} & ACCATTGCAATCTCCACCGT \\
\hline WSHBV1520 & Reverse & & & AGCCGTAAAAGGTTCCCAGG \\
\hline WSHBV1413 & Forward & \multirow{2}{*}{$1413-2191$} & \multirow{2}{*}{797} & TGTACCGGATTTCGCTGGAC \\
\hline WSHBV2210 & Reverse & & & AAGAAACAGCTACCACGGCA \\
\hline WSHBV1794 & Forward & \multirow{2}{*}{$1749-2210$} & \multirow{2}{*}{461} & ACACTCTCCTTCCTGCTCCA \\
\hline WSHBV2210 & Reverse & & & AAGAAACAGCTACCACGGCA \\
\hline WSHBV1908* & Forward & \multirow{2}{*}{$1908-2545$} & \multirow{2}{*}{461} & CCTGGGTAGCGCCATTTACT \\
\hline WSHBV2545* & Reverse & & & AAGCCAAGGTCACGAGTGAG \\
\hline WSHBV2526 & Forward & \multirow{2}{*}{$2526-2949$} & \multirow{2}{*}{423} & CTCACTCGTGACCTTGGCTT \\
\hline WSHBV2949 & Reverse & & & AAGCTAATATAATGTGTTTTCTTGCG \\
\hline WSHBV2806 & Forward & \multirow{2}{*}{$2806-3181$} & \multirow{2}{*}{375} & AGGAGCAGAACATCCAATGCT \\
\hline WSHBV3181 & Reverse & & & AGTGATGAGATGTGCATTTGGTC \\
\hline WSHBV2987 & Forward & \multirow{2}{*}{$2987-61$} & \multirow{2}{*}{592} & ACTGACCTGCTGATGGTTGA \\
\hline WSHBV61 & Reverse & & & TCCTTCTGATGGACATTTCAATAGT \\
\hline WSHBV3217 & Forward & \multirow{2}{*}{$3217-110$} & \multirow{2}{*}{435} & TGTTCGCCTTTGTGCTAATTCT \\
\hline WSHBV110 & Reverse & & & GCAGTTTGTGATTCACCCCAC \\
\hline
\end{tabular}




\begin{tabular}{|c|c|c|c|c|}
\hline WSHBV2191 ${ }^{* *}$ & Forward & \multirow{2}{*}{$2191-3295$} & \multirow{2}{*}{1104} & TGCCGTGGTAGCTGTTTCTT \\
\hline WSHBV3295 ${ }^{* *}$ & Reverse & & & GACTCCTTCCAAAGCTGCCT \\
\hline \multicolumn{2}{|c|}{ nCounter Probes } & Tm CP & Tm RP & Target Sequence \\
\hline \multicolumn{2}{|c|}{ Core } & 80 & 80 & $\begin{array}{l}\text { ACTGTTTAATGTGGGGTGAA } \\
\text { TCACAAACTGCAGAATATAC } \\
\text { TGCTAAACTTAGAAGTTGGC } \\
\text { TTATGACTCCAACGTCATATC } \\
\text { GCAATCAATATGCACCAAC }\end{array}$ \\
\hline
\end{tabular}


Supplemental Table 3. Conserved regions of wsHBV genome.

\begin{tabular}{|c|c|c|c|c|}
\hline Name & Accession & Description & Interval & E-value \\
\hline Hepatitis_core & Pfam00906 & Hepatitis core antigen & $46-204$ & $1.05 \mathrm{E}-05$ \\
\hline DNA_pol_viral_N & Pfam00242 & DNA polymerase (viral) N-terminal domain & $311-916$ & $5.40 \mathrm{E}-18$ \\
\hline DNA_pol_viral_C & Pfam00336 & DNA polymerase (viral) C-terminal domain & $1871-2482$ & $1.06 \mathrm{E}-16$ \\
\hline RT_DIRS1 & $\mathrm{Cd} 03714$ & $\begin{array}{l}\text { Reverse transcriptases (RTs) occurring in the DIRS1 group of } \\
\text { retransposons }\end{array}$ & $1427-1777$ & $2.54 \mathrm{E}-10$ \\
\hline RVT_1 & Pfam00078 & Reverse transcriptase (RNA-dependent DNA polymerase & $1385-1786$ & 4.41E-08 \\
\hline vMSA & Pfam00695 & Major surface antigen from hepadnavirus & $1281-1487$ & $4.00 \mathrm{E}-13$ \\
\hline Amelogenin & Smart00818 & $\begin{array}{l}\text { Amelogenins, cell adhesion proteins, play a role in the } \\
\text { biomineralisation of teeth }\end{array}$ & 834-1094 & $3.53 \mathrm{E}-03$ \\
\hline
\end{tabular}

